\title{
Habitual physical activity and food intake regulation : physiological and genetic aspects
}

Citation for published version (APA):

den Hoed, M. (2009). Habitual physical activity and food intake regulation : physiological and genetic aspects. [Doctoral Thesis, Maastricht University]. Universitaire Pers Maastricht. https://doi.org/10.26481/dis.20090703mh

Document status and date:

Published: 01/01/2009

DOI:

10.26481/dis.20090703mh

Document Version:

Publisher's PDF, also known as Version of record

\section{Please check the document version of this publication:}

- A submitted manuscript is the version of the article upon submission and before peer-review. There can be important differences between the submitted version and the official published version of record.

People interested in the research are advised to contact the author for the final version of the publication, or visit the DOI to the publisher's website.

- The final author version and the galley proof are versions of the publication after peer review.

- The final published version features the final layout of the paper including the volume, issue and page numbers.

Link to publication

\footnotetext{
General rights rights.

- You may freely distribute the URL identifying the publication in the public portal. please follow below link for the End User Agreement:

www.umlib.nl/taverne-license

Take down policy

If you believe that this document breaches copyright please contact us at:

repository@maastrichtuniversity.nl

providing details and we will investigate your claim.
}

Copyright and moral rights for the publications made accessible in the public portal are retained by the authors and/or other copyright owners and it is a condition of accessing publications that users recognise and abide by the legal requirements associated with these

- Users may download and print one copy of any publication from the public portal for the purpose of private study or research.

- You may not further distribute the material or use it for any profit-making activity or commercial gain

If the publication is distributed under the terms of Article $25 \mathrm{fa}$ of the Dutch Copyright Act, indicated by the "Taverne" license above, 


\section{Habitual physical activity and food intake regulation}

Physiological and genetic aspects 


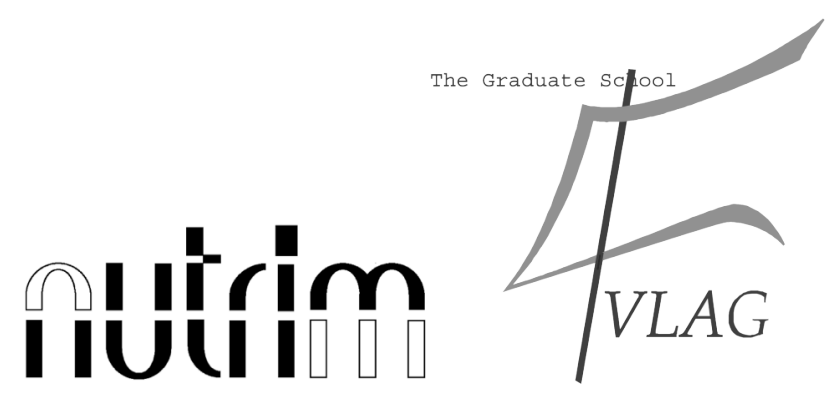

The studies presented in this thesis were performed at the Nutrition and Toxicology Research Institute Maastricht (NUTRIM), which participates in the graduate school VLAG (Food Technology, Agrobiotechnology, Nutrition and Health Sciences), accredited by the Royal Netherlands Academy of Arts and Sciences.

Cover design: $\quad$ Marcel den Hoed Layout: Marcel den Hoed

Printed by: Datawyse, Universitaire pers Maastricht

(C) Marcel den Hoed, Geldrop 2009

ISBN

978-90-5278-841-8 


\section{Habitual physical activity and food intake regulation}

Physiological and genetic aspects

PROEFSCHRIFT

ter verkrijging van de graad van doctor

aan de Universiteit Maastricht

op gezag van de Rector Magnificus

Prof. Mr. G.P.M.F. Mols

volgens het besluit van het College van Decanen

in het openbaar te verdedigen

op vrijdag 3 juli 2009 om 10:00 uur

door

Marcel den Hoed

Geboren te Nijmegen op 1 september 1980 


\section{Promotoren}

Prof. dr. K.R. Westerterp

Prof. dr. M.S. Westerterp-Plantenga

Prof. dr. E.C.M. Mariman

\section{Beoordelingscommissie}

Prof. dr. F-.J. van Schooten (voorzitter)

Prof. dr. R.A. Adan, University of Utrecht

Prof. dr. J. Geraedts

Prof. dr. H. Kuipers

Prof. dr. N.J. Wareham, MRC Epidemiology Unit, Cambridge

Financial support by the Dutch Diabetes Research Association and the Netherlands Association for the Study on Obesity (NASO) for the publication of this thesis is gratefully acknowledged 
General introduction

Chapter 2

Skeletal muscle fibre-type distribution and habitual physical activity in daily life

Chapter 3

Habitual physical activity in daily life correlates positively with markers for mitochondrial capacity

Chapter 4

Genetic variants in PPARD and PPARGC1A contribute to the inter-individual variation of habitual physical activity in unrelated subjects and twins

Chapter 5

Body composition is associated with physical activity in daily life as measured using a triaxial accelerometer in both men and women

Chapter 6

SNP analyses of postprandial responses in (an)orexigenic hormones and feelings of hunger reveal long-term physiological adaptations to facilitate homeostasis

Chapter 7

Postprandial responses in hunger and satiety are associated with the rs9939609 SNP in FTO

Chapter 8

General discussion

Summary

Samenvatting

Dankwoord

List of publications 157

Curriculum Vitae 

Chapter 1

General introduction 


\section{Introduction}

Habitual physical activity and food intake regulation are important determinants of energy balance. Energy balance can only be maintained when energy intake (EI) matches total energy expenditure (TEE). TEE consists of three components: Basal metabolic rate (BMR), diet-induced thermogenesis (DIT) and activity-related energy expenditure (AEE). DIT and BMR are a constant fraction of TEE and a function of body size, respectively. AEE on the other hand is the most variable component of TEE. (Figure 1) (1). A recent study performed in monozygotic twins shows that the intra-pair difference in TEE strongly correlates with the intra-pair difference in habitual physical activity (2). Adequate food intake regulation on the other hand is essential for EI to match TEE.

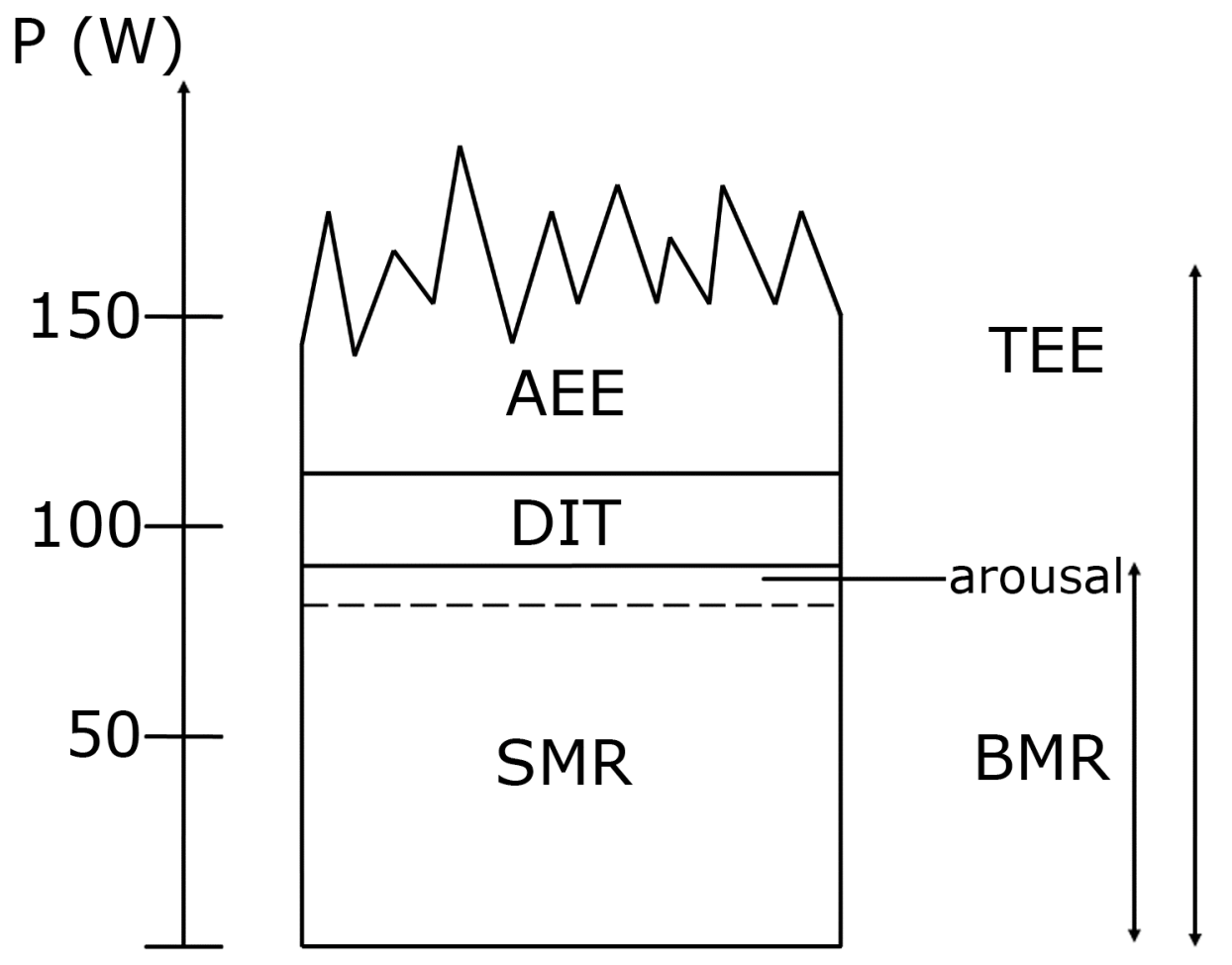

Figure 1: Components of total energy expenditure (TEE): sleeping metabolic rate (SMR), energy cost of arousal, basal metabolic rate (BMR), diet-induced thermogenesis (DIT), activity-related energy expenditure (AEE). Data are for a moderately active male adult weighing $70 \mathrm{~kg}$, with $15 \%$ body fat (157).

Sufficient habitual physical activity and adequate food intake regulation are crucial to preserve health status. A prolonged negative energy balance is shown to result in brady- 
cardia and hypotonia (3), whereas a positive energy balance results in weight gain and predisposes to developing obesity. Obesity in turn increases the risk for developing comorbidities like type 2 diabetes mellitus, osteoporosis, cardiovascular diseases and several types of cancer (4-7). A low level of habitual physical activity also independently increases the risk for developing these morbidities (8-11).

In our Westernized society with its readily available, high fat foods, many people experience problems in maintaining energy balance. In the Netherlands, $45 \%$ of the adult population is currently considered overweight and $10 \%$ is obese (12). This implies however, that there are still many individuals that manage to remain lean, which raises the question why some individuals have problems maintaining energy balance whereas others do not. Evidently, some people are less physically active than others and some experience problems matching EI to EE whereas others do not. To understand inter-individual differences, more knowledge on the aetiology of habitual physical activity and food intake regulation is required. Both parameters of energy balance are subject to genetically and environmentally driven physiological variation. Here, the focus is on the physiological and genetic aspects of habitual physical activity and food intake regulation (Figure 2).

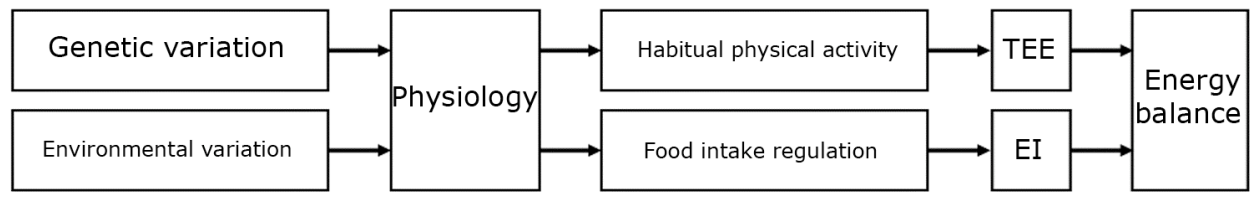

Figure 2: Habitual physical activity and food intake regulation are a function of genetic and environmental variation through physiology. In turn, they determine energy balance by affecting total energy expenditure (TEE) and energy intake (EI). 


\section{Habitual physical activity}

Habitual physical activity is defined as body movements resulting from skeletal muscle contractions and resulting in energy expenditure (13). It is a complex, multidimensional behaviour that is not easy to assess accurately (14). The gold standard for measuring habitual physical activity in daily life is measuring TEE using the doubly labelled water technique (15) and BMR using a ventilated hood system (16). The physical activity level (PAL) is subsequently calculated as the factor by which TEE exceeds BMR (1). PAL is not correlated with BMR and is therefore considered a valid index of TEE corrected for BMR (17). Due to its high cost, however, the doubly labelled water technique is only applicable in small study populations and can therefore not be used to study the aetiology of habitual physical activity. Questionnaires are a much-used alternative to measure habitual physical activity. Yet, these instruments are subject to interpretation, as the outcome depends on how the question is asked and what options are offered to respond. Together with the complex multidimensional character of the trait, this may explain why validation of questionnaires against doubly labelled water so far did not result in an explained variation in PAL over $45 \%$ (18).

A more objective alternative to measure habitual physical activity in daily life and for a prolonged period of time is using an accelerometer approach. A number of accelerometers are currently commercially available, although many of them have not yet been validated with doubly labelled water. The triaxial accelerometer for movement registration (Tracmor) was originally developed at Maastricht University (19) and was subsequently improved in cooperation with Philips Research (Philips Research, Eindhoven, The Netherlands). Validation with doubly labelled water shows that Tracmor output together with the subject characteristics age, height and body mass explains $83 \%$ of the interindividual variation in TEE. The output of the accelerometer contributes a significant $19 \%$ to the model and is solely responsible for $70 \%$ of the inter-individual variation in PAL, which is the highest value reported so far (20). In addition to providing valid and objective information about the total level of habitual physical activity, accelerometers also provide the opportunity to objectively evaluate the intensity and duration of the activities performed. These characteristics make accelerometers especially suitable to study the aetiology of habitual physical activity.

The importance of objectively measuring habitual physical activity becomes evident when comparing the results of studies evaluating the association between body composition and habitual physical activity. The studies that do not show an association differ from those that do show an association with respect to the age of the subjects as well as the objectivity of the method used to determine habitual physical activity. It appears that with increasing age, the association between body composition and habitual physical activity becomes weaker, possibly by compensating energy intake. Ekelund et al. show in middle-aged subjects that baseline AEE explains less than $1 \%$ of the gain in fat mass during a 5.6-year follow-up period. Even the most active quartile gained fat mass during follow-up, suggesting that other factors are more important for energy balance in these subjects (21). A compensatory mechanism with increasing age is suggested to be higher in women than in men, thereby accounting for the lack of association between body composition and habitual physical activity in middle-aged women in spite of measuring 
habitual physical activity using doubly labelled water and a ventilated hood system (22; 23). As for the methodology, the studies that do not show an association between body composition and habitual physical activity used questionnaires to determine the latter phenotype $(24 ; 25)$. Pietilaïnen et al. recently showed in 25 year-old MZ twins discordant for body mass index (BMI) that the obese co-twins are significantly less physically active than the non-obese co-twins as indicated by the Tracmor. The obese co-twins have less than half the activity levels of the non-obese co-twins and avoid high-intensity physical activity altogether. Retrospectively, the twins who ultimately became obese had been less physically active in adolescence than their non-obese co-twins (2). From age 12-18 to age 25 years, habitual physical activity declined even further in the subsequently obese MZ co-twin (26), suggesting that a sedentary lifestyle leads to obesity, independent of genetic factors (2).

Most human traits are a product of genetic and environmental variation. The individual contribution of the two can be determined using a twin model. Since MZ twins share $100 \%$ of their genes and a common environment, the extent to which they differ on a trait represents the effect of a unique environment in both $M Z$ and $D Z$ pairs (27). If there is no correlation within either MZ or DZ pairs, the observed phenotype is solely determined by the unique environment. An equal and positive within-pair correlation in $M Z$ and DZ pairs on the other hand implies that common environmental factors are responsible for the observed behaviour. Finally, a higher within pair correlation in MZ than DZ pairs indicates a genetic effect. More specifically, if the within pair correlation in MZ pairs is at least twice that of DZ pairs, genetic variation is responsible for all variation of the trait. If the within pair correlation in $M Z$ pairs is exactly twice that of $D Z$ pairs, additive influences of alleles at different loci are responsible. If the within pair correlation in $M Z$ twins is more than twice that of the DZ correlation, alleles within loci interact, resulting in non-additive or dominant genetic effects (28).

Twin studies in which habitual physical activity was measured using questionnaires show a range in heritability from $29 \%$ to $62 \%$ (28-31). Until now, few studies have determined the heritability of habitual physical activity by objectively measuring the phenotype. Using the actiwatch accelerometer, Cai et al. show that $55 \%$ of the inter-individual variation in habitual physical activity is explained by genetic variation (32). Joosen et al. show an additive genetic effect of $78 \%$ for habitual physical activity using the Tracmor. Unique environmental influences are concluded to account for the remaining variation (33), which confirms the results of Carlsson et al. (29). The results suggest a moderate to high heritability for habitual physical activity when measured objectively using an accelerometer approach. In other words: genetic variation determines to a large extent whether someone is prone to engaging in physical activities. Given the results of Joosen et al. and taking the complexity of the phenotype into account, the heritability of habitual physical activity is suggested to result from many functional sequence variants at different loci all exerting a small effect. So far, studies aiming to identify these variants using objective measures for habitual physical activity are scarce (32). 


\section{Physiological aspects}

One pathway by which genetic variation may affect habitual physical is that of physical fitness (34). According to Hedman et al., the capacity to perform physical activity largely depends on the degree of physical fitness, usually expressed as the whole body maximal oxygen uptake $\left(\mathrm{VO}_{2}\right.$-max) (35). During high-intensity physical activity, skeletal muscle accounts for approximately $70 \%$ of TEE (36), suggesting that the quantity of skeletal muscle influences $\mathrm{VO}_{2}$-max. Additionally, $\mathrm{VO}_{2}$-max is shown to be associated with the quality of skeletal muscle, correlating positively with the proportion of type I muscle fibres and negatively with the proportion of type $\mathrm{II}_{X}$ fibres (37). In untrained subjects, the type I fibres are characterized by a higher oxidative and lower glycolytic capacity, a higher capillary and mitochondrial density, a less extensive T-tubular system, a smaller area of the sarcoplasmic reticulum and thicker Z-lines compared with the type $\mathrm{II}_{\mathrm{X}}$ fibres (38). Type $\mathrm{II}_{\mathrm{A}}$ muscle fibres are intermediate in their contractile speed, but are metabolically more aligned with type I fibres (39).

Conclusions concerning the causality of the association between $\mathrm{VO}_{2}$-max and skeletal muscle fibre-type distribution remain ambiguous. On the one hand, endurance as well as strength training can induce a shift in muscle fibre-type distribution from type $\mathrm{II}_{\mathrm{X}}$ to type $\mathrm{II}_{\mathrm{A}}$, that is, towards a more oxidative phenotype (39-46). Staron et al. for example show in untrained subjects that the proportion of type $\mathrm{II}_{\mathrm{X}}$ muscle fibres decreases significantly after only four sessions of resistance training performed within two weeks (46). On the other hand, twin studies show a heritability of approximately $45 \%$ for the proportion of type I muscle fibres (47). Training studies either show no change $(40 ; 43 ; 48 ; 49)$ or a slight $(5-10 \%)$ increase $(42 ; 44-46 ; 50)$ in the proportion of type I muscle fibres in response to a period of endurance or strength training, suggesting that the proportion of type I fibres is relatively fixed (51). An increased proportion of type I fibres may thus predispose individuals for an increased $\mathrm{VO}_{2}$-max. Consequently, part of the genetic predisposition for habitual physical activity may result from the proportion of type I fibres in skeletal muscle. Indeed, positive associations were observed between leisure time physical activity as measured using questionnaires and interviews, and the proportion of type I muscle fibres $(11 ; 35 ; 51)$. Whether these associations can be extrapolated to the total level of habitual physical activity as objectively measured in daily life using an accelerometer approach remains to be established.

In spite of $\mathrm{VO}_{2}$-max being associated with skeletal muscle fibre-type distribution, several studies suggest that the latter is not a particularly good marker of skeletal muscle oxidative capacity. For example, muscles of athletes who are successful in the same event are characterized by a large variation in skeletal muscle fibre-type distribution (52). The adaptability of fibres for aerobic metabolism may be more important in training and performance than their basic composition (53). In line with this, type $\mathrm{I}, \mathrm{II}_{\mathrm{A}}$ and $\mathrm{II}_{\mathrm{X}}$ muscle fibres all show the ability to adjust their oxidative capacity on demand (54). In fact, endurance trained type $\mathrm{II}_{\mathrm{A}}$ fibres contain more mitochondria than untrained type I fibres and the same is observed for type $\mathrm{II}_{\mathrm{X}}$ compared with type $\mathrm{II}_{\mathrm{A}}$ fibres (42). Based on these and other studies (54-58), it is concluded that mitochondrial capacity is a more accurate determinant of skeletal muscle oxidative capacity than fibre-type distribution per se. 
Bouchard et al. show that $25-50 \%$ of the inter-individual variation in the capacity of regulatory enzymes from the Kreb's cycle is explained by genetic variation (59). This implies that a genetic predisposition for a high mitochondrial capacity can be hypothesized to predispose individuals to leading a physically active lifestyle. However, while it is obvious that mitochondrial capacity is higher in trained athletes than in sedentary controls $(41 ; 60)$, it is not known to date whether differences also exist within the range of normal daily life activities.

In summary, a genetic predisposition for an increased proportion of type I muscle fibres and an increased mitochondrial capacity are hypothesized to predispose individuals to leading a physically active lifestyle. One way to test this hypothesis is by evaluating whether habitual physical activity is associated with genetic variants in candidate genes. According to Franks and Loos, a biologically plausible candidate gene must 1 ) encode a protein that is important for the regulation of the phenotype or encode a protein that regulates the expression of other such genes; 2 ) be responsive to changes in lifestyle and 3 ) be characterized by functional variation within its nucleotide sequence (61). Genes that control the activity of many other genes like transcription factors and transcription factor co-activators are anticipated to be especially relevant because functional variation in these loci may have large consequences for metabolism (61). Therefore, the genes encoding the transcription factor-coactivator peroxisome proliferator-activated receptor (PPAR) $\gamma$-coactivator $1 \alpha($ PGC-1 $\alpha)(P P A R G C 1 A)$ as well as the transcription factors PPARS (PPARD) and nuclear respiratory factor 1 (NRF1) are considered candidate genes for habitual physical activity.

\section{Genetic aspects}

PGC-1 $\alpha$ is a master switch in mitochondrial biogenesis that is essential for the transcription of many genes required for the expansion and replication of mitochondria (62) (Figure 3). Among its target genes are NRF1 and NRF2 (63;64), which bind to and activate the promoters of many nuclear genes encoding components of the electron transport chain as well as mitochondrial transcription factor A, a key transcriptional activator that translocates to the mitochondria and activates the replication and transcription of mitochondrial DNA (64; 65) (Figure 3). Overexpression of PGC-1 $\alpha$ in skeletal muscle increases the capacity of citrate synthase (CS) (66), which catalyzes the rate-limiting step in the Kreb's cycle and is considered a classic marker for mitochondrial density (53), as well as the capacity of enzymes from the electron transport chain (67-69). In fact, Irrcher et al. show that over $50 \%$ of the variation in the capacity of cytochrome c oxidase (COX) is explained by the variation in PGC-1 $\alpha$ protein level (70). Overexpression of PGC$1 \alpha$ also increases the mRNA levels of the insulin sensitive glucose transporter GLUT4 (67) and the type I myosin heavy chain isoform $(64 ; 66 ; 71)$. These results imply that PGC-1 $\alpha$ induces a shift towards a more oxidative phenotype.

PGC- $1 \alpha$ is preferentially expressed in tissues with a high oxidative capacity, like heart, liver and type I muscle fibres $(64 ; 72 ; 73)$. The mRNA levels of PGC- $1 \alpha$ are reduced in skeletal muscle of type 2 diabetes mellitus patients compared with controls (74-76). Exercise training $(63 ; 77 ; 78)$ and electrical stimulation $(70 ; 78 ; 79)$ are able to increase 
PGC-1 $\alpha$ mRNA levels in skeletal muscle. Furthermore, endurance exercise training increases skeletal muscle PGC-1 $\alpha$ mRNA and protein levels (80). Furthermore, four weeks of one-legged knee-extension training increases the capacity of CS and $\beta$-hydroxyacylCoA dehydrogenase (HAD) in the trained leg but not in the untrained leg. This implies that mitochondrial biogenesis starts within the 4 weeks of training. Following acute exercise, PGC-1 $\alpha$ mRNA levels increase in both legs, but to a higher extent in the trained leg. Training apparently increases the acute response in PGC-1 $\alpha$ gene expression following exercise (63).

The mechanisms by which exercise stimulates PGC- $1 \alpha$ gene expression are schematically presented in Figure 3. Briefly, the impact of exercise is largely mediated by phosphorylating/activating CAMP response element binding protein (CREB) (81), myocyte enhancement factor 2 (MEF2) and p38 mitogen-activated protein kinase (p38 MAPK) (70; 82 ). CREB is phosphorylated/activated by exercise-induced increases in $\beta$-adrenergic stimulation (83), activation of AMP-kinase (AMPK), endothelial nitric oxide synthase (eNOS) $(78 ; 84-88)$ and free intracellular $\mathrm{Ca}^{2+}(83 ; 88 ; 89)$. MEF2 is also activated by free intracellular $\mathrm{Ca}^{2+}(90)$, whereas p38 MAPK is phosphorylated and hence activated by CAMP and cytokines like interleukin $1 \alpha$, interleukin $1 \beta$ and tumor necrosis factor $\alpha$ (TNF $\alpha$ ) (64), which are secreted during and after exercise $(64 ; 91 ; 92)$.

A common and widely studied single nucleotide polymorphism (SNP) in PPARGC1A is the $1444 G>A$ transition (rs8192678) in exon 8. The SNP results in an amino acid change from Glycine (Gly) to Serine (Ser) in codon 482. The minor Ser-encoding allele (A) was associated earlier with a lower effect of endurance training on anaerobic threshold compared with the common Gly-encoding allele (93). In line with this, the Ser-encoding allele is underrepresented among endurance-trained male athletes compared with sedentary controls (93; 94). Ling et al. observe an age-related decline in PGC-1 $\alpha$ mRNA levels in skeletal muscle in Ser allele carriers that is not present in subjects homozygous for the common Gly-encoding allele (95). In older subjects (aged $58 \pm 8$ years), Franks et al. show that PAL and $\mathrm{VO}_{2}$-max are not significantly different between subjects homozygous for the Ser-encoding allele and carriers of the Gly-encoding allele. However, the association between $\mathrm{VO}_{2}$-max and PAL is mediated by rs8192678, with subjects homozygous for the Ser-encoding allele showing a lower $\mathrm{VO}_{2}$-max than Gly allele carriers when sedentary but not when physically active (96). A low level of habitual physical activity may thus exert a health risk in subjects homozygous for the Ser-encoding allele. Indeed, a meta analysis including only older subjects reveals that the odds of having type two diabetes mellitus increases with $11 \%$ for each Ser-encoding allele (97).

A lack of association between habitual physical activity and rs8192678 in older subjects does not necessarily mean the SNP does not affect habitual physical activity. First of all, habitual physical activity is known to decrease with age (98). Secondly, the heritability of habitual physical activity is lower in middle-aged subjects than in young adults (29), suggesting a decreased effect of additive genetic factors on habitual physical activity with increasing age. Both effects may obscure a genotype driven discrepancy in habitual physical activity.

PPARs are nuclear receptors regulating the expression of genes involved in lipid and glucose metabolism in a tissue specific manner. Whereas PPAR $\alpha$ and PPAR $\gamma$ are predomi- 
nantly expressed in liver and adipose tissue, respectively, PPAR $\delta$ is ubiquitously expressed and is the predominant PPAR isoform in skeletal muscle (99). It influences fatty acid oxidation in skeletal muscle and adipose tissue by regulating the transcription of genes involved in $\beta$-oxidation (100) and energy uncoupling (99). PGC-1 $\alpha$ functions as its predominant co-activator $(99 ; 101)$, which explains the positive correlation between PPAR $\delta$ and PGC-1 $\alpha$ gene expression (102). PPAR $\delta$ mRNA levels also correlate positively with the expression of type $\mathrm{I}$ and $\mathrm{II}_{\mathrm{A}}$ myosin heavy chain isoforms $(72 ; 102)$.

Rodent studies show that administering a PPAR $\delta$ agonist increases the capacity for fatty acid $\beta$-oxidation $(99-101 ; 103 ; 104)$ as well as the expression of carnitine palmitoyl transferase (CPT)1B $(101 ; 103 ; 104)$ and CPT2 (103). Administering a PPAR $\delta$ agonist also switches muscle fuel selection towards decreased carbohydrate and increased lipid oxidation $(100 ; 101 ; 104-107)$ and increases the expression of uncoupling proteins (UCPs) $(99-101 ; 104 ; 105)$, thereby uncoupling substrate oxidation from ATP production. Muscle fibre-type conversions towards type I $(93 ; 106 ; 107)$ have been observed upon treatment with a PPAR agonist, accompanied by an increased running time and distance $(106 ; 107)$. In addition, mice transgenically overexpressing PPAR $\delta$ in skeletal muscle are characterized by a two-fold higher proportion of type I muscle fibres (107) and mitochondrial capacity as indicated by the capacity of CS and succinate dehydrogenase (SDH) $(99 ; 108 ; 109)$. The capacity of enzymes from the $\beta$-oxidation is also higher in these mice, whilst adipocyte size is lower $(108 ; 109)$. These metabolic adaptations protect mice overexpressing PPAR from high-fat diet induced obesity (99). The effects appear to be independent of PGC- $1 \alpha$, which remains unchanged in some studies $(107 ; 109)$. PPAR $\delta$ null mice show an approximately $70 \%$ reduced running time and distance compared with age- and weight matched wild-type controls (107) and gain more weight on a high-fat diet (99). In control mice on a high-fat diet, agonists specific for PPAR double PGC-1 $\alpha$ mRNA levels in skeletal muscle, increase mitochondrial density and energy expenditure and increase insulin sensitivity in spite of similar food consumption (100). The PPAR $\delta$ agonist also attenuates the increase in body fat mass in wild-type mice on a high-fat diet $(99 ; 100)$.

In humans, PPARס gene expression is significantly higher in young adults compared with older subjects ( $28 \pm 2$ versus $62 \pm 2$ years). In both age groups however, approximately $60 \%$ of the inter-individual variation in PPAR $\delta$ mRA levels is explained by genetic variation (102). Given the ability of PPAR to stimulate mitochondrial biogenesis and oxidative metabolism, Nilsson et al. conclude that PPAR $\delta$ is an important determinant of insulin resistance during aging (102). In line with this, Carey et al. show a downregulation of PPAR gene expression in skeletal muscle of type 2 diabetes mellitus patients compared with controls (74). Exercise increases PPAR gene expression $(72 ; 93)$ and protein levels (93). The mechanism responsible for the exercise-induced increase in PPAR $\delta$ is not fully elucidated yet, but may result from activation by fatty acids and their metabolites, PGC$1 \alpha$, and/or an upstream signalling component like a kinase cascade (99).

The PPARD gene is characterized by several intronic SNPs that are associated with phenotypes relevant for habitual physical activity. Twins homozygous for the common A allele in rs2076168 are characterized by significantly higher PPAR $\delta$ mRA levels than their co-twins carrying more $C$ alleles (102). As for the rs2267668 SNP in PPARD, G allele car- 
riers show a lower increase in anaerobic threshold and insulin sensitivity in response to nine months of self-monitored aerobic exercise training compared with subjects homozygous for the common A allele. During the course of the intervention, $\mathrm{VO}_{2}$-max even decreased in subjects carrying the $G$ allele. The effects are independent of the rs 8192678 SNP in PPARGC1A (93). Young adults (aged 26 years) carrying the minor $G$ allele in rs2267668 are additionally characterized by a lower mitochondrial capacity in vitro compared with subjects homozygous for the common A allele (93). The results suggest that genetic variation in PPARD may influence the likelihood of leading a physically active lifestyle. 


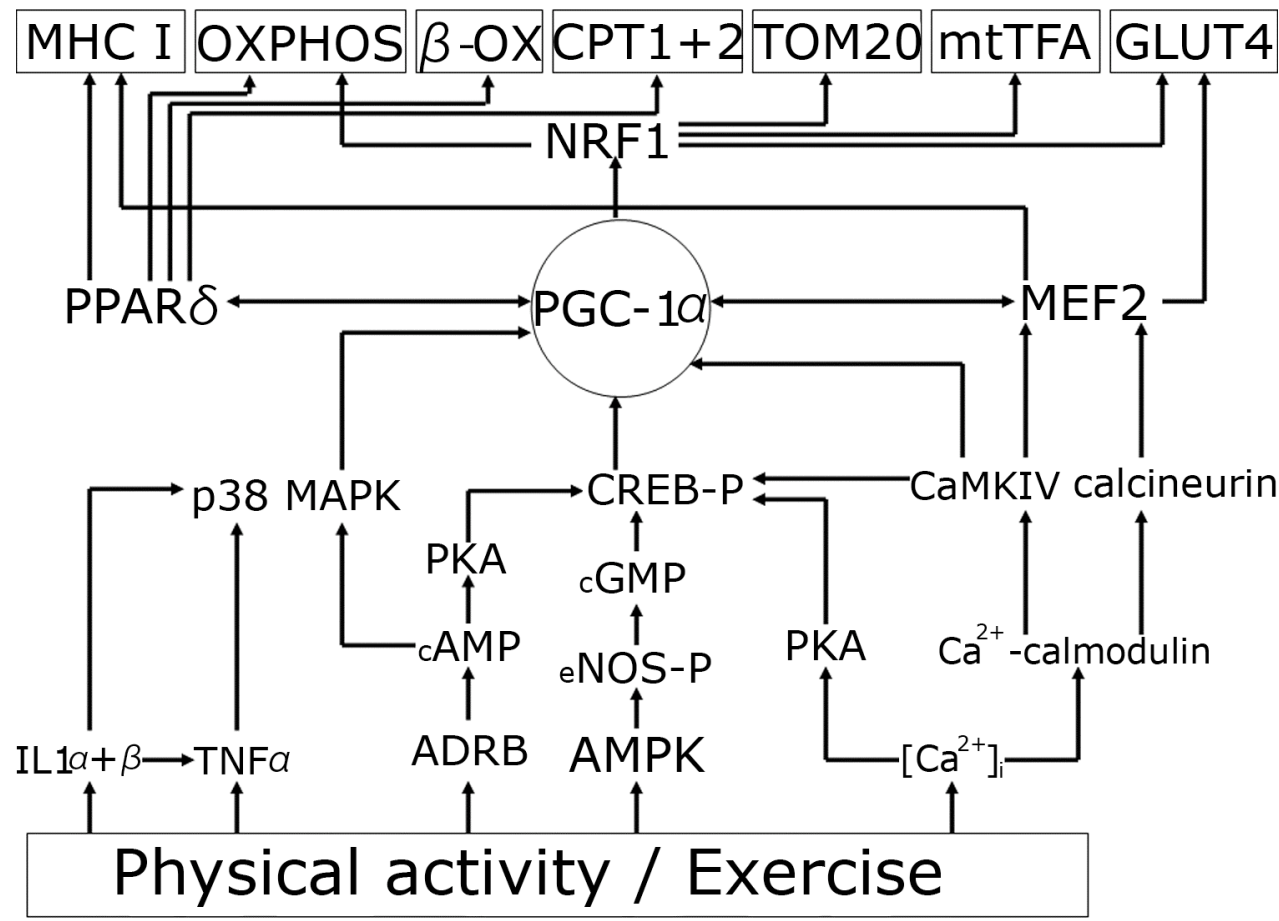

Figure 3: Pathways by which exercise affects skeletal muscle oxidative capacity. Peroxisome proliferator-activated receptor (PPAR) $\gamma$-coactivator-1 $\alpha$ (PGC-1 $\alpha$ ), a master switch for mitochondrial biogenesis, co-activates nuclear respiratory factor 1 (NRF1), which binds to and activates the promoters of many nuclear genes encoding components of the electron transport chain (OXPHOX) as well as mitochondrial transcription factor A (mtTFA), a key transcriptional activator essential for replication and transcription of mitochondrial DNA. Expression of TOM20, a protein essential for translocation of mitochondrial proteins over the outer mitochondrial membrane, is also controlled by NRF1. PGC-1 $\alpha$ also

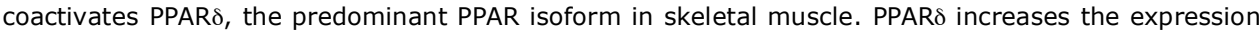
of the genes encoding key elements of $\beta$-oxidation $(\beta-O X)$ and electron transport chain as well as carnitine palmitoyl transferases $1 \mathrm{~B}$ and 2. (CPT1+2). Additionally, PPAR increases the expression of the type I myosin heavy chain isoform (MHC I).

Exercise increases the expression of PGC-1 $\alpha$ through p38 mitogen-activated protein kinase (p38 MAPK), CAMP response element binding protein (CREB), myocyte enhancement factor 2 (MEF2) and AMP-kinase (AMPK). AMPK is activated when cellular ATP levels are low. AMPK phosphorylates serine 1177 within the $\mathrm{COOH}$-terminal tail of nitric oxide synthase (eNOS), thereby activating the enzyme. eNOS in turn increases the intracellular concentration of guanosine $3^{\prime}, 5^{\prime}$-monophosphate (cGMP), which increases the phosphorylation of Serine 133 in CREB. CREB is also activated by $\beta$-adrenergic stimulation (ADRB) and increased levels of free intracellular $\mathrm{Ca}^{2+} . \beta$-adrenergic stimulation increases CAMP levels, which activates CREB through protein kinase A (PKA). $\mathrm{Ca}^{2+}$ activates CREB through $\mathrm{Ca}^{2+}$ calmodulin-dependent protein kinase IV (CaMK IV). Additionally, CaMK IV and the serine-threonine calcineurin both activate MEF2 (90), which also increases PGC-1 $\alpha$ gene expression and increases the expression of the insulin-sensitive glucose transporter GLUT4. p38 MAPK activates PGC-1 $\alpha$ in skeletal muscle as well. p38 MAPK is activated by cytokines like interleukin $1 \alpha$, interleukin $1 \beta$ and tumor necrosis factor $\alpha(\mathrm{TNF} \alpha)$ as well as by increased levels of cAMP. 


\section{Food intake regulation}

Adequate food intake regulation is essential to fine-tune energy intake (EI) to total energy expenditure (TEE). Food intake regulation consists of a homeostatic and a nonhomeostatic or hedonic component. Homeostatic food intake regulation is mainly a behavioural physiological interaction between the individual and the environment, with hypothalamic receptors responding to peripherally released (an)orexigenic hormones like leptin, peptide YY (PYY), glucagon-like peptide 1 (GLP-1) and ghrelin. Cognitive aspects reflecting the attitude towards eating are also involved in homeostatic food intake regulation. Cognitive aspects can be determined using the three-factor eating questionnaire (110). The first factor measures dietary restraint eating, that is, the control of food intake by thought and will power. The second factor, disinhibition, represents the incidental inability to resist eating cues and can hence be seen as inhibition of dietary restraint. In subjects with a healthy body mass, factor 2 represents emotional eating. The third factor represents the overall perception of hunger. Hedonic pathways of food intake regulation are associated with the rewarding value of food usually expressed as liking and wanting of food products in the absence of sheer hunger. Recently, acute stress was shown to increase eating in the absence of hunger in individuals with a high disinhibition. Stress appears to interfere in hedonic pathways of food intake regulation, such as food reward, resulting in a shift of food choice towards high-fat and sweet foods, ultimately resulting in an increased EI (111). Without contradicting the importance of the hedonic component, the focus here is on the homeostatic component of food intake regulation.

\section{Physiological aspects}

Leptin is mainly released from adipocytes as a signal of body fat stores (112). It decreases food intake through the leptin receptor (LEPR) by acting upon proopiomelanocortin (POMC), cocaine and amphetamine regulated transcript (CART) and agouti-related protein (AGRP). POMC expression in the arcuate nucleus of the hypothalamus is increased by leptin, resulting in the excitation of hypothalamic neurons expressing melanocortin 4 receptor (MC4R) via axons containing $\alpha$-melanocyte-stimulating hormone $(\alpha-M S H)(113)$. CART is also stimulated by leptin, thereby inhibiting feeding and antagonizing the feeding response induced by the orexigenic neuropeptide $Y$ (NPY) (114). AGRP on the other hand is downregulated by leptin $(115 ; 116)$, thereby disinhibiting both the MC4R and the NPY 2 receptor (NPY2R). Furthermore, evidence shows that physiological levels of leptin stimulate GLP-1 release in humans in a dose dependent manner (117). GLP-1 is a gastrointestinal peptide that is secreted by intestinal L cells in response to nutrient ingestion (118). It binds to G-protein linked receptors on islet $\beta$-cells and decreases food intake in healthy and obese subjects (119). PYY, released from gut $L$ cells, also reduces appetite and food intake (120). PYY exerts its effect by stimulating POMC neurons and inhibiting NPY neurons (121) through the NPY2R (122). In addition, infusion of PYY decreases plasma ghrelin levels during the fasting period and abolishes its preprandial rise (120). Ghrelin, a stomach derived hormone, is known to increase food intake through the ghrelin receptor (GHSR) by activating NPY and AGRP containing neu- 
rons in the hypothalamus $(123 ; 124)$. The interaction between (an)orexigenic hormones and their receptors is schematically presented in Figure 4.

\section{Genetic aspects}

As was shown for habitual physical activity, the inter-individual variation in parameters of food intake regulation is a function of genetic as well as environmental variation. The fasting levels of several (an)orexigenic hormones are associated with SNPs in the genes encoding them, suggesting a genetic background in homeostatic food intake regulation. Seventy-four percent of the variation in fasting serum leptin levels is explained by variation in fat mass (125). This suggests that factors other than fat mass still account for a substantial part of the inter-individual variation in fasting leptin levels. Fried et al. confirm this by showing a wide range in fasting leptin levels for any given body fat content (126). Part of the residual variation is explained by SNPs in the genes encoding leptin $(L E P)(127 ; 128)$ and its receptor (LEPR) $(129)$. These associations remain after taking adiposity into account. The $-2548 \mathrm{G}>\mathrm{A}$ SNP in the coding region of LEP (rs7799039) is hypothesized to affect the transcription rate of leptin, as AA carriers are characterized by approximately $50 \%$ higher fasting leptin levels than GG/GA carriers (127). Food intake regulation may be affected, as subjects with the GG genotype are overrepresented among extremely obese (130) and overweight individuals (128) compared with normal weight controls.

The functional $668 \mathrm{~A}>\mathrm{G}$ SNP in exon 6 of $L E P R$ (rs1137101) results in an amino acid substitution from glutamine (GIn) to arginine (Arg) at codon 223. The G allele of rs1137101 is hypothesized to alter the signalling capacity of leptin, resulting in a leptin resistant state $(125 ; 131)$. Resistance to leptin is known to increase food intake, in extreme cases resulting in early-onset morbid obesity $(132 ; 133)$. Indeed, the $G$ allele in rs1137101 is shown to be associated with a higher BMI than the A allele in several studies $(131 ; 134$ $136)$, suggesting a role for this genetic variant in food intake regulation. As for PYY, fasting plasma levels as well as the postprandial response are associated with a rare variant in the gene encoding this peptide ( $P Y Y$ ) (137). Fasting plasma ghrelin levels appear to be associated with the $-501 \mathrm{~A}>\mathrm{C}$ SNP (rs26802) in the promoter region of the ghrelin gene (GHRL) (138).

Most studies showing the association between plasma levels of (an)orexigenic hormones and SNPs in candidate genes focus on fasting plasma levels. However, humans are in a postprandial state during the largest part of the day, that is, from breakfast onward. This implies that postprandial responses of (an)orexigenic hormones are potentially important for food intake regulation as well. These postprandial responses are characterized by a large inter-individual variation (139) that can only partly be explained by confounders like BMI and sex $(140 ; 141)$. As is shown for fasting plasma levels, genetic variation is hypothesized to contribute to the inter-individual variation of the postprandial responses, which is endorsed by a heritability of $39 \%$ for the postprandial response in hunger (142). Common variants in the fat mass and obesity-associated gene (FTO) have recently become of interest in the context of food intake regulation. They are shown to be associated with the inter-individual variation in adiposity (143-148). The most widely studied 
SNP in FTO, the rs9939609 variant, explains approximately $1 \%$ of the inter-individual variation in BMI. Due to the high minor allele (A) frequency of rs9939609, the population-attributable risk for obesity associated with rs9939609 is suggested to be as high as $20 \%(145)$. FTO is highly expressed in adipose tissue as well as in the arcuate, paraventricular, dorsomedial and ventromedial nuclei of the hypothalamus $(149 ; 150)$. These sites are involved in food intake regulation, suggesting that FTO may influence adiposity by affecting appetite. Indeed, Timpson et al. show in children that energy intake from food is higher in TA/AA carriers than in children with the TT genotype (151). In addition, Wardle et al. show that children aged 8 to 11 years carrying the TA/AA genotype in rs9939609 are characterized by a reduced responsiveness to satiety cues than TT carriers (152), thereby increasing the risk for overeating and developing obesity (153). Whether or not FTO affects responsiveness to satiety cues in adults is currently unknown. Moreover, the mechanism by which FTO affects appetite remains to be established. Gerken et al. show that FTO may regulate the transcription of genes involved in metabolism by catalyzing DNA demethylation (149), whereas Qi et al. suggest that FTO likely forms part of a pathway mediating the neuroregulation, with blocking of the leptin signal inhibiting downstream changes in adipose tissue that induce the expression of FTO (147). Twin studies show that cognitive aspects of the attitude towards eating are moderately heritable. The heritability for dietary restraint, disinhibition and perceived hunger ranges from 28 to $59 \%, 0$ to $60 \%$ and 23 to $45 \%$, respectively (154-156). To our knowledge, no studies have yet identified genetic variants that contribute to the inter-individual variation of dietary restraint, disinhibition or perceived hunger. 


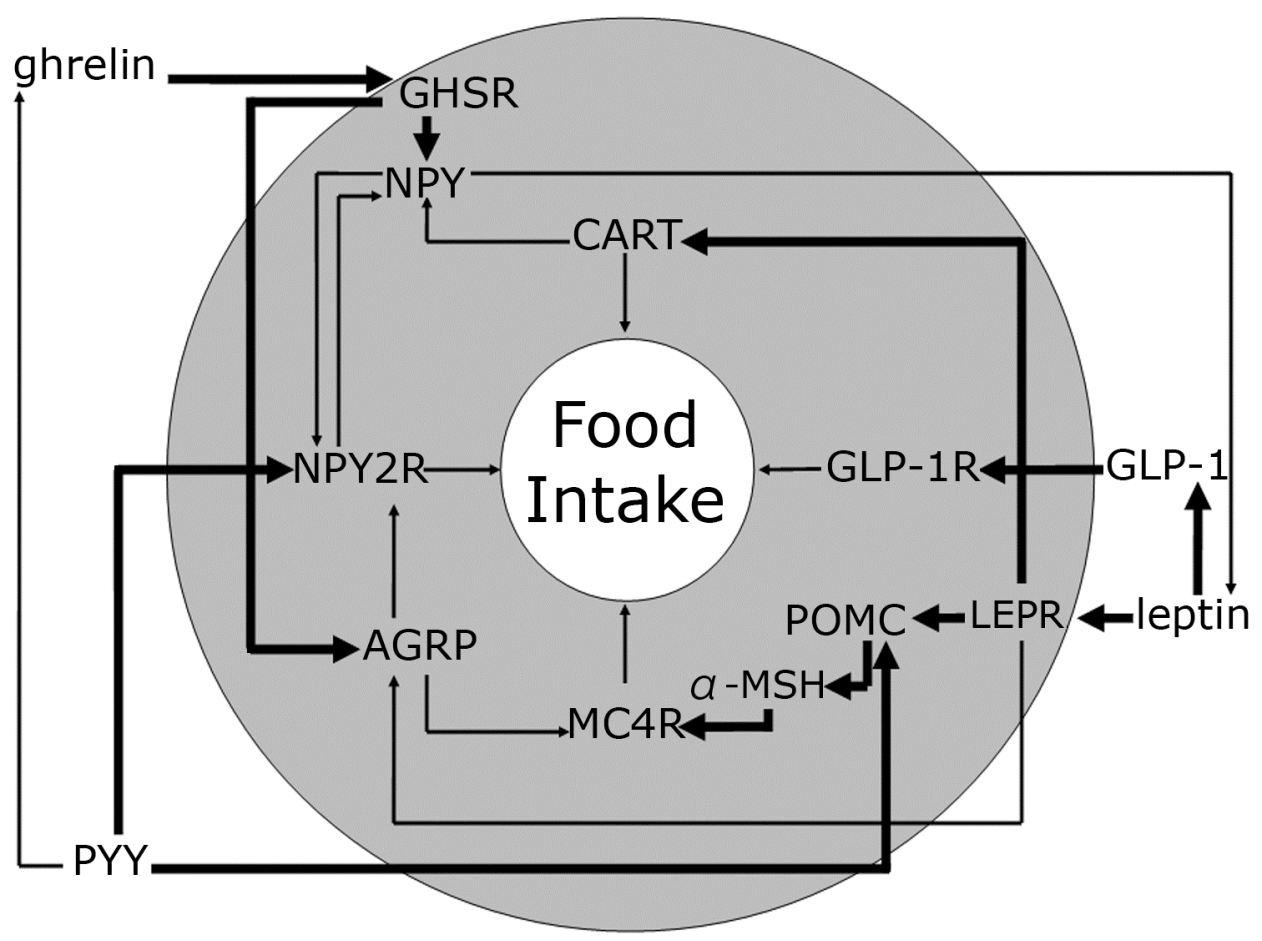

Figure 4: A model for the physiological regulation of food intake by peripherally released (an)orexigenic hormones and their hypothalamic receptors (in grey). GLP-1, Glucagon-like peptide 1; GLP-1R, G-protein coupled receptor islet $\beta$-cell; PYY, peptide YY; POMC, Pro-opiomelanocortin; AGRP, Agouti-related protein; CART, Cocaine and amphetamine-regulated transcript; NPY, Neuropeptide Y; $\alpha-\mathrm{MSH}$, Alpha-melanocyte-stimulating hormone; MC4R, Melanocortin 4 receptor; NPY2R, NPY 2 receptor. Bold lines represent excitatory effects, thin lines represent inhibitory effects. 


\section{Outline of the thesis}

The capacity to perform habitual physical activity largely depends on physical fitness. To determine whether the likelihood of leading a physically active lifestyle depends on skeletal muscle fibre-type distribution, the association between the latter two variables was determined in a population of healthy young adults (chapter two). The association between habitual physical activity and markers for mitochondrial capacity was determined as well (chapter three). To draw conclusions concerning the causality of these correlations, the association between habitual physical activity and single nucleotide polymorphisms (SNPS) in genes encoding proteins involved in mitochondrial biogenesis and energy metabolism (PPARD, PPARGC1A, FRAP1 and NRF1) was determined in unrelated subjects as well as in a group of monozygotic and dizygotic same-sex twin pairs. Together with a heritability analysis for habitual physical activity and the intensity and duration of the activities performed, the results are described in chapter four. As the impact of habitual physical activity on body composition is still subject to debate, the association between percentage body fat and habitual physical activity was determined as well (chapter 5).

Parameters of food intake regulation like fasting concentrations of anorexigenic and orexigenic hormones are a function of genetic variation. To determine whether their postprandial responses are also subject to genetic factors, the association was determined between postprandial responses in ghrelin, PYY and GLP-1 as well as hunger and satiety with SNPs encoding these hormones and their hypothalamic receptors. Together with the associations observed for dietary restraint, disinhibition and perceived hunger, the results are described in chapter six. Finally, adiposity is associated with genetic variants in FTO that were recently suggested to affect appetite. The association between postprandial responses in hunger and satiety with a common variant in the FTO gene is described in chapter 7. 


\section{References}

1. Westerterp KR, Plasqui G: Physical activity and human energy expenditure. Curr Opin Clin Nutr Metab Care 7:607-613, 2004

2. Pietilaïnen $\mathrm{KH}$, Kaprio J, Borg P, Plasqui G, Yki-Jarvinen $H$, Kujala UM, Rose RJ, Westerterp KR, Rissanen A: Physical inactivity and obesity: a vicious circle. Obesity (Silver Spring) 16:409-414, 2008

3. Keys A, Brozek J, Henschel A, Mickelsen O, Taylor H: The biology of human starvation. Minneapolis, MN: University of Minnesota Press, 1950

4. Donahue RP, Abbott RD: Central obesity and coronary heart disease in men. Lancet 2:1215, 1987

5. Hubert HB, Feinleib M, McNamara PM, Castelli WP: Obesity as an independent risk factor for cardiovascular disease: a 26-year follow-up of participants in the Framingham Heart Study. Circulation 67:968-977, 1983

6. Lew EA: Mortality and weight: insured lives and the American Cancer Society studies. Ann Intern Med 103:1024-1029, 1985

7. Pi-Sunyer FX: Medical hazards of obesity. Ann Intern Med 119:655-660, 1993

8. Hu G, Qiao Q, Silventoinen K, Eriksson JG, Jousilahti P, Lindstrom J, Valle TT, Nissinen A, Tuomilehto J: Occupational, commuting, and leisure-time physical activity in relation to risk for Type 2 diabetes in middle-aged Finnish men and women. Diabetologia 46:322-329, 2003

9. Neville CE, Murray LJ, Boreham CA, Gallagher AM, Twisk J, Robson PJ, Savage JM, Kemper HC, Ralston SH, Davey Smith G: Relationship between physical activity and bone mineral status in young adults: the Northern Ireland Young Hearts Project. Bone 30:792-798, 2002

10. Panagiotakos DB, Chrysohoou C, Pitsavos C, Menotti A, Dontas A, Skoumas J, Stefanadis $C$, Toutouzas P: Risk factors of stroke mortality: a 40-year follow-up of the Corfu cohort from the Seven-Countries Study. Neuroepidemiology 22:332-338, 2003

11. Tikkanen HO, Hamalainen E, Sarna S, Adlercreutz H, Harkonen M: Associations between skeletal muscle properties, physical fitness, physical activity and coronary heart disease risk factors in men. Atherosclerosis 137:377-389, 1998

12. Health Council of The Netherlands: Overweight and obesity. The Hague: Health Council of The Netherlands, publication no. 2003/07, 2003

13. Caspersen CJ, Powell KE, Christenson GM: Physical activity, exercise, and physical fitness: definitions and distinctions for health-related research. Public Health Rep 100:126-131, 1985

14. Wareham NJ, van Sluijs EM, Ekelund U: Physical activity and obesity prevention: a review of the current evidence. Proc Nutr Soc 64:229-247, 2005

15. Schoeller DA, Hnilicka JM: Reliability of the doubly labeled water method for the measurement of total daily energy expenditure in free-living subjects. J Nutr 126:348S354S, 1996

16. Adriaens MP, Schoffelen PF, Westerterp KR: Intra-individual variation of basal metabolic rate and the influence of daily habitual physical activity before testing. $\mathrm{Br} \mathrm{J}$ Nutr 90:419-423, 2003

17. Black $A E$, Coward WA, Cole TJ, Prentice AM: Human energy expenditure in affluent societies: an analysis of 574 doubly-labelled water measurements. Eur J Clin Nutr 50:7292, 1996

18. Philippaerts RM, Westerterp KR, Lefevre J: Doubly labelled water validation of three physical activity questionnaires. Int J Sports Med 20:284-289, 1999

19. Meijer GA, Westerterp KR, Koper H, ten Hoor F: Assessment of energy expenditure by recording heart rate and body acceleration. Med Sci Sports Exerc 21:343-347, 1989

20. Plasqui G, Joosen AM, Kester AD, Goris AH, Westerterp KR: Measuring free-living energy expenditure and physical activity with triaxial accelerometry. Obes Res 13:13631369,2005 
21. Ekelund U, Brage S, Franks PW, Hennings S, Emms S, Wong MY, Wareham NJ: Physical activity energy expenditure predicts changes in body composition in middle-aged healthy whites: effect modification by age. Am J Clin Nutr 81:964-969, 2005

22. Paul DR, Novotny JA, Rumpler WV: Effects of the interaction of sex and food intake on the relation between energy expenditure and body composition. Am J Clin Nutr 79:385-389, 2004

23. Westerterp KR, Goran MI: Relationship between physical activity related energy expenditure and body composition: a gender difference. Int J Obes Relat Metab Disord 21:184-188, 1997

24. Hakala P, Rissanen A, Koskenvuo M, Kaprio J, Ronnemaa T: Environmental factors in the development of obesity in identical twins. Int J Obes Relat Metab Disord 23:746753, 1999

25. Rissanen A, Hakala P, Lissner L, Mattlar CE, Koskenvuo M, Ronnemaa T: Acquired preference especially for dietary fat and obesity: a study of weight-discordant monozygotic twin pairs. Int J Obes Relat Metab Disord 26:973-977, 2002

26. Kriska AM, Knowler WC, LaPorte RE, Drash AL, Wing RR, Blair SN, Bennett PH, Kuller $\mathrm{LH}$ : Development of questionnaire to examine relationship of physical activity and diabetes in Pima Indians. Diabetes Care 13:401-411, 1990

27. Ramakrishnan V, Goldberg J, Henderson WG, Eisen SA, True W, Lyons MJ, Tsuang MT: Elementary methods for the analysis of dichotomous outcomes in unselected samples of twins. Genet Epidemiol 9:273-287, 1992

28. Lauderdale DS, Fabsitz R, Meyer JM, Sholinsky P, Ramakrishnan V, Goldberg J: Familial determinants of moderate and intense physical activity: a twin study. Med Sci Sports Exerc 29:1062-1068, 1997

29. Carlsson S, Andersson T, Lichtenstein P, Michaelsson K, Ahlbom A: Genetic effects on physical activity: results from the Swedish Twin Registry. Med Sci Sports Exerc 38:1396-1401, 2006

30. Kaprio J, Koskenvuo M, Sarna S: Cigarette smoking, use of alcohol, and leisure-time physical activity among same-sexed adult male twins. Prog Clin Biol Res 69 Pt C:3746, 1981

31. Perusse L, Tremblay A, Leblanc C, Bouchard C: Genetic and environmental influences on level of habitual physical activity and exercise participation. Am J Epidemiol 129:1012-1022, 1989

32. Cai G, Cole SA, Butte N, Bacino C, Diego V, Tan K, Goring HH, O'Rahilly S, Farooqi IS, Comuzzie AG: A quantitative trait locus on chromosome 18q for physical activity and dietary intake in Hispanic children. Obesity (Silver Spring) 14:1596-1604, 2006

33. Joosen AM, Gielen M, Vlietinck R, Westerterp KR: Genetic analysis of physical activity in twins. Am J Clin Nutr 82:1253-1259, 2005

34. Stubbe JH, Boomsma DI, De Geus EJ: Sports participation during adolescence: a shift from environmental to genetic factors. Med Sci Sports Exerc 37:563-570, 2005

35. Hedman A, Byberg L, Reneland R, Lithell HO: Muscle morphology, self-reported physical activity and insulin resistance syndrome. Acta Physiol Scand 175:325-332, 2002

36. Helge JW, Fraser AM, Kriketos AD, Jenkins AB, Calvert GD, Ayre KJ, Storlien LH: Interrelationships between muscle fibre type, substrate oxidation and body fat. Int J Obes Relat Metab Disord 23:986-991, 1999

37. Lortie G, Simoneau JA, Hamel P, Boulay MR, Bouchard C: Relationships between skeletal muscle characteristics and aerobic performance in sedentary and active subjects. Eur J Appl Physiol Occup Physiol 54:471-475, 1985

38. Eisenberg B: Quantitative ultrastructure of mammalian skeletal muscle. Handbook of Physiology Section 10: Skeletal muscle:73-1121, 1983

39. Andersen $P$, Henriksson J: Training induced changes in the subgroups of human type II skeletal muscle fibres. Acta Physiol Scand 99:123-125, 1977

40. Coggan AR, Spina RJ, King DS, Rogers MA, Brown M, Nemeth PM, Holloszy JO: Skeletal muscle adaptations to endurance training in 60- to 70-yr-old men and women. J Appl Physiol 72:1780-1786, 1992 
41. Hansen AK, Fischer CP, Plomgaard P, Andersen JL, Saltin B, Pedersen BK: Skeletal muscle adaptation: training twice every second day vs. training once daily. J Appl Physiol 98:93-99, 2005

42. Howald $H$, Hoppeler $H$, Claassen $H$, Mathieu $O$, Straub R: Influences of endurance training on the ultrastructural composition of the different muscle fiber types in humans. Pflugers Arch 403:369-376, 1985

43. Ingjer F: Effects of endurance training on muscle fibre ATP-ase activity, capillary supply and mitochondrial content in man. J Physiol 294:419-432, 1979

44. Sale DG, MacDougall JD, Jacobs I, Garner S: Interaction between concurrent strength and endurance training. J Appl Physiol 68:260-270, 1990

45. Simoneau JA, Lortie G, Boulay MR, Marcotte M, Thibault MC, Bouchard C: Human skeletal muscle fiber type alteration with high-intensity intermittent training. Eur J Appl Physiol Occup Physiol 54:250-253, 1985

46. Staron RS, Karapondo DL, Kraemer WJ, Fry AC, Gordon SE, Falkel JE, Hagerman FC, Hikida RS: Skeletal muscle adaptations during early phase of heavy-resistance training in men and women. J Appl Physiol 76:1247-1255, 1994

47. Simoneau JA, Bouchard C: Genetic determinism of fiber type proportion in human skeletal muscle. Faseb J 9:1091-1095, 1995

48. Gollnick PD, Armstrong RB, Saltin B, Saubert CWt, Sembrowich WL, Shepherd RE: Effect of training on enzyme activity and fiber composition of human skeletal muscle. J Appl Physiol 34:107-111, 1973

49. Saltin B, Nazar K, Costill DL, Stein E, Jansson E, Essen B, Gollnick D: The nature of the training response; peripheral and central adaptations of one-legged exercise. Acta Physiol Scand 96:289-305, 1976

50. Simoneau JA, Lortie G, Boulay MR, Marcotte M, Thibault MC, Bouchard C: Inheritance of human skeletal muscle and anaerobic capacity adaptation to high-intensity intermittent training. Int J Sports Med 7:167-171, 1986

51. Karjalainen J, Tikkanen H, Hernelahti M, Kujala UM: Muscle fiber-type distribution predicts weight gain and unfavorable left ventricular geometry: a 19 year follow-up study. BMC Cardiovasc Disord 6:2, 2006

52. Gollnick PD, Matoba $\mathrm{H}$ : The muscle fiber composition of skeletal muscle as a predictor of athletic success. An overview. Am J Sports Med 12:212-217, 1984

53. Gollnick PD, Armstrong RB, Saubert CWt, Piehl K, Saltin B: Enzyme activity and fiber composition in skeletal muscle of untrained and trained men. J Appl Physiol 33:312319,1972

54. Essen-Gustavsson B, Henriksson J: Enzyme levels in pools of microdissected human muscle fibres of identified type. Adaptive response to exercise. Acta Physiol Scand 120:505-515, 1984

55. Bassett DR, Jr.: Skeletal muscle characteristics: relationships to cardiovascular risk factors. Med Sci Sports Exerc 26:957-966, 1994

56. Jaworowski A, Porter MM, Holmback AM, Downham D, Lexell J: Enzyme activities in the tibialis anterior muscle of young moderately active men and women: relationship with body composition, muscle cross-sectional area and fibre type composition. Acta Physiol Scand 176:215-225, 2002

57. Mootha VK, Lindgren CM, Eriksson KF, Subramanian A, Sihag S, Lehar J, Puigserver P, Carlsson E, Ridderstrale M, Laurila E, Houstis N, Daly MJ, Patterson N, Mesirov JP, Golub TR, Tamayo P, Spiegelman B, Lander ES, Hirschhorn JN, Altshuler D, Groop LC: PGC-1 $\alpha$-responsive genes involved in oxidative phosphorylation are coordinately downregulated in human diabetes. Nat Genet 34:267-273, 2003

58. Simoneau JA, Bouchard C: Skeletal muscle metabolism and body fat content in men and women. Obes Res 3:23-29, 1995

59. Bouchard C, Simoneau JA, Lortie G, Boulay MR, Marcotte M, Thibault MC: Genetic effects in human skeletal muscle fiber type distribution and enzyme activities. Can J Physiol Pharmacol 64:1245-1251, 1986 
60. Tarnopolsky MA, Rennie CD, Robertshaw HA, Fedak-Tarnopolsky SN, Devries MC, Hamadeh $\mathrm{MJ}$ : Influence of endurance exercise training and sex on intramyocellular lipid and mitochondrial ultrastructure, substrate use, and mitochondrial enzyme activity. Am J Physiol Regul Integr Comp Physiol 292:R1271-1278, 2007

61. Franks PW, Loos RJ: PGC-1 $\alpha$ gene and physical activity in type 2 diabetes mellitus. Exerc Sport Sci Rev 34:171-175, 2006

62. McCarty MF: Up-regulation of PPAR $\gamma$ coactivator- $1 \alpha$ as a strategy for preventing and reversing insulin resistance and obesity. Med Hypotheses 64:399-407, 2005

63. Pilegaard $H$, Saltin B, Neufer PD: Exercise induces transient transcriptional activation of the PGC-1 $\alpha$ gene in human skeletal muscle. J Physiol 546:851-858, 2003

64. Puigserver $P$, Spiegelman BM: Peroxisome proliferator-activated receptor- $\gamma$ coactivator $1 \alpha($ PGC-1 $\alpha)$ : transcriptional coactivator and metabolic regulator. Endocr Rev 24:7890, 2003

65. Dhar SS, Ongwijitwat S, Wong-Riley MT: Nuclear respiratory factor 1 regulates all ten nuclear-encoded subunits of cytochrome c oxidase in neurons. J Biol Chem 283:31203129, 2008

66. Mortensen $\mathrm{OH}$, Frandsen L, Schjerling P, Nishimura E, Grunnet N: PGC- $1 \alpha$ and PGC-1 $\beta$ have both similar and distinct effects on myofiber switching toward an oxidative phenotype. Am J Physiol Endocrinol Metab 291:E807-816, 2006

67. Michael LF, Wu Z, Cheatham RB, Puigserver P, Adelmant G, Lehman JJ, Kelly DP, Spiegelman BM: Restoration of insulin-sensitive glucose transporter (GLUT4) gene expression in muscle cells by the transcriptional coactivator PGC-1. Proc Natl Acad Sci $U$ S A 98:3820-3825, 2001

68. Puigserver P, Wu Z, Park CW, Graves R, Wright M, Spiegelman BM: A cold-inducible coactivator of nuclear receptors linked to adaptive thermogenesis. Cell 92:829-839, 1998

69. Wu Z, Puigserver P, Andersson U, Zhang C, Adelmant G, Mootha V, Troy A, Cinti S, Lowell B, Scarpulla RC, Spiegelman BM: Mechanisms controlling mitochondrial biogenesis and respiration through the thermogenic coactivator PGC-1. Cell 98:115-124, 1999

70. Irrcher I, Adhihetty PJ, Sheehan T, Joseph AM, Hood DA: PPAR $\gamma$ coactivator-1 $\alpha$ expression during thyroid hormone- and contractile activity-induced mitochondrial adaptations. Am J Physiol Cell Physiol 284:C1669-1677, 2003

71. Lin J, Wu H, Tarr PT, Zhang CY, Wu Z, Boss O, Michael LF, Puigserver P, Isotani E, OIson EN, Lowell BB, Bassel-Duby R, Spiegelman BM: Transcriptional co-activator PGC-1 $\alpha$ drives the formation of slow-twitch muscle fibres. Nature 418:797-801, 2002

72. Kramer DK, Ahlsen M, Norrbom J, Jansson E, Hjeltnes N, Gustafsson T, Krook A: Human skeletal muscle fibre type variations correlate with PPAR $\alpha$, PPAR $\delta$ and PGC-1 $\alpha$ mRNA. Acta Physiol (Oxf) 188:207-216, 2006

73. Leick L, Wojtaszewski JF, Johansen ST, Kiilerich K, Comes G, Hellsten Y, Hidalgo J, Pilegaard H: PGC- $1 \alpha$ is not mandatory for exercise- and training-induced adaptive gene responses in mouse skeletal muscle. Am J Physiol Endocrinol Metab 294:E463-474, 2008

74. Carey AL, Petersen EW, Bruce CR, Southgate RJ, Pilegaard H, Hawley JA, Pedersen BK, Febbraio MA: Discordant gene expression in skeletal muscle and adipose tissue of patients with type 2 diabetes: effect of interleukin-6 infusion. Diabetologia 49:10001007, 2006

75. Mensink M, Hesselink MK, Russell AP, Schaart G, Sels JP, Schrauwen P: Improved skeletal muscle oxidative enzyme activity and restoration of PGC- $1 \alpha$ and PPAR $\beta / \delta$ gene expression upon rosiglitazone treatment in obese patients with type 2 diabetes mellitus. Int J Obes (Lond) 31:1302-1310, 2007

76. Patti ME, Butte AJ, Crunkhorn S, Cusi K, Berria R, Kashyap S, Miyazaki Y, Kohane I, Costello M, Saccone R, Landaker EJ, Goldfine AB, Mun E, DeFronzo R, Finlayson J, Kahn $\mathrm{CR}$, Mandarino $\mathrm{L}$ : Coordinated reduction of genes of oxidative metabolism in humans 
with insulin resistance and diabetes: Potential role of PGC1 and NRF1. Proc Natl Acad Sci U S A 100:8466-8471, 2003

77. Norrbom J, Sundberg CJ, Ameln H, Kraus WE, Jansson E, Gustafsson T: PGC-1 $\alpha$ mRNA expression is influenced by metabolic perturbation in exercising human skeletal muscle. J Appl Physiol 96:189-194, 2004

78. Terada S, Goto M, Kato M, Kawanaka K, Shimokawa T, Tabata I: Effects of lowintensity prolonged exercise on PGC-1 mRNA expression in rat epitrochlearis muscle. Biochem Biophys Res Commun 296:350-354, 2002

79. Silveira LR, Pilegaard H, Kusuhara K, Curi R, Hellsten $Y$ : The contraction induced increase in gene expression of peroxisome proliferator-activated receptor (PPAR)- $\gamma$ coactivator $1 \alpha(P G C-1 \alpha)$, mitochondrial uncoupling protein 3 (UCP3) and hexokinase II (HKII) in primary rat skeletal muscle cells is dependent on reactive oxygen species. Biochim Biophys Acta 1763:969-976, 2006

80. Russell AP, Feilchenfeldt J, Schreiber S, Praz M, Crettenand A, Gobelet C, Meier CA, Bell DR, Kralli A, Giacobino JP, Deriaz O: Endurance training in humans leads to fiber type-specific increases in levels of peroxisome proliferator-activated receptor- $\gamma$ coactivator- 1 and peroxisome proliferator-activated receptor- $\alpha$ in skeletal muscle. Diabetes 52:2874-2881, 2003

81. Pilz RB, Casteel DE: Regulation of gene expression by cyclic GMP. Circ Res 93:10341046, 2003

82. Akimoto T, Pohnert SC, Li P, Zhang M, Gumbs C, Rosenberg PB, Williams RS, Yan Z: Exercise stimulates $P g c-1 \alpha$ transcription in skeletal muscle through activation of the p38 MAPK pathway. J Biol Chem 280:19587-19593, 2005

83 Andrisani OM: CREB-mediated transcriptional control. Crit Rev Eukaryot Gene Expr 9:19-32, 1999

84. Chen ZP, Mitchelhill KI, Michell BJ, Stapleton D, Rodriguez-Crespo I, Witters LA, Power DA, Ortiz de Montellano PR, Kemp BE: AMP-activated protein kinase phosphorylation of endothelial NO synthase. FEBS Lett 443:285-289, 1999

85. Fryer LG, Hajduch E, Rencurel F, Salt IP, Hundal HS, Hardie DG, Carling D: Activation of glucose transport by AMP-activated protein kinase via stimulation of nitric oxide synthase. Diabetes 49:1978-1985, 2000

86. Gudi T, Casteel DE, Vinson C, Boss GR, Pilz RB: NO activation of fos promoter elements requires nuclear translocation of G-kinase I and CREB phosphorylation but is independent of MAP kinase activation. Oncogene 19:6324-6333, 2000

87. Nisoli E, Clementi E, Paolucci C, Cozzi V, Tonello C, Sciorati C, Bracale R, Valerio A, Francolini M, Moncada S, Carruba MO: Mitochondrial biogenesis in mammals: the role of endogenous nitric oxide. Science 299:896-899, 2003

88. Zong H, Ren JM, Young LH, Pypaert M, Mu J, Birnbaum MJ, Shulman GI: AMP kinase is required for mitochondrial biogenesis in skeletal muscle in response to chronic energy deprivation. Proc Natl Acad Sci U S A 99:15983-15987, 2002

89. Sun $P$, Enslen $H$, Myung PS, Maurer RA: Differential activation of CREB by $\mathrm{Ca}^{2+} /$ calmodulin-dependent protein kinases type II and type IV involves phosphorylation of a site that negatively regulates activity. Genes Dev 8:2527-2539, 1994

90. Koulmann N, Bigard AX: Interaction between signalling pathways involved in skeletal muscle responses to endurance exercise. Pflugers Arch 452:125-139, 2006

91. Nieman DC, Davis JM, Henson DA, Gross SJ, Dumke CL, Utter AC, Vinci DM, Carson JA, Brown A, McAnulty SR, McAnulty LS, Triplett NT: Muscle cytokine mRNA changes after $2.5 \mathrm{~h}$ of cycling: influence of carbohydrate. Med Sci Sports Exerc 37:1283-1290, 2005

92. Pedersen BK, Toft AD: Effects of exercise on lymphocytes and cytokines. Br J Sports Med 34:246-251, 2000

93. Stefan N, Thamer C, Staiger H, Machicao F, Machann J, Schick F, Venter C, Niess A, Laakso M, Fritsche A, Haring HU: Genetic variations in PPARD and PPARGC1A determine mitochondrial function and change in aerobic physical fitness and insulin sensitivity during lifestyle intervention. J Clin Endocrinol Metab 92:1827-1833, 2007 
94. Lucia A, Gomez-Gallego F, Barroso I, Rabadan M, Bandres F, San Juan AF, Chicharro $\mathrm{JL}$, Ekelund U, Brage S, Earnest CP, Wareham NJ, Franks PW: PPARGC1A genotype (Gly482Ser) predicts exceptional endurance capacity in European men. J Appl Physiol 99:344-348, 2005

95. Ling C, Poulsen P, Carlsson E, Ridderstrale M, Almgren P, Wojtaszewski J, Beck-Nielsen $H$, Groop L, Vaag A: Multiple environmental and genetic factors influence skeletal muscle $P G C-1 \alpha$ and $P G C-1 \beta$ gene expression in twins. J Clin Invest 114:1518-1526, 2004

96. Franks PW, Barroso I, Luan J, Ekelund U, Crowley VE, Brage S, Sandhu MS, Jakes RW, Middelberg RP, Harding AH, Schafer AJ, O'Rahilly S, Wareham NJ: PGC-1 $\alpha$ genotype modifies the association of volitional energy expenditure with $\mathrm{VO}_{2 \max }$. Med Sci Sports Exerc 35:1998-2004, 2003

97. Barroso I, Luan J, Sandhu MS, Franks PW, Crowley V, Schafer AJ, O'Rahilly S, Wareham NJ: Meta-analysis of the Gly482Ser variant in PPARGC1A in type 2 diabetes and related phenotypes. Diabetologia 49:501-505, 2006

98. Meijer EP, Goris AH, Wouters L, Westerterp KR: Physical inactivity as a determinant of the physical activity level in the elderly. Int J Obes Relat Metab Disord 25:935-939, 2001

99. Wang YX, Lee CH, Tiep S, Yu RT, Ham J, Kang H, Evans RM: Peroxisome-proliferatoractivated receptor $\delta$ activates fat metabolism to prevent obesity. Cell 113:159-170, 2003

100. Tanaka T, Yamamoto J, Iwasaki S, Asaba H, Hamura H, Ikeda $Y$, Watanabe M, Magoori K, Ioka RX, Tachibana K, Watanabe Y, Uchiyama Y, Sumi K, Iguchi H, Ito S, Doi T, Hamakubo T, Naito M, Auwerx J, Yanagisawa M, Kodama T, Sakai J: Activation of peroxisome proliferator-activated receptor $\delta$ induces fatty acid $\beta$-oxidation in skeletal muscle and attenuates metabolic syndrome. Proc Natl Acad Sci U S A 100:15924-15929, 2003

101. Dressel U, Allen TL, Pippal JB, Rohde PR, Lau P, Muscat GE: The peroxisome proliferator-activated receptor $\beta / \delta$ agonist, GW501516, regulates the expression of genes involved in lipid catabolism and energy uncoupling in skeletal muscle cells. Mol Endocrinol 17:2477-2493, 2003

102. Nilsson E, Poulsen P, Sjogren M, Ling C, Ridderstrale M, Groop L, Vaag A: Regulation of

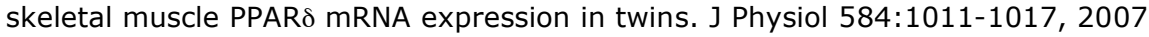

103. Djouadi F, Aubey F, Schlemmer D, Bastin J: Peroxisome proliferator activated receptor $\delta$ (PPAR $\delta$ ) agonist but not PPAR $\alpha$ corrects carnitine palmitoyl transferase 2 deficiency in human muscle cells. J Clin Endocrinol Metab 90:1791-1797, 2005

104. Jucker BM, Yang D, Casey WM, Olzinski AR, Williams C, Lenhard SC, Legos JJ, Hawk CT, Sarkar SK, Newsholme SJ: Selective PPARd agonist treatment increases skeletal muscle lipid metabolism without altering mitochondrial energy coupling: an in vivo magnetic resonance spectroscopy study. Am J Physiol Endocrinol Metab 293:E12561264,2007

105. Constantin D, Constantin-Teodosiu D, Layfield R, Tsintzas K, Bennett AJ, Greenhaff PL: PPAR agonism induces a change in fuel metabolism and activation of an atrophy programme, but does not impair mitochondrial function in rat skeletal muscle. J Physiol 583:381-390, 2007

106. Riserus U, Sprecher D, Johnson T, Olson E, Hirschberg S, Liu A, Fang Z, Hegde P, Richards D, Sarov-Blat L, Strum JC, Basu S, Cheeseman J, Fielding BA, Humphreys SM, Danoff T, Moore NR, Murgatroyd P, O'Rahilly S, Sutton P, Willson T, Hassall D, Frayn $\mathrm{KN}$, Karpe F: Activation of peroxisome proliferator-activated receptor (PPAR) $\delta$ promotes reversal of multiple metabolic abnormalities, reduces oxidative stress, and increases fatty acid oxidation in moderately obese men. Diabetes 57:332-339, 2008

107. Wang YX, Zhang CL, Yu RT, Cho HK, Nelson MC, Bayuga-Ocampo CR, Ham J, Kang H, Evans RM: Regulation of muscle fiber type and running endurance by PPARS. PLoS Biol 2:e294, 2004 
108. Grimaldi PA: Roles of PPAR in the control of muscle development and metabolism. Biochem Soc Trans 31:1130-1132, 2003

109. Luquet S, Lopez-Soriano J, Holst D, Fredenrich A, Melki J, Rassoulzadegan M, Grimaldi PA: Peroxisome proliferator-activated receptor $\delta$ controls muscle development and oxidative capability. Faseb J 17:2299-2301, 2003

110. Stunkard AJ, Messick S: The three-factor eating questionnaire to measure dietary restraint, disinhibition and hunger. J Psychosom Res 29:71-83, 1985

111. Rutters F, Nieuwenhuizen AG, Lemmens SG, Born JM, Westerterp-Plantenga MS: Acute Stress-related Changes in Eating in the Absence of Hunger. Obesity (Silver Spring) 17:72-77, 2009

112. Tartaglia LA, Dembski M, Weng X, Deng N, Culpepper J, Devos R, Richards GJ, Campfield LA, Clark FT, Deeds J, Muir C, Sanker S, Moriarty A, Moore KJ, Smutko JS, Mays GG, Wool EA, Monroe CA, Tepper RI: Identification and expression cloning of a leptin receptor, OB-R. Cell 83:1263-1271, 1995

113. Flier JS, Harris M, Hollenberg AN: Leptin, nutrition, and the thyroid: the why, the wherefore, and the wiring. J Clin Invest 105:859-861, 2000

114. Kristensen $P$, Judge ME, Thim L, Ribel U, Christjansen KN, Wulff BS, Clausen JT, Jensen PB, Madsen OD, Vrang N, Larsen PJ, Hastrup S: Hypothalamic CART is a new anorectic peptide regulated by leptin. Nature 393:72-76, 1998

115. Ebihara K, Ogawa Y, Katsuura G, Numata Y, Masuzaki H, Satoh N, Tamaki M, Yoshioka T, Hayase M, Matsuoka N, Aizawa-Abe M, Yoshimasa Y, Nakao K: Involvement of agouti-related protein, an endogenous antagonist of hypothalamic melanocortin receptor, in leptin action. Diabetes 48:2028-2033, 1999

116. Mizuno TM, Mobbs CV: Hypothalamic agouti-related protein messenger ribonucleic acid is inhibited by leptin and stimulated by fasting. Endocrinology 140:814-817, 1999

117. Anini $Y$, Brubaker PL: Role of leptin in the regulation of glucagon-like peptide-1 secretion. Diabetes 52:252-259, 2003

118. Kreymann B, Williams G, Ghatei MA, Bloom SR: Glucagon-like peptide-1 7-36: a physiological incretin in man. Lancet 2:1300-1304, 1987

119. Drucker DJ: Glucagon-like peptides. Diabetes 47:159-169, 1998

120. Batterham RL, Cohen MA, Ellis SM, Le Roux CW, Withers DJ, Frost GS, Ghatei MA, Bloom SR: Inhibition of food intake in obese subjects by peptide $\mathrm{YY}_{3-36}$. N Engl J Med 349:941-948, 2003

121. McGowan BM, Bloom SR: Peptide YY and appetite control. Curr Opin Pharmacol 4:583588,2004

122. Tovar SA, Seoane LM, Caminos JE, Nogueiras R, Casanueva FF, Dieguez C: Regulation of peptide YY levels by age, hormonal, and nutritional status. Obes Res 12:1944-1950, 2004

123. Chen HY, Trumbauer ME, Chen AS, Weingarth DT, Adams JR, Frazier EG, Shen Z, Marsh DJ, Feighner SD, Guan XM, Ye Z, Nargund RP, Smith RG, Van der Ploeg LH, Howard AD, MacNeil DJ, Qian S: Orexigenic action of peripheral ghrelin is mediated by neuropeptide $Y$ and agouti-related protein. Endocrinology 145:2607-2612, 2004

124. Kamegai J, Tamura H, Shimizu T, Ishii S, Sugihara H, Wakabayashi I: Chronic central infusion of ghrelin increases hypothalamic neuropeptide $Y$ and Agouti-related protein mRNA levels and body weight in rats. Diabetes 50:2438-2443, 2001

125. Chagnon YC, Wilmore JH, Borecki IB, Gagnon J, Perusse L, Chagnon M, Collier GR, Leon AS, Skinner JS, Rao DC, Bouchard C: Associations between the leptin receptor gene and adiposity in middle-aged Caucasian males from the HERITAGE family study. J Clin Endocrinol Metab 85:29-34, 2000

126. Fried SK, Ricci MR, Russell CD, Laferrere B: Regulation of leptin production in humans. J Nutr 130:3127S-3131S, 2000

127. Hoffstedt J, Eriksson P, Mottagui-Tabar S, Arner P: A polymorphism in the leptin promoter region (-2548 G/A) influences gene expression and adipose tissue secretion of leptin. Horm Metab Res 34:355-359, 2002 
128. Mammes O, Betoulle D, Aubert R, Herbeth B, Siest G, Fumeron F: Association of the G$2548 \mathrm{~A}$ polymorphism in the $5^{\prime}$ region of the $L E P$ gene with overweight. Ann Hum Genet 64:391-394, 2000

129. Zitzmann M, Gromoll J, von Eckardstein A, Nieschlag E: The CAG repeat polymorphism in the androgen receptor gene modulates body fat mass and serum concentrations of leptin and insulin in men. Diabetologia 46:31-39, 2003

130. Wang TN, Huang MC, Chang WT, Ko AM, Tsai EM, Liu CS, Lee CH, Ko YC: G-2548A polymorphism of the leptin gene is correlated with extreme obesity in Taiwanese aborigines. Obesity (Silver Spring) 14:183-187, 2006

131. Yiannakouris N, Yannakoulia M, Melistas L, Chan JL, Klimis-Zacas D, Mantzoros CS: The Q223R polymorphism of the leptin receptor gene is significantly associated with obesity and predicts a small percentage of body weight and body composition variability. J Clin Endocrinol Metab 86:4434-4439, 2001

132. Clement K, Vaisse C, Lahlou N, Cabrol S, Pelloux V, Cassuto D, Gourmelen M, Dina C, Chambaz J, Lacorte JM, Basdevant A, Bougneres P, Lebouc Y, Froguel P, Guy-Grand B: A mutation in the human leptin receptor gene causes obesity and pituitary dysfunction. Nature 392:398-401, 1998

133. Lahlou N, Clement K, Carel JC, Vaisse C, Lotton C, Le Bihan Y, Basdevant A, Lebouc Y, Froguel P, Roger M, Guy-Grand B: Soluble leptin receptor in serum of subjects with complete resistance to leptin: relation to fat mass. Diabetes 49:1347-1352, 2000

134. Chagnon YC, Chung WK, Perusse L, Chagnon M, Leibel RL, Bouchard C: Linkages and associations between the leptin receptor (LEPR) gene and human body composition in the Quebec Family Study. Int J Obes Relat Metab Disord 23:278-286, 1999

135. Mattevi VS, Zembrzuski VM, Hutz MH: Association analysis of genes involved in the leptin-signaling pathway with obesity in Brazil. Int J Obes Relat Metab Disord 26:11791185,2002

136. van der Vleuten GM, Kluijtmans LA, Hijmans A, Blom HJ, Stalenhoef AF, de Graaf J: The Gln223Arg polymorphism in the leptin receptor is associated with familial combined hyperlipidemia. Int J Obes (Lond) 30:892-898, 2006

137. Ahituv N, Kavaslar N, Schackwitz W, Ustaszewska A, Collier JM, Hebert S, Doelle H, Dent R, Pennacchio LA, McPherson R: A PYY Q62P variant linked to human obesity. Hum Mol Genet 15:387-391, 2006

138. Vartiainen J, Kesaniemi YA, Ukkola O: Sequencing analysis of ghrelin gene 5 ' flanking region: relations between the sequence variants, fasting plasma total ghrelin concentrations, and body mass index. Metabolism 55:1420-1425, 2006

139. Diepvens K, Haberer D, Westerterp-Plantenga MS: Different proteins and biopeptides differently affect satiety and anorexigenic/orexigenic hormones in healthy humans. Int J Obes (Lond) 32: 510-518, 2008

140. Batterham RL, Heffron H, Kapoor S, Chivers JE, Chandarana K, Herzog H, Le Roux CW, Thomas EL, Bell JD, Withers DJ: Critical role for peptide YY in protein-mediated satiation and body-weight regulation. Cell Metab 4:223-233, 2006

141. Makovey J, Naganathan V, Seibel M, Sambrook P: Gender differences in plasma ghrelin and its relations to body composition and bone - an opposite-sex twin study. Clin Endocrinol (Oxf) 66:530-537, 2007

142. De Castro JM: Heritability of hunger relationships with food intake in free-living humans. Physiol Behav 67:249-258, 1999

143. Dina C, Meyre D, Gallina S, Durand E, Korner A, Jacobson P, Carlsson LM, Kiess W, Vatin V, Lecoeur C, Delplanque J, Vaillant E, Pattou F, Ruiz J, Weill J, Levy-Marchal C, Horber F, Potoczna N, Hercberg S, Le Stunff C, Bougneres P, Kovacs P, Marre M, Balkau B, Cauchi S, Chevre JC, Froguel P: Variation in FTO contributes to childhood obesity and severe adult obesity. Nat Genet 39:724-726, 2007

144. Do R, Bailey SD, Desbiens K, Belisle A, Montpetit A, Bouchard C, Perusse L, Vohl MC, Engert JC: Genetic variants of FTO influence adiposity, insulin sensitivity, leptin levels, and resting metabolic rate in the Quebec Family Study. Diabetes 57:1147-1150, 2008 
145. Frayling TM, Timpson NJ, Weedon MN, Zeggini E, Freathy RM, Lindgren CM, Perry JR, Elliott KS, Lango H, Rayner NW, Shields B, Harries LW, Barrett JC, Ellard S, Groves CJ, Knight B, Patch AM, Ness AR, Ebrahim S, Lawlor DA, Ring SM, Ben-Shlomo Y, Jarvelin MR, Sovio U, Bennett AJ, Melzer D, Ferrucci L, Loos RJ, Barroso I, Wareham NJ, Karpe F, Owen KR, Cardon LR, Walker M, Hitman GA, Palmer CN, Doney AS, Morris AD, Smith GD, Hattersley AT, McCarthy MI: A common variant in the FTO gene is associated with body mass index and predisposes to childhood and adult obesity. Science 316:889894, 2007

146. Hinney A, Nguyen TT, Scherag A, Friedel S, Bronner G, Muller TD, Grallert H, Illig T, Wichmann HE, Rief W, Schafer H, Hebebrand J: Genome wide association (GWA) study for early onset extreme obesity supports the role of fat mass and obesity associated gene (FTO) variants. PLoS ONE 2:e1361, 2007

147. Qi L, Kang K, Zhang C, van Dam RM, Kraft P, Hunter D, Lee CH, Hu FB: FTO Gene Variant Is Associated with Obesity: Longitudinal Analyses in Two Cohort Studies and Functional Test. Diabetes 57:3145-3151, 2008

148. Scuteri A, Sanna S, Chen WM, Uda M, Albai G, Strait J, Najjar S, Nagaraja R, Orru M, Usala G, Dei M, Lai S, Maschio A, Busonero F, Mulas A, Ehret GB, Fink AA, Weder AB, Cooper RS, Galan P, Chakravarti A, Schlessinger D, Cao A, Lakatta E, Abecasis GR: Genome-wide association scan shows genetic variants in the FTO gene are associated with obesity-related traits. PLoS Genet 3:e115, 2007

149. Gerken T, Girard CA, Tung YC, Webby CJ, Saudek V, Hewitson KS, Yeo GS, McDonough MA, Cunliffe S, McNeill LA, Galvanovskis J, Rorsman P, Robins P, Prieur X, Coll AP, Ma M, Jovanovic Z, Farooqi IS, Sedgwick B, Barroso I, Lindahl T, Ponting CP, Ashcroft FM, O'Rahilly S, Schofield CJ: The obesity-associated FTO gene encodes a 2-oxoglutaratedependent nucleic acid demethylase. Science 318:1469-1472, 2007

150. Stratigopoulos G, Padilla SL, Leduc CA, Watson E, Hattersley AT, McCarthy MI, Zeltser LM, Chung WK, Leibel RL: Regulation of Fto/Ftm gene expression in mice and humans. Am J Physiol Regul Integr Comp Physiol 294:R1185-1196, 2008

151. Timpson NJ, Emmett PM, Frayling TM, Rogers I, Hattersley AT, McCarthy MI, Davey Smith G: The fat mass- and obesity-associated locus and dietary intake in children. Am J Clin Nutr 88:971-978, 2008

152. Wardle J, Carnell S, Haworth CM, Farooqi IS, O'Rahilly S, Plomin R: Obesity associated genetic variation in FTO is associated with diminished satiety. J Clin Endocrinol Metab 93:3640-3643, 2008

153. Schachter S: Obesity and eating. Internal and external cues differentially affect the eating behavior of obese and normal subjects. Science 161:751-756, 1968

154. De Castro JM, Lilenfeld LR: Influence of heredity on dietary restraint, disinhibition, and perceived hunger in humans. Nutrition 21:446-455, 2005

155. Steinle NI, Hsueh WC, Snitker S, Pollin TI, Sakul H, St Jean PL, Bell CJ, Mitchell BD, Shuldiner AR: Eating behavior in the Old Order Amish: heritability analysis and a genome-wide linkage analysis. Am J Clin Nutr 75:1098-1106, 2002

156. Tholin S, Rasmussen F, Tynelius $P$, Karlsson J: Genetic and environmental influences on eating behavior: the Swedish Young Male Twins Study. Am J Clin Nutr 81:564-569, 2005

157. Westerterp, KR: Energy expenditure. In: Food intake and energy expenditure. Westerterp-plantenga MS, Fredrix EWHM, Steffens AB (Eds): CRC Press, 1994, pp 235257 

Chapter 2

Skeletal muscle fibre-type distribution and habitual physical activity in daily life

Marcel den Hoed, Matthijs KC Hesselink and Klaas R Westerterp

Scand J Med Sci Sports. E-publication 


\begin{abstract}
The capacity to perform habitual physical activity largely depends on physical fitness. Muscle fibre-type distribution (Muscle ${ }_{\mathrm{FTD}}$ ) is associated with physical fitness and may influence the capacity to perform habitual physical activity. The purpose of this study was to determine whether habitual physical activity in daily life and Muscle $_{\text {FTD }}$ are related. Thirty-eight healthy non-athletes (31 women, 7 men) were recruited. Habitual physical activity was measured twice for 14 days using a triaxial accelerometer for movement registration (Tracmor). From Tracmor output, the proportion of time subjects were physically active at a low, moderate and high intensity was determined (\%Low, \%Moderate and \%High, respectively). A total activity index $\left(\mathrm{PA}_{\text {index }}\right)$ and sub-scores on work, leisure time and sports were obtained using the Baecke questionnaire. Muscle ${ }_{\mathrm{FTD}}$ was determined using immunofluorescence against respective myosin heavy chain isoforms. No relation-

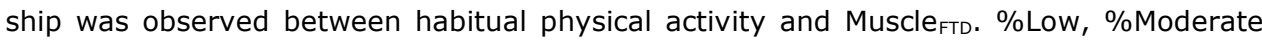
and \%High, as well as $\mathrm{PA}_{\text {index }}$ and its sub-scores were not related to Muscle ${ }_{\text {TTD }}$ either. The time spent on sports was associated with the proportion of type I and $\mathrm{II}_{\mathrm{X}}$ fibres $(P=0.06$ and $P<0.01$, respectively). In conclusion, Muscle Fтр $_{\text {p }}$ probably cannot explain why some people are more prone to engaging in physical activities than others.
\end{abstract}




\section{Introduction}

Activity-related energy expenditure is the most variable component of total energy expenditure (1) and appears to be an important determinant of energy balance (2). This implies that a reduced habitual physical activity is a potentially important contributor to a predisposition to obesity (3-7). In a recent twin study, habitual physical activity was determined using a triaxial accelerometer for movement registration. Based on the difference in intra-pair correlation for habitual physical activity between monozygotic and dizygotic twins ( $R=0.88$ and 0.42 , respectively), additive genetic factors were concluded to explain $78 \%$ of the inter-subject variation in habitual physical activity (8). This suggests that genes determine to a large extent whether a person is prone to engaging in physical activities. How habitual physical activity is affected by the genotype remains to be established.

One of the potential factors through which the genetic background could affect habitual physical activity is skeletal muscle fibre-type distribution (Muscle ${ }_{\text {FTD }}$ ) (9-13), defined as the relative number of type $\mathrm{I}, \mathrm{II}_{\mathrm{A}}$ and $\mathrm{II}_{\mathrm{X}}$ muscle fibres (\%Type $\mathrm{I}, \%$ Type $\mathrm{II}_{\mathrm{A}}$ and \%Type $\mathrm{II}_{\mathrm{X}}$, respectively). Based on monozygotic and dizygotic twin studies, it has been estimated that approximately $45 \%$ of the variation in \%Type I is associated with inherited

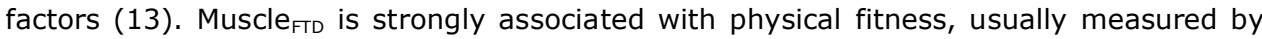
maximal oxygen uptake $\left(\mathrm{VO}_{2}\right.$-max), and might thereby influence the capacity to perform physical activity (14). Indeed, positive associations between leisure time physical activity ( $\left.\mathrm{PA}_{\text {leisure }}\right)$, measured using questionnaires and interviews, and \%Type I have been observed (14-16). Considering the aforementioned, it might well be that part of the genetic

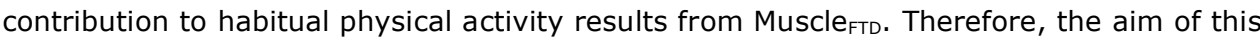
study was to examine the association between habitual physical activity and muscle fibre-type distribution in a population of healthy, young adults. Habitual physical activity was hypothesized to be higher in subjects with a Muscle $e_{\text {FT }}$ previously associated with a higher physical fitness, that is, a higher \%Type I and a lower \%Type $\mathrm{II}_{\mathrm{X}}(10)$.

\section{Methods}

\section{Subjects}

Based on an effect size of 0.25 , a power calculation indicated that 33 subjects are required for a power of 0.8 in simple linear regression analyses. Taking a dropout rate of $15 \%$ into account, 38 healthy, non-smoking subjects (31 females, 7 males) aged 20 2 years were recruited to participate in this study. Subjects were not using any medication except for oral contraceptives. Recruitment was carried out using flyers in the university building. Subjects spending over $2 \mathrm{~h}$ /week on endurance sports, or $5 \mathrm{~h}$ on sports in general, were excluded from participation to minimize the effect of exercise training on Muscle $_{\text {FTD }}$. The subjects that were recruited either did not participate in sports or met the aforementioned criterion. These subjects participated in sports on a recreational basis and in a wide range of sports. Information about the purpose and protocol of the study, 
as well as its risks and discomfort were provided both orally and in writing. All subjects provided written informed consent before participating in the study. The study conformed to the standards set by the Declaration of Helsinki and the local Ethics Committee approved the study. Subject characteristics $(n=38)$ are presented in Table 1.

Table 1: Subject characteristics

\begin{tabular}{lll}
\hline & Men & Women \\
\hline $\mathrm{n}$ & 7 & 31 \\
Age $(\mathrm{y})$ & $20 \pm 2$ & $20 \pm 2$ \\
$\mathrm{BM}(\mathrm{kg})$ & $79.3 \pm 14.1$ & $63.1 \pm 8.2^{\#}$ \\
Height $(\mathrm{m})$ & $1.84 \pm 0.06$ & $1.69 \pm 0.06^{\#}$ \\
BMI $\left(\mathrm{kg} / \mathrm{m}^{2}\right)$ & $23.2 \pm 3.0$ & $22.0 \pm 2.5$ \\
\hline
\end{tabular}

BM, Body mass; BMI, body mass index; Values are means \pm SD. Significant sex difference \# $P<0.001$.

\section{Habitual physical activity}

Habitual physical activity was measured using a triaxial accelerometer for movement registration (Tracmor IV; Philips research, Eindhoven, The Netherlands) sensitive to a wide range of body movements. The accelerometer has been validated with doubly labelled water, the gold standard for measuring energy expenditure in daily life (17). The Tracmor registers accelerations of the trunk along the anterio-posterior, medio-lateral and longitudinal axis using three uniaxial piezo-electric accelerometers (details are provided elsewhere (17)). To ensure a valid reflection of long-term daily life activities, the accelerometer was worn for two 14-day periods under free-living conditions. Subsequently, habitual physical activity was acquired by summing the output of all three axes and is presented as Megacounts per day (MCnts/day). Habitual physical activity was defined as the average of both measurement periods.

Subjects were instructed to wear the Tracmor from the moment they woke up in the morning until they went back to bed at night. To verify whether subjects lived up to this instruction, waking hours and clock times of wearing the Tracmor were noted. To make sure only representative days were included, the difference between the total time the subject was awake and the time the accelerometer was worn was not allowed to exceed $75 \mathrm{~min} /$ day. The few days during which this difference was more than 75 min were excluded from the analysis. This resulted in an average of 26 representative days per subject. To make sure the subjects met the inclusion criterion concerning their participation in sports, the actual sporting hours were also recorded in the diary.

Using Tracmor data, the proportion of time subjects were physically active at a low, moderate and high intensity (\%Low, \%Moderate and \%High, respectively) was determined. The cut-off points for the intensity categories were determined in a pilot study $(n=5)$. The cut-off point for low-intensity physical activity was set by Tracmor outputs associated with walking on a treadmill at $3.5 \mathrm{~km} / \mathrm{h}$, which corresponds with approximately 3 metabolic equivalents (METs). For moderate-intensity physical activity, a Tracmor output associated with walking on a treadmill at $5 \mathrm{~km} / \mathrm{h}$ was used, which corresponds with approximately 4.5 METs (18). All physical activity associated with a Tracmor 
output higher than the latter cut-off point was considered high-intensity physical activity.

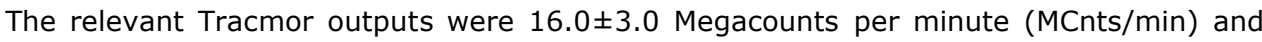
$28.9 \pm 3.0 \mathrm{MCnts} / \mathrm{min}$, respectively. The proportion of time per intensity category was calculated as the sum of all min per intensity category divided by the total duration of the measurement, that is, 28 days minus the number of excluded days.

Using linear regression analysis in a population similar to the present study with respect to habitual physical activity, body composition and age, Plasqui et al. were able to predict the physical activity level (PAL) with an explained variation of $70 \%$ using only habitual physical activity (17). This regression equation was used in the present study to estimate PAL.

Measures for physical activity during work, sports and leisure time were obtained using the Baecke questionnaire (19). Summing the scores of each section provided a total activity index $\left(\mathrm{PA}_{\text {index }}\right)$. Like the Tracmor, the Baecke questionnaire has been validated with doubly labelled water with the $\mathrm{PA}_{\text {index }}$ explaining $45 \%$ of the variation in PAL (20).

\section{Muscle sample analysis}

A muscle biopsy was obtained from the M. Vastus Lateralis under local anaesthesia (xylocaine $2 \%$ ) using a Bergström needle with suction (21). The Vastus Lateralis was selected because of the absence of large vessels or nerves in the region, the presence of type I, $\mathrm{II}_{\mathrm{A}}$ and $\mathrm{II}_{\mathrm{X}}$ muscle fibres in an ample amount (22) and the large inter-individual variation in Muscle $_{\text {FTD }}(23 ; 24)$. Biopsies were frozen in melting isopentane and stored in a precooled aluminium cryo-vial at $-80^{\circ} \mathrm{C}$ until analyzed.

Serial transverse cryosections were cut $(5 \mu \mathrm{m})$ in a crysostat microtome (Leica; CM 3050, Rijswijk, The Netherlands) and thaw-mounted on uncoated pre-cleaned glassslides. After air-drying for $\sim 120 \mathrm{~min}$, sections were again stored at $-80^{\circ} \mathrm{C}$ until processing for routine immunofluorescent staining against distinct myosin heavy chain (MHC) isoforms.

Muscle fibres were characterized as type $\mathrm{I}_{1} \mathrm{II}_{\mathrm{A}}$ or $\mathrm{II}_{\mathrm{X}}$ using antibodies against the respective $\mathrm{MHC}$ isoforms. Briefly, air-dried cryosections were treated for 5 min with $0.5 \%$ triton $X-100$ in PBS and washed for 5 min with PBS. Thereafter, a $0.05 \%$ Tween20/PBS dilution containing the primary antibody for MHCI diluted 1:50 (A4.840, DSHB; Iowa city, Iowa, USA), $\mathrm{MHC} \mathrm{II}_{\mathrm{A}}$ diluted 1:50 (N2.261, DSHB; Iowa city, Iowa, USA) and Anti-laminin diluted 1:200 (L-9393, Sigma; Zwijndrecht, The Netherlands) was applied for 45 min. After three 5 minute washes with PBS the appropriate secondary antibodies (Alexa Fluor 555 Goat anti-Mouse IgM diluted 1:500 (A-21426), Alexa Fluor 488 Goat anti-Mouse IgG1 diluted 1:200 (A-21121) and Alexa Fluor 350 Goat anti-Rabbit IgG diluted 1:130 (A11069) (Molecular Probes Invitrogen; Breda, The Netherlands)) were applied for $45 \mathrm{~min}$ at room temperature. Again, sections were washed with PBS three times for 5 min and embedded in Mowiol 4-88 (475904, Calbiochem; Amsterdam, The Netherlands).

After $24 \mathrm{~h}$, the slides were examined using a Nikon E800 Fluorescence microscope (Uvikon; Bunnik, The Netherlands). Images were captured using a colour CCD camera (Basler $113 \mathrm{C}$ ) with $\mathrm{MHCI}$ in red, $\mathrm{MHC} \mathrm{II}_{\mathrm{A}}$ in green and laminin, a basement membrane 
marker to identify the myofibre boundary, in blue. All fibres without intracellular staining were considered type $\mathrm{II}_{\mathrm{X}}$ muscle fibres.

Digitally captured images (20x magnification) were processed and analyzed using Lucia 4.8 software (Nikon; Düsseldorf, Germany). Muscle fibre typology was measured semiautomatically using a custom written macro that identifies individual muscle fibres. Upon thresholding, red $(\mathrm{MHCI})$, green $\left(\mathrm{MHC} \mathrm{II}_{\mathrm{A}}\right)$ and unstained fibres $\left(\mathrm{MHC} \mathrm{II}_{\mathrm{X}}\right.$ ) were identified and expressed as percentage of the total number of fibres identified. On average, Muscle $_{\text {FTD }}$ was determined in $290 \pm 135$ fibres per subject.

\section{Maximal oxygen uptake}

$\mathrm{VO}_{2}$-max was determined during an incremental maximal intensity test on a calibrated electromechanically braked cycle ergometer (Lode Excalibur; Lode, Groningen, The Netherlands). The initial workload was set at $100 \mathrm{~W}$ for men and $75 \mathrm{~W}$ for women. Subjects were instructed to maintain their crank rate between 80 and $100 \mathrm{rpm}$ at all times during the test. After 5 min of warming-up, workload increased with $50 \mathrm{~W}$ every 2.5 min until exhaustion. Exhaustion was defined as a sudden drop in crank rate below $60 \mathrm{rpm}$, usually resulting in the subjects giving up. Throughout the test, gas exchange was measured continuously using an Oxycon $\beta$ (Oxycon; Mijnhardt, Bunnik, The Netherlands). The analyser was calibrated daily using a 3 litre calibrated syringe (Sensormedics, Anaheim, CA, USA) and a gas mixture of known concentration $\left(5.0 \% \mathrm{CO}_{2}, 95.0 \% \mathrm{~N}_{2}\right) . \mathrm{VO}_{2}$-max was determined using a third order polynome fitted through the data. The maximal value obtained by this polynome was considered the $\mathrm{VO}_{2}$-max.

\section{Body composition}

Fat-free mass (FFM) and fat mass (FM) were determined as subject comparative measures for body composition. Therefore, anthropometric measurements were carried out in the morning after an overnight fast. Body mass was measured on an electric scale (ID 1 Plus; Mettler Toledo, Giessen; Germany) to the nearest $0.01 \mathrm{~kg}$. Height was measured to the nearest $0.1 \mathrm{~cm}$ (Mod. 220; SECA, Hamburg, Germany). Body volume was determined using the underwater weighing technique while correcting for residual long volume using the helium dilution technique (Volugraph VG 2000; Mijnhardt, Bunnik, The Netherlands). Total body water was determined overnight using the deuterium dilution technique according to the Maastricht protocol (25). Body composition was subsequently calculated from body volume and total body water using Siri's three-compartment model (26).

\section{Statistics}

Differences between men and women were tested using Student's t-tests for unpaired samples. Differences in habitual physical activity between the two measurement periods were evaluated using a Student's t-test for paired samples. Bivariate correlation was used to test the association between parameters of physical activity and Muscle FTD. To evaluate the relationship between \%Low, \%Moderate, \%High, and the time spent on 
sports with Muscle $\mathrm{FTD}_{\mathrm{FT}}$ all variables were natural log (In) transformed. This transformation was applied to obtain a normal distribution of the residuals with homoscedasticity, that is, an equal variance over the entire range of predicted values. Statistical analyses were carried out using the Statistical Package for Social Sciences (SPSS) version 11 for Macintosh OS X (SPSS Inc.; Chicago, Illinois, USA). Data are expressed as means \pm SD. For associations, unstandardized coefficients and $95 \%$ confidence intervals, as well as $P$ values are provided. $P$-values $<0.05$ were considered statistically significant.

\section{Results}

Habitual physical activity was not significantly different between the two 14 day measurement periods $(P=0.14)$. Results on habitual physical activity averaged over both periods, as well as on the proportion of time spent in each intensity category are presented in Table 2. $\mathrm{PA}_{\text {index }}$ and Baecke sub-scores, as well as the weekly time spent on sports, Muscle $_{\mathrm{FTD}}, \mathrm{VO}_{2}$-max and body composition are also shown in Table 2.

Habitual physical activity was comparable for men and women: 4128 versus 3704 MCnts/day, respectively (Table 2). The proportion of time spent in each intensity category was comparable between sexes as well, although \%High was significantly higher in men: $1.2 \%$ versus $0.7 \%$ in women $(P<0.01)$. Men and women combined were physically active at a low, moderate and high intensity for approximately $97 \%, 2 \%$ and $1 \%$ of the time, respectively. This corresponds with 30 and 11 min of moderate- and high-intensity physical activity per day. Applying the regression equation developed by Plasqui et al. (17) to the present population showed that PAL ranged from 1.62 to 2.04 . Muscle FTD $_{\text {was }}$ not significantly different between men and women, which confirms the findings of previous studies $(22 ; 27-30)$. When averaged for both sexes, Muscle ${ }_{\text {FTD }}$ was approximately $59 \%$ type $\mathrm{I}, 38 \%$ type $\mathrm{II}_{\mathrm{A}}$ and $3 \%$ type $\mathrm{II}_{\mathrm{X}}$.

No difference was found between men and women for the $\mathrm{PA}_{\text {index }}$ and Baecke sub-scores on work and sports (Table 2). Only the Baecke sub-score for physical activity during leisure time was significantly different between sexes: $3.0 \pm 0.3$ versus $3.4 \pm 0.4$ for men and women, respectively $(P<0.05)$. The weekly time spent on sports did not differ between men and women (Table 2). On average, subjects reported to spend approximately 2 h/week on sports, which corresponds with approximately $17 \mathrm{~min} /$ day.

FFM is the strongest independent predictor of $\mathrm{VO}_{2}$-max, alone explaining $86 \%$ of its variation $(P<0.001)$. Although $\mathrm{VO}_{2}$-max was significantly higher in men than in women, this difference did not remain after adjusting $\mathrm{VO}_{2}$-max for FFM. Based on these results, both sexes were combined for further analyses.

$\mathrm{VO}_{2}$-max expressed per $\mathrm{kg}$ FFM was positively associated with \%Type I $\left(R^{2}=0.13\right.$; $P<0.05)$, and correlated borderline significantly with \%Type $\operatorname{II}_{X}\left(R^{2}=0.10 ; P=0.05\right)$ (Figure 1). A trend towards a positive association was observed between habitual physical activity and $\mathrm{VO}_{2}$-max adjusted for FFM $(P=0.09)$. Habitual physical activity on the other hand was not significantly associated with Muscle FTD $(P$-values $>0.7)$ (Figure 1$)$. No associations were found between \%Low, \%Moderate and \%High with Muscle ${ }_{\text {FTD }}$ either $(P$ values $>0.2)$. Moreover, neither the $\mathrm{PA}_{\text {index }}$ nor the Baecke sub-scores were significantly correlated with Muscle $\mathrm{FTD}_{\mathrm{FT}}(P$-values $>0.2)$. On the contrary, the time weekly spent on 
sports was negatively associated with \%Type $\operatorname{II}_{X}\left(R^{2}=0.19 ; P<0.01\right)$ and tended to correlate positively with \%Type I $\left(R^{2}=0.09 ; P=0.06\right)$. (Figure 2$)$. All unstandardized regression coefficients, $95 \%$ confidence intervals and $P$-values are provided in Table 3.

Table 2: Results on habitual physical activity, muscle fibre-type distribution and body composition

\begin{tabular}{|c|c|c|}
\hline & Men & Women \\
\hline HPA (MCnts/day) & $4128 \pm 636$ & $3704 \pm 675$ \\
\hline PAL & $1.88 \pm 0.10$ & $1.80 \pm 0.11$ \\
\hline \%Low & $96.5 \pm 1.0$ & $97.3 \pm 1.0$ \\
\hline$\%$ Moderate & $2.3 \pm 0.5$ & $2.1 \pm 0.9$ \\
\hline$\%$ High & $1.2 \pm 0.8$ & $0.7 \pm 0.4^{\S}$ \\
\hline $\mathrm{PA}_{\text {index }}$ & $8.1 \pm 1.0$ & $8.6 \pm 0.9$ \\
\hline Baecke Work & $2.0 \pm 0.3$ & $2.2 \pm 0.3$ \\
\hline Baecke Sport & $3.2 \pm 0.7$ & $3.0 \pm 0.6$ \\
\hline Baecke Leisure & $3.0 \pm 0.3$ & $3.4 \pm 0.4^{*}$ \\
\hline Sports (h/week) & $2.2 \pm 1.8$ & $2.1 \pm 1.7$ \\
\hline \%Тype I & $56.6 \pm 12.9$ & $59.6 \pm 10.6$ \\
\hline$\%$ Type $\mathrm{II}_{\mathrm{A}}$ & $39.4 \pm 11.6$ & $37.1 \pm 10.3$ \\
\hline \%Type $\mathrm{II}_{\mathrm{x}}$ & $3.9 \pm 3.9$ & $3.3 \pm 5.1$ \\
\hline $\mathrm{VO}_{2}-\max (\mathrm{I} / \mathrm{min})$ & $4.0 \pm 0.8$ & $2.7 \pm 0.4^{\#}$ \\
\hline $\mathrm{VO}_{2}-\mathrm{max}(\mathrm{ml} / \mathrm{min} / \mathrm{kg} \mathrm{BM})$ & $51.1 \pm 5.1$ & $42.8 \pm 4.7^{\#}$ \\
\hline $\mathrm{VO}_{2}-\mathrm{max}(\mathrm{ml} / \mathrm{min} / \mathrm{kg} \mathrm{FFM})$ & $60.8 \pm 4.8$ & $58.4 \pm 5.7$ \\
\hline FFM $(\mathrm{kg})$ & $66.3 \pm 9.9$ & $46.0 \pm 4.6^{\#}$ \\
\hline FM $(\mathrm{kg})$ & $13.0 \pm 6.3$ & $17.1 \pm 4.8$ \\
\hline
\end{tabular}

HPA, habitual physical activity as measured using a triaxial accelerometer during two periods of two weeks; MCnts, Megacounts; PAL, physical activity level, that is, the factor by which total energy expenditure exceeds resting energy expenditure; \%Low, \%Moderate and \%High, proportion of time subjects were physically active at a low, moderate and high intensity, respectively; $\mathrm{PA}_{\text {index, }}$ total activity index measured with the Baecke questionnaire; Baecke Work, Sport and Leisure, scores on each section of the Baecke questionnaire; Sports, the time spent on sports; FFM, fat-free mass; FM, fat mass; \%Type I, \%Type $\mathrm{II}_{\mathrm{A}}$ and \%Type $\mathrm{II}_{\mathrm{x}}$, proportion of type $\mathrm{I}, \mathrm{II}_{\mathrm{A}}$ and $\mathrm{II}_{\mathrm{X}}$ muscle fibres; $\mathrm{VO}_{2}-\mathrm{max}_{\text {, }}$ maximal oxygen uptake, either absolute, or relative to body mass or FFM; Data are means \pm SD. Significant sex difference $* P<0.05 ; \S P<0.01 ; \# P<0.001$.

\section{Discussion}

The capacity to perform physical activity was proposed earlier to depend on physical fitness $(14 ; 16)$. Since Muscle FTD $_{\text {was }}$ wound to be strongly associated with physical fitness (14), the former was considered a candidate to explain (part of) the inter-individual variation in habitual physical activity. Therefore, the aim of the present study was to determine whether habitual physical activity was associated with Muscle $\mathrm{FTD}_{\mathrm{FT}}$. To this end, habitual physical activity was measured for two periods of 14 days using the Tracmor; a validated triaxial accelerometer for movement registration. The associations observed earlier between physical activity and $\mathrm{VO}_{2}$-max and between $\mathrm{VO}_{2}$-max and Muscle $\mathrm{FTT}_{\text {FD }}$ were confirmed in the present study. This affirms Muscle FrD $_{\text {as a }}$ candidate to influence the capacity to perform physical activity.

To prevent an effect of physical exercise training on Muscle $\mathrm{F}_{\mathrm{FT}}$, subjects spending more than $2 \mathrm{~h}$ /week on endurance sports or more than $5 \mathrm{~h} /$ week on sports in general were excluded from participation. This resulted in an average engagement in sports of $2 \mathrm{~h} /$ week. 
Still, a wide range in habitual physical activity was observed and the range in PAL observed indicates that sedentary as well as physically active subjects were recruited ( 31 ; 32). Subjects spent 30 and $11 \mathrm{~min} /$ day on moderate- and high-intensity physical activity, respectively. These values are close to those recently reported in other studies that used accelerometers in healthy, young adults $(33 ; 34)$. McClain et al. recruited regular runners and obtained a \%Moderate similar to that observed in the present study ( $27 \mathrm{~min} /$ day). $\% H i g h$ on the other hand was more pronounced in the subjects recruited by McClain et al. (48 min/day) (35). This indicates that although physically active subjects were evidently recruited in the present study, the proportion of high-intensity physical activity was lower than observed previously for people actively engaged in endurance sports.
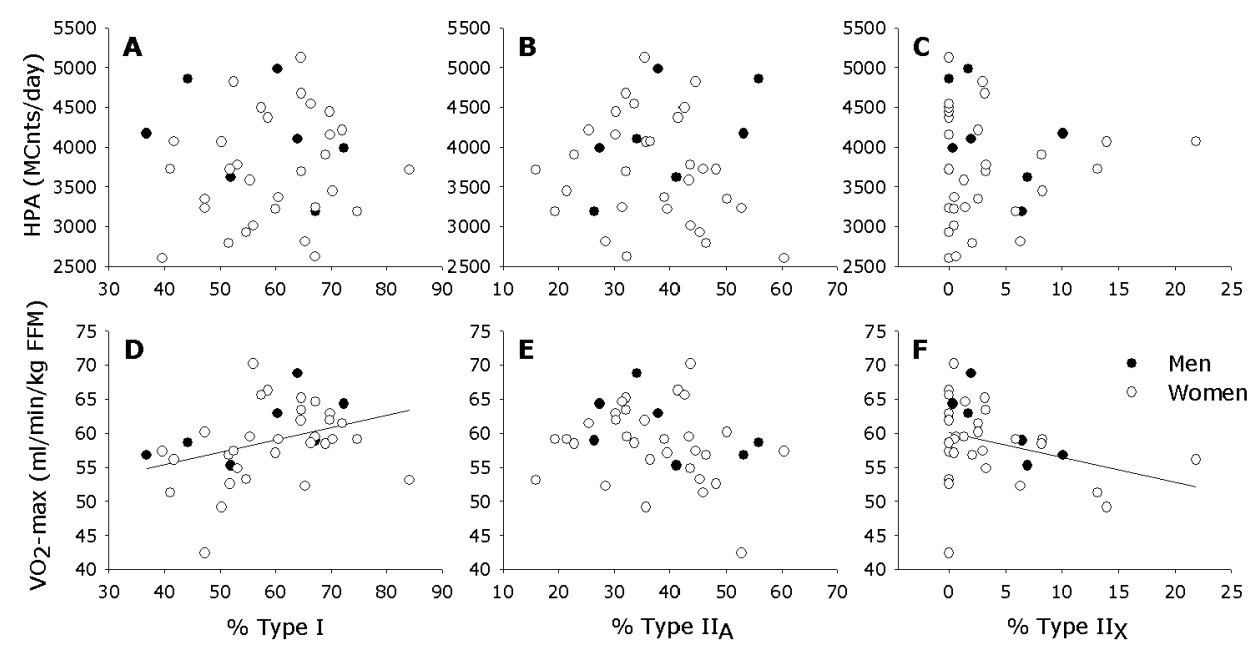

Figure 1: Habitual physical activity and maximal oxygen uptake per $\mathrm{kg}$ fat-free mass as a function of muscle fibre-type distribution. Figures A, B and C show habitual physical activity (HPA) as a function of the proportion of type $\mathrm{I}, \mathrm{II}_{\mathrm{A}}$ and $\mathrm{II}_{\mathrm{X}}$ muscle fibres, respectively. Figures $\mathrm{D}, \mathrm{E}$ and $\mathrm{F}$ show maximal oxygen uptake $\left(\mathrm{VO}_{2}\right.$-max) expressed per $\mathrm{kg}$ fat-free mass (FFM) as a function of the proportion of type $\mathrm{I}_{,} \mathrm{II}_{\mathrm{A}}$ and $\mathrm{II}_{\mathrm{X}}$ muscle fibres, respectively. $\mathrm{D}: P<0.05 ; \mathrm{F}: P=0.05$.

No evidence was found for a relationship between habitual physical activity and Muscle $_{\text {FTD. }}$ The accelerometer used in this study was also used by Joosen et al., who showed that the largest part of inter-subject variation in habitual physical activity results from

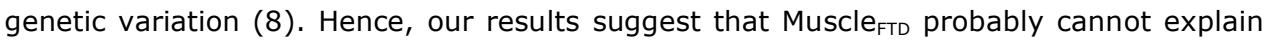
the large inter-individual variation in habitual physical activity that results from genetic variation. In concurrence with this finding, no association was found between the $\mathrm{PA}_{\text {index }}$ and Muscle $\mathrm{FTD}_{\mathrm{FT}}$. Moreover, no relationship was observed between \%Low, \%Moderate and $\%$ High with Muscle ${ }_{\mathrm{FTD}}$, indicating that Muscle $_{\mathrm{FTD}}$ does not affect the proportion of time subjects spend in each of the three intensity categories. 

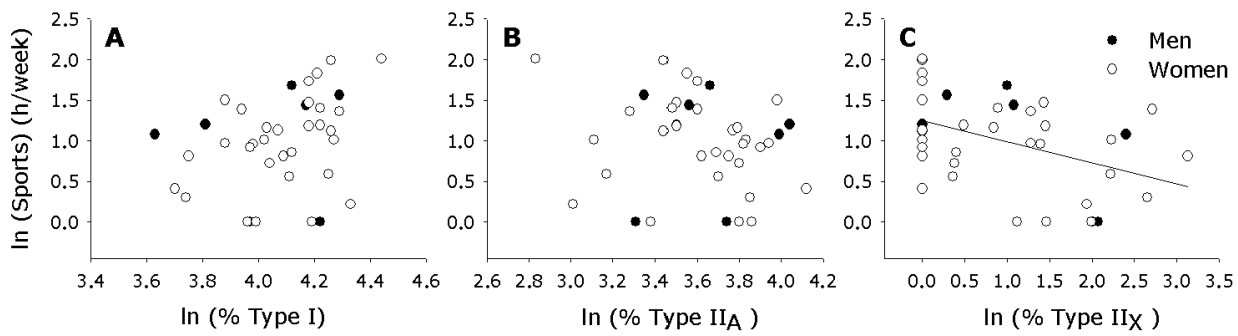

Figure 2: The time spent on sports as a function of the proportion of type $I(A), I_{A}(B)$ and $I_{X}(C)$ muscle fibres after natural log (In) transformation of both variables. $A: P=0.06 ; C: P<0.01$.

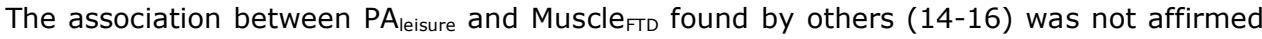
in the present study. This discrepancy may partly result from a difference in the health status of the subjects. Contrary to our population, which consists of healthy subjects only, Hedman et al. recruited subjects from a cohort of 70 year-old men. When performing the analysis on healthy subjects only, no association between PA $A_{\text {leisure }}$ and Muscle ${ }_{\text {FTD }}$ remained (14). In the study of Tikkanen et al. (16) and a recent follow-up study in the same population (15) only healthy subjects were recruited. However, the method used in these studies to assess $\mathrm{PA}_{\text {leisure }}$ did not distinguish between physical activity during leisure time and sports. As an association between the weekly time spent on sports and Muscle $_{\text {FTD }}$ was observed in the present study, we speculate that the relationship between $\mathrm{PA}_{\text {leisure }}$ and Muscle $\mathrm{FTD}_{\mathrm{FT}}$ found by Tikkanen et al. and Karjalainen et al. actually resulted from sports rather than leisure time per se.

On average, subjects reported to spend 2 h/week on sports. A significant relationship was observed between the time weekly spent on sports and \%Type $\mathrm{II}_{\mathrm{x}}$. The power of this association was $0.84\left(\alpha=0.05,1\right.$ predictor, $\left.R^{2}=0.19, n=38\right)$. Furthermore, the weekly time spent on sports tended to correlate positively with \%Type I. Due to the crosssectional design of this study, no conclusions about causality can be drawn. However, previous studies showed that both endurance and strength training can induce a shift in Muscle $_{\mathrm{FTD}}$ from type $\mathrm{II}_{\mathrm{X}}$ to type $\mathrm{II}_{\mathrm{A}}$, i.e. towards a more oxidative phenotype $(11 ; 24 ; 36$ 40). For example, Staron et al. showed that in untrained subjects, \%Type $\mathrm{II}_{X}$ decreased significantly already after four sessions of strength training within two weeks (24). This implies that even a small difference in training status may have resulted in the relationship found between the time spent on sports and \%Type $\mathrm{II}_{\mathrm{X}}$. The decreased \%Type $\mathrm{II}_{\mathrm{X}}$ is therefore considered an effect rather than a cause of an increased time spent on sports.

Contrary to transitions from type $\mathrm{II}_{\mathrm{X}}$ to type $\mathrm{II}_{\mathrm{A}}$, the majority of studies performed did not find an increased \%Type I following a period of either endurance or strength training $(24 ; 36 ; 37 ; 39 ; 41 ; 42)$. For example, \%Type I was not altered after 24 weeks of intensive endurance training in previously untrained women (39). Therefore, the increased time spent on sports may actually result from an increased \%Type I. In other words: subjects with a higher \%Type I may be more prone to engaging in sports. Since the time 
spent on sports was used as an exclusion criterion, its range was limited. This may explain why the association with \%Type I did not reach significance.

In conclusion, Muscle ${ }_{\text {FTD }}$ probably cannot explain why some people are more prone to engaging in physical activities than others. To generalize the findings, the measurements should be replicated.

\section{Acknowledgements}

We thank Milou Beelen, Luc van Loon and René Koopman for their skilful way of obtaining the muscle biopsies. We also thank Gert Schaart for his technical assistance and Loek Wouters for analyzing the deuterium samples. 


\section{References}

1. Ravussin E, Swinburn BA: Pathophysiology of obesity. Lancet 340:404-408, 1992

2. Schoeller DA, Shay K, Kushner RF: How much physical activity is needed to minimize weight gain in previously obese women? Am J Clin Nutr 66:551-556, 1997

3. Ekelund U, Aman J, Yngve A, Renman C, Westerterp K, Sjostrom M: Physical activity but not energy expenditure is reduced in obese adolescents: a case-control study. Am J Clin Nutr 76:935-941, 2002

4. Esparza J, Fox C, Harper IT, Bennett PH, Schulz LO, Valencia ME, Ravussin E: Daily energy expenditure in Mexican and USA Pima indians: low physical activity as a possible cause of obesity. Int J Obes Relat Metab Disord 24:55-59, 2000

5. Heitmann BL, Kaprio J, Harris JR, Rissanen A, Korkeila M, Koskenvuo M: Are genetic determinants of weight gain modified by leisure-time physical activity? A prospective study of Finnish twins. Am J Clin Nutr 66:672-678, 1997

6. Wardle J, Guthrie C, Sanderson S, Birch L, Plomin R: Food and activity preferences in children of lean and obese parents. Int J Obes Relat Metab Disord 25:971-977, 2001

7. Weinsier RL, Hunter GR, Heini AF, Goran MI, Sell SM: The etiology of obesity: relative contribution of metabolic factors, diet, and physical activity. Am J Med 105:145-150, 1998

8. Joosen AM, Gielen M, Vlietinck R, Westerterp KR: Genetic analysis of physical activity in twins. Am J Clin Nutr 82:1253-1259, 2005

9. Komi PV, Viitasalo JH, Havu M, Thorstensson A, Sjodin B, Karlsson J: Skeletal muscle fibres and muscle enzyme activities in monozygous and dizygous twins of both sexes. Acta Physiol Scand 100:385-392, 1977

10. Gollnick PD, Matoba H: The muscle fiber composition of skeletal muscle as a predictor of athletic success. An overview. Am J Sports Med 12:212-217, 1984

11. Simoneau JA, Lortie G, Boulay MR, Marcotte M, Thibault MC, Bouchard C: Human skeletal muscle fiber type alteration with high-intensity intermittent training. Eur J Appl Physiol Occup Physiol 54:250-253, 1985

12. Lortie G, Simoneau, J-A, Boulay, MR and Bouchard, C: Muscle fiber type composition and enzyme activities in brothers and monozygotic twins. Champaign, IL, human kinetics, 1986

13. Simoneau JA, Bouchard C: Genetic determinism of fiber type proportion in human skeletal muscle. Faseb J 9:1091-1095, 1995

14. Hedman A, Byberg L, Reneland R, Lithell HO: Muscle morphology, self-reported physical activity and insulin resistance syndrome. Acta Physiol Scand 175:325-332, 2002

15. Karjalainen J, Tikkanen $H$, Hernelahti $M$, Kujala UM: Muscle fiber-type distribution predicts weight gain and unfavorable left ventricular geometry: a 19 year follow-up study. BMC Cardiovasc Disord 6:2, 2006

16. Tikkanen HO, Hamalainen E, Sarna S, Adlercreutz H, Harkonen M: Associations between skeletal muscle properties, physical fitness, physical activity and coronary heart disease risk factors in men. Atherosclerosis 137:377-389, 1998

17. Plasqui $G$, Joosen $A M$, Kester $A D$, Goris $A H$, Westerterp KR: Measuring free-living energy expenditure and physical activity with triaxial accelerometry. Obes Res 13:1363-1369, 2005

18. Ainsworth $B E$, Haskell WL, Whitt MC, Irwin ML, Swartz AM, Strath SJ, O'Brien WL, Bassett DR, Jr., Schmitz KH, Emplaincourt PO, Jacobs DR, Jr., Leon AS: Compendium of physical activities: an update of activity codes and MET intensities. Med Sci Sports Exerc 32:S498-504, 2000

19. Baecke JA, Burema J, Frijters JE: A short questionnaire for the measurement of habitual physical activity in epidemiological studies. Am J Clin Nutr 36:936-942,

20. PQBip paerts RM, Westerterp KR, Lefevre J: Doubly labelled water validation of three physical activity questionnaires. Int J Sports Med 20:284-289, 1999 
21. Bergstrom J: Percutaneous needle biopsy of skeletal muscle in physiological and clinical research. Scand J Clin Lab Invest 35:609-616, 1975

22. Staron RS, Hagerman FC, Hikida RS, Murray TF, Hostler DP, Crill MT, Ragg KE, Toma K: Fiber type composition of the vastus lateralis muscle of young men and women. J Histochem Cytochem 48:623-629, 2000

23. Edstrom L, Nystrom B: Histochemical types and sizes of fibres in normal human muscles. A biopsy study. Acta Neurol Scand 45:257-269, 1969

24. Staron RS, Karapondo DL, Kraemer WJ, Fry AC, Gordon SE, Falkel JE, Hagerman FC, Hikida RS: Skeletal muscle adaptations during early phase of heavy-resistance training in men and women. J Appl Physiol 76:1247-1255, 1994

25. Westerterp KR, Wouters L, van Marken Lichtenbelt WD: The Maastricht protocol for the measurement of body composition and energy expenditure with labeled water. Obes Res 3 Suppl 1:49-57, 1995

26. Siri WE: Body composition from fluid spaces and density: analysis of methods. 1961. Nutrition 9:480-491; discussion 480, 492, 1993

27. Bell RD, MacDougall JD, Billeter R, Howald $\mathrm{H}$ : Muscle fiber types and morphometric analysis of skeletal msucle in six-year-old children. Med Sci Sports Exerc 12:28-31, 1980

28. Evertsen F, Medbo JI, Jebens E, Gjovaag TF: Effect of training on the activity of five muscle enzymes studied on elite cross-country skiers. Acta Physiol Scand 167:247257,1999

29. Jaworowski A, Porter MM, Holmback AM, Downham D, Lexell J: Enzyme activities in the tibialis anterior muscle of young moderately active men and women: relationship with body composition, muscle cross-sectional area and fibre type composition. Acta Physiol Scand 176:215-225, 2002

30. Kriketos AD, Baur LA, O'Connor J, Carey D, King S, Caterson ID, Storlien LH: Muscle fibre type composition in infant and adult populations and relationships with obesity. Int J Obes Relat Metab Disord 21:796-801, 1997

31. Black AE, Coward WA, Cole TJ, Prentice AM: Human energy expenditure in affluent societies: an analysis of 574 doubly-labelled water measurements. Eur J Clin Nutr 50:72-92, 1996

32. Westerterp KR: Pattern and intensity of physical activity. Nature 410:539, 2001

33. Dinger MK, Behrens TK: Accelerometer-determined physical activity of free-living college students. Med Sci Sports Exerc 38:774-779, 2006

34. Yoshioka M, Ayabe M, Yahiro T, Higuchi H, Higaki Y, St-Amand J, Miyazaki H, Yoshitake $\mathrm{Y}$, Shindo M, Tanaka H: Long-period accelerometer monitoring shows the role of physical activity in overweight and obesity. Int J Obes (Lond) 29:502-508, 2005

35. McClain JJ, Sisson SB, Tudor-Locke C: Actigraph accelerometer interinstrument reliability during free-living in adults. Med Sci Sports Exerc 39:1509-1514, 2007

36. Andersen $\mathrm{P}$, Henriksson J: Training induced changes in the subgroups of human type II skeletal muscle fibres. Acta Physiol Scand 99:123-125, 1977

37. Coggan AR, Spina RJ, King DS, Rogers MA, Brown M, Nemeth PM, Holloszy JO: Skeletal muscle adaptations to endurance training in 60- to 70 -yr-old men and women. J Appl Physiol 72:1780-1786, 1992

38. Howald $\mathrm{H}$, Hoppeler $\mathrm{H}$, Claassen $\mathrm{H}$, Mathieu $\mathrm{O}$, Straub R: Influences of endurance training on the ultrastructural composition of the different muscle fiber types in humans. Pflugers Arch 403:369-376, 1985

39. Ingjer $\mathrm{F}$ : Effects of endurance training on muscle fibre ATP-ase activity, capillary supply and mitochondrial content in man. J Physiol 294:419-432, 1979

40. Sale DG, MacDougall JD, Jacobs I, Garner S: Interaction between concurrent strength and endurance training. J Appl Physiol 68:260-270, 1990

41. Gollnick PD, Armstrong RB, Saltin B, Saubert CWt, Sembrowich WL, Shepherd RE: Effect of training on enzyme activity and fiber composition of human skeletal muscle. J Appl Physiol 34:107-111, 1973 
42. Saltin B, Nazar K, Costill DL, Stein E, Jansson E, Essen B, Gollnick D: The nature of the training response; peripheral and central adaptations of one-legged exercise. Acta Physiol Scand 96:289-305, 1976 

Chapter 3

\section{Habitual physical activity in daily life correlates positively with markers for mitochondrial capacity}

Marcel den Hoed, Matthijs KC Hesselink, Gerrit PJ van Kranenburg and Klaas R Westerterp

J Appl Physiol 105:561-568, 2008 


\begin{abstract}
Physical exercise training is a powerful tool to maintain or improve mitochondrial density and function (mitochondrial capacity). This study aims to determine whether mitochondrial capacity is also associated with habitual physical activity.

The capacity of classic markers for mitochondrial density, that is, the capacity of citrate synthase (CS) and succinate dehydrogenase (SDH), as well the capacity of cytochrome c oxidase (COX) and $\beta$-hydroxyacyl-CoA dehydrogenase (HAD) was determined in homogenized muscle biopsy samples obtained from the $M$. Vastus Lateralis of nonexercising healthy, young (aged $20 \pm 2$ years) subjects (31 women, 7 men). Habitual physical activity was measured during 2 periods of 14 days using a triaxial accelerometer for movement registration.

CS, SDH and COX were positively associated with habitual physical activity $(P<0.05$, $\mathrm{R}=0.36,95 \% \mathrm{CI}: 1.3 \cdot 10^{-4}$ to $2.2 \cdot 10^{-3} ; P<0.05, \mathrm{R}=0.39,95 \% \mathrm{CI}: 1.1 \cdot 10^{-5}$ to $9.9 \cdot 10^{-5}$ and $P<0.05, \mathrm{R}=0.33,95 \% \mathrm{CI}: 7.5 \cdot 10^{-6}$ to $3.6 \cdot 10^{-4}$, respectively) and HAD tended to correlate positively with habitual physical activity $\left(P=0.06, \mathrm{R}=0.31,95 \% \mathrm{CI}:-2.2 \cdot 10^{-5}\right.$ to $\left.1.1 \cdot 10^{-3}\right)$. The population was subsequently stratified based on the intensity of the activities performed. CS was only associated with habitual physical activity in subjects spending more time on high-intensity physical activity whereas HAD was only associated with habitual physical activity in subjects spending less time on low-intensity physical activity.

We are the first to report that even within the range of normal daily life activities, mitochondrial capacity is positively associated with the level of habitual physical activity in daily life. Thus, an active lifestyle may help to maintain or improve mitochondrial capacity.
\end{abstract}




\section{Introduction}

In Westernized societies, the prevalence of type 2 diabetes and obesity has increased significantly over the last few decades $(1 ; 2)$. A decreased physical activity has been associated with both type 2 diabetes $(3 ; 4)$ and obesity (5). Part of the pathophysiology related to these diseases has been attributed to a reduced mitochondrial capacity: the product of mitochondrial density and function (6-8).

Mitochondria are vital organelles in the oxidative degradation of macronutrients to maintain cellular ATP levels. Mitochondrial aberrations, resulting in a reduced mitochondrial capacity, may therefore seriously impair normal energy and substrate metabolism. Mitochondrial aberrations have not only been reported for metabolic disorders like type 2 diabetes and obesity but also in diseases like chronic heart failure and chronic obstructive pulmonary disease $(9 ; 10)$.

Proper mitochondrial function and maintenance of mitochondrial capacity rely on a delicate balance between mitochondrial biogenesis and degradation. While the precise mechanisms of mitochondrial biogenesis and degradation are not fully elucidated yet, it has been known for decades that one of the most potent triggers to improve or maintain mitochondrial capacity is physical exercise (11). Engagement in physical exercise programs results in increased mitochondrial biogenesis and improved mitochondrial function in healthy controls $(12 ; 13)$ and is even capable of restoring mitochondrial capacity in diseased states like type 2 diabetes and obesity $(14 ; 15)$. Unfortunately, long-term adherence to strenuous exercise programs is limited (16) and life-long engagement in sports and exercise to prevent mitochondrial aberrations may be an unrealistic goal in Westernized societies. If, however, mitochondrial capacity can also be maintained by high levels of habitual physical activity in daily life, the goal of maintaining mitochondrial capacity and preventing mitochondrial aberrations by physical activity may become feasible.

Interestingly, wide ranges in habitual physical activity have been reported (17) with the most active people showing daily life activity levels approaching those reported for people actively engaged in endurance sports (18). While it is obvious that mitochondrial capacity is higher in trained athletes than in sedentary controls, it is not known to date whether differences also exist within the ranges of normal daily life activities. The aim of the present study was therefore to examine the association between markers of mitochondrial capacity with habitual physical activity in daily life in a young and healthy population. To this end, classic markers for muscle mitochondrial density; the capacity of citrate synthase (CS) and succinate dehydrogenase (SDH) (19) were measured along with the capacity of cytochrome c oxidase or complex IV (COX) from the electron transport chain and $\beta$-hydroxyacyl-CoA dehydrogenase (HAD) from the $\beta$-oxidation $(20 ; 21)$. Habitual physical activity was recorded using our validated non-invasive triaxial accelerometer approach (17). We hypothesized a higher mitochondrial enzymatic capacity in subjects with a higher habitual physical activity. 


\section{Methods}

\section{Subjects}

Thirty-eight healthy, non-smoking subjects (31 females, 7 males) aged $20 \pm 2$ years (means $\pm S D$ ) gave written informed consent to participate in this study. To minimize the effect of physical exercise training, subjects spending over $2 \mathrm{~h} /$ week on endurance sports or $5 \mathrm{~h}$ /week on sports in general were excluded from participation. Information about the purpose and protocol of the study, as well as its risks and discomfort were provided both orally and in writing. The study conformed to the standards set by the Declaration of Helsinki and the local Ethics Committee approved the study.

\section{Habitual physical activity}

Habitual physical activity was measured using a triaxial accelerometer for movement registration (Tracmor IV; Philips research, Eindhoven, The Netherlands) sensitive to a wide range of body movements. The accelerometer has been validated with doubly labelled water, the gold standard for measuring energy expenditure in daily life (17). The Tracmor registers accelerations of the trunk along the anterio-posterior, medio-lateral and longitudinal axis using three uniaxial piezo-electric accelerometers (details are provided elsewhere (17)). To ensure a valid reflection of long-term daily life activities, the accelerometer was worn for two 14-day periods under free-living conditions. Subsequently, habitual physical activity was defined as the average of both measurement periods.

Subjects were instructed to wear the Tracmor from the moment they woke up in the morning until they went back to bed at night. To verify whether subjects lived up to this instruction, waking hours and clock times of wearing the Tracmor were noted. To make sure only representative days were included, the difference between the total time the subject was awake and the time the accelerometer was worn was not allowed to exceed $75 \mathrm{~min} /$ day. The few days during which this difference exceeded $75 \mathrm{~min}$ were excluded from the analysis. This resulted in an average of 26 representative days per subject. To ensure that subjects met the inclusion criterion concerning their participation in sports, the actual sporting hours were also recorded in the diary.

Habitual physical activity was acquired by summing the output of all three axes and is presented as Megacounts per day (MCnts/day). Using Tracmor data, the proportion of time subjects were physically active at a low, moderate and high intensity (\%Low, $\%$ Moderate and \%High, respectively) was determined. The cut-off points for the intensity categories were determined in a pilot study $(n=5)$. The cut-off point for low-intensity physical activity was set by Tracmor outputs associated with walking on a treadmill at $3.5 \mathrm{~km} / \mathrm{h}$, which corresponds with approximately 3 metabolic equivalents (METs), i.e. three times basal metabolic rate. For moderate-intensity physical activity, a Tracmor output associated with walking on a treadmill at $5 \mathrm{~km} / \mathrm{h}$ was used, which corresponds

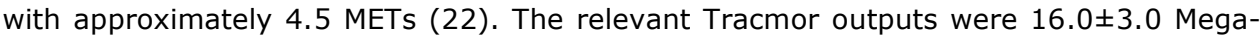


counts per minute (MCnts/min) and 28.9 $\pm 3.0 \mathrm{MCnts} / \mathrm{min}$, respectively. All physical activity associated with a Tracmor output higher than the latter cut-off point was considered high-intensity physical activity. The proportion of time per intensity category was calculated as the sum of all min per intensity category divided by the total duration of the measurement, that is, 28 days minus the number of excluded days.

Using linear regression analysis in a population similar to the present study with respect to habitual physical activity, body composition and age, Plasqui et al. were able to predict the physical activity level (PAL), i.e. the factor by which average daily metabolic rate exceeds basal metabolic rate, with an explained variation of $70 \%$ using only MCnts/day (17). Whereas the MET score represents the factor by which energy expenditure exceeds basal metabolic rate for a certain pre-defined physical activity, PAL represents the factor by which energy expenditure exceeds basal metabolic rate during $24 \mathrm{~h}$. For a proper reflection of $24 \mathrm{~h}$ daily life energy expenditure under free-living conditions, PAL thus provides a more valid reflection than MET scores, which in turn provide a more valid reflection of energy expenditure when considering predefined physical activities. The regression equation developed by Plasqui et al. was used in the present study to estimate PAL.

\section{Muscle biopsies}

A muscle biopsy was obtained after an overnight fast with subjects refraining from strenuous physical activity for $24 \mathrm{~h}$ before the collection. The biopsy was obtained from the M. Vastus Lateralis under local anaesthesia (xylocaine $2 \%$ ) using a Bergström needle with suction (23). After muscle samples were freed from blood, visible fat and connective tissue they were immediately frozen in liquid nitrogen and stored at $-80^{\circ} \mathrm{C}$ until analyzed.

\section{Measurements of enzyme activities}

SET buffer was prepared by dissolving $8.557 \mathrm{~g}$ sucrose $(250 \mathrm{mM}), 0.211 \mathrm{~g}$ tris $(10 \mathrm{mM})$ and $0.0744 \mathrm{~g}$ EDTA $(2 \mathrm{mM})$ in $80 \mathrm{ml}$ distilled water. $\mathrm{pH}$ was adjusted to 7.4 and distilled water was added to a final volume of $100 \mathrm{ml}$. Muscle samples were weighed (means \pm SD: $39.0 \pm 18.8 \mathrm{mg}$ ) and homogenized in $1 \mathrm{ml}$ of SET buffer using a Polytron homogenizer (Polytron-Aggregate; Kinematica, Littau, Luzern, Switzerland). Homogenates were frozen and thawed two additional times using liquid nitrogen to break mitochondrial membranes and were subsequently stored at $-80^{\circ} \mathrm{C}$ until analyzed.

Upon analysis, muscle homogenates were centrifuged at $13,000 \mathrm{~g}$ for $2 \mathrm{~min}$. Supernatant was used for analysis. Absorbance changes for all enzyme assays were measured in a COBAS-FARA semiautomatic analyzer (COBAS-FARA; Roche, Basel, Switzerland). The molar extinction coefficients used were $13,600 \mathrm{l} / \mathrm{mol} / \mathrm{cm}$ for Coenzyme A-DTNB at 412 $\mathrm{nm}$ for CS, 21,000 l/mol/cm for dichlorophenol indophenol (DCPIP) at $600 \mathrm{~nm}$ for SDH, $15,300 \mathrm{l} / \mathrm{mol} / \mathrm{cm}$ for reduced cytochrome $\mathrm{c}$ at $550 \mathrm{~nm}$ for COX and 63,000 l/mol/cm for nicotinamide-adenine dinucleotide $(\mathrm{NADH})$ at $340 \mathrm{~nm}$ for HAD. Enzyme capacities were expressed as $\mu \mathrm{mol} / \mathrm{min} / \mathrm{g}$ wet weight. The composition of the assay solutions was as follows: 
I) CS: For reagent $1,1.21 \mathrm{~g}$ tris $(100 \mathrm{mM}), 4 \mathrm{mg}$ DTNB $(100 \mu \mathrm{M})$ and $4.2 \mathrm{mg}$ acetyl CoA $(50 \mu \mathrm{M})$ were dissolved in $80 \mathrm{ml}$ distilled water, $\mathrm{pH}$ was adjusted to 8.0 and distilled water was added to a total volume of $100 \mathrm{ml}$. For reagent 2 (starting reagent), $3.3 \mathrm{mg}$ oxalo-acetate was dissolved in $1 \mathrm{ml}$ distilled water.

II) SDH: For $\mathrm{NaP}_{\mathrm{i}} 50 \mathrm{mM}$ buffer, $0.890 \mathrm{~g} \mathrm{Na}_{2} \mathrm{HPO}_{4} \cdot 2 \mathrm{H}_{2} \mathrm{O}(50 \mathrm{mM})(A)$ and $0.780 \mathrm{~g}$ $\mathrm{NaH}_{2} \mathrm{PO}_{4} \cdot 2 \mathrm{H}_{2} \mathrm{O}(50 \mathrm{mM})(B)$ were both dissolved in $100 \mathrm{ml}$ distilled water. Subsequently $B$ was added to $A$ until the $\mathrm{pH}$ was 7.4. For reaction reagent, $6.5 \mathrm{mg} \mathrm{KCN}(1 \mathrm{mM}), 1.7 \mathrm{mg}$ 2,6 DCPIP $(0.06 \mathrm{mM}), 162 \mathrm{mg}$ sodium succinate $(10 \mathrm{mM})$ and $50 \mathrm{mg}$ albumin were dissolved in $100 \mathrm{ml} \mathrm{KP_{i }}$ buffer.

III) COX: For $\mathrm{KP}_{\mathrm{i}} 50 \mathrm{mM}$ buffer, $0.684 \mathrm{~g} \mathrm{KH}_{2} \mathrm{PO}_{4}(50 \mathrm{mM})$ and $1.14 \mathrm{~g} \mathrm{~K}_{2} \mathrm{HPO}_{4}(50 \mathrm{mM})$ were both dissolved in $100 \mathrm{ml}$ distilled water. Subsequently, both solutions were mixed and $\mathrm{pH}$ was adjusted to 7.4 using $\mathrm{KOH}$. For reduced Cytochrome c solution, $17.6 \mathrm{mg}$

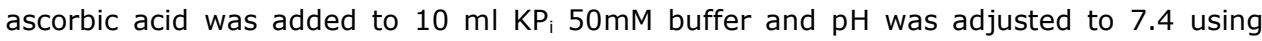
$\mathrm{NaOH} 1 \mathrm{M}$. One hundred microlitres of this ascorbic acid solution and $25 \mathrm{mg}$ cytochrome $\mathrm{C}$ were mixed. This mixture was incubated at $25^{\circ} \mathrm{C}$ for $5 \mathrm{~min}$ before $900 \mu \mathrm{l} \mathrm{KP_{i }} 50 \mathrm{mM}$ buffer was added. The solution was kept on ice until analyzed. $\mathrm{MgCl}_{2}$ solution: $566 \mathrm{mg}$ $\mathrm{MgCl}_{2}$ was dissolved in $10 \mathrm{ml}$ distilled water (final volume). For reaction reagent, $10 \mathrm{ml}$ $\mathrm{KP}_{\mathrm{i}} 50 \mathrm{mM}$ buffer, $200 \mu \mathrm{l} \mathrm{MgCl}_{2}$ solution and $400 \mu \mathrm{l}$ reduced cytochrome $\mathrm{C}$ solution were mixed. Fifty microlitres supernatant was mixed with $200 \mu \mathrm{KP} 50 \mathrm{mM}$ buffer, which was kept on ice for $10 \mathrm{~min}$ before analysis.

IV) $\beta$-hydroxyacyl-CoA dehydrogenase: For buffer: $3.3 \mathrm{~g}$ tetra-sodium pyrophosphate $(100 \mathrm{mM})$ was dissolved in $80 \mathrm{ml}$ distilled water, $\mathrm{pH}$ was adjusted to 7.3 and distilled water was added to a total volume of $100 \mathrm{ml}$. For NADH solution, $8.0 \mathrm{mg} \mathrm{NADH}$ was dissolved in $1 \mathrm{ml}$ distilled water. For reagent $1,10 \mathrm{ml}$ buffer and $200 \mu \mathrm{lNADH}$ solution were mixed. For reagent 2 (starting reagent), $5.0 \mathrm{mg}$ acetoacetyl-CoA was dissolved in $2.5 \mathrm{ml}$ distilled water.

All analyses for a given enzyme were performed simultaneously at $37^{\circ} \mathrm{C}$. Enzyme capacities were measured twice on the same homogenate for each subject. Intra-assay coefficients of variation were $2.0 \%$ for CS, $2.1 \%$ for $\mathrm{SDH}, 5.0 \%$ for COX and $1.7 \%$ for HAD, indicating that the capacity of mitochondrial enzymes was reproducibly determined.

\section{Body composition}

Body mass and height were measured in the morning after an overnight fast (ID 1 Plus; Mettler Toledo, Giessen, Germany \& Mod. 220; SECA, Hamburg, Germany). Body volume was determined using the underwater weighing technique while correcting for residual lung volume using the helium dilution technique (Volugraph VG 2000; Mijnhardt, Bunnik, The Netherlands). Total body water was determined overnight using the deuterium dilution technique (24). \%BF was subsequently calculated using Siri's three-compartment model (25). 


\section{Statistics}

Differences in habitual physical activity, the capacity of mitochondrial enzymes and body composition between men and women were tested using Student's t-tests for unpaired samples. Simple linear regression was used to test the association between CS, SDH, COX and HAD on the one hand and habitual physical activity on the other hand. Multiple linear regression analyses were used to test the interaction between sex and habitual physical activity for the capacity of the mitochondrial enzymes. Backward multiple linear regression analyses were used to correct the associations between the capacity of mitochondrial enzymes and habitual physical activity for sex, age and body mass index (BMI). On log transformation, the association between habitual physical activity and the capacity of the mitochondrial enzymes with \%Low, \%Moderate and \%High was determined using simple linear regression analyses.

Statistical analyses were carried out using the Statistical Package for Social Sciences (SPSS) version 11 for Macintosh OS X (SPSS Inc.; Chicago, Illinois, USA). Data are expressed as means \pm SD. $P$-values $<0.05$ were considered statistically significant. $95 \%$ confidence intervals ( $95 \% \mathrm{CI})$ are provided.

\section{Results}

Habitual physical activity was similar between men and women (Table 1 ). The proportion of time subjects were physically active at a low, moderate and high intensity was also comparable between sexes, although \%High was significantly higher in men: $18 \mathrm{~min} /$ day versus 9 in women $(P<0.01,95 \% \mathrm{CI}: 2.4$ to 14.3). No significant differences between men and women were found for CS, SDH, COX or HAD, which confirms the findings of previous studies $(13 ; 26 ; 27)$. Furthermore, no interaction was observed between sex and habitual physical activity for the capacity of the mitochondrial enzymes. Hence, both sexes were combined for further analyses.

\section{Capacity of mitochondrial enzymes and habitual physical activity}

Applying the regression equation developed by Plasqui et al. (17) to the present population showed that the physical activity level, PAL, ranged from 1.62 to 2.04 . Positive associations were observed between $\mathrm{CS}, \mathrm{SDH}$ and $\mathrm{COX}$ with habitual physical activity $\left(P<0.05, \mathrm{R}=0.36,95 \% \mathrm{CI}: 1.3 \cdot 10^{-4}\right.$ to $2.2 \cdot 10^{-3} ; P<0.05, \mathrm{R}=0.39,95 \% \mathrm{CI}: 1.1 \cdot 10^{-5}$ to 9.9.10 $0^{-5}$ and $P<0.05, \mathrm{R}=0.33,95 \% \mathrm{CI}: 7.5 \cdot 10^{-6}$ to $3.6 \cdot 10^{-4}$, respectively). HAD tended to correlate positively with habitual physical activity $\left(P=0.06, \mathrm{R}=0.31,95 \% \mathrm{CI}:-2.2 \cdot 10^{-5}\right.$ to $1.1 \cdot 10^{-3}$ ) (Figure 1 ). These associations remained when sex, age and/or BMI were taken into account.

Habitual physical activity was positively associated with \%Moderate and \%High $\left(P<0.001, \mathrm{R}=0.74,95 \% \mathrm{CI}: 3.3 \cdot 10^{-1}\right.$ to $6.3 \cdot 10^{-1}$ and $P<0.001, \mathrm{R}=0.74,95 \% \mathrm{CI}: 1.4 \cdot 10^{-1}$ to $2.6 \cdot 10^{-1}$, respectively) and negatively with \%Low ( $P<0.001, \mathrm{R}=0.86,95 \% \mathrm{CI}:-20.4$ to -13.7). CS and HAD tended to correlate positively with \%High $(P=0.06, \mathrm{R}=0.31,95 \% \mathrm{CI}$ : 
$-4.5 \cdot 10^{-3}$ to $2.6 \cdot 10^{-1}$ and $P=0.07, \mathrm{R}=0.30,95 \% \mathrm{CI}:-1.0 \cdot 10^{-2}$ to $2.5 \cdot 10^{-1}$, respectively). COX and SDH on the other hand correlated positively with \%Moderate $(P<0.05, \mathrm{R}=0.37$, $95 \% \mathrm{CI}: 1.1 \cdot 10^{-1}$ to $1.3 \cdot 10^{\circ}$ and $P<0.05, \mathrm{R}=0.37,95 \% \mathrm{CI}: 2.6 \cdot 10^{-2}$ to $3.3 \cdot 10^{-1}$, respectively). To examine if the associations between markers for mitochondrial capacity and habitual physical activity were influenced by the intensity of the activities performed, the population was subsequently stratified based on the intensity of the activities measured.

Table 1: Results

\begin{tabular}{|c|c|c|}
\hline & Men & Women \\
\hline $\mathrm{N}$ & 7 & 31 \\
\hline Age $(y)$ & $20 \pm 2$ & $20 \pm 2$ \\
\hline Body mass (kg) & $79.3 \pm 14.1$ & $63.1 \pm 8.2^{\#}$ \\
\hline Height (m) & $1.84 \pm 0.06$ & $1.69 \pm 0.06^{\#}$ \\
\hline BMI $\left(\mathrm{kg} / \mathrm{m}^{2}\right)$ & $23.2 \pm 3.0$ & $22.0 \pm 2.5$ \\
\hline$\% B F$ & $15.9 \pm 5.8$ & $26.7 \pm 4.6$ \\
\hline HPA (MCnts/day) & $4128 \pm 636$ & $3704 \pm 675$ \\
\hline \%Low (min/day) & $1390 \pm 15$ & $1401 \pm 15$ \\
\hline \%Moderate (min/day) & $33 \pm 8$ & $30 \pm 13$ \\
\hline$\% H i g h$ (min/day) & $18 \pm 11$ & $9 \pm 6 \S$ \\
\hline PAL & $1.88 \pm 0.10$ & $1.80 \pm 0.11$ \\
\hline $\mathrm{CS}(\mu \mathrm{mol} / \mathrm{min} / \mathrm{g})$ & $9.30 \pm 1.75$ & $8.05 \pm 2.33$ \\
\hline $\mathrm{SDH}(\mu \mathrm{mol} / \mathrm{min} / \mathrm{g})$ & $0.70 \pm 0.11$ & $0.73 \pm 0.10$ \\
\hline $\operatorname{COX}(\mu \mathrm{mol} / \mathrm{min} / \mathrm{g})$ & $0.67 \pm 0.30$ & $0.77 \pm 0.39$ \\
\hline $\operatorname{HAD}(\mu \mathrm{mol} / \mathrm{min} / \mathrm{g})$ & $5.10 \pm 1.47$ & $4.79 \pm 1.20$ \\
\hline
\end{tabular}

BMI, body mass index; \%BF, percentage body fat; HPA, habitual physical activity as measured in daily life using a triaxial accelerometer during two periods of two weeks; MCnts, Megacounts; \%Low, $\%$ Moderate and \%High, proportion of time subjects were physically active at a low, moderate and high intensity, respectively; PAL, physical activity level, that is, the factor by which total energy expenditure exceeds resting energy expenditure; CS, SDH, COX and HAD, capacity of citrate synthase, succinate dehydrogenase, Cytochrome $\mathrm{C}$ oxidase and $\beta$-hydroxyacyl-CoA dehydrogenase, expressed as micromole substrate converted per minute per gram wet muscle weight. Data are means \pm SD. Significant sex difference: $\S P<0.01 ; \# P<0.001$.

\section{Capacity of mitochondrial enzymes and habitual physical activity stratified based on the intensity and duration of the activities performed}

Stratification of the population based on the median of \%High resulted in a cut-off point of $8 \mathrm{~min} /$ day. Within the population stratified based on \%High, CS was only associated with habitual physical activity in the sub-group spending more than $8 \mathrm{~min} /$ day on highintensity physical activity $\left(P<0.05,95 \% \mathrm{CI}: 7.5 \cdot 10^{-5}\right.$ to $\left.2.9 \cdot 10^{-3}\right)$. SDH also correlated positively with habitual physical activity in the sub-group spending more than $8 \mathrm{~min} / \mathrm{day}$ on high-intensity physical activity but tended to correlate positively with habitual physical activity in the sub-group spending less time on high-intensity physical activity as well $\left(P<0.01,95 \% \mathrm{CI}: 2.4 \cdot 10^{-5}\right.$ to $1.2 \cdot 10^{-4}$ and $P=0.07,95 \% \mathrm{CI}:-1.1 \cdot 10^{-5}$ to $2.1 \cdot 10^{-4}$, respectively). COX tended to correlate positively with habitual physical activity in both the subgroup spending more and less than $8 \mathrm{~min} /$ day on high-intensity physical activity ( $P=0.06,95 \% \mathrm{CI}:-1.3 \cdot 10^{-5}$ to $4.5 \cdot 10^{-4}$ and $P=0.09,95 \% \mathrm{CI}:-7.2 \cdot 10^{-5}$ to $7.7 \cdot 10^{-4}$, respectively) and HAD was not associated with habitual physical activity in either the sub-group spending more or less time on high-intensity physical activity (Figure 2). 

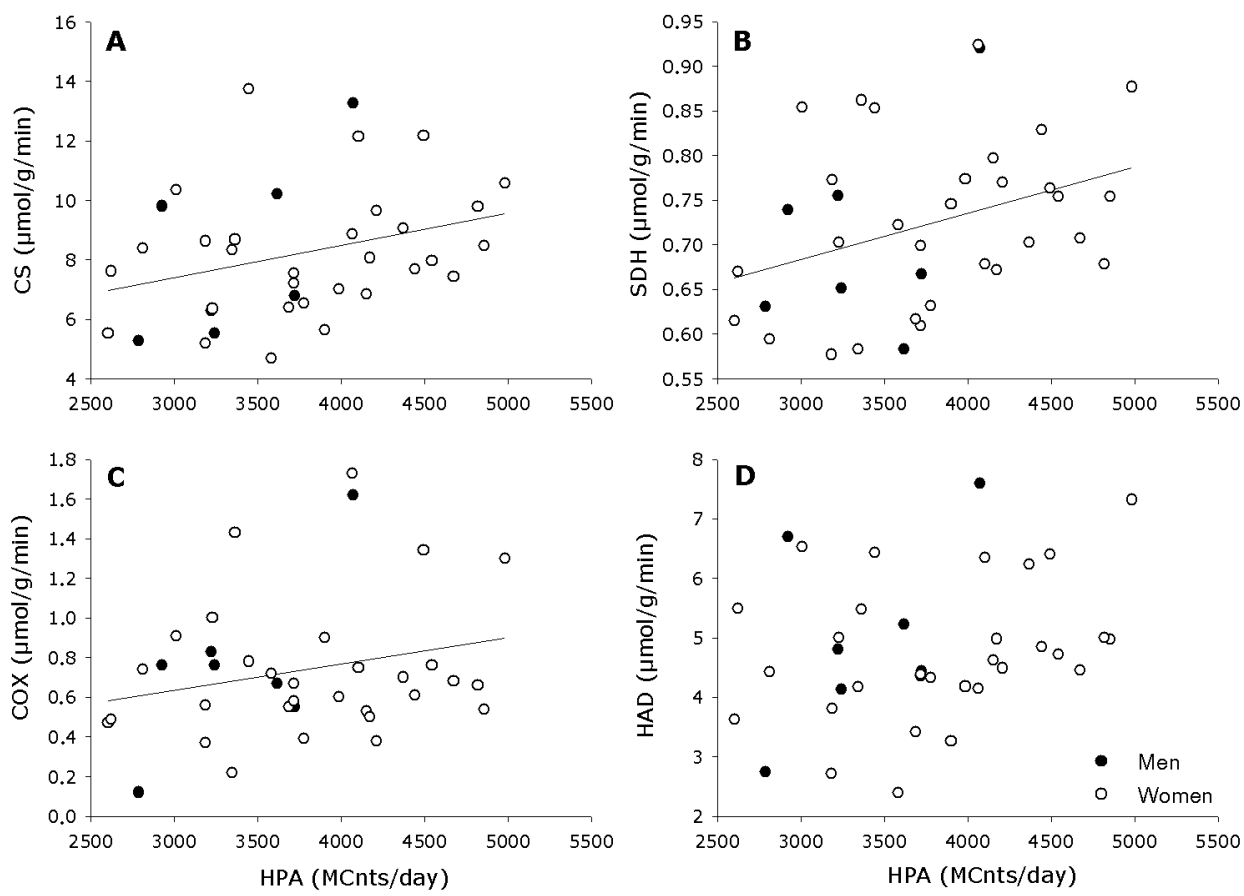

Figure 1: Capacity of CS (A), SDH (B), COX (C) and HAD (D) as a function of habitual physical activity (HPA), measured using a triaxial accelerometer for movement registration, for men and women combined. A, B and C: $P<0.05$; D: $P=0.06$. MCnts, Megacounts.

Stratification of the population based on the median of \%Moderate resulted in a cut-off point of $29 \mathrm{~min} /$ day. Within the population stratified based on \%Moderate, no associations were observed between markers for mitochondrial capacity and habitual physical activity in either the sub-group spending more or less time on moderate-intensity physical activity.

Stratification of the population based on the median of \%Moderate and \%High combined resulted in a cut-off point of $39 \mathrm{~min} /$ day. Within the population stratified based on the proportion of moderate- and high-intensity physical activity, CS and HAD were only positively associated with habitual physical activity in the sub-group spending more time on moderate- and high-intensity physical activity $\left(P<0.05,95 \% \mathrm{CI}: 1.9 \cdot 10^{-4}\right.$ to $4.1 \cdot 10^{-3}$ and $P<0.01,95 \% \mathrm{CI}: 5.7 \cdot 10^{-4}$ to $2.6 \cdot 10^{-3}$, respectively). SDH and COX were positively associated with habitual physical activity in both the sub-group spending more and less time on moderate- and high-intensity physical activity $\left(P<0.01,95 \% \mathrm{CI}: 3.8 \cdot 10^{-5}\right.$ to $1.7 \cdot 10^{-4}$ and $P<0.05,95 \% \mathrm{CI}: 1.1 \cdot 10^{-5}$ to $2.4 \cdot 10^{-4}$ for SDH, $P<0.05,95 \% \mathrm{CI}: 2.2 \cdot 10^{-5}$ to $6.0 \cdot 10^{-4}$ and $P<0.05,95 \% \mathrm{CI}: 8.4 \cdot 10^{-5}$ to $9.6 \cdot 10^{-4}$ for COX) (Figure 3 ). 

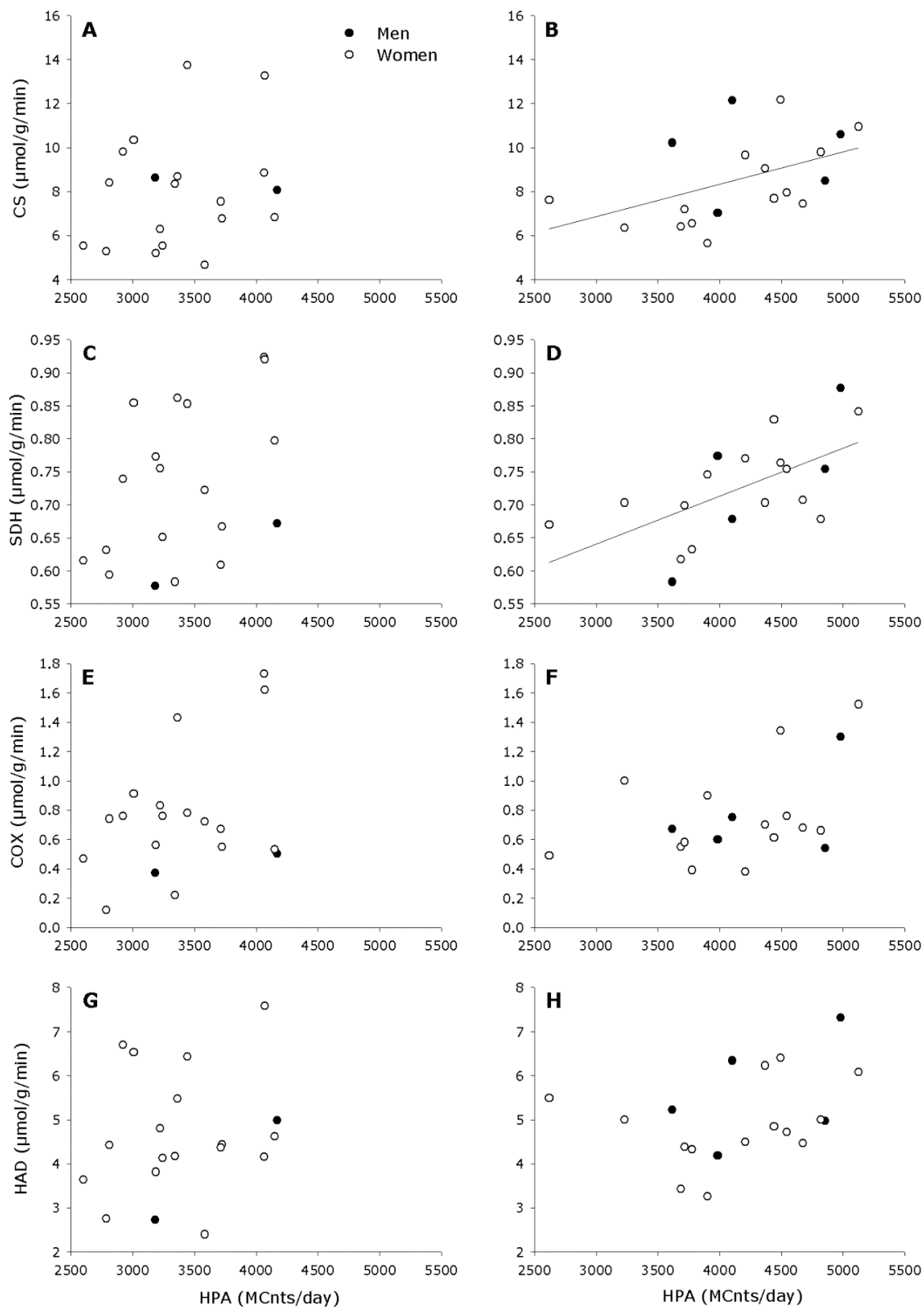

Figure 2: Capacity of CS ( $A$ and $B), \operatorname{SDH}(C$ and $D), \operatorname{COX}(E$ and $F$ ) and HAD ( $G$ and $H$ ) as a function of habitual physical activity (HPA), measured using a triaxial accelerometer for movement registration, stratified based on the proportion of time subjects were physically active at a high intensity. A, $\mathrm{C}, \mathrm{E}$ and $\mathrm{G}$ show the association for subjects spending 2 to $8 \mathrm{~min} /$ day on high-intensity physical activity and $\mathrm{B}, \mathrm{D}, \mathrm{F}$ and $\mathrm{H}$ for subjects spending 9 to $34 \mathrm{~min} /$ day on high-intensity physical activity. $\mathrm{B}$ : $P<0.05$; C: $P=0.07 ; \mathrm{D}: P<0.01 ; \mathrm{E}: P=0.09 ; \mathrm{F}: P=0.06$. 

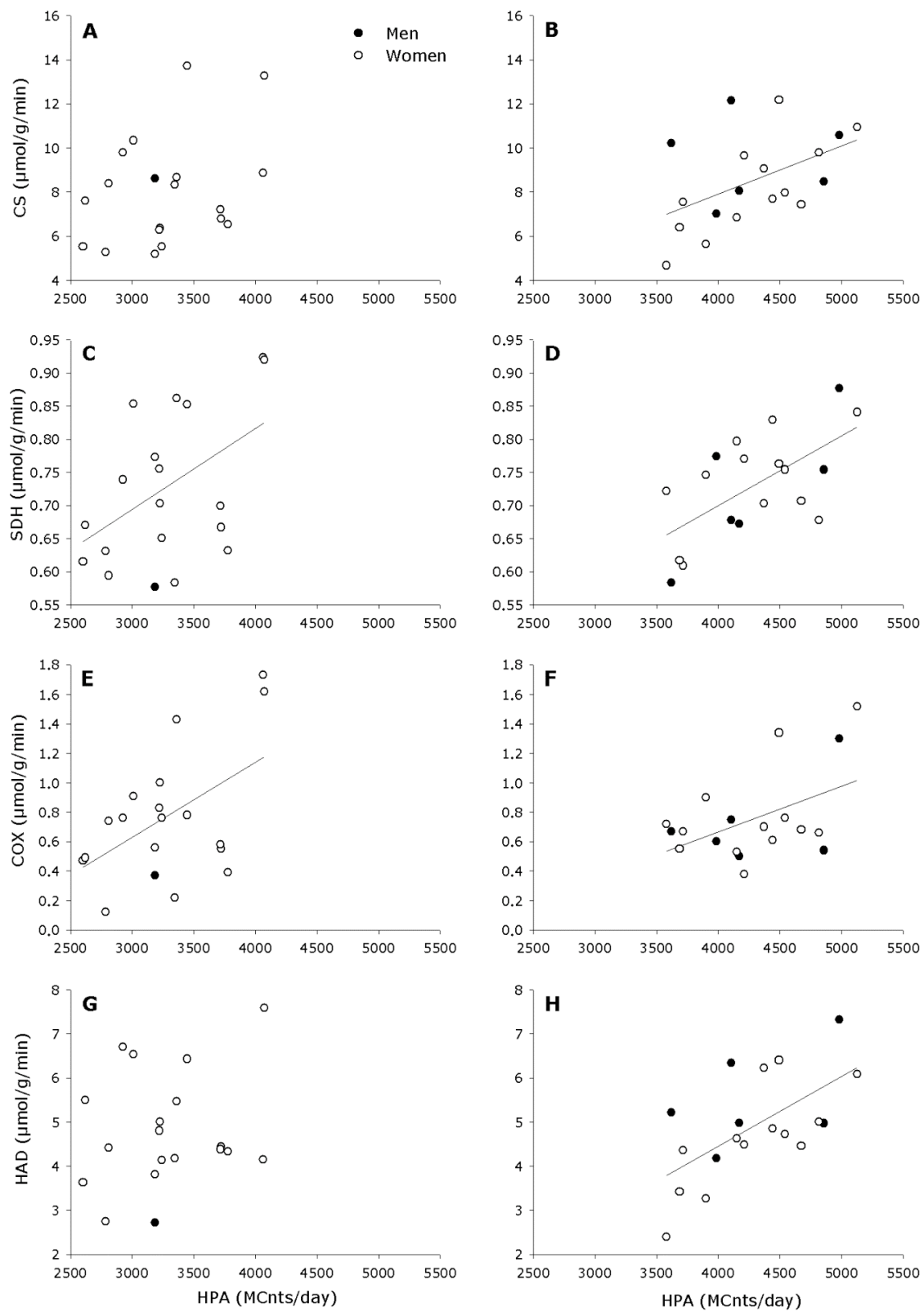

Figure 3: Capacity of CS ( $A$ and $B$ ), SDH ( $C$ and $D), \operatorname{COX}(E$ and $F$ ) and HAD ( $G$ and $H$ ) as a function of habitual physical activity (HPA), measured using a triaxial accelerometer for movement registration, stratified based on the proportion of time subjects were physically active at a moderate and high intensity. A, C, E and G show the association for subjects spending 18 to $39 \mathrm{~min} /$ day on moderateand high-intensity physical activity and $B, D, F$ and $H$ for subjects spending 39 to $72 \mathrm{~min} /$ day on moderate- and high-intensity physical activity. B, C, E and F: $P<0.05 ; \mathrm{D}$ and $\mathrm{H}: P<0.01$. 


\section{Discussion}

We are the first to show that within the range of normal daily life activities, mitochondrial capacity, measured as the capacity of CS, SDH and COX, correlates positively with habitual physical activity and HAD capacity tends $(P=0.06)$ to correlate positively with habitual physical activity. These associations are independent of sex, age and BMI.

PAL can vary from 1.2 to 2.5 in sustainable lifestyles with 1.2 observed in bed-bound subjects that are still eating and 2.5 being defined as a highly physically active lifestyle (28). In extreme situations, such as the Tour the France cycling competition, PAL has been shown to increase up to 5 (29). The range in PAL obtained in the current study was 1.6 to 2.0 , so lower than the 2.5 observed for highly physically active lifestyles. A PAL of 1.6 is regarded to reflect a sedentary lifestyle (28) and a PAL of 2.1 represents a physically active lifestyle (30). Thus, our subjects covered the range of normal daily life activity levels as reflected in PAL but were not highly physically active.

The normal range of daily life activities in the present population is confirmed by the proportion of time that subjects on average spent on moderate- and high-intensity physical activity, i.e. 30 and $11 \mathrm{~min}$, respectively. These proportions are close to those recently reported in other studies that used accelerometry in healthy, young adults $(31 ; 32)$. McClain et al. on the other hand recruited regular endurance runners and although \%Moderate was similar in their study (27 min/day), \%High was more pronounced (48 min/day) compared with the present population (33). This suggests that although physically active subjects were evidently recruited in the present study, the proportion of high-intensity physical activity was much lower than observed previously for people actively engaged in endurance sports.

Habitual physical activity correlated positively with \%Moderate and with \%High. Furthermore, positive associations were observed between markers for mitochondrial capacity and both \%Moderate and \%High. This suggests that the intensity of the activities performed may have affected the association between our markers for mitochondrial capacity and habitual physical activity. Indeed, stratification of the population based on the intensity of the activities performed made the association between markers for mitochondrial capacity and habitual physical activity more prominent. Evidently, as a classic marker for mitochondrial density, CS was only associated with habitual physical activity in the sub-group spending more than $8 \mathrm{~min} /$ day on high-intensity physical activity. Importantly, this suggests that although CS was associated with habitual physical activity in the entire population, there may be a lower limit for the time spent on high-intensity physical activity that should be met for the association to become apparent. Since habitual physical activity and \%High were both significantly higher in the sub-group spending more time on high-intensity physical activity (data not shown), the association found could theoretically also result from an increased habitual physical activity. However, stratification of the population based on \%Moderate did not reveal an association between CS or any other marker for mitochondrial capacity and habitual physical activity in either the sub-group spending more or less than $29 \mathrm{~min} /$ day on moderate-intensity physical activity. Therefore, we conclude that high-intensity physical activity may be a prerequisite for a positive association between CS and habitual physical activity. 
Within the population stratified based on the median of the time spent on moderate- and high-intensity physical activity combined, HAD showed a positive association with habitual physical activity in subjects spending more but not in subjects spending less than 39 min/day on moderate- and high-intensity physical activity. On first thought, this seems inconsistent since HAD was not associated with habitual physical activity within the population stratified based on \%Moderate or \%High separately. However, the time spent on moderate- and high-intensity physical activity combined is by definition the inverse of the time spent on low-intensity physical activity. In other words, the association observed between HAD and habitual physical activity in subjects spending more than 39 min/day on moderate- and high-intensity physical activity probably results from a decreased time spent on low-intensity physical activity. This implies that the capacity to oxidize fatty acids is positively associated with habitual physical activity in daily life if the latter is accompanied by a decreased time spent on low-intensity physical activity.

For SDH and COX, a positive association with habitual physical activity was found both in subjects spending more and less than $39 \mathrm{~min} /$ day on moderate- and high-intensity physical activity. Comparable results were obtained within the population stratified based on \%High, suggesting that SDH and $\mathrm{COX}$ are associated with habitual physical activity in daily life irrespective of the intensity of the activities performed.

In general, it can be concluded that a sedentary lifestyle does not result in positive associations with mitochondrial capacity, whilst an active lifestyle does. The intensity of the activities performed influences the association with habitual physical activity differently for different markers of mitochondrial capacity; it does not appear to affect the association between SDH and COX with habitual physical activity whereas a limited time spent on low-intensity physical activity appears to be a prerequisite for a positive association between HAD and habitual physical activity. CS on the other hand only correlated positively with habitual physical activity in subjects spending more time on high-intensity physical activity. Interestingly though, spending more than $8 \mathrm{~min} /$ day on high-intensity physical activity already resulted in a positive association between CS and habitual physical activity in healthy young subjects. Whether or not the positive association between mitochondrial capacity and habitual physical activity persists in populations at risk for developing type 2 diabetes and obesity remains to be established. More importantly, it should be examined if spending more than $8 \mathrm{~min} /$ day on high-intensity physical activity accompanied by a high level of habitual physical activity suffices to maintain or improve proper mitochondrial capacity in populations at risk for developing type 2 diabetes and obesity. It should be stressed that even if this association holds in populations at risk, no extrapolations to prevention of type 2 diabetes and obesity can be made. In fact, based on previous studies, 8 min of high-intensity physical activity per day is unlikely to be sufficient to delay the development of type 2 diabetes and obesity $(34 ; 35)$.

In conclusion, evidence was found for a positive association between CS, SDH and COX with habitual physical activity and a trend towards a positive association between HAD and habitual physical activity irrespective of sex, age and BMI. With CS and SDH as classic markers for mitochondrial density, mitochondrial capacity was found to be positively associated with habitual physical activity. Thus, in our population of healthy young adults, an active lifestyle within the range of normal daily life activities is associated with 
a higher mitochondrial capacity than a sedentary lifestyle and may help to maintain or improve mitochondrial capacity.

\section{Acknowledgements}

We thank Milou Beelen, Luc van Loon and René Koopman for their skilful way of obtaining the muscle biopsies. We also thank Loek Wouters for analyzing the deuterium samples. 


\section{References}

1. Kuczmarski RJ, Flegal KM, Campbell SM, Johnson CL: Increasing prevalence of overweight among US adults. The National Health and Nutrition Examination Surveys, 1960 to 1991. Jama 272:205-211, 1994

2. Seidell JC: Dietary fat and obesity: an epidemiologic perspective. Am J Clin Nutr 67:546S-550S, 1998

3. Hu G, Qiao Q, Silventoinen K, Eriksson JG, Jousilahti P, Lindstrom J, Valle TT, Nissinen A, Tuomilehto J: Occupational, commuting, and leisure-time physical activity in relation to risk for Type 2 diabetes in middle-aged Finnish men and women. Diabetologia 46:322-329, 2003

4. Kriska AM, Saremi A, Hanson RL, Bennett PH, Kobes S, Williams DE, Knowler WC: Physical activity, obesity, and the incidence of type 2 diabetes in a high-risk population. Am J Epidemiol 158:669-675, 2003

5. Jebb SA, Moore MS: Contribution of a sedentary lifestyle and inactivity to the etiology of overweight and obesity: current evidence and research issues. Med Sci Sports Exerc 31:S534-541, 1999

6. Befroy DE, Petersen KF, Dufour S, Mason GF, de Graaf RA, Rothman DL, Shulman GI: Impaired mitochondrial substrate oxidation in muscle of insulin-resistant offspring of type 2 diabetic patients. Diabetes 56:1376-1381, 2007

7. Kelley DE, He J, Menshikova EV, Ritov VB: Dysfunction of mitochondria in human skeletal muscle in type 2 diabetes. Diabetes 51:2944-2950, 2002

8. Mogensen M, Sahlin K, Fernstrom M, Glintborg D, Vind BF, Beck-Nielsen H, Hojlund K: Mitochondrial respiration is decreased in skeletal muscle of patients with type 2 diabetes. Diabetes 56:1592-1599, 2007

9. Gosker HR, Hesselink MK, Duimel H, Ward KA, Schols AM: Reduced mitochondrial density in the vastus lateralis muscle of patients with COPD. Eur Respir J, 2007

10. Santoro C, Cosmas A, Forman D, Morghan A, Bairos L, Levesque S, Roubenoff R, Hennessey J, Lamont L, Manfredi T: Exercise training alters skeletal muscle mitochondrial morphometry in heart failure patients. J Cardiovasc Risk 9:377-381, 2002

11. Gollnick PD, Armstrong RB, Saltin B, Saubert CWt, Sembrowich WL, Shepherd RE: Effect of training on enzyme activity and fiber composition of human skeletal muscle. J Appl Physiol 34:107-111, 1973

12. Hansen AK, Fischer CP, Plomgaard P, Andersen JL, Saltin B, Pedersen BK: Skeletal muscle adaptation: training twice every second day vs. training once daily. J Appl Physiol 98:93-99, 2005

13. Tarnopolsky MA, Rennie CD, Robertshaw HA, Fedak-Tarnopolsky SN, Devries MC, Hamadeh MJ: Influence of endurance exercise training and sex on intramyocellular lipid and mitochondrial ultrastructure, substrate use, and mitochondrial enzyme activity. Am J Physiol Regul Integr Comp Physiol 292:R1271-1278, 2007

14. Menshikova EV, Ritov VB, Ferrell RE, Azuma K, Goodpaster BH, Kelley DE: Characteristics of skeletal muscle mitochondrial biogenesis induced by moderate-intensity exercise and weight loss in obesity. J Appl Physiol 103:21-27, 2007

15. Toledo FG, Menshikova EV, Ritov VB, Azuma K, Radikova Z, DeLany J, Kelley DE: Effects of physical activity and weight loss on skeletal muscle mitochondria and relationship with glucose control in type 2 diabetes. Diabetes 56:2142-2147, 2007

16. Westerterp KR, Meijer GA, Janssen EM, Saris WH, Ten Hoor F: Long-term effect of physical activity on energy balance and body composition. Br J Nutr 68:21-30, 1992

17. Plasqui $G$, Joosen $A M$, Kester $A D$, Goris $A H$, Westerterp KR: Measuring free-living energy expenditure and physical activity with triaxial accelerometry. Obes Res 13:13631369, 2005

18. Bouten CV, Verboeket-van de Venne WP, Westerterp KR, Verduin M, Janssen JD: Daily physical activity assessment: comparison between movement registration and doubly labeled water. J Appl Physiol 81:1019-1026, 1996 
19. Gollnick PD, Armstrong RB, Saubert CWt, Piehl K, Saltin B: Enzyme activity and fiber composition in skeletal muscle of untrained and trained men. J Appl Physiol 33:312319,1972

20. Faxen K, Gilderson G, Adelroth P, Brzezinski P: A mechanistic principle for proton pumping by cytochrome c oxidase. Nature 437:286-289, 2005

21. Stryer L: Biochemistry. New York, W.H. Freeman and Company, 1999

22. Ainsworth BE, Haskell WL, Whitt $M C$, Irwin $M L$, Swartz AM, Strath SJ, O'Brien WL, Bassett DR, Jr., Schmitz KH, Emplaincourt PO, Jacobs DR, Jr., Leon AS: Compendium of physical activities: an update of activity codes and MET intensities. Med Sci Sports Exerc 32:S498-504, 2000

23. Bergstrom J: Percutaneous needle biopsy of skeletal muscle in physiological and clinical research. Scand J Clin Lab Invest 35:609-616, 1975

24. Westerterp KR, Wouters L, van Marken Lichtenbelt WD: The Maastricht protocol for the measurement of body composition and energy expenditure with labeled water. Obes Res 3 Suppl 1:49-57, 1995

25. Siri WE: Body composition from fluid spaces and density: analysis of methods. 1961. Nutrition 9:480-491; discussion 480, 492, 1993

26. Jaworowski A, Porter MM, Holmback AM, Downham D, Lexell J: Enzyme activities in the tibialis anterior muscle of young moderately active men and women: relationship with body composition, muscle cross-sectional area and fibre type composition. Acta Physiol Scand 176:215-225, 2002

27. Simoneau JA, Bouchard C: Human variation in skeletal muscle fiber-type proportion and enzyme activities. Am J Physiol 257:E567-572, 1989

28. Black AE, Coward WA, Cole TJ, Prentice AM: Human energy expenditure in affluent societies: an analysis of 574 doubly-labelled water measurements. Eur J Clin Nutr 50:7292, 1996

29. Westerterp KR, Saris WH, van Es M, ten Hoor F: Use of the doubly labeled water technique in humans during heavy sustained exercise. J Appl Physiol 61:2162-2167, 1986

30. Westerterp KR: Pattern and intensity of physical activity. Nature 410:539, 2001

31. Dinger MK, Behrens TK: Accelerometer-determined physical activity of free-living college students. Med Sci Sports Exerc 38:774-779, 2006

32. Yoshioka M, Ayabe M, Yahiro T, Higuchi H, Higaki Y, St-Amand J, Miyazaki H, Yoshitake $\mathrm{Y}$, Shindo M, Tanaka H: Long-period accelerometer monitoring shows the role of physical activity in overweight and obesity. Int J Obes (Lond) 29:502-508, 2005

33. McClain JJ, Sisson SB, Tudor-Locke C: Actigraph accelerometer interinstrument reliability during free-living in adults. Med Sci Sports Exerc 39:1509-1514, 2007

34. Brooks GA, Butte NF, Rand WM, Flatt JP, Caballero B: Chronicle of the Institute of Medicine physical activity recommendation: how a physical activity recommendation came to be among dietary recommendations. Am J Clin Nutr 79:921S-930S, 2004

35. Laaksonen DE, Lindstrom J, Lakka TA, Eriksson JG, Niskanen L, Wikstrom K, Aunola S, Keinanen-Kiukaanniemi S, Laakso M, Valle TT, Ilanne-Parikka P, Louheranta A, Hamalainen H, Rastas M, Salminen V, Cepaitis Z, Hakumaki M, Kaikkonen H, Harkonen P, Sundvall J, Tuomilehto J, Uusitupa M: Physical activity in the prevention of type 2 diabetes: the Finnish diabetes prevention study. Diabetes 54:158-165, 2005 
Chapter 4

\section{Genetic variants in PPARD and PPARGC1A contribute to the inter-individual variation of habitual physical activity in unrelated subjects and twins}

Marcel den Hoed, Marij Gielen, Margriet S Westerterp-Plantenga, Freek G Bouwman, Annemiek MCP Joosen, Robert Vlietinck, Catherine Derom, Maurice P Zeegers, Edwin CM Mariman and Klaas R Westerterp

Submitted for publication 


\begin{abstract}
Objective: Twin studies suggest a high heritability for habitual physical activity. This study aims to replicate this finding and to identify relevant genetic variants. Single nucleotide polymorphisms (SNPS) in PPARD, PPARGC1A, NRF1 and FRAP1 were considered candidates.

Research Design and Methods: Habitual physical activity was measured for 14 days with a validated triaxial accelerometer (Tracmor). Fifty-two and 65 unrelated men and women (aged $21 \pm 2$ years, BMI $22.0 \pm 2.5 \mathrm{~kg} / \mathrm{m}^{2}$ ) as well as 28 monozygotic and 24 dizygotic same-sex twin pairs (aged $22 \pm 5$ years, BMI $21.8 \pm 3.4 \mathrm{~kg} / \mathrm{m}^{2}, 21$ male and 31 female pairs) were included.

Results: A heritability of $57 \%$ is observed for habitual physical activity. In both groups, AG/GG carriers in rs2267668 and AC/CC carriers in rs2076168 (PPARD) were less physically active than AA carriers (additive model, $P<0.05$ ). In addition, carriers of the AA CG haplotype in these SNPs tended to be less physically active than carriers of the AA AA haplotype. The risk alleles were associated earlier with a reduced mitochondrial capacity in vitro and reduced PPAR $\delta$ mRNA levels. GA/AA carriers in rs8192678 (PPARGC1A), who have an increased the risk for type 2 diabetes, spend more time on high-intensity physical activity than GG carriers in both groups $(P<0.05)$. No associations were observed with SNPs in NRF1 and FRAP1.

Conclusions: SNPs in genes involved in mitochondrial biogenesis contribute to the interindividual variation in habitual physical activity. One pathway shows a genetic predisposition to physiologically limited habitual physical activity; another pathway shows the requirement of high-intensity physical activity to prevent or delay the genetically predisposed development of type 2 diabetes.
\end{abstract}




\section{Introduction}

Activity-related energy expenditure is the most variable component of total energy expenditure (1) and an important determinant of energy balance (2). As such, a reduced habitual physical activity is a potentially important contributor to the development of obesity $(3 ; 4)$. Moreover, a low level of habitual physical activity is an independent risk factor for developing cardiovascular diseases $(5 ; 6)$, osteoporosis $(7 ; 8)$ and type 2 diabetes (9-11). Maintaining a reasonable level of habitual physical activity therefore appears a prerequisite to prevent or delay these causes of morbidity and mortality.

Twin studies in which habitual physical activity was assessed using questionnaires show a heritability between $29 \%$ and $62 \%(12-14)$. However, questionnaires are subject to interpretation and may, together with the complex multidimensional character of the phenotype, result in misreporting. Accelerometers provide an objective alternative to measure habitual physical activity. They can be used for a prolonged period of time in free living conditions and additionally provide information about the intensity and duration of the activities performed. Until now, few studies have determined the heritability of habitual physical activity as measured objectively using an accelerometer approach. Using a uniaxial device, Cai et al. show in siblings that $55 \%$ of the inter-individual variation in habitual physical activity is explained by genetic variation (15). In a twin study, Joosen et al. show an additive genetic effect of $78 \%$ for habitual physical activity using the triaxial Tracmor accelerometer (Philips Research, Eindhoven, The Netherlands). Unique environmental influences were concluded to account for the remaining variation (16), which was later confirmed by the results of Carlsson et al. (12). The results suggest a moderate to high heritability for habitual physical activity when measured objectively using an accelerometer approach. In other words: genetic variation determines to a large extent whether someone is prone to engaging in physical activities. Given the results of Joosen et al. (16) and taking the complexity of the phenotype into account, the heritability of habitual physical activity is suggested to result from many functional sequence variants at different loci all exerting a small effect. So far, studies aiming to identify these variants using objective measures for habitual physical activity are scarce (15).

We showed earlier that within the range of normal daily life activities, habitual physical activity correlates positively with markers for mitochondrial capacity (17). As $25-50 \%$ of the variation in the capacity of regulatory enzymes of the Kreb's cycle can be explained by genetic variation (18), single nucleotide polymorphisms (SNPs) in genes encoding proteins involved in mitochondrial biogenesis and energy metabolism are considered candidates to contribute to the inter-individual variation in habitual physical activity. Peroxisome proliferator-activated receptor (PPAR) $\gamma$ co-activator $1 \alpha$ (PGC-1 $\alpha$ ), PPAR $\delta$, nuclear respiratory factor (NRF)1 and mammalian target of rapamycin (mTOR) are such proteins. PGC- $1 \alpha$ is a transcription factor co-activator that is essential for the transcription of many genes required for the expansion and replication of mitochondria (19). One of its targets is NRF1 $(20 ; 21)$, which binds to and activates the promoters of nuclear genes encoding for components of the electron transport chain (22) as well as for mitochondrial transcription factor A (21). Ultimately, PGC-1 $\alpha$ is able to drive a muscle fiber type transition from type II to I, that is, towards a more oxidative phenotype $(23 ; 24)$. PPAR, the predominant PPAR isoform in skeletal muscle, is also co-activated by PGC-1 $\alpha$ (25). Much like 
PGC- $1 \alpha$, PPAR $\delta$ regulates fatty acid oxidation via the transcription of genes involved in $\beta$ oxidation and energy uncoupling $(25 ; 26)$. In addition, PPAR is able to induce a muscle fiber type switch from type II to I, independent of PGC-1 $\alpha$ (27). As for mTOR, Schieke et al. show that the mTOR-raptor complex directly associates with the mitochondria and that its disruption reduces the oxidative capacity of the cell, which reflects intrinsic mitochondrial properties (28). Cunningham et al. show that treating mTOR-raptor with rapamycin, a specific mTOR inhibitor, suppresses the expression of many mitochondrial genes that are induced by PGC-1 $\alpha$. Apparently, mTOR controls mitochondrial gene expression by directly altering the physical interaction between PGC-1 $\alpha$ and YY1, a transcription factor that binds directly to mitochondrial gene promoters (29).

The aim of the present study was to confirm the heritability of habitual physical activity as objectively measured using a triaxial accelerometer. In addition, we aimed to identify genetic factors that contribute to the inter-individual variation in habitual physical activity. Considering the role that PPAR $\delta$ PGC- $1 \alpha$, NRF1 and mTOR play in mitochondrial biogenesis and energy metabolism, SNPs in the genes encoding these proteins (PPARD, PPARGC1A, NRF1 and FRAP1) were hypothesized to contribute to the inter-individual variation in habitual physical activity as well as the intensity and duration of the activities performed.

\section{Methods}

\section{Subjects}

Associations were tested in two healthy populations: 1) a group of 117 healthy, unrelated adults (65 women, 52 men, aged $21 \pm 2$ years, BMI $22.0 \pm 2.5 \mathrm{~kg} / \mathrm{m}^{2}$ ); 2) A group of 51 same-sex twin pairs and one same-sex (male) triplet of similar age and BMI (16 monozygotic (MZ) female, 15 dizygotic (DZ) female, $12 \mathrm{MZ}$ male and $8 \mathrm{DZ}$ male pairs, aged $22 \pm 5$ years, BMI $21.8 \pm 3.4 \mathrm{~kg} / \mathrm{m}^{2}$ ). Thirty-five twin pairs as well as the triplet were contacted and recruited by the East-Flanders Prospective Twin Survey (EFPTS) (30). The remaining sixteen pairs were recruited earlier by Joosen et al. (16). All subjects were from Western European descent and had been weight stable for at least 6 months prior to the study. The study conformed to the standards set by the Declaration of Helsinki and the local Ethics Committee approved the study. All subjects provided written informed consent before participating.

\section{Habitual physical activity}

Habitual physical activity, as well as the intensity and duration of the activities performed, were measured using a triaxial accelerometer for movement registration (Tracmor IV; Philips research, Eindhoven, The Netherlands). The Tracmor registers accelerations of the trunk along the anterio-posterior, medio-lateral and longitudinal axis using three unaxial piezo-electric accelerometers (details are provided elsewhere (31)). The Tracmor 
has been validated with doubly labelled water (31). To ensure a valid reflection of longterm daily life activities, the accelerometer was worn for 14 days under free-living conditions. Subjects wore the Tracmor from the time they woke up in the morning until they went back to bed at night. Habitual physical activity was subsequently acquired by summing the output of all three axes and is presented as Megacounts per day (Mcnts/d). Using Tracmor data, the time spent on low-, moderate- and high-intensity physical activity was determined. More detailed information on the protocol used to measure habitual physical activity as well as on the cut-off points for the intensity categories is provided elsewhere (32).

Using linear regression analysis in a population similar to that of the present study with respect to habitual physical activity, body composition and age, Plasqui et al. were able to predict the physical activity level (PAL) with an explained variation of $70 \%$ using only the Tracmor output (31). This regression equation was used in the present study to estimate PAL.

\section{Body Composition}

In the unrelated subjects, body mass was measured to the nearest $0.01 \mathrm{~kg}$ (ID 1 Plus, Mettler, Toledo, Giessen, Germany) and height to the nearest $0.1 \mathrm{~cm}$ (Mod. 220, SECA. Hamburg, Germany). \%BF was determined by hydrostatic weighing and deuterium dilution according to Siri's three-compartment model (33). More information on these techniques is provided elsewhere (32).

In the twins, body mass was measured to the nearest $0.1 \mathrm{~kg}$ (HF380, Philips, Eindhoven, The Netherlands) and height to the nearest $0.1 \mathrm{~cm}$ using a tape measure. \%BF was determined using deuterium dilution.

\section{DNA isolation and SNP genotyping}

Genomic DNA was isolated from peripheral blood leukocytes (unrelated subjects) using the QIAamp blood kit and from mouth swabs and/or placental tissue collected at birth (twins) using the DNA minikit (Qiagen, Amsterdam, The Netherlands). Candidate SNPs were selected in PPARD, PPARGC1A, FRAP1 and NRF1 with a minor allele frequency in Europeans of at least $10 \%$ as indicated by the SNP public database (dbSNP; http://www.ncbi.nlm.nih.gov/SNP). Only tag SNPs or SNPs that were associated earlier with relevant phenotypes including mRNA or protein level, $\mathrm{BMI}$ or $\mathrm{VO}_{2}$-max were considered. This resulted in the selection of five SNPs in four genes (Table 1).

Genotyping was performed using commercially available TaqMan SNP genotyping assays from Applied Biosystems (Foster City, California, USA). The procedure was performed according to the manufacturer's protocol and measured on an Applied Biosystems 7900 HT Fast Real-Time PCR System. Allelic calls were determined semi-automatically using the allelic discrimination software of Applied Biosystems. 


\section{Statistical analysis}

\section{Descriptive statistical analysis}

The time spent on low-, moderate- and high-intensity physical activity was log transformed to obtain a normal distribution of the residuals. Results are presented as means \pm SD (median \pm SD for the variables that were log transformed). A $\chi^{2}$-test was used to check whether the allele frequencies were in Hardy-Weinberg equilibrium for both groups separately. In twin pairs, one twin was randomly selected per pair for this analysis. The triplet was randomly included in the heritability analysis as a DZ male pair and in the association analyses as a DZ male pair and one solitary individual.

Table 1: Genotypic and allelic distributions per single nucleotide polymorphism for unrelated subjects

\begin{tabular}{|c|c|c|c|c|c|c|c|c|c|c|c|}
\hline Gene & SNP & G & $\begin{array}{l}F_{U} \\
(N)\end{array}$ & $\begin{array}{l}F_{U} \\
(\%)\end{array}$ & $\begin{array}{l}\mathrm{F}_{\mathrm{T}} \\
(\mathrm{N})\end{array}$ & $\begin{array}{l}\mathrm{F}_{\mathrm{T}} \\
(\%)\end{array}$ & Allele & $\begin{array}{l}F_{U} \\
(\%)\end{array}$ & $\begin{array}{l}\mathrm{F}_{\mathrm{T}} \\
(\%)\end{array}$ & $\mathrm{HWE}_{U}$ & $\mathrm{HWE}_{\mathrm{T}}$ \\
\hline \multirow[t]{6}{*}{ PPARD } & rs2267668 & AA & 91 & 77.8 & 56 & 54.4 & A & 87.6 & 76.2 & 0.31 & 0.12 \\
\hline & $A>G$ & AG & 23 & 19.7 & 45 & 43.7 & G & 12.4 & 23.8 & & \\
\hline & (Intron) & GG & 3 & 2.6 & 2 & 1.9 & & & & & \\
\hline & rs2076168 & $A A$ & 80 & 68.4 & 53 & 51.5 & A & 82.1 & 73.8 & 0.44 & 0.26 \\
\hline & $A>C$ & $A C$ & 32 & 27.4 & 46 & 44.7 & $\mathrm{C}$ & 17.9 & 26.2 & & \\
\hline & (Intron) & $\mathrm{CC}$ & 5 & 4.3 & 4 & 3.9 & & & & & \\
\hline \multicolumn{2}{|c|}{ PPARGC1A rs8192678 } & GG & 47 & 40.2 & 25 & 25.3 & G & 65.8 & 54.0 & 0.13 & 0.14 \\
\hline & $1444 G>A$ & GA & 60 & 51.3 & 57 & 57.6 & $\mathrm{C}$ & 34.1 & 46.0 & & \\
\hline & (Gly482Ser) & $A A$ & 10 & 8.5 & 17 & 17.2 & & & & & \\
\hline \multirow[t]{3}{*}{ FRAP1 } & rs11121691 & $\mathrm{CC}$ & 60 & 51.3 & 52 & 57.1 & $\mathrm{C}$ & 73.9 & 76.4 & 0.06 & 0.65 \\
\hline & $6909 \mathrm{C}>\mathrm{T}$ & $\mathrm{CT}$ & 53 & 45.3 & 35 & 38.5 & $\mathrm{~T}$ & 26.1 & 23.6 & & \\
\hline & (Leu2303Leu) & TT & 4 & 3.4 & 4 & 4.4 & & & & & \\
\hline \multirow[t]{3}{*}{$N R F 1$} & rs1882094 & TT & 63 & 53.8 & 33 & 36.2 & $\mathrm{~T}$ & 73.5 & 61.2 & 0.16 & 0.01 \\
\hline & $141 \mathrm{~T}>\mathrm{G}$ & TG & 46 & 39.3 & 60 & 65,9 & G & 26.5 & 38.8 & & \\
\hline & (Ser47Ser) & GG & 8 & 6.8 & 10 & 11.0 & & & & & \\
\hline
\end{tabular}

G, genotype; F, Frequency, both absolute $(\mathrm{n})$ and relative $(\%) ; P$-values obtained from the $\chi^{2}$ test of Hardy Weinberg equilibrium (HWE) in unrelated subjects $(U)$ and twins (T).

\section{Heritability analysis}

The heritability of habitual physical activity as well as of the intensity and duration of the activities performed was determined as described in detail by Joosen et al. (16). Briefly, structural equation modeling was used to separate and quantify the observed phenotypic variance $\left(\mathrm{V}_{\text {tot }}\right)$ in habitual physical activity and the time spent on low-, moderate- and high-intensity physical activity into its different components: additive genetic contribution $\left(a^{2}=V_{A} / V_{\text {tot }}\right)$, dominant genetic contribution $\left(d^{2}=V_{D} / V_{\text {tot }}\right)$, common environmental contribution $\left(c^{2}=V_{C} / V_{t o t}\right)$ and unique environmental contribution $\left(e^{2}=V_{E} / V_{\text {tot }}\right)$ using $M x$ software (34). First, we tested whether the unstandardized path coefficients $\left(V_{A}, V_{D}, V_{C}\right.$ and $\left.V_{E}\right)$ were equal for men and women. Alternative univariate models ( $A C E, C E, A E$ and $E ; A D E$, $A E$ and $E$ ) with sex and age as explanatory variables were fitted to the raw data. For models, a maximum likelihood approach with accompanying Akaike's information criterion (AIC) was used (35). The model with the lowest AIC reflects the best model in which the 
pattern of variance and covariance is explained by the smallest number of measurements possible. The goodness of fit was additionally evaluated by hierarchical $\chi^{2}$-tests. When the $\chi^{2}$ was not statistically significant $(P>0.05)$ the most parsimonious model was selected, that is, the model with the best fit given the number of degrees-of-freedom.

\section{Association analysis}

Before the association analysis was performed, the effects of potential covariates was evaluated for habitual physical activity as well as for the time spent on low-, moderateand high-intensity physical activity. The influence of sex, age and seasonality was evaluated, whereas zygosity was additionally taken into account in the twin population. Covariates were incorporated into the model when $P<0.05$. A general association test was performed without assuming a mode of inheritance by entering the genotype in the optimized model (with the significant covariates) as class variables. The mode of inheritance was further investigated by testing additive, dominant and recessive models.

In the unrelated subjects, (multiple) linear regression was used (SPSS version 13 for Macintosh OS X, SPSS Inc.; Chicago, Illinois, USA). In the twins, multilevel analysis (proc mixed) was performed taking clustering of the twin pairs into account by adding a random effect to the model. The intercept of each twin pair was modeled as a function of the population intercept plus a unique contribution of the pair. The variance-covariance structure was allowed to differ between MZ and DZ pairs (SAS package version 9.1, SAS Institute Inc., Cary, NC, USA).

Linkage disequilibrium (LD) was evaluated for the two SNPs in PPARD using Haploview (36). Haplotypes were estimated using PHASE (37). Haplotype analyses were subsequently performed in SAS using linear regression or multilevel analysis (proc mixed) analogue to the analyses mentioned above.

\section{Results}

\section{Descriptive analysis}

Subject characteristics are shown in Table 2. Habitual physical activity as well as the intensity and duration of the activities performed are similar in men and women in both groups, except for the male twins spending more time on moderate-intensity physical activity than their female counterparts $(P<0.05)$. PAL ranges from 1.5 to 2.2 in both populations.

\section{Heritability}

Pearson's intra-pair correlation coefficients for habitual physical activity are higher in MZ than DZ pairs $(0.64$ versus 0.36$)$, indicating that genetic factors contribute to the inter- 
individual variation in habitual physical activity. Similar results are obtained for the intensity and duration of the activities performed.

A model including additive genetic as well as unique environmental factors provides the best model for all four parameters of physical activity (Table 3). Taking sex and age into account, $57 \%$ of the inter-individual variation in habitual physical activity is explained by additive genetic factors. Similar values are obtained for the time spent on moderate(55\%) and high-intensity physical activity (47\%). For habitual physical activity as well as the time spent on low-, moderate- and high-intensity physical activity, unstandardized additive genetic path coefficients $\left(V_{A}\right)$ are equal for men and women. The contribution of additive genetic factors $\left(\mathrm{a}^{2}\right)$ to the time spent on low-intensity physical activity is lower in men than in women ( $38 \%$ versus $72 \%$, respectively), resulting from the unstandardized unique environmental path coefficient $\left(\mathrm{V}_{\mathrm{E}}\right)$ for low-intensity physical activity being lower in women than in men.

Table 2: Subject characteristics

\begin{tabular}{|c|c|c|c|c|}
\hline & Unrelated su & & Twins & \\
\hline & Men & Women & Men & Women \\
\hline $\mathrm{N}$ & 52 & 65 & 43 & 62 \\
\hline & & & (21 pairs & (31 pairs) \\
\hline Age (vears) & $21 \pm 2$ & $21 \pm 2$ & $22+4$ & $23+5$ \\
\hline Body mass (kg) & $76.0 \pm 10.1$ & $63.4 \pm 7.9 \#$ & $72.4 \pm 12.1$ & $62.4 \pm 10.4$ \# \\
\hline Height (m) & $1.85 \pm 0.06$ & $1.70 \pm 0.06^{\#}$ & $1.82 \pm 0.08$ & $1.69 \pm 0.07$ \# \\
\hline BMI $\left(\mathrm{kg} / \mathrm{m}^{2}\right)$ & $22.3 \pm 2.4$ & $21.8 \pm 2.6$ & $21.9 \pm 3.0$ & $21.8 \pm 3.6$ \\
\hline$\% B F$ & $13.9 \pm 5.5$ & $26.3 \pm 4.9^{\#}$ & $19.1 \pm 6.9$ & $29.4 \pm 7.5^{\#}$ \\
\hline HPA (MCnts/day) & $3761 \pm 813$ & $3796 \pm 718$ & $3871 \pm 991$ & $3666 \pm 1016$ \\
\hline PAL & $1.82 \pm 0.13$ & $1.83 \pm 0.12$ & $1.84 \pm 0.16$ & $1.80 \pm 0.17$ \\
\hline \%Low (min/day) & $1403 \pm 17$ & $1399 \pm 15$ & $1402 \pm 25$ & $1411 \pm 20$ \\
\hline \%Moderate (min/day) & $27 \pm 12$ & $29 \pm 12$ & $31 \pm 21$ & $23 \pm 15^{*}$ \\
\hline$\% H i g h$ (min/day) & $9 \pm 8$ & $8 \pm 6$ & $5 \pm 8$ & $6 \pm 9$ \\
\hline
\end{tabular}

BMI, body mass index; \%BF, percentage body fat; HPA, Habitual physical activity as measured with a triaxial accelerometer for a period of two weeks; MCnts, Megacounts; PAL, physical activity level; \%Low, \%Moderate and \%High, proportion of time subjects were physically active at a low, moderate and high intensity, respectively; Values are means \pm SD (Median \pm SD for \%Low, \%Moderate and $\%$ High). Significant difference between men and women within a population: ${ }^{*} P<0.05, \# P<0.001$.

\section{Genetic association}

The genotypic and allelic distributions of the determined SNPs are provided in Table 1. All SNPs are in Hardy-Weinberg equilibrium in both populations, except for the rs1882094 SNP (NRF1) in the twins. Of the covariates evaluated, age contributes significantly to the explained variation in the time spent on low- and moderate-intensity physical activity in the twins and is therefore taken into account for these phenotypes. No significant interactions were observed between SNPs. 
General association tests show a significant association between habitual physical activity and the intronic rs2267668 SNP in the unrelated subjects $(P=0.034)$ and a trend towards an association in the twins $(P=0.120)$. An additive model fits the data best, with habitual physical activity being significantly lower in AG/GG carriers compared with AA carriers $(P=0.012$ in unrelated subjects, $P=0.050$ in twins; Figure $1 \mathrm{~A}-\mathrm{B})$. Given the small number of GG carriers, a dominant model was evaluated as well ( $P=0.009$ in unrelated subjects, $P=0.099$ in twins). Similar associations were observed for the intronic rs2076168 SNP in the same gene, with $\mathrm{AC} / \mathrm{CC}$ carriers leading a less physically active lifestyle than AA carriers under an additive model ( $P=0.091$ in unrelated subjects, $P=0.006$ in twins; Figure 1C-D). Again, a dominant model was additionally evaluated ( $P=0.148$ in unrelated subjects, $P=0.023$ in twins).

As the rs2267668 and rs2076168 SNPs are in strong LD in both groups $\left(D^{\prime}=0.91\right.$ and $\mathrm{R}^{2}=0.54$ in unrelated subjects, $\mathrm{D}^{\prime}=0.84$ and $\mathrm{R}^{2}=0.61$ in twins), haplotype analyses were additionally performed. In both groups, three common haplotype combinations accounted for over $92 \%$ of all combinations (unrelated individuals 94\%; twins 92\%): 1) AA and AA carriers; 2) $A A$ and $C A$ carriers; and 3) $A A$ and $C G$ carriers. In the unrelated individuals, $67 \%(n=78)$ were $A A$ and $A A, 10 \%(n=12)$ were $A A$ and $C A$ and $17 \%(n=20)$ were $A A$ and CG. In the twins, $47 \%(n=51)$ were $A A$ and $A A, 8 \%(n=9)$ were $A A$ and $C A$ and $37 \%$ $(n=40)$ were AA and CG. Habitual physical activity tends to be lower in AA and CG haplotype carriers ( $P A L=1.78$ in unrelated subjects and twins) than in the other two haplotype combinations ( $P A L=1.84$ for both haplotype combinations in unrelated subjects and twins) ( $P=0.068$ in unraleted subjects, $P=0.135$ in twins).

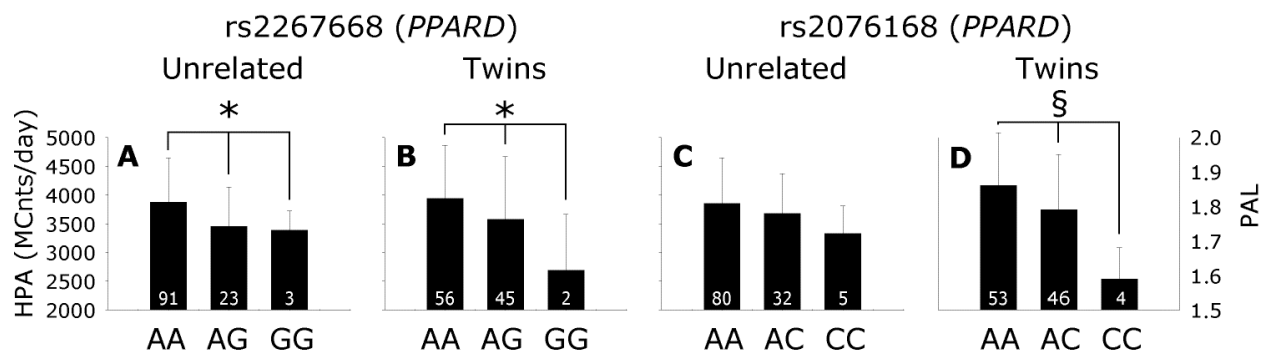

Figure 1: Habitual physical activity (HPA) and the physical activity level (PAL) as a function of $P P A R D$ genotype. Figures A-B show the associations with the intronic rs2267668 SNP, C-D with the rs2076168 SNP. Associations are shown for unrelated subjects ( $A$ and $C$ ) and twins ( $B$ and $D$ ) assuming an additive model. The number of subjects within a genotype-group is indicated in each bar. * $P<0.05$, § $P<0.01$.

\section{PPARGC1A}

No association was observed between habitual physical activity and the rs8192678 SNP (Gly482Ser). However, a general association test reveals a significant association between the time spent on high-intensity physical activity and the rs8192678 SNP in the 
unrelated subjects $(P=0.017)$ and a trend towards an association in the twins $(P=0.080)$. An additive model shows that GA/AA carriers spend more time on high intensity physical activity than GG carriers $(P=0.065$ and $P=0.039$ for unrelated subjects and twins, respectively). The best fit however is obtained with a recessive model in the unrelated subjects $(P=0.004)$ and a dominant model in the twins $(P=0.036)$.

$$
\text { rs8192678 (PPARGC1A) }
$$
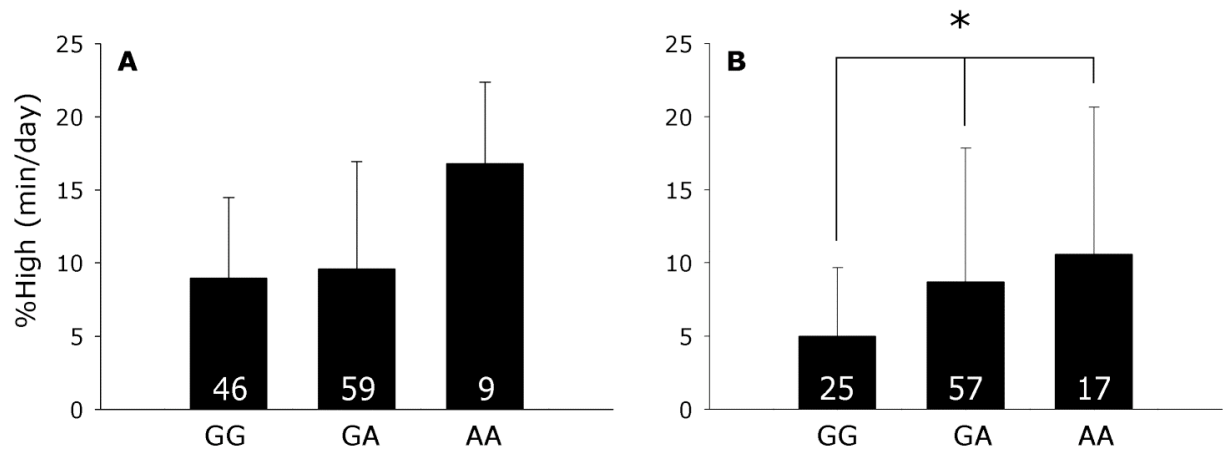

Figure 2: The time spent on high-intensity physical activity (\%High) as a function of PPARGC1A genotype. Associations are shown for unrelated subjects (A) and twins (B) with an additive model. The number of individuals within a genotype-group is indicated in each bar. $* P<0.05$.

\section{FRAP1}

No significant association was observed between habitual physical activity and rs11121691 in either the general association test or when assuming a mode of inheritance. The time spent on high-intensity physical activity on the other hand tends to be associated with the rs11121691 SNP in twins $(P=0.090)$. A dominant model fits the data best, with twins with the CC genotype in rs11121691 spending significantly more time on highintensity physical activity than $\mathrm{CT} / \mathrm{TT}$ carriers $(P=0.032)$. This association is not observed in the unrelated subjects.

NRF1

General association tests do not reveal significant associations between either habitual physical activity or the intensity and duration of the activities performed and the rs1882094 SNP in either group. No associations are observed with an additive, dominant or recessive model either. 


\section{Discussion}

This study confirms that genetic variation is responsible for the largest part of the interindividual variation in habitual physical activity as measured with a validated triaxial accelerometer (16). Wer are the first to show that part of the inter-individual variation in habitual physical activity is accounted for by variants in genes involved in mitochondrial biogenesis and energy metabolism in two independent populations.

The heritability of $57 \%$ observed in the present population is somewhat lower than the $78 \%$ observed by Joosen et al. (16) but agrees well with the $55 \%$ observed by Cai et al. (15). In concordance with other twin studies, the present study shows that the residual variation in habitual physical activity $(43 \%)$ is explained by unique environmental variation $(12 ; 16)$.

The results show that part of the additive genetic variation associated with habitual physical activity is located in the PPARD gene, whereas the time spent on high-intensity physical activity is associated with variation in the PPARGC1A gene. Nilsson et al. show an additive genetic effect for PPAR $\delta$ mRA levels in young $\left(\mathrm{h}^{2}=0.59\right)$ and elderly twins $\left(\mathrm{h}^{2}=0.63\right)$. Moreover, twins carrying more $\mathrm{C}$ alleles in the intronic rs2076168 SNP in PPARD have significantly lower PPAR $\mathrm{mRNA}$ levels than their co-twins carrying more common A alleles at this position (38). Given the role that PPAR $\delta$ plays in mitochondrial energy metabolism, AC/CC carriers appear to be genetically predisposed to a lower mitochondrial capacity than subjects with the AA genotype. In line with this, Stefan et al. show for the intronic rs2267668 SNP in PPARD, that young AG/GG carriers are characterized by a lower mitochondrial capacity in vitro compared with AA carriers (39). The present study shows that carriers of the AG/GG and AC/CC genotypes, that is, the genotypes predisposing to a reduced mitochondrial capacity in vitro and reduced PPARD mRNA levels, are characterized by a lower level of habitual physical activity compared with carriers of the AA genotype. We previously showed a positive association between mitochondrial capacity and habitual physical activity and concluded that an active lifestyle may increase mitochondrial capacity (17). The results from the present study imply that the latter association may also result from a genetic predisposition, with subjects genetically predisposed to a lower mitochondrial capacity leading a more sedentary lifestyle than subjects genetically predisposed to a higher mitochondrial capacity. No conclusions can be drawn concerning the mode of inheritance, as both additive and dominant models reveal significant associations. Future studies with larger populations will have to address this issue.

Carriers of the GA/AA genotype in rs8192678 (PPARGC1A) spend significantly more time on high-intensity physical activity than GG carriers. High-intensity physical activity is known to increase skeletal muscle PGC-1 $\alpha$ protein content $(20 ; 40)$, mitochondrial capacity $(41 ; 42)$ and maximal oxygen uptake $\left(\mathrm{VO}_{2}\right.$-max) $(43)$. Based on these associations, the GA/AA genotypes are anticipated to protect against developing morbidities like cardiovascular diseases and type 2 diabetes. However, GA/AA carriers have an increased risk for developing type 2 diabetes $(40 ; 44)$. In fact, Barroso et al. show that the odds of having type 2 diabetes increases with $11 \%$ for each Ser encoding allele (A) (44). This paradox can be explained by the results of Barroso et al. being based on a meta analysis performed in older subjects (44). Ling et al. also show that in older subjects, the Ser en- 
coding allele is associated with reduced basal skeletal muscle PGC- $1 \alpha$ mRNA levels and a lower $\mathrm{VO}_{2}$-max (45). However, they did not observe this association in younger subjects and conclude that age modifies the genetic susceptibility for type 2 diabetes. Franks et al. refine this by showing in older subjects that those homozygous for the Ser encoding allele are less physically fit than those homozygous for the common Gly encoding allele (GG) when sedentary, but not when physically active (46). This means that physical activity and not age itself mediates the association between the risk for developing type 2 diabetes and the Ser encoding allele in rs8192678 (46). Physical activity, and especially high-intensity physical activity, are known to decrease with age (47). This implies that at a younger age, the increased risk for developing type 2 diabetes in GA/AA carriers may be compensated for by an increased time spent on high-intensity physical activity. The decrease in high-intensity physical activity with age probably explains why the increased risk for developing type 2 diabetes associated with the Ser encoding allele only becomes evident at a later stage in life (45), when little high-intensity physical activity remains. In addition to the results of Franks et al., the results of the present study stress the importance for GA/AA carriers to remain participating in high-intensity physical activity throughout life to prevent or delay the onset of type 2 diabetes.

Twins with the common CC genotype in rs11121691 (FRAP1) spent significantly more time on high-intensity physical activity than CT/TT carriers. mTOR, the protein encoded by FRAP1, is thought to control mitochondrial gene expression by directly altering the physical interaction between YY1 and PGC-1 $\alpha$, thereby inhibiting their function and decreasing the expression of mitochondrial genes like NRF1 (29). Based on the association between the time spent on high-intensity physical activity and the rs11121691 SNP in twins, the latter is anticipated to affect mitochondrial gene expression. To our knowledge however, no studies have yet evaluated the functional relevance of this SNP or any other polymorphism in FRAP1 on gene expression or protein level. To increase our understanding on the role of mTOR in mitochondrial biogenesis and energy metabolism, such studies are essential. The association between the time spent on high-intensity physical activity and rs11131691 in twins was not observed in the unrelated subjects. This suggests that the association in twins may reflect a false positive result. The association should be replicated before definite conclusions can be drawn concerning the role of genetic variants in FRAP1 on habitual physical activity.

Taken together, the present study confirms the degree of heritability of objectively measured habitual physical activity and shows that variation in the PPARD and $P P A R G C 1 A$ genes contributes to the inter-individual variation in habitual physical activity and the intensity and duration of the activities performed. The genotypes in PPARD that predispose individuals for a decreased mitochondrial capacity and reduced PPAR $\mathrm{mRNA}$ levels are associated with lower levels of habitual physical activity. On the other hand, high intensity physical activity appears to mediate the association between the onset of type 2 diabetes and a genetic predisposition in PPARGC1A. In conclusion, one pathway shows compliance with a genetic predisposition of physiologically limited habitual physical activity; another pathway shows the requirement of high-intensity physical activity to prevent or delay the genetically predisposed development of type 2 diabetes. 


\section{Acknowledgements}

The authors appreciate the effort made by the East-Flanders Prospective Twin Survey (EFPTS) to recruit twin pairs. Since it's origin, the EFPTS has been partly supported by grants from the Fund of Scientific Research, Flanders and Twins, a non-profit Association for Scientific Research in Multiple Births (Belgium). 


\section{References}

1. Ravussin E, Swinburn BA: Pathophysiology of obesity. Lancet 340:404-408, 1992

2. Schoeller DA, Shay K, Kushner RF: How much physical activity is needed to minimize weight gain in previously obese women? Am J Clin Nutr 66:551-556, 1997

3. Ekelund U, Aman J, Yngve A, Renman C, Westerterp K, Sjostrom M: Physical activity but not energy expenditure is reduced in obese adolescents: a case-control study. Am J Clin Nutr 76:935-941, 2002

4. Weinsier RL, Hunter GR, Heini AF, Goran MI, Sell SM: The etiology of obesity: relative contribution of metabolic factors, diet, and physical activity. Am J Med 105:145-150, 1998

5. Fang J, Wylie-Rosett J, Cohen HW, Kaplan RC, Alderman MH: Exercise, body mass index, caloric intake, and cardiovascular mortality. Am J Prev Med 25:283-289, 2003

6. Panagiotakos DB, Chrysohoou C, Pitsavos C, Menotti A, Dontas A, Skoumas J, Stefanadis C, Toutouzas P: Risk factors of stroke mortality: a 40-year follow-up of the Corfu cohort from the Seven-Countries Study. Neuroepidemiology 22:332-338, 2003

7. Kai MC, Anderson M, Lau EM: Exercise interventions: defusing the world's osteoporosis time bomb. Bull World Health Organ 81:827-830, 2003

8. Neville CE, Murray LJ, Boreham CA, Gallagher AM, Twisk J, Robson PJ, Savage JM, Kemper HC, Ralston SH, Davey Smith G: Relationship between physical activity and bone mineral status in young adults: the Northern Ireland Young Hearts Project. Bone 30:792-798, 2002

9. Hu FB, Li TY, Colditz GA, Willett WC, Manson JE: Television watching and other sedentary behaviors in relation to risk of obesity and type 2 diabetes mellitus in women. Jama 289:1785-1791, 2003

10. Hu G, Qiao Q, Silventoinen K, Eriksson JG, Jousilahti P, Lindstrom J, Valle TT, Nissinen A, Tuomilehto J: Occupational, commuting, and leisure-time physical activity in relation to risk for Type 2 diabetes in middle-aged Finnish men and women. Diabetologia 46:322-329, 2003

11. Kriska AM, Saremi A, Hanson RL, Bennett PH, Kobes S, Williams DE, Knowler WC: Physical activity, obesity, and the incidence of type 2 diabetes in a high-risk population. Am J Epidemiol 158:669-675, 2003

12. Carlsson $S$, Andersson $T$, Lichtenstein $P$, Michaelsson $K$, Ahlbom A: Genetic effects on physical activity: results from the Swedish Twin Registry. Med Sci Sports Exerc 38:1396-1401, 2006

13. Kaprio J, Koskenvuo M, Sarna S: Cigarette smoking, use of alcohol, and leisure-time physical activity among same-sexed adult male twins. Prog Clin Biol Res 69 Pt C:3746,1981

14. Lauderdale DS, Fabsitz R, Meyer JM, Sholinsky P, Ramakrishnan V, Goldberg J: Familial determinants of moderate and intense physical activity: a twin study. Med Sci Sports Exerc 29:1062-1068, 1997

15. Cai G, Cole SA, Butte N, Bacino C, Diego V, Tan K, Goring HH, O'Rahilly S, Farooqi IS, Comuzzie AG: A quantitative trait locus on chromosome 18q for physical activity and dietary intake in Hispanic children. Obesity (Silver Spring) 14:1596-1604, 2006

16. Joosen AM, Gielen M, Vlietinck R, Westerterp KR: Genetic analysis of physical activity in twins. Am J Clin Nutr 82:1253-1259, 2005

17. den Hoed M, Hesselink MK, van Kranenburg GP, Westerterp KR: Habitual physical activity in daily life correlates positively with markers for mitochondrial capacity. J Appl Physiol, 2008

18. Bouchard C, Simoneau JA, Lortie G, Boulay MR, Marcotte M, Thibault MC: Genetic effects in human skeletal muscle fiber type distribution and enzyme activities. Can J Physiol Pharmacol 64:1245-1251, 1986

19. McCarty MF: Up-regulation of PPAR $\gamma$ coactivator- $1 \alpha$ as a strategy for preventing and reversing insulin resistance and obesity. Med Hypotheses 64:399-407, 2005 
20. Pilegaard $H$, Saltin $B$, Neufer PD: Exercise induces transient transcriptional activation of the PGC-1 $\alpha$ gene in human skeletal muscle. J Physiol 546:851-858, 2003

21. Puigserver $\mathbf{P}$, Spiegelman BM: Peroxisome proliferator-activated receptor- $\gamma$ coactivator $1 \alpha($ PGC-1 $\alpha)$ : transcriptional coactivator and metabolic regulator. Endocr Rev 24:7890,2003

22. Dhar SS, Ongwijitwat S, Wong-Riley MT: Nuclear respiratory factor 1 regulates all ten nuclear-encoded subunits of cytochrome c oxidase in neurons. J Biol Chem 283:31203129, 2008

23. Lin J, Wu H, Tarr PT, Zhang CY, Wu Z, Boss O, Michael LF, Puigserver P, Isotani E, OIson EN, Lowell BB, Bassel-Duby R, Spiegelman BM: Transcriptional co-activator PGC-1 $\alpha$ drives the formation of slow-twitch muscle fibres. Nature 418:797-801, 2002

24. Mortensen $\mathrm{OH}$, Frandsen L, Schjerling P, Nishimura E, Grunnet N: PGC-1 $\beta$ and PGC-1 $\beta$ have both similar and distinct effects on myofiber switching toward an oxidative phenotype. Am J Physiol Endocrinol Metab 291:E807-816, 2006

25. Wang YX, Lee CH, Tiep S, Yu RT, Ham J, Kang H, Evans RM: Peroxisome-proliferatoractivated receptor $\delta$ activates fat metabolism to prevent obesity. Cell 113:159-170, 2003

26. Tanaka $\mathrm{T}$, Yamamoto J, Iwasaki $\mathrm{S}$, Asaba $\mathrm{H}$, Hamura $\mathrm{H}$, Ikeda $\mathrm{Y}$, Watanabe $\mathrm{M}$, Magoori K, Ioka RX, Tachibana K, Watanabe Y, Uchiyama Y, Sumi K, Iguchi H, Ito S, Doi T, Hamakubo T, Naito M, Auwerx J, Yanagisawa M, Kodama T, Sakai J: Activation of peroxisome proliferator-activated receptor $\delta$ induces fatty acid $\beta$-oxidation in skeletal muscle and attenuates metabolic syndrome. Proc Natl Acad Sci U S A 100:15924-15929, 2003

27. Wang $\mathrm{YX}$, Zhang $\mathrm{CL}$, Yu RT, Cho HK, Nelson MC, Bayuga-Ocampo CR, Ham J, Kang $\mathrm{H}$, Evans RM: Regulation of muscle fiber type and running endurance by PPARס. PLoS Biol 2:e294, 2004

28. Schieke SM, Phillips D, McCoy JP, Jr., Aponte AM, Shen RF, Balaban RS, Finkel T: The mammalian target of rapamycin (mTOR) pathway regulates mitochondrial oxygen consumption and oxidative capacity. J Biol Chem 281:27643-27652, 2006

29. Cunningham JT, Rodgers JT, Arlow DH, Vazquez F, Mootha VK, Puigserver P: mTOR controls mitochondrial oxidative function through a YY1-PGC-1 $\alpha$ transcriptional complex. Nature 450:736-740, 2007

30. Derom CA, Vlietinck RF, Thiery EW, Leroy FO, Fryns JP, Derom RM: The East Flanders Prospective Twin Survey (EFPTS). Twin Res Hum Genet 9:733-738, 2006

31. Plasqui $G$, Joosen $A M$, Kester $A D$, Goris $A H$, Westerterp KR: Measuring free-living energy expenditure and physical activity with triaxial accelerometry. Obes Res 13:13631369,2005

32. den Hoed M, Westerterp KR: Body composition is associated with physical activity in daily life as measured using a triaxial accelerometer in both men and women. Int J Obes (Lond), 2008

33. Siri WE: Body composition from fluid spaces and density: analysis of methods. 1961. Nutrition 9:480-491; discussion 480, 492, 1993

34. Neale MC BS, Xie G, Maes HH: Mx: statistical modeling. 2002

35. Neale MC CL: Methodology for genetic studies of twins and families. Dordrecht, Netherlands: Kluwer Academic, 1992

36. Barrett JC, Fry B, Maller J, Daly MJ: Haploview: analysis and visualization of LD and haplotype maps. Bioinformatics 21:263-265, 2005

37. Stephens $M$, Smith NJ, Donnelly P: A new statistical method for haplotype reconstruction from population data. Am J Hum Genet 68:978-989, 2001

38. Nilsson $E$, Poulsen $P$, Sjogren M, Ling C, Ridderstrale M, Groop L, Vaag A: Regulation of skeletal muscle PPARס mRNA expression in twins. J Physiol 584:1011-1017, 2007

39. Stefan N, Thamer C, Staiger H, Machicao F, Machann J, Schick F, Venter C, Niess A, Laakso M, Fritsche A, Haring HU: Genetic variations in PPARD and PPARGC1A deter- 
mine mitochondrial function and change in aerobic physical fitness and insulin sensitivity during lifestyle intervention. J Clin Endocrinol Metab 92:1827-1833, 2007

40. Franks PW, Loos RJ: PGC-1 $\alpha$ gene and physical activity in type 2 diabetes mellitus. Exerc Sport Sci Rev 34:171-175, 2006

41. Tarnopolsky MA, Rennie CD, Robertshaw HA, Fedak-Tarnopolsky SN, Devries MC, Hamadeh MJ: Influence of endurance exercise training and sex on intramyocellular lipid and mitochondrial ultrastructure, substrate use, and mitochondrial enzyme activity. Am J Physiol Regul Integr Comp Physiol 292:R1271-1278, 2007

42. Tonkonogi M, Sahlin K: Physical exercise and mitochondrial function in human skeletal muscle. Exerc Sport Sci Rev 30:129-137, 2002

43. Gavin TP, Ruster RS, Carrithers JA, Zwetsloot KA, Kraus RM, Evans CA, Knapp DJ, Drew JL, McCartney JS, Garry JP, Hickner RC: No difference in the skeletal muscle angiogenic response to aerobic exercise training between young and aged men. J Physiol 585:231-239, 2007

44. Barroso I, Luan J, Sandhu MS, Franks PW, Crowley V, Schafer AJ, O'Rahilly S, Wareham NJ: Meta-analysis of the Gly482Ser variant in PPARGC1A in type 2 diabetes and related phenotypes. Diabetologia 49:501-505, 2006

45. Ling C, Poulsen P, Carlsson E, Ridderstrale M, Almgren P, Wojtaszewski J, Beck-Nielsen $H$, Groop L, Vaag A: Multiple environmental and genetic factors influence skeletal muscle $P G C-1 \alpha$ and $P G C-1 \beta$ gene expression in twins. J Clin Invest 114:1518-1526, 2004

46. Franks PW, Barroso I, Luan J, Ekelund U, Crowley VE, Brage S, Sandhu MS, Jakes RW, Middelberg RP, Harding AH, Schafer AJ, O'Rahilly S, Wareham NJ: PGC-1alpha genotype modifies the association of volitional energy expenditure with $\mathrm{VO}_{2 \max }$. Med Sci Sports Exerc 35:1998-2004, 2003

47. Meijer EP, Goris AH, Wouters L, Westerterp KR: Physical inactivity as a determinant of the physical activity level in the elderly. Int J Obes Relat Metab Disord 25:935-939, 2001 
Chapter 5

Body composition is associated with physical activity in daily life as measured using a triaxial accelerometer in both men and women

Marcel den Hoed and Klaas R Westerterp

Int J Obes (Lond) 32: 1262-1270, 2008 


\section{Abstract}

Background: Activity-related energy expenditure is the most variable component of total energy expenditure and thus an important determinant of energy balance.

Objective: To determine whether body composition is related to habitual physical activity in both men and women.

Design: A total of 134 healthy subjects were recruited (80 women, 54 men; aged $21 \pm 2$ years; BMI $22.0 \pm 2.4 \mathrm{~kg} / \mathrm{m}^{2}$ ). Habitual physical activity was measured for a period of 2 weeks using a triaxial accelerometer for movement registration (Tracmor). Percentage body fat $(\% \mathrm{BF})$ was determined by underwater weighing and deuterium dilution according to Siri's three-compartment model.

Results: The subject characteristics body mass, height and sex together explained a substantial part of the variation in $\% B F\left(R^{2}=0.75, S E E=4.0 \%\right)$. Adding habitual physical activity to the model increased the explained variation in \%BF with $4 \%\left(R^{2}=0.79\right.$, SEE $=3.7 \%, P<0.001)$. Taking seasonality into account by adding the number of daylight hours as an independent variable further increased the explained variation with $1 \%$ $\left(\mathrm{R}^{2}=0.80, \mathrm{SEE}=3.7 \%, P<0.05\right)$. In analogy, the association was evaluated for both sexes separately. In women, \%BF and habitual physical activity were significantly associated $(P<0.001)$. In men, \%BF was only associated with habitual physical activity when seasonality was taken into account as well $(P<0.05)$. This probably resulted from men participating more in season bound sports, because an association was found without adjusting for seasonality when only men with a consistent year-round participation in sports were considered.

Conclusion: Evidence was found for an association between body composition and habitual physical activity in both men and women. A consistent year-round degree of habitual physical activity appears to be a prerequisite to reveal the association. Moreover, Tracmor assessed habitual physical activity improves the estimate of \%BF when a subject's characteristics are taken into account. 


\section{Introduction}

In Westernized societies, the prevalence of obesity is still increasing $(1 ; 2)$, thereby increasing the population's risk for secondary diseases like type 2 diabetes mellitus, cardiovascular diseases and several types of cancer (3-6). Obesity develops when energy intake exceeds energy expenditure for a prolonged period of time. In free-living humans, activity-related energy expenditure is the most variable component of total energy expenditure (7). The physical activity level (PAL), that is, the factor by which total energy expenditure exceeds resting energy expenditure, was shown to range from 1.2 to 2.5 for completely sedentary and very physically active lifestyles, respectively (8; 9). Habitual physical activity thus sets the upper limit for total energy expenditure (10). Consequently, a reduced habitual physical activity is a potentially important risk factor for a positive energy balance that could ultimately result in the onset of obesity (11-16).

Previously, an association between body composition and activity-related energy expenditure has been shown in men but not in women $(17 ; 18)$. Westerterp and Goran concluded that the association was probably not observed in women due to an increased energy intake to compensate for a higher degree of habitual physical activity. Furthermore, a 16 months exercise intervention resulted in a significant loss of fat mass in men, whereas fat mass was not decreased in women (19). This supports the idea that women compensate for an increased total energy expenditure by increasing their energy intake more than men do (17). However, Westerterp and Goran recruited women aged 19-49 (18) and Paul et al. recruited women with an average age of $48 \pm 10$ years (17). When Stubbs et al. increased energy expenditure over a period of 7 days by implementing 80 min of exercise per day in women aged $23 \pm 0.6$ years, they did not find any compensation in energy intake (20). This suggests that whether or not women compensate their energy intake to meet energy expenditure may depend on age. Consequently, the lack of association between body composition and activity-related energy expenditure in women may represent an age effect. Therefore, the aim of the present study was to determine the association between $\% \mathrm{BF}$ and habitual physical activity in a population of young men and women, with habitual physical activity measured objectively during a prolonged period of time using a validated triaxial accelerometer.

\section{Methods}

\section{Subjects}

A total of 134 healthy, non-smoking subjects ( 80 females, 54 males) aged $21 \pm 2$ years were recruited to participate in this study. Subjects were weight stable for at least 6 months and were not using any medication except for oral contraceptives. Recruitment was carried out using flyers in the university building. Information about the purpose and protocol of the study was provided both orally and in writing. All subjects provided written informed consent before participating in the study. The study conformed to the standards set by the Declaration of Helsinki and the local Ethics Committee approved the 
study. We certify that all applicable institutional and governmental regulations concerning the ethical use of human volunteers were followed during this research. Subject characteristics $(n=134)$ are presented in Table 1.

Table 1: Subject characteristics

\begin{tabular}{lll}
\hline & Men & Women \\
\hline $\mathrm{N}$ & 54 & 80 \\
Age (years) & $21 \pm 2$ & $21 \pm 2$ \\
Body mass $(\mathrm{kg})$ & $76.1 \pm 9.9$ & $63.1 \pm 7.9^{\#}$ \\
Height $(\mathrm{m})$ & $1.85 \pm 0.06$ & $1.70 \pm 0.06^{\#}$ \\
BMI $\left(\mathrm{kg} / \mathrm{m}^{2}\right)$ & $22.3 \pm 2.4$ & $21.8 \pm 2.5^{\#}$ \\
\%BF & $14.0 \pm 5.5$ & $26.3 \pm 5.1{ }^{\#}$ \\
HPA (MCnts/day) & $3789 \pm 813$ & $3773 \pm 816$ \\
PAL & $1.82 \pm 0.13$ & $1.82 \pm 0.13$ \\
\%Low & $97.3 \pm 1.2$ & $97.0 \pm 1.2$ \\
\%Moderate & $2.0 \pm 0.8$ & $2.3 \pm 0.9$ \\
\%High & $0.7 \pm 0.6$ & $0.7 \pm 0.5$ \\
Sports (h/week) & $2.9 \pm 2.2$ & $2.4 \pm 1.9$ \\
\hline
\end{tabular}

BMI, body mass index; \%BF, percentage body fat; HPA, Habitual physical activity as measured in daily life using a triaxial accelerometer during a period of two weeks; MCnts, Megacounts; PAL, physical activity level; \%Low, \%Moderate and \%High, proportion of time subjects were physically active at a low, moderate and high intensity, respectively; Sports, time spent on sports; Values are means \pm SD. Significant difference between sexes: \# $P<0.001$.

\section{Body composition}

$\% \mathrm{BF}$ was determined as a measure for body composition. Therefore, anthropometric measurements were carried out in the morning after an overnight fast. Body mass was measured on an electric scale (ID 1 Plus; Mettler Toledo, Giessen, Germany) to the nearest $0.01 \mathrm{~kg}$. Height was measured to the nearest $0.1 \mathrm{~cm}$ (Mod. 220; SECA, Hamburg, Germany). Body volume was determined using the underwater weighing technique while correcting for residual long volume using the helium dilution technique (Volugraph VG 2000; Mijnhardt, Bunnik, The Netherlands). Total body water was determined overnight using the deuterium dilution technique according to the Maastricht protocol (21). Body composition was subsequently calculated from body volume and total body water using Siri's three-compartment model (22).

\section{Habitual physical activity}

Habitual physical activity was measured using a triaxial accelerometer for movement registration (Tracmor IV; Philips research, Eindhoven, The Netherlands) sensitive to a wide range of body movements. The accelerometer has been validated with doubly labelled water, the gold standard for measuring energy expenditure in daily life (23). The Tracmor registers accelerations of the trunk along the anterio-posterior, medio-lateral and longitudinal axis using three uniaxial piezo-electric accelerometers (details are provided elsewhere (23)). To ensure a valid reflection of long-term daily life activities, the accelerometer was worn for 14 days under free-living conditions. 
Subjects were instructed to wear the Tracmor from the moment they woke up in the morning until they went back to bed at night. To verify whether subjects lived up to this instruction, waking hours and clock times of wearing the Tracmor were noted. To make sure only representative days were included, the difference between the total time the subject was awake and the time the accelerometer was worn was not allowed to exceed $75 \mathrm{~min} /$ day. The few days during which this difference exceeded $75 \mathrm{~min}$ were excluded from the analysis.

Habitual physical activity was acquired by summing the output of all three axes and is presented as Megacounts per day (MCnts/day). Using Tracmor data, the proportion of time subjects were physically active at a low, moderate and high intensity (\%Low, $\%$ Moderate and \%High, respectively) was determined. The cut-off points for the intensity categories were determined in a pilot study $(n=5)$. The cut-off point for low-intensity physical activity was set by Tracmor outputs associated with walking on a treadmill at $3.5 \mathrm{~km} / \mathrm{h}$, which corresponds with approximately 3 metabolic equivalents (METs). For moderate-intensity physical activity, a Tracmor output associated with walking on a treadmill at $5 \mathrm{~km} / \mathrm{h}$ was used, which corresponds with approximately 4.5 METs (24). The relevant Tracmor outputs were 16.0 \pm 3.0 Megacounts per minute (MCnts/min) and 28.9 $\$ 3.0 \mathrm{MCnts} / \mathrm{min}$, respectively. All physical activity associated with a Tracmor output higher than the latter cut-off point was considered high-intensity physical activity. The proportion of time per intensity category was calculated as the sum of all minutes per intensity category divided by the total duration of the measurement, that is, 14 days minus the number of excluded days.

Using linear regression analysis in a population similar to the present study with respect to habitual physical activity, body composition and age, Plasqui et al. were able to predict the physical activity level (PAL) with an explained variation of $70 \%$ using only Tracmor output (23). This regression equation was used in the present study to estimate PAL.

\section{Statistics}

Differences between sexes were tested using Student's t-tests for unpaired samples. Multiple linear regression analysis was used to test the association between \%BF and habitual physical activity. Body mass, height and sex were taken into account as known predictors (25). Furthermore, Plasqui et al. previously showed that PAL is higher in summer than in winter. In the present study habitual physical activity was monitored year-round. Therefore, the effect of seasonality was taken into account using the number of relevant daylight hours for the two weeks monitored (26). The association between $\% \mathrm{BF}$ and the proportion of time subjects were physically active at a low, moderate and high intensity was determined using multiple linear regression. The association between $\% \mathrm{BF}$ and habitual physical activity was additionally determined for men and women separately taking body mass and height into account. The models obtained using multiple linear regression were checked for (multi-)collinearity using the variance inflation factor. 
Statistical analysis was carried out using the Statistical Package for Social Sciences (SPSS) version 11 for Macintosh OS X (SPSS Inc.; Chicago, Illinois, USA). Data are expressed as means \pm SD. $P$-values $<0.05$ were considered statistically significant.

\section{Results}

There was no significant difference between the habitual physical activity of men and women (Table 1). However, the number of daylight hours during the two weeks monitored was significantly higher in women: $11.7 \pm 2.9$ versus $9.5 \pm 2.0 \mathrm{~h} / \mathrm{day}(P<0.001)$. After adjusting for seasonality, habitual physical activity was significantly higher in men $(P<0.001)$. PAL values ranged from 1.50 to 2.27 with a mean of $1.82 \pm 0.13$ (Table 1 ). There was no difference between the proportion of time spent in each intensity category for men and women. Body mass and height were significantly higher in men $(P<0.001)$. Whereas BMI was comparable between sexes, \%BF was significantly higher in women $(P<0.001)$ (Table 1$)$.

The subject characteristics body mass, height and sex together explained a large part of the variation in \%BF $\left(R^{2}=0.75, S E E=4.0 \%\right)$. Still, adding habitual physical activity to the model significantly increased the explained variation in $\% B F$ with $4 \% \quad\left(R^{2}=0.79\right.$, $\mathrm{SEE}=3.7 \%, P<0.001$ ) with \%BF beingnegatively associated with habitual physical activity (Figure 1). A significant positive association was observed between habitual physical activity and the number of daylight hours during the two weeks monitored $(P<0.01)$. Adding the number of daylight hours to the model to take seasonality into account further increased the explained variation in \%BF with $1 \%$ (Table 2 ).

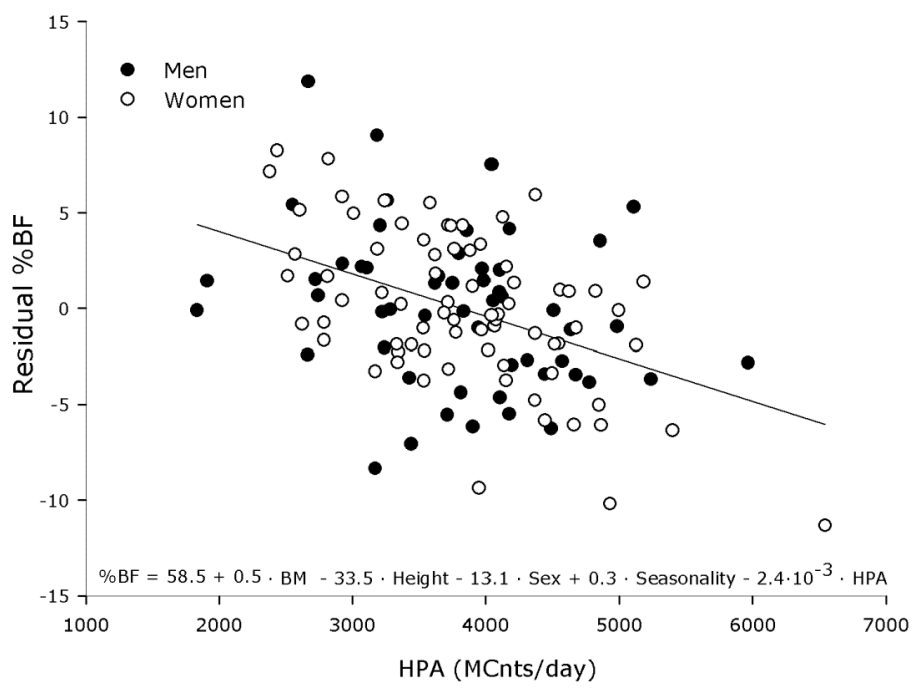

Figure 1: The residual of percentage body fat (\%BF) that cannot be explained by body mass, height, sex and seasonality as a function of habitual physical activity (HPA) $(P<0.001)$. BM, body mass in $\mathrm{kg}$; height in $\mathrm{m}$; sex, 0 for women, 1 for men; seasonality, the average number of daylight hours during the two weeks monitored; MCnts, Megacounts. 
Table 2: Unstandardized regression coefficients, $95 \%$ confidence intervals and $P$-values with percentage body fat as the dependent variable

\begin{tabular}{|c|c|c|c|c|}
\hline & $\mathrm{B}$ & \multicolumn{2}{|c|}{$95 \%$ CI for $\mathrm{B}$} & \multirow[t]{2}{*}{$P$} \\
\hline & \multirow{2}{*}{\multicolumn{4}{|c|}{$\mathrm{R}^{2}=0.80, \mathrm{SEE}=3.7 \%$}} \\
\hline Constant & & & & \\
\hline Body mass (kg) & 0.5 & 0.4 & 0.6 & $2.3 \cdot 10^{-20 \#}$ \\
\hline Height $(m)$ & -33.5 & -45.1 & -22.0 & $6.7 \cdot 10^{-8 \#}$ \\
\hline $\operatorname{Sex}(w=0, m=1)$ & -13.1 & -15.1 & -11.0 & $6.8 \cdot 10^{-24 ~ \#}$ \\
\hline HPA (MCnts/day) & $-2.4 \cdot 10^{-3}$ & $-3.0 \cdot 10^{-3}$ & $-2.0 \cdot 10^{-3}$ & $8.3 \cdot 10^{-7} \#$ \\
\hline \multirow[t]{2}{*}{ Seasonality (daylight h) } & 0.3 & 0.1 & 0.6 & $1.9 \cdot 10^{-2 *}$ \\
\hline & \multicolumn{4}{|c|}{$\mathrm{R}^{2}=0.77, \mathrm{SEE}=3.9 \%$} \\
\hline Constant & \multicolumn{4}{|c|}{-54.0} \\
\hline Body mass (kg) & 0.5 & 0.4 & 0.5 & $1.4 \cdot 10^{-17} \#$ \\
\hline Height (m) & -32.2 & -44.5 & -19.9 & $8.4 \cdot 10^{-7} \#$ \\
\hline $\operatorname{Sex}(w=0, m=1)$ & -13.8 & -15.9 & -11.7 & $1.0 \cdot 10^{-24} \#$ \\
\hline \multirow[t]{2}{*}{$\%$ Low } & 1.1 & 0.5 & 1.7 & $3.3 \cdot 10^{-4} \#$ \\
\hline & \multicolumn{4}{|c|}{$\mathrm{R}^{2}=0.76, \mathrm{SEE}=4.0 \%$} \\
\hline Constant & \multicolumn{4}{|c|}{53.3} \\
\hline Body mass (kg) & 0.4 & 0.4 & 0.5 & $1.6 \cdot 10^{-16 \#}$ \\
\hline Height $(m)$ & -30.8 & -16.0 & -11.6 & $3.9 \cdot 10^{-6} \#$ \\
\hline $\operatorname{Sex}(w=0, m=1)$ & -13.3 & -15.6 & -11.1 & $7.4 \cdot 10^{-24} \#$ \\
\hline \multirow[t]{2}{*}{ \%Moderate } & -1.1 & -2.0 & -0.3 & $6.7 \cdot 10^{-3} \S$ \\
\hline & \multicolumn{4}{|c|}{$\mathrm{R}^{2}=0.77, \mathrm{SEE}=3.9 \%$} \\
\hline Constant & 59.5 & & & \\
\hline Body mass (kg) & 0.5 & 0.4 & 0.6 & $2.7 \cdot 10^{-18 \#}$ \\
\hline Height (m) & -36.0 & -48.3 & -23.6 & $6.1 \cdot 10^{-8} \#$ \\
\hline $\operatorname{Sex}(w=0, m=1)$ & -13.2 & -15.3 & -11.1 & $9.4 \cdot 10^{-24} \#$ \\
\hline$\%$ High & -2.6 & -3.9 & -1.2 & $2.4 \cdot 10^{-4} \#$ \\
\hline
\end{tabular}

B, Unstandardized regression coefficient; $95 \%$ CI for B, 95\% confidence interval for B; HPA, habitual physical activity as measured in daily life using a triaxial accelerometer during a period of two weeks; MCnts, Megacounts; Seasonality, the average number of daylight hours during the two weeks monitored; \%Low, \%Moderate and \%High, proportion of time subjects were physically active at a low, moderate and high intensity, respectively; Statistically significant association: $* P<0.05 ; \S P<0.01 ; \#$ $P<0.001$.

Adding \%Low, \%Moderate or \%High to a regression model with body mass, height and sex as independent variables significantly increased the explained variation in \%BF for each intensity category $(P<0.001, P<0.01$ and $P<0.001$, respectively). \%BF was positively associated with \%Low and negatively with \%Moderate and \%High (Figure 2). Of the three intensity categories, only \%Low and \%Moderate were significantly associated with seasonality (negatively, $P<0.001$ and positively, $P<0.001$, respectively).

When analyzing both sexes separately, a discrepancy was observed in the association between habitual physical activity and seasonality. In women, no association was found $(P=0.2)$ whereas in men there was $(P<0.001)$. In women, body mass and height together explained $41 \%$ of the variation in $\% B F\left(R^{2}=0.41, S E E=3.9 \%\right)$. Adding habitual physical activity to the model significantly increased the explained variation in \%BF with $17 \%$ (Table 3 ). Adding the number of daylight hours as an independent variable did not further improve the model. In men, $46 \%$ of the variation in $\% B F$ can be explained by body mass and height (Table 3 ). Adding habitual physical activity only improved the model if seasonality was taken into account as well (Table 3). Approximately two out of 
three sports practiced by men were highly season bound with a peak in the summer season, compared with one out of three in women. When the analysis was repeated for men who either did not participate in sports or who participated for at least nine months per year $(n=30)$, adding habitual physical activity to a model with body mass and height significantly improved the explained variation in \%BF with $7 \%$ without taking seasonality into account $\left(\mathrm{R}^{2}=0.60 ; \mathrm{SEE}=4.3 \% ; P<0.05\right)$. When only data for the remaining men was analyzed, that is, those participating in sports but for less than nine months per year $(n=24)$, habitual physical activity did not contribute to the explained variation in \%BF $(P>0.9)$.

Table 3: Unstandardized regression coefficients, $95 \%$ confidence intervals and $P$-values with percentage body fat as the dependent variable for both sexes separately

\begin{tabular}{|c|c|c|c|c|}
\hline & $\mathrm{B}$ & $95 \% \mathrm{CI} \mathrm{f}$ & & $P$ \\
\hline Women & \multicolumn{4}{|c|}{$\mathrm{R}^{2}=0.58, \mathrm{SEE}=3.3 \%$} \\
\hline Constant & \multicolumn{4}{|c|}{48.1} \\
\hline Body mass (kg) & 0.4 & 0.4 & 0.6 & $2.4 \cdot 10^{-12}$ \\
\hline Height $(\mathrm{m})$ & -23.7 & -36.7 & -10.6 & $5.6 \cdot 10^{-4} \#$ \\
\hline HPA (MCnts/day) & $-2.6 \cdot 10^{-3}$ & $-4.0 \cdot 10^{-3}$ & $-2.0 \cdot 10^{-3}$ & $2.7 \cdot 10^{-7} \#$ \\
\hline Men & \multicolumn{4}{|c|}{$R^{2}=0.52, S E E=3.9 \%$} \\
\hline Constant & 58.1 & & & \\
\hline Body mass (kg) & 0.5 & 0.3 & 0.6 & $7.2 \cdot 10^{-9} \#$ \\
\hline Height $(m)$ & -42.7 & -63.6 & -21.9 & $1.4 \cdot 10^{-4} \#$ \\
\hline Seasonality (daylight h) & 0.6 & $-1.5 \cdot 10^{-2}$ & 1.2 & $5.5 \cdot 10^{-2}$ \\
\hline $\begin{array}{l}\text { Physical activity } \\
\text { (MCnts/day) }\end{array}$ & $-1.9 \cdot 10^{-3}$ & $-3.0 \cdot 10^{-2}$ & 0 & $2.2 \cdot 10^{-2} *$ \\
\hline
\end{tabular}

B, Unstandardized regression coefficient; $95 \%$ CI for B, 95\% confidence interval for B; HPA, habitual physical activity as measured in daily life using a triaxial accelerometer during a period of two weeks; MCnts, Megacounts; Seasonality, the average number of daylight hours during the two weeks monitored; Statistically significant association: $* P<0.05 ; \# P<0.001$.

\section{Discussion}

The aim of this study was to determine whether body composition is associated with habitual physical activity in both sexes. Therefore, \%BF was determined in a population of 134 young adults using underwater weighing and deuterium dilution according to Siri's three-compartment model. Habitual physical activity was determined in daily life during a prolonged period of time using a triaxial accelerometer for movement registration. Evidence was found for an association between \%BF and habitual physical activity in both men and women.

In a study population consisting of 747 adults, Deurenberg et al. previously showed that the subject characteristics BMI, age and sex together explained $79 \%$ of the variation in \%BF measured by underwater weighing (25). Similar results were obtained here, although in the present study, age did not contribute significantly to the model. A small range in age in the present study population can explain this discrepancy. As habitual physical activity is known to decrease with increasing age $(8 ; 27)$, the age range of 18 27 can probably also explain why the average PAL of 1.82 found here is higher than the previously reported population average of $1.77(8 ; 28)$. In a population with a compara- 
ble range in age, Plasqui et al. also found an average PAL of 1.82 (29). The range in PAL from 1.50 to 2.27 found in the present population indicates that both sedentary and physically active subjects were included.
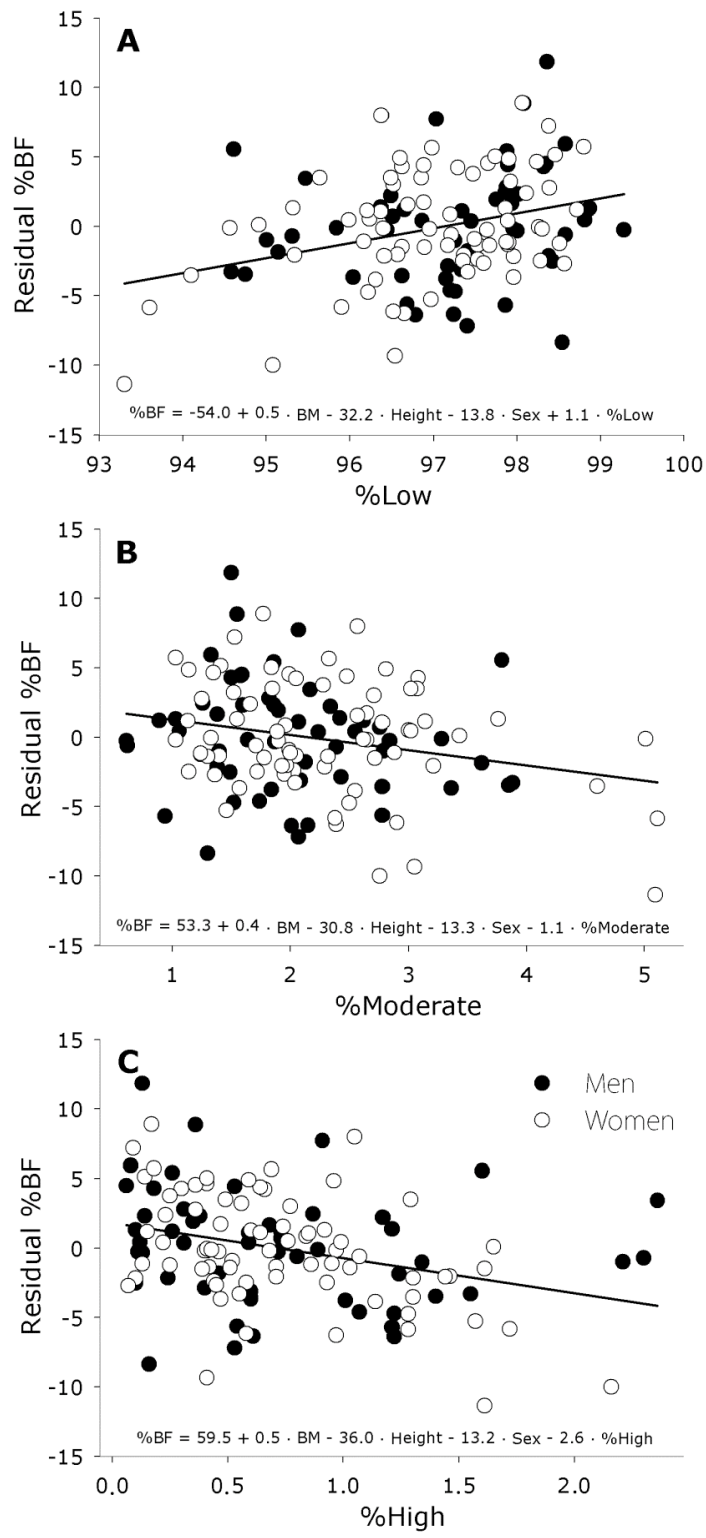

Figure 2: The residual of percentage body fat (\%BF) that cannot be explained by body mass, height and sex as a function of the proportion of time subjects were physically active at a low $(A, P<0.001)$, moderate $(B, P<0.01)$ and high intensity $(C, P<0.001)(\%$ Low, \%Moderate and \%High, respectively). $\mathrm{BM}$, body mass in $\mathrm{kg}$; height in $\mathrm{m}$; sex, 0 for women, 1 for men. 
Adding habitual physical activity to a model with body mass, height and sex as independent variables added a significant $4 \%$ to the explained variation in $\% B F$. This implies that with basic subject characteristics taken into account, \%BF was significantly associated with habitual physical activity. \%BF was also positively associated with \%Low and negatively with \%Moderate and \%High. In other words, \%BF was negatively associated with all physical activity with a higher intensity than that associated with walking at 3.5 $\mathrm{km} / \mathrm{h}$. Exchanging habitual physical activity for PAL in the model in Table 2 indicates that when assuming causality, an increase of 0.1 in PAL, decreases \%BF with $1.5 \%$ (data not shown). As was shown in table 1, the distribution of BMI in the present population was quite narrow. It can be argued that with a higher range in BMI, the association between $\% B F$ and habitual physical activity would have been even stronger.

Adjusting the association between \%BF and habitual physical activity for seasonality by adding the number of daylight hours as an independent variable further increased the explained variation in \%BF with $1 \%$. Habitual physical activity was monitored year-round and was previously shown to be higher in summer than in winter (29). The longitudinal results from Plasqui et al. were confirmed here, because a significant, positive association was observed between habitual physical activity and the number of daylight hours during the two weeks monitored.

Analyzing the results for both sexes separately showed an association between \%BF and habitual physical activity in women but not in men. However, seasonal differences in habitual physical activity were previously shown to be higher in men than in women (29). In the present population, analyzing the data for men and women separately resulted in an association between habitual physical activity and the number of daylight hours in men only. Consequently, taking seasonality into account by adding the number of daylight hours to a model with body mass, height and habitual physical activity as independent variables did not increase the explained variation in \%BF in women. In men on the other hand, taking seasonality into account was a prerequisite for an association between $\% \mathrm{BF}$ and habitual physical activity to be revealed. Plasqui et al. attributed the higher seasonal differences in habitual physical activity in men compared with women to a higher PAL for men in the summer season. Furthermore, they concluded from their data that the more active subjects were in summer, the less likely it was they maintained their activity level in the winter season (29). Due to the cross sectional design of the present study, no conclusions about intra-individual seasonal differences in habitual physical activity can be drawn. However, approximately two out of three sports practiced by men were highly season bound with peaks in the summer season, compared with only one out of three in women. This difference may explain why, in the present study, habitual physical activity was only associated with seasonality in men and why taking seasonality into account was required for the association between \%BF and habitual physical activity to be revealed in men. Indeed, when repeating the analysis for men with a consistent yearround participation in sports, that is, those either not participating in sports or doing so for at least 9 months per year, a significant association between \%BF and habitual physical activity was shown without taking seasonality into account. This association was not observed when the analysis was repeated for the remaining men, that is, those participating in sports but for less than 9 months per year. The results suggest that \%BF is 
only negatively associated with habitual physical activity in subjects with a consistent year-round participation in sports. In other words, a variable year-round degree of habitual physical activity obscures the association between \%BF and habitual physical activity. As described earlier, the discrepancy between sexes in the association between body composition and activity-related energy expenditure shown in previous studies was concluded to result from an increased energy intake to compensate for a higher energy expenditure in women compared with men (18). Given that in young women, no compensation in energy intake was shown in response to an increase in energy expenditure (20), we hypothesized an age effect for this compensatory mechanism. This hypothesis is affirmed by the association between body composition and habitual physical activity shown in the present study.

In conclusion, evidence was found for a negative association between \%BF and habitual physical activity in both men and women. A consistent year-round degree of habitual physical activity appears to be a prerequisite to reveal the association. Finally, Tracmor assessed habitual physical activity improves the estimate of \%BF when a subject's characteristics are taken into account.

\section{Acknowledgements}

The authors thank Loek Wouters for analyzing the deuterium samples. 


\section{References}

1. Heini AF, Weinsier RL: Divergent trends in obesity and fat intake patterns: the American paradox. Am J Med 102:259-264, 1997

2. Seidell JC: Dietary fat and obesity: an epidemiologic perspective. Am J Clin Nutr 67:546S-550S, 1998

3. Donahue RP, Abbott RD: Central obesity and coronary heart disease in men. Lancet 2:1215, 1987

4. Hubert HB, Feinleib M, McNamara PM, Castelli WP: Obesity as an independent risk factor for cardiovascular disease: a 26-year follow-up of participants in the Framingham Heart Study. Circulation 67:968-977, 1983

5. Lew EA: Mortality and weight: insured lives and the American Cancer Society studies. Ann Intern Med 103:1024-1029, 1985

6. Pi-Sunyer FX: Medical hazards of obesity. Ann Intern Med 119:655-660, 1993

7. Ravussin E, Swinburn BA: Pathophysiology of obesity. Lancet 340:404-408, 1992

8. Black $A E$, Coward WA, Cole TJ, Prentice AM: Human energy expenditure in affluent societies: an analysis of 574 doubly-labelled water measurements. Eur J Clin Nutr 50:7292, 1996

9. Westerterp KR: Pattern and intensity of physical activity. Nature 410:539, 2001

10. Westerterp KR, Plasqui G: Physical activity and human energy expenditure. Curr Opin Clin Nutr Metab Care 7:607-613, 2004

11. Ekelund U, Aman J, Yngve A, Renman C, Westerterp K, Sjostrom M: Physical activity but not energy expenditure is reduced in obese adolescents: a case-control study. Am J Clin Nutr 76:935-941, 2002

12. Esparza J, Fox C, Harper IT, Bennett PH, Schulz LO, Valencia ME, Ravussin E: Daily energy expenditure in Mexican and USA Pima indians: low physical activity as a possible cause of obesity. Int J Obes Relat Metab Disord 24:55-59, 2000

13. Heitmann BL, Kaprio J, Harris JR, Rissanen A, Korkeila M, Koskenvuo M: Are genetic determinants of weight gain modified by leisure-time physical activity? A prospective study of Finnish twins. Am J Clin Nutr 66:672-678, 1997

14. Rising R, Harper IT, Fontvielle AM, Ferraro RT, Spraul M, Ravussin E: Determinants of total daily energy expenditure: variability in physical activity. Am J Clin Nutr 59:800804,1994

15. Wardle J, Guthrie C, Sanderson S, Birch L, Plomin R: Food and activity preferences in children of lean and obese parents. Int J Obes Relat Metab Disord 25:971-977, 2001

16. Weinsier RL, Hunter GR, Heini AF, Goran MI, Sell SM: The etiology of obesity: relative contribution of metabolic factors, diet, and physical activity. Am J Med 105:145-150, 1998

17. Paul DR, Novotny JA, Rumpler WV: Effects of the interaction of sex and food intake on the relation between energy expenditure and body composition. Am J Clin Nutr 79:385-389, 2004

18. Westerterp KR, Goran MI: Relationship between physical activity related energy expenditure and body composition: a gender difference. Int J Obes Relat Metab Disord 21:184-188, 1997

19. Donnelly JE, Hill JO, Jacobsen DJ, Potteiger J, Sullivan DK, Johnson SL, Heelan K, Hise M, Fennessey PV, Sonko B, Sharp T, Jakicic JM, Blair SN, Tran ZV, Mayo M, Gibson C, Washburn RA: Effects of a 16-month randomized controlled exercise trial on body weight and composition in young, overweight men and women: the Midwest Exercise Trial. Arch Intern Med 163:1343-1350, 2003

20. Stubbs RJ, Sepp A, Hughes DA, Johnstone AM, King N, Horgan G, Blundell JE: The effect of graded levels of exercise on energy intake and balance in free-living women. Int J Obes Relat Metab Disord 26:866-869, 2002

21. Westerterp KR, Wouters L, van Marken Lichtenbelt WD: The Maastricht protocol for the measurement of body composition and energy expenditure with labeled water. Obes Res 3 Suppl 1:49-57, 1995 
22. Siri WE: Body composition from fluid spaces and density: analysis of methods. 1961. Nutrition 9:480-491; discussion 480, 492, 1993

23. Plasqui $G$, Joosen $A M$, Kester $A D$, Goris $A H$, Westerterp KR: Measuring free-living energy expenditure and physical activity with triaxial accelerometry. Obes Res 13:13631369, 2005

24. Ainsworth BE, Haskell WL, Whitt MC, Irwin ML, Swartz AM, Strath SJ, O'Brien WL, Bassett DR, Jr., Schmitz KH, Emplaincourt PO, Jacobs DR, Jr., Leon AS: Compendium of physical activities: an update of activity codes and MET intensities. Med Sci Sports Exerc 32:S498-504, 2000

25. Deurenberg P, Weststrate JA, Seidell JC: Body mass index as a measure of body fatness: age- and sex-specific prediction formulas. Br J Nutr 65:105-114, 1991

26. Wilkin TJ, Mallam KM, Metcalf BS, Jeffery AN, Voss LD: Variation in physical activity lies with the child, not his environment: evidence for an 'activitystat' in young children (EarlyBird 16). Int J Obes (Lond) 30:1050-1055, 2006

27. Westerterp KR, Meijer EP: Physical activity and parameters of aging: a physiological perspective. J Gerontol A Biol Sci Med Sci 56 Spec No 2:7-12, 2001

28. Westerterp KR: Obesity and physical activity. Int J Obes Relat Metab Disord 23 Suppl $1: 59-64,1999$

29. Plasqui G, Westerterp KR: Seasonal variation in total energy expenditure and physical activity in Dutch young adults. Obes Res 12:688-694, 2004 

Chapter 6

SNP analyses of postprandial responses in (an)orexigenic hormones and feelings of hunger reveal long-term physiological adaptations to facilitate homeostasis

Marcel den Hoed, Astrid JPG Smeets, Margriet AB Veldhorst, Arie G Nieuwenhuizen, Freek G Bouwman, A Geert Heidema, Edwin CM Mariman, Margriet S Westerterp-Plantenga and Klaas R Westerterp

Int J Obes (Lond) 32: 1790-1798, 2008 


\section{Abstract}

Background: The postprandial responses in (an)orexigenic hormones and feelings of hunger are characterized by large inter-individual differences. Food intake regulation was shown earlier to be partly under genetic control.

Objective: This study aimed to determine whether the postprandial responses in (an)orexigenic hormones and parameters of food intake regulation are associated with single nucleotide polymorphisms (SNPs) in genes encoding these hormones and their receptors.

Design: Peptide YY (PYY), Glucagon-like peptide 1 (GLP-1) and ghrelin levels as well as feelings of hunger and satiety were determined pre- and postprandially in 62 women and 41 men (aged $31 \pm 14$ years; body mass index $25.0 \pm 3.1 \mathrm{~kg} / \mathrm{m}^{2}$ ). Dietary restraint, disinhibition and perceived hunger were determined using the three-factor eating questionnaire (TFEQ). SNPS were determined in the GHRL, GHSR, LEP, LEPR, PYY, NPY, NPY2R and CART genes.

Results: The postprandial response in plasma ghrelin levels was associated with SNPs in PYY (215G $>C, P<0.01$ ) and LEPR (326A $>$ G and 688A $>$ G, $P<0.01$ ), and in plasma PYY levels with SNPs in GHRL $(-501 \mathrm{~A}>\mathrm{C}, P<0.05)$ and GHSR $(477 \mathrm{G}>\mathrm{A}, P<0.05)$. The postprandial response in feelings of hunger was characterized by a SNP-SNP interaction involving SNPS in $L E P R$ and NPY2R (668A $>G$ and $585 T>C, P<0.05)$. Dietary restraint and disinhibition were associated with a SNP in GHSR (477G>A, $P<0.05)$, and perceived hunger with SNPs in GHSR and NPY (477G $>$ A and 204T>C, $P<0.05)$.

Conclusions: Part of the inter-individual variability in postprandial responses in (an)orexigenic hormones can be explained by genetic variation. These postprandial responses represent either long-term physiological adaptations that facilitate homeostasis or reinforce direct genetic effects. 


\section{Introduction}

Energy balance is maintained when energy intake matches energy expenditure. To finetune energy intake to energy expenditure, an adequate food intake regulation is crucial. Food intake regulation is mainly a behavioural-physiological interaction between the individual and the environment, with hypothalamic receptors responding to peripherally released (an)orexigenic hormones like leptin, peptide YY (PYY), glucagon-like peptide 1 (GLP-1) and ghrelin. Leptin decreases food intake through the leptin receptor (LEPR) by acting upon pro-opiomelanocortin (POMC), cocaine and amphetamine regulated transcript (CART) and agouti-related protein (AGRP). POMC expression in the arcuate nucleus is increased by leptin, resulting in the excitation of hypothalamic neurons expressing melanocortin 4 receptor (MC4R) through axons containing $\alpha$-melanocyte-stimulating hormone $(\alpha-M S H)(1)$. CART is also stimulated by leptin, thereby inhibiting feeding and antagonizing the feeding response induced by the orexigenic neuropeptide $Y$ (NPY) (2). AGRP on the other hand is downregulated by leptin $(3 ; 4)$, thereby disinhibiting both the MC4R and the NPY 2 receptor (NPY2R). Furthermore, there is evidence that physiological levels of leptin stimulate GLP-1 release in humans in a dose dependent manner (5). GLP1 binds to G-protein linked receptors on islet $\beta$-cells and decreases food intake in healthy and obese subjects (6). PYY also reduces appetite and food intake (7), by stimulating POMC neurons and by inhibiting NPY neurons (8) through the NPY2R (9). In addition, infusion of PYY decreased plasma ghrelin levels during the fasting period and abolished its preprandial rise (7). Ghrelin is known to increase food intake through the ghrelin receptor (GHSR) by activating NPY and AGRP-containing neurons in the hypothalamus (10; 11). The interaction between these (an)orexigenic hormones and their receptors is schematically presented in figure 1 .

Fasting levels of several (an)orexigenic hormones were shown to be strongly genotype dependent, suggesting a genetic background in the physiological regulation of food intake. Fasting leptin levels were associated with the -2548G $>$ A single nucleotide polymorphism (SNP) in the coding region of the leptin gene (LEP) and the 668A>G SNP in the leptin receptor gene (LEPR) (12-14), fasting plasma PYY levels were associated with a rare variant in the PYY gene $(P Y Y)(15)$ and fasting plasma ghrelin levels appeared to be associated with the $-501 \mathrm{~A}>\mathrm{C}$ SNP in the promoter region of the ghrelin gene (GHRL) (16).

Cognitive aspects, such as dietary restraint, disinhibition and perceived hunger, also play a role in food intake regulation. A genetic component has been shown in this respect as well, with the heritability for dietary restraint, disinhibition and perceived hunger ranging from $23 \%$ to $59 \%, 0 \%$ to $60 \%$ and $23 \%$ to $45 \%$, respectively (17-19). The genes involved in these predispositions have not yet been identified. 


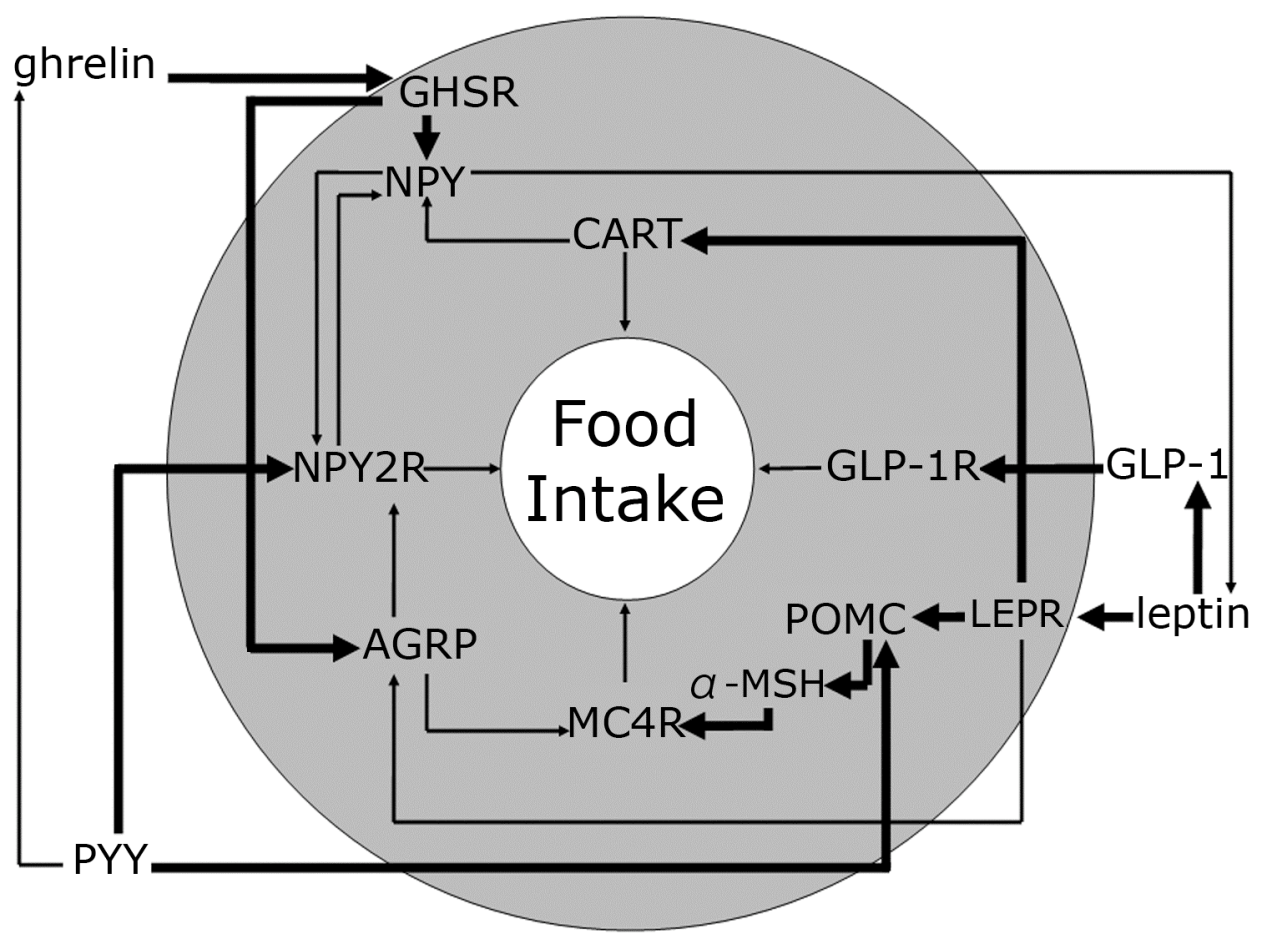

Figure 1: A model for the physiological regulation of food intake by peripherally released (an)orexigenic hormones and their hypothalamic receptors (in grey). GLP-1, Glucagon-like peptide 1; GLP-1R, G-protein coupled receptor islet $\beta$-cell; PYY, peptide YY; POMC, Pro-opiomelanocortin; AGRP, Agouti-related protein; CART, Cocaine and amphetamine-regulated transcript; NPY, Neuropeptide Y; $\alpha-\mathrm{MSH}$, Alpha-melanocyte-stimulating hormone; MC4R, Melanocortin 4 receptor; NPY2R, NPY 2 receptor. Bold lines represent excitatory effects, thin lines represent inhibitory effects.

Most studies in which the associations between plasma levels of (an)orexigenic hormones and genetic polymorphisms were determined focused on fasting hormone levels. However, humans are in a postprandial state during the largest part of the day, that is, from breakfast onward. Therefore, the postprandial responses of these hormones are potentially important for the physiological regulation of food intake as well. These postprandial responses are characterized by a large inter-individual variability (20) that can only partly be explained by confounders like body mass index (BMI) and sex $(21 ; 22)$. We hypothesized that part of this variability can be explained by genetic variation. To increase our understanding of food intake regulation, the objective of this study was to determine whether the postprandial responses in (an)orexigenic hormones and feelings of hunger and satiety are associated with SNPs in genes encoding these proteins and their receptors. Moreover, possible associations between dietary restraint, disinhibition and perceived hunger, measured using the three-factor eating questionnaire (TFEQ), and these SNPs were investigated. 


\section{Methods}

Data were collected from intervention studies on the effect of proteins and/or protein contents on the postprandial responses in plasma PYY, GLP-1 and ghrelin levels as well as feelings of hunger and satiety. Subjects came to the university in the morning and received fixed meals in energy balance and according to energy requirement as calculated using the formula of Harris and Benedict (23). The meals contained 27, 45 and 28 percent of energy from protein, carbohydrate and fat, respectively.

\section{Subjects}

Subjects were recruited using flyers in the university building and advertisements in a local newspaper. Postprandial responses of (an)orexigenic hormones and feelings of hunger and satiety were determined in a total of 103 subjects of Western European descent ( 62 women and 41 men, age $31 \pm 14$ years, BMI $25.0 \pm 3.1 \mathrm{~kg} / \mathrm{m}^{2}$ ). For plasma PYY, GLP-1 and ghrelin levels and feelings of hunger and satiety, 60, 78, 70, 102 and 103 subjects, respectively were available. The study conformed to the standards set by the Declaration of Helsinki and the local Ethics Committee approved the study. Subjects provided written informed consent before participating.

\section{Phenotypes}

Plasma concentrations of PYY (3-36), active GLP-1 and active ghrelin were determined pre- and postprandially as described previously (24). Feelings of hunger and satiety were determined using visual analogue scales. After adjusting for baseline levels, the postprandial responses of plasma PYY (increases), GLP-1 (increases) and ghrelin (decreases) levels as well as of feelings of hunger (decreases) and satiety (increases) were determined. For all responses, subjects were characterized as responders or non-responders on 1 ) the initial rate of the response; 2 ) the absolute response, that is, the difference between the baseline level and the maximal/minimal postprandial level obtained and 3) the postprandial area under the curve, measured until 3-4.5 h postprandially. A high postprandial response can either refer to a strong postprandial increase (for plasma PYY and GLP-1 levels as well as for feelings of satiety), or a strong postprandial decrease (for plasma ghrelin levels and for feelings of hunger). Subjects were dichotomized using sexand study-specific median values, resulting in an approximately equal number of responders and non-responders per phenotype, meanwhile taking possible sex differences into account.

Attitude towards eating was determined using the Dutch translation of the Three-Factor Eating Questionnaire (TFEQ) (25). The first factor measures dietary restraint eating, that is, the control of food intake by thought and will power. The second factor, disinhibition, represents the incidental inability to resist eating cues and can also be seen as inhibition of dietary restraint; in normal weight subjects it represents emotional eating. Factor three represents the overall feeling of hunger. 


\section{DNA isolation and SNP genotyping}

Genomic DNA was isolated from peripheral blood leukocytes using the QIAamp blood kit from Qiagen (Amsterdam, The Netherlands). SNPs in genes encoding proteins that exert or mediate (an)orexigenic effects were selected. To ensure an ample number of subjects are homozygous for the minor alleles, candidate SNPs should have a minor allele frequency in Europeans of at least $25 \%$ as indicated by the SNP public database (dbSNP; http://www.ncbi.nlm.nih.gov/SNP). Moreover, only SNPs that were associated earlier with relevant phenotypes, such as BMI or body composition, were considered. This resulted in the selection of nine SNPs in eight genes (Table 1): the $-501 \mathrm{~A}>\mathrm{C}$ SNP in the promoter region of GHRL (rs26802); the silent 477G>A SNP in codon 159 (Arg) of the ghrelin receptor gene (GHSR) (rs572169); the -2548G>A SNP in the coding region of LEP (rs7799039); the 326A>G and 668A $>$ G SNPs in $L E P R$ resulting in amino acid substitutions Lys109Arg and Gln223Arg (rs1137100 and rs1137101, respectively); the 215G>C SNP in PYY resulting in the non-synonymous amino acid substitution Arg72Thr (rs1058046); the silent 204T>C SNP in codon 68 (Ser) of the neuropeptide Y gene (NPY) (rs5574); the silent 585T>C SNP in codon 195 (Ile) of the neuropeptide Y 2 receptor gene $(N P Y 2 R)$ (rs1047214) and the $-156 \mathrm{~A}>\mathrm{G}$ SNP in the promoter region of the cocaine and amphetamine regulated transcript gene (CART) (rs35862863).

Genotyping was performed using commercially available TaqMan SNP genotyping assays from Applied Biosystems (Foster City, California, USA). The procedure was performed according to the manufacturer's protocol and measured on an Applied Biosystems 7900 HT Fast Real-Time PCR System. Allelic calls were determined semi-automatically using the allelic discrimination software of Applied Biosystems. Results for SNPs that were determined in reversed direction are reported as if performed forward, i.e. in accordance with the literature.

\section{Statistics}

Data for the postprandial responses were analyzed with dichotomized responses per phenotype $\left('{ }^{\prime}=\right.$ non-responder, ' 1 '=responder $)$ as dependent variables. For dichotomized responses per phenotype, logistic regression analyses with two dummy variables per SNP were used to determine parameter estimates for the heterozygous and homozygous mutant genotypes. Subjects homozygous for the common allele were used as the reference group. When six or less subjects were homozygous for the minor allele, carriers of the minor allele were pooled to decrease the chance of false positive results. This was the case for the postprandial response in plasma PYY levels in 477G>A in GHSR and for the $326 \mathrm{~A}>\mathrm{G}$ SNP in LEPR.

As age and BMI were not normally distributed among subjects, the Kruskal Wallis and Mann-Whitney $U$ tests were used to determine the associations between BMI and the SNPs and between the postprandial responses and BMI, respectively.

For the postprandial response in feelings of hunger and satiety, the number of subjects was sufficient to test for epistatic interactions. To identify these interactions, the multifactor dimensionality reduction (MDR) method was used. MDR is a frequently used multi- 
locus method (26-28) that was applied as described earlier by Heidema et al. (29). Briefly, we applied the MDR software (http://www.epistasis.org) to our dataset using 10fold cross-validation to determine the best model for main SNP-SNP effects. The 10-fold cross-validation was repeated 10 times, using a different seed value each time to protect against chance divisions of the dataset. Finally, applying the MDR permutation module, we tested the significance of the testing accuracy of the best model by forming a 1000 datasets with the case status permuted randomly. This way, we validated for each phenotype whether the model was significantly associated with responder status. Subsequently, logistic regression was used for the significant models to obtain a statistical interpretation (29).

As dietary restraint, disinhibition and perceived hunger were not normally distributed among subjects, the Kruskal Wallis test was used to determine the association between these phenotypes and the relevant SNPs. Age, BMI, dietary restraint, disinhibition and perceived hunger were subsequently log-transformed for further analyses. Multiple linear regression analyses were used to test for associations between dietary restraint, disinhibition and perceived hunger with the selected SNPs taking subject characteristics into account. $P$-values $<0.05$ were considered statistically significant.

\section{Results}

The genotypic and allelic distributions of the determined SNPs are provided in Table 1. All SNPs were in Hardy Weinberg equilibrium. The 326A $>$ G SNP and the 668A $>\mathrm{G}$ SNP $(\angle E P R)$ were in linkage disequilibrium (LD) $(R=0.66, P<0.0001)$, indicating that the information these SNPs provide overlaps. Both SNPs were included for further analyses.

For all SNPs, BMI was similar between genotypes $(P>0.05)$. BMI was also similar between responders and non-responders for all postprandial responses $(P>0.05)$. Correcting the associations for age and BMI did not change the results. The associations between postprandial responses in plasma PYY, GLP-1 and ghrelin levels with the SNPs determined are described below and are shown in Figure 3.

Postprandial responses in plasma PYY, GLP-1 and ghrelin levels as well as feelings of hunger and satiety: single-SNP associations

Baseline values for plasma PYY, GLP-1 and ghrelin levels, as well as for feelings of hunger and satiety were similar between genotypes $(P>0.05)$ (Table 2$)$. Subjects with a high postprandial response in plasma PYY levels were overrepresented among the $C C$ and $A C$ genotypes of the $-501 \mathrm{~A}>\mathrm{C}$ SNP $(G H R L)$ compared with the AA genotype $(P<0.05)$. Subjects with a high postprandial response in plasma PYY levels were also more frequently homozygous for the common $\mathrm{G}$ allele of the $477 \mathrm{G}>\mathrm{A}$ SNP (GHSR) than expected based on chance $(P<0.05)$ (Table 3$)$. No associations were found between the postprandial response in plasma GLP-1 levels and any of the SNPs determined. 
Table 1: Genotypic and allelic distributions per single nucleotide polymorphism

\begin{tabular}{|c|c|c|c|c|c|c|c|}
\hline Gene & SNP & Genotype & $F(n)$ & $F(\%)$ & Allele & $\mathrm{F}(\%)$ & HWE \\
\hline \multirow[t]{3}{*}{$\overline{G H S R}$} & $477 \mathrm{G}>\mathrm{A}$ & GG & 38 & 36.9 & $\mathrm{G}$ & 61.7 & 0.63 \\
\hline & (Arg159Arg) & GA & 51 & 49.5 & A & 38.3 & \\
\hline & & $A A$ & 14 & 13.6 & & & \\
\hline \multirow[t]{3}{*}{ GHRL } & $-501 A>C$ & $A A$ & 46 & 44.7 & A & 66.0 & 0.63 \\
\hline & & $A C$ & 44 & 42.7 & $\mathrm{C}$ & 34.0 & \\
\hline & & $\mathrm{CC}$ & 13 & 12.6 & & & \\
\hline \multirow[t]{6}{*}{$L E P R$} & $326 A>G$ & AA & 45 & 43.7 & A & 68.9 & 0.07 \\
\hline & (Lys109Arg) & AG & 52 & 50.5 & G & 31.1 & \\
\hline & & GG & 6 & 5.8 & & & \\
\hline & $668 A>G$ & AA & 29 & 28.2 & A & 52.9 & 0.95 \\
\hline & (Gln223Arg) & AG & 51 & 49.5 & G & 47.1 & \\
\hline & & GG & 23 & 22.3 & & & \\
\hline \multirow[t]{3}{*}{ LEP } & $-2548 G>A$ & GG & 29 & 28.2 & G & 51.0 & 0.38 \\
\hline & & GA & 47 & 45.6 & $A$ & 49.0 & \\
\hline & & AA & 27 & 26.2 & & & \\
\hline \multirow[t]{3}{*}{$P Y Y$} & $215 G>C$ & GG & 38 & 36.9 & G & 62.1 & 0.46 \\
\hline & (Arg72Thr) & GC & 52 & 50.5 & C & 37.9 & \\
\hline & & $\mathrm{CC}$ & 13 & 12.6 & & & \\
\hline \multirow[t]{3}{*}{$N P Y$} & $204 \mathrm{~T}>\mathrm{C}$ & $\pi$ & 30 & 29.1 & T & 53.4 & 0.80 \\
\hline & (Ser68Ser) & $\mathrm{TC}$ & 50 & 48.5 & C & 46.6 & \\
\hline & & $\mathrm{CC}$ & 23 & 22.3 & & & \\
\hline \multirow[t]{3}{*}{ NPY2R } & $585 T>C$ & $\pi T$ & 34 & 33.0 & $\mathrm{~T}$ & 55.3 & 0.33 \\
\hline & (Ile195Ile) & $\mathrm{TC}$ & 46 & 44.7 & C & 44.7 & \\
\hline & & $\mathrm{CC}$ & 23 & 22.3 & & & \\
\hline \multirow[t]{3}{*}{$C A R T$} & $-156 A>G$ & AA & 26 & 25.2 & $A$ & 52.9 & 0.26 \\
\hline & & AG & 57 & 55.3 & G & 47.1 & \\
\hline & & GG & 20 & 19.4 & & & \\
\hline
\end{tabular}

F, Frequency, either absolute ( $n$ ) or relative (\%); HWE, $P$-value obtained from the $\chi^{2}$ test of Hardy Weinberg equilibrium. For all single nucleotide polymorphisms (SNPs), a $100 \%$ success rate was accomplished.

Subjects with a high postprandial response in plasma ghrelin levels were overrepresented among carriers of 109Arg-encoding allele of the 326A>G SNP (LEPR) compared with subjects homozygous for the common 109Lys-encoding allele $(P<0.01)$. Furthermore, subjects with a high postprandial response in plasma ghrelin levels were overrepresented among those homozygous for the 223Arg-encoding allele of the 668A>G SNP (LEPR) compared with those homozygous for the 223Gln-encoding allele $(P<0.01)$. The postprandial response in plasma ghrelin levels was also associated with the 215G $>C$ SNP $(P Y Y)$; subjects with a high postprandial response were more frequently homozygous for the 72Thr-encoding allele than expected based on chance. As none of the subjects homozygous for the 72Thr-encoding allele was characterized by a low postprandial response in plasma ghrelin levels, it was not possible to obtain a parameter estimate for this association by logistic regression. Therefore, the Fisher's exact test was used instead $(P<0.01$ ) (Table 3).

Subjects with a high postprandial response in feelings of hunger were overrepresented among subjects homozygous for the common $G$ allele of the -2548G >A SNP (LEP) compared with heterozygous subjects $(P<0.05)$ but not compared with subjects homozygous for the A allele. Similarly, subjects with a high postprandial response in feelings of hun- 
ger were overrepresented among subjects homozygous for the common 223GIn-encoding allele of the $668 \mathrm{~A}>\mathrm{G}$ SNP $(L E P R)$ compared with heterozygous subjects $(P<0.05)$ but not compared with subjects homozygous for the 223Arg-encoding allele. No associations were observed between the postprandial response in feelings of satiety and any of the SNPs determined. An overview of all significant associations with odds ratios, $95 \%$ confidence intervals and $P$-values is provided in Table 3.

Table 2: Baseline PYY, GLP-1 and ghrelin levels per genotype

\begin{tabular}{|c|c|c|c|c|c|}
\hline Gene & SNP & Genotypes & PYY (pmol/L) & GLP-1 (pmol/L) & Ghrelin (pmol/L) \\
\hline \multirow[t]{3}{*}{ GHSR } & $477 \mathrm{G}>\mathrm{A}$ & GG & $32.8 \pm 7.6(25)$ & $3.3 \pm 3.5(30)$ & $26.0 \pm 17.5(26)$ \\
\hline & (Arg159Arg) & GA & $31.0 \pm 6.6(30)$ & $2.6 \pm 3.6(39)$ & $27.7 \pm 24.6(32)$ \\
\hline & & $A A$ & $29.4 \pm 3.9(5)$ & $2.4 \pm 2.0(9)$ & $22.8 \pm 17.6(12)$ \\
\hline \multirow[t]{3}{*}{ GHRL } & $-501 A>C$ & $A A$ & $32.8 \pm 7.3(25)$ & $2.0 \pm 2.8(32)$ & $26.4 \pm 21.8(31)$ \\
\hline & & $A C$ & $32.2 \pm 5.9(25)$ & $3.5 \pm 3.8(34)$ & $23.4 \pm 14.7(31)$ \\
\hline & & $\mathrm{CC}$ & $27.4 \pm 7.1(10)$ & $3.1 \pm 3.6(12)$ & $36.4 \pm 34.2(8)$ \\
\hline \multirow[t]{6}{*}{$L E P R$} & $326 A>G$ & $A A$ & $32.0 \pm 6.9(31)$ & $3.2 \pm 3.9(38)$ & $26.5 \pm 19.3(27)$ \\
\hline & (Lys109Arg) & $A G$ & $30.6 \pm 6.7(25)$ & $2.7 \pm 3.0(36)$ & $26.9 \pm 22.2(41)$ \\
\hline & & GG & $35.2 \pm 8.3(4)$ & $1.1 \pm 0.3(4)$ & $08.8 \pm 2.9(2)$ \\
\hline & $668 A>G$ & $A A$ & $32.0 \pm 7.3(21)$ & $3.4 \pm 4.0(26)$ & $30.4 \pm 21.4(19)$ \\
\hline & (GIn223Arg) & AG & $30.6 \pm 6.6(29)$ & $2.2 \pm 2.5(35)$ & $25.5 \pm 22.3(33)$ \\
\hline & & GG & $33.7 \pm 6.8(10)$ & $3.3 \pm 4.0(17)$ & $23.0 \pm 17.7(18)$ \\
\hline \multirow[t]{3}{*}{$\angle E P$} & $-2548 G>A$ & GG & $30.7 \pm 7.2(18)$ & $2.5 \pm 2.6(21)$ & $31.5 \pm 30.4(16)$ \\
\hline & & GA & $31.3 \pm 7.7(25)$ & $2.4 \pm 3.4(34)$ & $26.6 \pm 20.2(34)$ \\
\hline & & $A A$ & $33.2 \pm 5.3(17)$ & $3.9 \pm 3.9(23)$ & $21.4 \pm 9.7(20)$ \\
\hline \multirow[t]{3}{*}{ PYY } & $215 G>C$ & GG & $32.8 \pm 8.5(25)$ & $3.2 \pm 4.1$ & $25.3 \pm 12.4(25)$ \\
\hline & (Arg72Thr) & GC & $30.7 \pm 5.6(27)$ & $2.8 \pm 3.1(36)$ & $24.6 \pm 22.0(27)$ \\
\hline & & $\mathrm{CC}$ & $31.2 \pm 5.0(8)$ & $1.8 \pm 1.2(10)$ & $36.6 \pm 34.5(8)$ \\
\hline \multirow[t]{3}{*}{$N P Y$} & $204 T>C$ & $\mathrm{TT}$ & $28.5 \pm 6.6(19)$ & $2.8 \pm 3.7(27)$ & $33.6 \pm 27.0(21)$ \\
\hline & (Ser68Ser) & TC & $33.3 \pm 7.7(24)$ & $2.6 \pm 2.6(31)$ & $21.9 \pm 18.7(36)$ \\
\hline & & $\mathrm{CC}$ & $32.8 \pm 4.8(17)$ & $3.3 \pm 4.1(20)$ & $26.3 \pm 10.7(13)$ \\
\hline \multirow[t]{3}{*}{ NPY $2 R$} & $585 \mathrm{~T}>\mathrm{C}$ & $T T$ & $30.5 \pm 6.4(23)$ & $2.4 \pm 3.1(28)$ & $31.0 \pm 21.2(18)$ \\
\hline & (Ile195Ile) & TC & $33.4 \pm 8.2(24)$ & $3.0 \pm 3.5(35)$ & $25.9 \pm 20.9(34)$ \\
\hline & & $\mathrm{CC}$ & $30.3 \pm 4.1(13)$ & $3.3 \pm 3.9(15)$ & $22.1 \pm 20.8(18)$ \\
\hline \multirow[t]{3}{*}{$C A R T$} & $-156 A>G$ & $A A$ & $32.4 \pm 6.3(16)$ & $3.0 \pm 4.1(21)$ & $23.7 \pm 21.8(16)$ \\
\hline & & $A G$ & $31.8 \pm 8.2(29)$ & $3.0 \pm 3.6(40)$ & $25.2 \pm 18.5(44)$ \\
\hline & & GG & $30.5 \pm 4.5(15)$ & $2.3 \pm 1.8(17)$ & $34.7 \pm 28.5(10)$ \\
\hline
\end{tabular}

No significant differences in plasma PYY, GLP-1 and ghrelin levels were observed between genotypes. Data are presented as means \pm SD (number of subjects).

Postprandial responses in plasma PYY, GLP-1 and ghrelin levels as well as feelings of hunger and satiety: epistatic interactions

MDR revealed a significant epistatic interaction for the postprandial response in feelings of hunger involving the 668A $>$ G SNP ( $L E P R)$ and the 585T>C SNP (NPY2R) (Figure 2A). The prediction accuracy of the model was $66.1 \%(P=0.05)$. Logistic regression subsequently showed that subjects with a high postprandial response in feelings of hunger were overrepresented among subjects homozygous for the common allele in both SNPs compared with subjects carrying at least one 223Arg-encoding allele in 668A $>\mathrm{G}$ and at least one $\mathrm{C}$ allele in 585T $>C(P<0.05)$ (Figure $2 \mathrm{~B})$. 
Table 3: Associations between postprandial responses and single nucleotide polymorphisms

\begin{tabular}{|c|c|c|c|c|c|c|c|}
\hline Gene & SNP & Response & Genotype & OR & $95 \% \mathrm{CI}$ & & $P$-value \\
\hline \multirow[t]{2}{*}{$\overline{G H R L}$} & $-501 A>C$ & PYY $Y_{A B S}$ & $\mathrm{AC}$ & 3.27 & 1.01 & 10.62 & 0.05 \\
\hline & & & $\mathrm{CC}$ & 10.29 & 1.74 & 60.90 & 0.01 \\
\hline GHSR & $477 G>A$ & $\mathrm{PYY}_{\mathrm{ABS}}$ & $\mathrm{GA} / \mathrm{AA}$ & 0.33 & 0.11 & 0.97 & 0.04 \\
\hline \multirow[t]{8}{*}{$L E P R$} & $326 A>G$ & Ghrelin $_{A B S}$ & AG/GG & 4.01 & 1.43 & 11.25 & 0.01 \\
\hline & & Ghrelin $_{\text {AUC }}$ & AG/GG & 4.01 & 1.43 & 11.25 & 0.01 \\
\hline & $668 A>G$ & Ghrelin $_{\mathrm{AUC}}$ & AG & 2.98 & 0.87 & 10.2 & 0.08 \\
\hline & & & GG & 7.28 & 1.71 & 31.08 & 0.01 \\
\hline & & Hunger $_{\mathrm{ABS}}$ & AG & 0.34 & 0.13 & 0.88 & 0.03 \\
\hline & & & GG & 1.13 & 0.35 & 3.67 & 0.84 \\
\hline & & Hunger $_{\text {AUC }}$ & AG & 0.26 & 0.09 & 0.72 & 0.01 \\
\hline & & & GG & 0.37 & 0.11 & 1.26 & 0.11 \\
\hline$P Y Y$ & $215 G>C$ & Ghrelin $_{\text {AUC }}$ & $\mathrm{GC} / \mathrm{CC}$ & - & - & - & $0.01^{a}$ \\
\hline \multirow[t]{2}{*}{$\angle E P$} & $-2548 G>A$ & Hunger $_{\text {RATE }}$ & $\mathrm{GA}$ & 0.30 & 0.11 & 0.79 & 0.01 \\
\hline & & & $A A$ & 0.84 & 0.28 & 2.53 & 0.76 \\
\hline
\end{tabular}

Response, dependent variable; Genotype, independent variable; OR, odds ratio; 95\% CI, 95\% confidence interval for odds ratio; ABS, Absolute postprandial response, i.e. the absolute difference between the baseline value and the minimal/maximal postprandial value; AUC, postprandial area under the curve; RATE, initial postprandial rate of response. All responses were dichotomized (' 0 '=nonresponders; '1'=responders) and models were obtained using logistic regression. For all SNPs, the effects shown are relative to the subjects homozygous for the wildtype allele (reference group). For $477 \mathrm{G}>\mathrm{A}$ and $326 \mathrm{~A}>\mathrm{G}$, data were pooled for the least frequent allele. For $215 \mathrm{G}>\mathrm{C}$, subjects homozygous for the minor allele $(C)$ were not represented among the non-responders. Consequently, the $P$ value of the Fisher's exact test was used for this SNP (a).

A

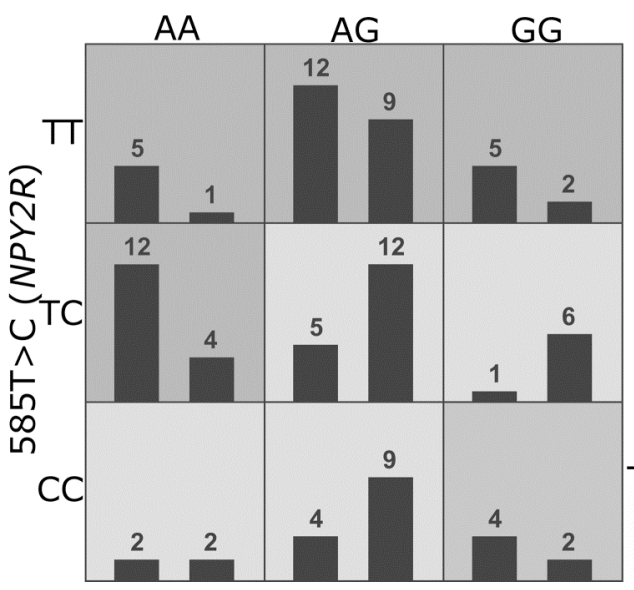

B

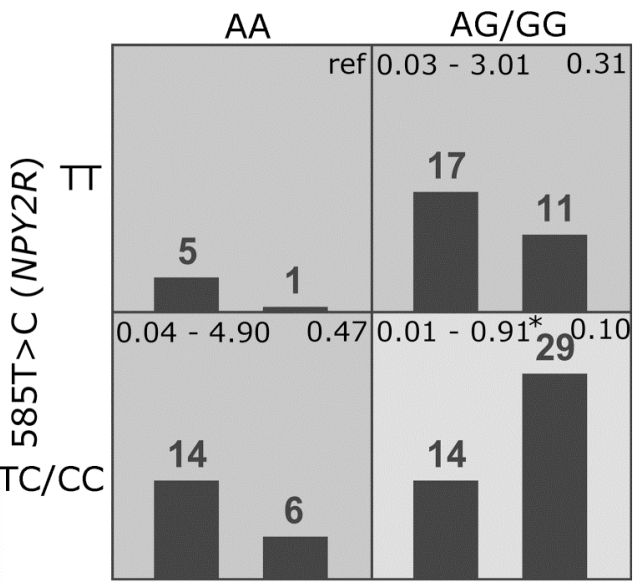

Figure 2: SNP-SNP interaction for the postprandial response in feelings of hunger (area under the curve) involving the 668A>G SNP (LEPR) and the 585T>C SNP (NPY2R). In each segment, the bar on the left represents the number of responders, i.e. the subjects with a high postprandial response in feelings of hunger, and the bar on the right represents the number of non-responders. A shows the output obtained using Multifactor Dimensionality Reduction (MDR) $(P=0.05)$. B provides the statistical interpretation of the model obtained using logistic regression with AATT carriers as the reference group. Carriers of the 223Arg-encoding allele $\mathrm{G}$ in $668 \mathrm{~A}>\mathrm{G}$ and carriers of the $\mathrm{C}$ allele in 585T>C were pooled (AG/GG and TC/CC, respectively). For each segment, the $95 \%$ confidence interval is shown in the left upper corner and the odds ratio in the right upper corner. $* P<0.05$. 


\section{Dietary restraint, disinhibition and perceived hunger: single-SNP associations}

Values obtained for dietary restraint, disinhibition and perceived hunger were $5.1 \pm 2.8$, $4.5 \pm 2.4$ and $4.3 \pm 2.7$, respectively. Dietary restraint and disinhibition were higher in GA and AA carriers of the $477 \mathrm{G}>\mathrm{A}$ SNP (GHSR) than in subjects homozygous for the common $G$ allele $(5.6 \pm 2.8$ versus $4.2 \pm 2.5$ and $4.9 \pm 2.4$ versus $3.6 \pm 2.2$ for dietary restraint and disinhibition, respectively $(P<0.05))$. Perceived hunger was significantly associated with the 477G >A SNP (GHSR) and the 204T>C SNP (NPY) considered together, with perceived hunger being higher in subjects carrying the $A$ allele in $477 \mathrm{G}>\mathrm{A}$ and the $\mathrm{C}$ allele in 204T>C compared with subjects homozygous for the $G$ and $T$ alleles, respectively $\left(P<0.05, \mathrm{R}^{2}=0.13\right)$ (Table 4$)$.

Dietary restraint was significantly associated with sex and BMI $\left(P<0.001, \mathrm{R}^{2}=0.15\right)$. Adding the 477G $>$ A SNP (GHSR) to a model with sex and BMI significantly increased the explained variation to $20 \%(P<0.05)$, indicating an additional effect (Table 4$)$. Disinhibition and perceived hunger were not associated with sex, age or BMI. As a result, correcting the associations for these variables did not change the results.

Table 4: Associations between dietary restraint, disinhibition and perceived hunger with single nucleotide polymorphisms

\begin{tabular}{|c|c|c|c|c|c|c|c|}
\hline \multirow{2}{*}{$\begin{array}{l}\text { Gene(s) } \\
\text { GHSR }\end{array}$} & \multirow{2}{*}{$\begin{array}{l}\text { SNP } \\
477 G>A\end{array}$} & \multirow{2}{*}{$\begin{array}{l}\text { Response } \\
\text { Dietary restraint }\end{array}$} & \multirow{2}{*}{$\begin{array}{l}\text { Parameter } \\
\text { GA }\end{array}$} & \multirow{2}{*}{$\frac{B}{0.30}$} & \multicolumn{2}{|c|}{$95 \% \mathrm{CI}$} & \multirow{2}{*}{$\begin{array}{l}P \text {-value } \\
0.03\end{array}$} \\
\hline & & & & & 0.03 & 0.57 & \\
\hline & & & $\mathrm{AA}$ & 0.35 & -0.04 & 0.73 & 0.08 \\
\hline & & & Sex & -0.36 & -0.61 & -0.11 & 0.006 \\
\hline & & & BMI & 1.61 & 0.61 & 2.61 & 0.002 \\
\hline \multirow[t]{2}{*}{ GHSR } & $477 G>A$ & Disinhibition & GA & 0.36 & 0.10 & 0.62 & 0.01 \\
\hline & & & $A A$ & 0.43 & 0.05 & 0.82 & 0.03 \\
\hline \multirow[t]{2}{*}{ GHSR } & $477 G>A$ & Perceived hunger & GA & 0.33 & 0.03 & 0.64 & 0.03 \\
\hline & & & $A A$ & 0.54 & 0.08 & 1.00 & 0.02 \\
\hline \multirow[t]{2}{*}{$N P Y$} & $204 T>C$ & & TC & 0.44 & 0.11 & 0.78 & 0.01 \\
\hline & & & $\mathrm{CC}$ & 0.42 & 0.02 & 0.83 & 0.04 \\
\hline
\end{tabular}

Response, dependent variable; Parameter, independent variable; $B$, unstandardized regression coefficient; 95\% CI, 95\% confidence interval for B. Models were obtained using linear regression analyses. For all SNPS, the effects shown are relative to the subjects homozygous for the common allele (reference group).

\section{Discussion}

Single SNP associations were observed between the postprandial response in plasma PYY levels and SNPs in GHRL and GHSR and between the postprandial response in plasma ghrelin levels and SNPs in $P Y Y$ and LEPR. An epistatic interaction for the postprandial response in feelings of hunger was observed involving SNPS in LEPR and NPY2R. Dietary restraint and disinhibition were associated with a SNP in GHSR. Perceived hunger was associated with SNPs in GHSR and NPY.

$C$ allele carriers of the $-501 \mathrm{~A}>\mathrm{C}$ SNP (GHRL) were shown earlier to have higher fasting ghrelin levels than subjects with the AA genotype (16). Increased plasma ghrelin levels are known to initiate meals (30) and increase food intake (31) in humans. Based on fast- 
ing plasma ghrelin levels, CC carriers are thus at increased risk for overeating. However, subjects homozygous for the $\mathrm{C}$ allele had a lower BMI and tended to have a lower waist circumference than AA and AC carriers (16), suggesting an adequate food intake regulation. This paradox may be explained by an association observed in the present study; subjects with a high postprandial response in the anorectic hormone PYY were overrepresented among subjects homozygous for the $C$ allele compared with subjects homozygous for the common A allele. This association can be regarded as a long-term physiological adaptation required to facilitate homeostasis in these subjects at increased risk for overeating since they are homozygous for the $C$ allele in $-501 \mathrm{~A}>\mathrm{C}$.

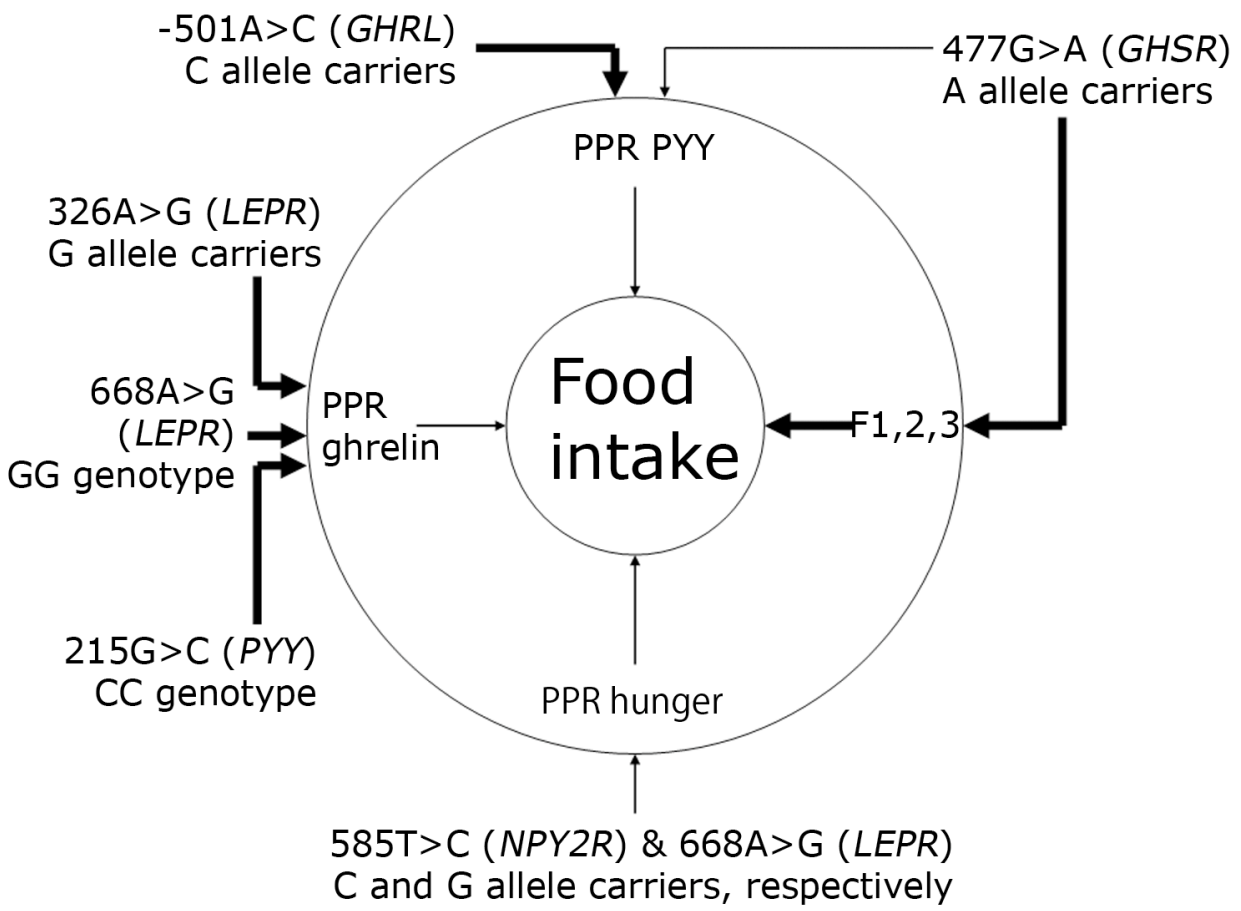

Figure 3: A model for the association between the postprandial response (PPR) in plasma ghrelin and PYY levels and feelings of hunger, as well as cognitive aspects of food intake regulation (in grey) with SNPs encoding (an)orexigenic hormones and their receptors. F1,2,3, Scores on dietary restraint, disinhibition of dietary restraint and perceived hunger as obtained using the Three-Factor Eating Questionnaire. Bold lines represent excitatory effects, thin lines represent inhibitory effects. The effects represent the genotypes shown compared with subjects homozygous for the common allele.

The idea of genotype-related long-term physiological adaptations that facilitate homeostasis is supported by another observation. The 668A>G SNP (LEPR) was hypothesized earlier to affect the functionality of the leptin receptor, with the variant $G$ allele (Arg) resulting in a leptin resistant state $(14 ; 32)$. Resistance to leptin is known to increase food 
intake, in extreme cases resulting in early-onset morbid obesity (33; 34). However, subjects homozygous for the 223Arg-encoding allele had a higher BMI than subjects homozygous for the common $223 \mathrm{Gln}$-encoding allele in some $(14 ; 35 ; 36)$, but not all studies (37; 38). Again, long-term physiological adaptations required to facilitate homeostasis may be involved. First of all, subjects homozygous for the 223Arg-encoding allele were shown earlier to have higher plasma leptin levels $(14 ; 35)$. Moreover, in the present study, subjects with a high postprandial response in plasma ghrelin levels were overrepresented among subjects homozygous for the 223Arg-encoding allele compared with subjects homozygous for the $223 \mathrm{GIn}$-encoding allele. Both effects protect subjects homozygous for the 223Arg-encoding allele from overeating, thereby facilitating homeostasis.

Analogous to the association shown for $668 \mathrm{~A}>\mathrm{G}$, subjects with a higher postprandial response in plasma ghrelin levels were overrepresented among carriers of the 109Argencoding allele $(G)$ of the $326 \mathrm{~A}>\mathrm{G}$ SNP (LEPR) compared with subjects homozygous for the common 109Lys-encoding allele (A). These SNPs were in LD, as was observed by others $(35 ; 37 ; 39)$. The association reduces the risk for overeating in subjects homozygous for the 109Arg-encoding allele, consistent with results from Rosmond et al. who showed a lower BMI and abdominal sagittal diameter in subjects with this genotype (38). The association between the postprandial response in plasma ghrelin levels and the $326 \mathrm{~A}>\mathrm{G}$ SNP thus seems to reflect a long-term physiological adaptation that facilitates homeostasis as well. However, in spite of their LD, no association was observed earlier between fasting plasma leptin levels and the 326A>G SNP $(14 ; 35)$.

Two cases in which the postprandial responses in (an)orexigenic hormones actually reinforce direct effects were also identified in the present study. First of all, the A allele of the $477 \mathrm{G}>\mathrm{A}$ SNP (GHSR) was shown earlier to increase the risk for obesity between $41 \%$ and $56 \%(40)$. Baessler et al. concluded that the promoter regulatory elements of transcriptional initiation were probably affected. This way, genetic variation in GHSR alters expression of the ghrelin receptor protein, which affects ghrelin signalling and ultimately food intake regulation. We showed that the increased risk for obesity in A allele carriers was reinforced by a reduced postprandial response in plasma PYY levels in subjects with this genotype. A cognitive component may also be involved, since A allele carriers of the 477G $>$ A SNP had a higher dietary restraint, disinhibition and perceived hunger than subjects homozygous for the $G$ allele. Restrained eaters were shown earlier to consume less energy, take fewer meals and show a higher preference for low-calorie foods than unrestrained eaters $(41 ; 42)$. This suggests that subjects carrying the A allele may be at reduced risk for overeating. However, energy balance can only be maintained when a high score on dietary restraint is combined with a low score on disinhibition (43). Furthermore, subjects suffering from feelings of hunger were previously concluded to be especially vulnerable to disinhibit dietary restraint (44). In subjects carrying the A allele, a high score on dietary restraint is accompanied by high scores on disinhibition and perceived hunger, thereby providing a cognitive explanation for an increased risk for overeating in these subjects, which is in line with the SNP's direct effect on ghrelin signalling. Secondly, subjects homozygous for the common 72Arg-encoding allele (G) in the $215 G>C$ SNP (PYY) were previously shown to have $20 \%$ lower fasting plasma PYY levels than subjects homozygous for the minor 72Thr-encoding allele (C) (45). Considering the 
role of PYY as an anorectic hormone, this is anticipated to increase the risk for overeating in subjects homozygous for the 72Arg-encoding allele. Indeed, these subjects had a higher risk for developing obesity than carriers of the 72Thr-encoding allele (45). The present study showed that subjects with a higher postprandial response in plasma ghrelin levels were overrepresented among subjects homozygous for the 72Thr-encoding allele compared with subjects homozygous for the common 72Arg-encoding allele. This provides subjects homozygous for the $72 \mathrm{Thr}$ encoding allele with additional protection against overeating compared with subjects homozygous for the 72Arg-encoding allele.

Subjects with a high postprandial response in feelings of hunger were overrepresented among subjects homozygous for the common 223Gln-encoding allele in 668A>G (LEPR) compared with heterozygous subjects. However, subjects with a high postprandial response in feelings of hunger were equally distributed among subjects homozygous for the 223Gln- and 223Arg-encoding alleles, making it difficult to explain this finding. A previously unidentified epistatic interaction for the postprandial response in feelings of hunger, involving the 668A > G (LEPR) and 585T>C (NPY2R) SNPs provided more insight; subjects with a high postprandial response in feelings of hunger appeared to be overrepresented among subjects homozygous for the common 223Gln-encoding allele (A), irrespective of the 585T>C SNP (Figure 2B). In contrast, in subjects carrying at least one 223Arg-encoding allele $(G)$, subjects with a high postprandial response in feelings of hunger were overrepresented among subjects homozygous for the common $T$ allele in 585T > C compared with subjects carrying at least one C allele. Since the 585T >C SNP is a silent transition, this SNP is likely to be in LD with a functional variant in the NPY2R locus (46). To summarize, the 223Arg-encoding allele may increase food intake by decreasing leptin sensitivity, it may decrease food intake by increasing plasma leptin levels and by increasing the postprandial response in plasma ghrelin levels, and it may either increase or decrease food intake by influencing the postprandial response in feelings of hunger depending on the 585T>C SNP (NPY2R).

As the phenotypes determined in the present study were not independent and two of the SNPs evaluated were in LD, correcting for multiple comparisons in a conventional way may discard true associations. Moreover, the study was explorative in nature: associations between the postprandial responses in (an)orexigenic hormones as well as feelings of hunger and satiety with genes encoding these proteins and their receptors have not been reported before. Therefore, we did not correct for multiple testing.

In conclusion, we are the first to show that the postprandial responses in (an)orexigenic hormones and feelings of hunger to fixed meals provided in energy balance are associated with SNPs in genes encoding these proteins and their receptors. Indeed, part of the large inter-individual variability in these postprandial responses can thus be explained by genetic variation. Postprandial responses in (an)orexigenic hormones either represent long-term physiological adaptations that facilitate homeostasis or reinforce direct genetic effects. Finally, the present study shows that evaluating SNP-SNP interactions in addition to the conventional single-SNP associations can elucidate findings that would otherwise remain inexplicable. 


\section{Acknowledgements}

The authors thank Kristel Diepvens, Manuela Lejeune and Ananda Hochstenbach-Waelen for their contributions in acquiring the data on postprandial responses in (an)orexigenic hormones and feelings of hunger and satiety. 


\section{References}

1. Flier JS, Harris M, Hollenberg AN: Leptin, nutrition, and the thyroid: the why, the wherefore, and the wiring. J Clin Invest 105:859-861, 2000

2. Kristensen $P$, Judge ME, Thim L, Ribel U, Christjansen KN, Wulff BS, Clausen JT, Jensen PB, Madsen OD, Vrang N, Larsen PJ, Hastrup S: Hypothalamic CART is a new anorectic peptide regulated by leptin. Nature 393:72-76, 1998

3. Ebihara K, Ogawa Y, Katsuura G, Numata Y, Masuzaki H, Satoh N, Tamaki M, Yoshioka T, Hayase M, Matsuoka N, Aizawa-Abe M, Yoshimasa Y, Nakao K: Involvement of agouti-related protein, an endogenous antagonist of hypothalamic melanocortin receptor, in leptin action. Diabetes 48:2028-2033, 1999

4. Mizuno TM, Mobbs CV: Hypothalamic agouti-related protein messenger ribonucleic acid is inhibited by leptin and stimulated by fasting. Endocrinology 140:814-817, 1999

5. Anini Y, Brubaker PL: Role of leptin in the regulation of glucagon-like peptide-1 secretion. Diabetes 52:252-259, 2003

6. Drucker DJ: Glucagon-like peptides. Diabetes 47:159-169, 1998

7. Batterham RL, Cohen MA, Ellis SM, Le Roux CW, Withers DJ, Frost GS, Ghatei MA, Bloom SR: Inhibition of food intake in obese subjects by peptide $\mathrm{YY}_{3-36}$. N Engl J Med 349:941-948, 2003

8. McGowan BM, Bloom SR: Peptide YY and appetite control. Curr Opin Pharmacol 4:583588,2004

9. Tovar SA, Seoane LM, Caminos JE, Nogueiras R, Casanueva FF, Dieguez C: Regulation of peptide YY levels by age, hormonal, and nutritional status. Obes Res 12:1944-1950, 2004

10. Chen HY, Trumbauer ME, Chen AS, Weingarth DT, Adams JR, Frazier EG, Shen Z, Marsh DJ, Feighner SD, Guan XM, Ye Z, Nargund RP, Smith RG, Van der Ploeg LH, Howard AD, MacNeil DJ, Qian S: Orexigenic action of peripheral ghrelin is mediated by neuropeptide $Y$ and agouti-related protein. Endocrinology 145:2607-2612, 2004

11. Kamegai J, Tamura H, Shimizu T, Ishii S, Sugihara H, Wakabayashi I: Chronic central infusion of ghrelin increases hypothalamic neuropeptide $Y$ and Agouti-related protein mRNA levels and body weight in rats. Diabetes 50:2438-2443, 2001

12. Hoffstedt J, Eriksson P, Mottagui-Tabar S, Arner P: A polymorphism in the leptin promoter region $(-2548 \mathrm{G} / \mathrm{A})$ influences gene expression and adipose tissue secretion of leptin. Horm Metab Res 34:355-359, 2002

13. Mammes O, Betoulle D, Aubert R, Herbeth B, Siest G, Fumeron F: Association of the G2548A polymorphism in the 5' region of the LEP gene with overweight. Ann Hum Genet 64:391-394, 2000

14. Yiannakouris N, Yannakoulia M, Melistas L, Chan JL, Klimis-Zacas D, Mantzoros CS: The Q223R polymorphism of the leptin receptor gene is significantly associated with obesity and predicts a small percentage of body weight and body composition variability. J Clin Endocrinol Metab 86:4434-4439, 2001

15. Ahituv N, Kavaslar N, Schackwitz W, Ustaszewska A, Collier JM, Hebert S, Doelle H, Dent R, Pennacchio LA, McPherson R: A PYY Q62P variant linked to human obesity. Hum Mol Genet 15:387-391, 2006

16. Vartiainen J, Kesaniemi YA, Ukkola O: Sequencing analysis of ghrelin gene $5^{\prime}$ flanking region: relations between the sequence variants, fasting plasma total ghrelin concentrations, and body mass index. Metabolism 55:1420-1425, 2006

17. De Castro JM, Lilenfeld LR: Influence of heredity on dietary restraint, disinhibition, and perceived hunger in humans. Nutrition 21:446-455, 2005

18. Steinle NI, Hsueh WC, Snitker S, Pollin TI, Sakul H, St Jean PL, Bell CJ, Mitchell BD, Shuldiner AR: Eating behavior in the Old Order Amish: heritability analysis and a genome-wide linkage analysis. Am J Clin Nutr 75:1098-1106, 2002

19. Tholin S, Rasmussen F, Tynelius P, Karlsson J: Genetic and environmental influences on eating behavior: the Swedish Young Male Twins Study. Am J Clin Nutr 81:564-569, 2005 
20. Diepvens K, Haberer D, Westerterp-Plantenga MS: Effects of different proteins and biopeptides on satiety and 'satiety' or 'orexigenic' hormones. Int J Obes (Lond), 2008 (in press)

21. Batterham RL, Heffron H, Kapoor S, Chivers JE, Chandarana K, Herzog H, Le Roux CW, Thomas EL, Bell JD, Withers DJ: Critical role for peptide $Y Y$ in protein-mediated satiation and body-weight regulation. Cell Metab 4:223-233, 2006

22. Makovey J, Naganathan V, Seibel M, Sambrook P: Gender differences in plasma ghrelin and its relations to body composition and bone - an opposite-sex twin study. Clin Endocrinol (Oxf) 66:530-537, 2007

23. Harris JAB, F.G.: A biometric study of basal metabolism in man. Washington, DC: Carnegie institution of Washington:279, 1919

24. Smeets AJ, Soenen S, Luscombe-Marsh ND, Ueland O, Westerterp-Plantenga MS: Energy expenditure, satiety, and plasma ghrelin, glucagon-like peptide 1, and peptide tyrosine-tyrosine concentrations following a single high-protein lunch. J Nutr 138:698702, 2008

25. Stunkard AJ, Messick S: The three-factor eating questionnaire to measure dietary restraint, disinhibition and hunger. J Psychosom Res 29:71-83, 1985

26. Heidema AG, Boer JM, Nagelkerke N, Mariman EC, van der AD, Feskens EJ: The challenge for genetic epidemiologists: how to analyze large numbers of SNPs in relation to complex diseases. BMC Genet 7:23, 2006

27. Moore $\mathrm{JH}$ : Computational analysis of gene-gene interactions using multifactor dimensionality reduction. Expert Rev Mol Diagn 4:795-803, 2004

28. Ritchie MD, Hahn LW, Roodi N, Bailey LR, Dupont WD, Parl FF, Moore JH: Multifactordimensionality reduction reveals high-order interactions among estrogen-metabolism genes in sporadic breast cancer. Am J Hum Genet 69:138-147, 2001

29. Heidema AG, Feskens EJ, Doevendans PA, Ruven HJ, van Houwelingen HC, Mariman EC, Boer JM: Analysis of multiple SNPs in genetic association studies: comparison of three multi-locus methods to prioritize and select SNPs. Genet Epidemiol 31:910-921, 2007

30. Cummings DE, Purnell JQ, Frayo RS, Schmidova K, Wisse BE, Weigle DS: A preprandial rise in plasma ghrelin levels suggests a role in meal initiation in humans. Diabetes 50:1714-1719, 2001

31. Wren AM, Seal LJ, Cohen MA, Brynes AE, Frost GS, Murphy KG, Dhillo WS, Ghatei MA, Bloom SR: Ghrelin enhances appetite and increases food intake in humans. J Clin Endocrinol Metab 86:5992, 2001

32. Chagnon YC, Chung WK, Perusse L, Chagnon M, Leibel RL, Bouchard C: Linkages and associations between the leptin receptor (LEPR) gene and human body composition in the Quebec Family Study. Int J Obes Relat Metab Disord 23:278-286, 1999

33. Clement K, Vaisse C, Lahlou N, Cabrol S, Pelloux V, Cassuto D, Gourmelen M, Dina C, Chambaz J, Lacorte JM, Basdevant A, Bougneres P, Lebouc Y, Froguel P, Guy-Grand B: A mutation in the human leptin receptor gene causes obesity and pituitary dysfunction. Nature 392:398-401, 1998

34. Lahlou N, Clement K, Carel JC, Vaisse C, Lotton C, Le Bihan Y, Basdevant A, Lebouc Y, Froguel P, Roger M, Guy-Grand B: Soluble leptin receptor in serum of subjects with complete resistance to leptin: relation to fat mass. Diabetes 49:1347-1352, 2000

35. Chagnon YC, Wilmore JH, Borecki IB, Gagnon J, Perusse L, Chagnon M, Collier GR, Leon AS, Skinner JS, Rao DC, Bouchard C: Associations between the leptin receptor gene and adiposity in middle-aged Caucasian males from the HERITAGE family study. J Clin Endocrinol Metab 85:29-34, 2000

36. Mattevi VS, Zembrzuski VM, Hutz MH: Association analysis of genes involved in the leptin-signaling pathway with obesity in Brazil. Int J Obes Relat Metab Disord 26:11791185, 2002

37. Gotoda T, Manning BS, Goldstone AP, Imrie H, Evans AL, Strosberg AD, McKeigue PM, Scott J, Aitman TJ: Leptin receptor gene variation and obesity: lack of association in a white British male population. Hum Mol Genet 6:869-876, 1997 
38. Rosmond R, Chagnon YC, Holm G, Chagnon M, Perusse L, Lindell K, Carlsson B, Bouchard C, Bjorntorp P: Hypertension in obesity and the leptin receptor gene locus. J Clin Endocrinol Metab 85:3126-3131, 2000

39. Wauters M, Mertens I, Chagnon M, Rankinen T, Considine RV, Chagnon YC, Van Gaal LF, Bouchard C: Polymorphisms in the leptin receptor gene, body composition and fat distribution in overweight and obese women. Int J Obes Relat Metab Disord 25:714720, 2001

40. Baessler A, Hasinoff MJ, Fischer M, Reinhard W, Sonnenberg GE, Olivier M, Erdmann J, Schunkert $H$, Doering A, Jacob HJ, Comuzzie AG, Kissebah AH, Kwitek AE: Genetic linkage and association of the growth hormone secretagogue receptor (ghrelin receptor) gene in human obesity. Diabetes 54:259-267, 2005

41. Laessle RG, Tuschl RJ, Kotthaus BC, Pirke KM: Behavioral and biological correlates of dietary restraint in normal life. Appetite 12:83-94, 1989

42. TuschI RJ, Platte P, Laessle RG, Stichler W, Pirke KM: Energy expenditure and everyday eating behavior in healthy young women. Am J Clin Nutr 52:81-86, 1990

43. Vogels N, Mariman, ECM, Bouwman, FG, Diepvens, K and Westerterp-Plantenga, MS: Relationship of weight maintenance and dietary restraint with PPAR 2 , GRL and CNTF polymorphisms. Am J Clin Nutr 82:740-746, 2005

44. Vogels N, Westerterp-Plantenga MS: Categorical strategies based on subject characteristics of dietary restraint and physical activity, for weight maintenance. Int J Obes Relat Metab Disord 29:849-857, 2005

45. Torekov SS, Larsen LH, Glumer C, Borch-Johnsen K, Jorgensen T, Holst JJ, Madsen OD, Hansen T, Pedersen O: Evidence of an association between the Arg72 allele of the peptide $Y Y$ and increased risk of type 2 diabetes. Diabetes 54:2261-2265, 2005

46. Lavebratt C, Alpman A, Persson B, Arner P, Hoffstedt J: Common neuropeptide Y2 receptor gene variant is protective against obesity among Swedish men. Int J Obes (Lond) 30:453-459, 2006 
Chapter 7

\section{Postprandial responses in hunger and satiety are associated with the rs9939609 SNP in FTO}

Marcel den Hoed, Margriet S Westerterp-Plantenga, Freek G Bouwman, Edwin CM Mariman and Klaas R Westerterp

Submitted for publication 


\section{Abstract}

Background: The common rs9939609 single nucleotide polymorphism (SNP) in FTO is associated with adiposity, possibly by affecting satiety responsiveness. The current study aims to determine whether postprandial responses in hunger and satiety are associated with rs9939609, taking variation in other relevant candidate genes into account.

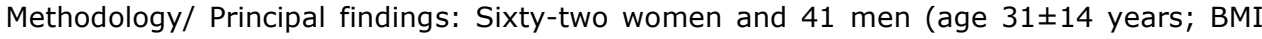
$25.0 \pm 3.1 \mathrm{~kg} / \mathrm{m}^{2}$ ) were genotyped for five SNPs in FTO, DNMT1, DNMT3B, LEP and LEPR. Subjects subsequently received fixed meals provided in energy balance. Hunger and satiety were determined pre- and postprandially using visual analogue scales. A general association test shows a significant association between postprandial responses in hunger and satiety with rs9939609 ( $P=0.036$ and $P=0.050$, respectively). Subjects with low postprandial responses in hunger and satiety are significantly overrepresented among carriers of the TA/AA genotype in rs9939609 (FTO) compared with carriers of the TT genotype (dominant model, $P=0.013$ and additive model, $P=0.020$, respectively). Moreover, multifactor dimensionality reduction shows epistatic interactions for the postprandial response in hunger involving rs9939609 (FTO) and rs992472 (DNMT3B) as well as rs9939609 (FTO) and rs1137101 (LEPR) ( $P=0.050$ and $P=0.040$, respectively). Logistic regression subsequently shows that subjects with a low postprandial response in hunger are overrepresented among carriers of the TA/AA, CC/CA and AG/GG genotypes in rs9939609 (FTO), rs992472 (DNMT3B) and rs1137101 (LEPR), respectively $(\mathrm{n}=39)$, compared with subjects homozygous for at least one protective allele (the TT, AA and AA genotypes, respectively) $(P=0.00001)$. Each SNP has an additional effect.

Conclusions/ significance: Our results confirm a role for FTO in responsiveness to hunger and satiety cues in adults in an experimental setting. The epistatic interaction involving SNPs in FTO, DNTM3B and LEPR for the postprandial response in hunger suggests that DNA methylation, an epigenetic process, affects appetite. 


\section{Introduction}

Twin studies show a heritability of $70-80 \%$ for obesity related phenotypes $(1 ; 2)$. This implies that genetic variation determines to a large extent whether an individual is prone to develop obesity when food availability is not limited. Since obesity is a complex metabolic disorder, a genetic predisposition for obesity is anticipated to consist of many nucleic variants all exerting a small effect. In line with this, Frayling et al. show that the variance in BMI explained by a variant in the fat mass and obesity-associated gene (FTO) (rs9939609) is approximately $1 \%$ (3). However, the minor allele frequency of this single nucleotide polymorphism (SNP) is as high as $39 \%$, resulting in a population attributable risk for obesity and overweight of approximately $20 \%$ and $13 \%$, respectively (3). Since then, the association between adiposity and SNPs in FTO has been confirmed in many genome wide association $(4 ; 5)$ and candidate gene studies $(6-8)$, together comprising over 38,000 individuals.

Frayling et al. show that the A allele in rs9939609 is not associated with fetal growth, but with increases in BMI and obesity in children from the age of 7 onward, persisting into the prepubertal period and beyond (3). In young children, the association of the A allele with body mass is almost exclusively attributable to changes in fat mass (3). In adults, individuals with the AA genotype on average weigh $3 \mathrm{~kg}$ more than those with the TT genotype and each A allele increases BMI with approximately $0.4 \mathrm{~kg} / \mathrm{m}^{2}(3)$.

The physiological pathway by which variation in the FTO gene influences the risk for developing obesity largely remains to be established. Recent studies show that FTO is highly expressed in adipose tissue as well as in the arcuate, paraventricular, dorsomedial and ventromedial nuclei of the hypothalamus (9-11). These sites are involved in food intake regulation, suggesting that FTO may influence adiposity by affecting appetite. Indeed, energy intake from food is higher in children carrying the TA/AA genotype than in children with the $\Pi$ genotype $(12 ; 13)$. In addition, Wardle et al. show that children aged 8 to 11 years carrying the TA/AA genotype in rs9939609 are characterized by a reduced responsiveness to satiety cues $(14 ; 15)$, thereby increasing the risk for overeating and developing obesity (16).

Whether or not FTO affects responsiveness to satiety cues in adults is currently unknown. Moreover, the mechanism by which FTO affects appetite remains to be established. Gerken et al. show that FTO may regulate the transcription of genes involved in metabolism by catalyzing DNA demethylation (10). Moreover, Qi et al. suggest that FTO likely forms part of a pathway mediating the neuroregulation, with blocking of the leptin signal inhibiting downstream changes in adipose tissue that induce the expression of FTO (8). The aim of the present study is to find out whether the common rs9939609 variant in FTO is associated with hunger and satiety responsiveness in adults. Given the proposed role of FTO as a DNA demethylation catalyst and the anticipated interaction between FTO and leptin, common variants in the genes encoding DNA methyltransferases (DNMT) 1 and $3 \mathrm{~B}$, as well as for leptin ( $L E P)$ and the leptin receptor (LEPR) are taken into account. The rationale for the SNPs chosen is provided in the methods section. 


\section{Results}

The genotypic and allelic distributions of the determined SNPs are provided in Table 1. All SNPs are in Hardy Weinberg equilibrium and BMI is similar between genotypes for all SNPs, including the rs9939609 variant in FTO. BMI is also similar between responders and non-responders for the postprandial responses in hunger and satiety. Correcting the associations for age and/or BMI does not change the results.

Table 1: Genotypic and allelic distributions per single nucleotide polymorphism

\begin{tabular}{|c|c|c|c|c|c|c|c|}
\hline Gene & SNP & Genotype & $F(n)$ & $\mathrm{F}(\%)$ & Allele & $\mathrm{F}(\%)$ & $\mathrm{HWE}^{\mathrm{a}}$ \\
\hline \multirow[t]{3}{*}{ FTO } & rs9939609 & $\mathrm{TT}$ & 38 & 36.9 & $\mathrm{~T}$ & 60.7 & 0.97 \\
\hline & $\mathrm{T}>\mathrm{A}$ & TA & 49 & 47.6 & $A$ & 39.3 & \\
\hline & & $A A$ & 16 & 15.5 & & & \\
\hline \multirow[t]{3}{*}{ DNMT1 } & rs2290684 & GG & 30 & 29.1 & G & 53.9 & 0.97 \\
\hline & $\mathrm{G}>\mathrm{A}$ & GA & 51 & 49.5 & A & 46.1 & \\
\hline & & $A A$ & 22 & 21.4 & & & \\
\hline \multirow[t]{3}{*}{ DNMT3B } & rs992472 & $\mathrm{CC}$ & 38 & 36.9 & C & 60.2 & 0.78 \\
\hline & $C>A$ & CA & 48 & 46.6 & A & 39.8 & \\
\hline & & $A A$ & 17 & 16.5 & & & \\
\hline \multirow[t]{3}{*}{$\angle E P$} & rs7799039 & GG & 29 & 28.2 & G & 51.0 & 0.38 \\
\hline & $-2548 G>A$ & GA & 47 & 45.6 & A & 49.0 & \\
\hline & & AA & 27 & 26.2 & & & \\
\hline \multirow[t]{3}{*}{$\angle E P R$} & rs1137101 & AA & 29 & 28.2 & A & 52.9 & 0.95 \\
\hline & $668 A>G$ & AG & 51 & 49.5 & G & 47.1 & \\
\hline & Gln223Arg & GG & 23 & 22.3 & & & \\
\hline
\end{tabular}

$\mathrm{F}$, Frequency, either absolute ( $\mathrm{n}$ ) or relative (\%); a $P$-value obtained from the $\chi^{2}$ test of Hardy Weinberg equilibrium (HWE). For all single nucleotide polymorphisms (SNPS), a $100 \%$ success rate was accomplished.

\section{Single-SNP associations for rs9939609}

Baseline values for hunger and satiety are similar between genotypes. A general association test reveals a significant association between the postprandial response in hunger (area under the curve) and the rs9939609 SNP $(P=0.036)$. Although we cannot exclude an additive mode of inheritance $(P=0.051)$, a dominant model fits the data best, with subjects with a low postprandial response (decrease) in hunger being overrepresented among carriers of the TA/AA genotype compared with subjects with the TT genotype $(P=0.013$, Table 2, Figure $1 \mathrm{~A})$. A significant association is also observed between the absolute postprandial response in satiety (absolute increase) and rs9939609 $(P=0.050)$. An additive model fits the data best, with subjects with a low postprandial response (increase) in satiety being overrepresented among subjects with the TA/AA genotype in rs9939609 compared with the TT genotype ( $P=0.020$, Table 2, Figure 1B). However, a dominant $(P=0.065)$ or recessive $(P=0.049)$ model cannot be excluded for the latter association. 
Table 2: Associations between postprandial responses in hunger and satiety with rs9939609 obtained using (multiple) logistic regression

\begin{tabular}{|c|c|c|c|c|c|c|}
\hline SNP & Phenotype & $\begin{array}{l}\text { MOI/ } \\
\text { Genotype }\end{array}$ & OR & $95 \%$ & $\mathrm{CI}$ & $P$-value \\
\hline rs9939609 (FTO) & Hunger & Dominant & 0.33 & 0.14 & 0.79 & $1.3 \cdot 10^{-1}$ \\
\hline rs9939609 (FTO) & Satiety & Additive & 0.49 & 0.27 & 0.90 & $2.0 \cdot 10^{-2}$ \\
\hline $\begin{array}{l}\text { rs9939609 (FTO) \& } \\
\text { rs992472 (DNMT3B) }\end{array}$ & Hunger & $\begin{array}{l}\text { TA/AA \& } \\
\text { CC/CA }\end{array}$ & 0.20 & 0.08 & 0.48 & $2.5 \cdot 10^{-4}$ \\
\hline $\begin{array}{l}\text { rs9939609 (FTO) \& } \\
\text { rs1137101 (LEPR) }\end{array}$ & Hunger & $\begin{array}{l}\text { TA/AA \& } \\
\text { AG/GG }\end{array}$ & 0.18 & 0.08 & 0.44 & $1.3 \cdot 10^{-4}$ \\
\hline rs9939609 (FTO) \& & Hunger & TA/AA \& & 0.12 & 0.05 & 0.32 & $1.3 \cdot 10^{-5}$ \\
\hline $\begin{array}{l}\text { rs992472 (DNMT3B) \& } \\
\text { rs1137101 (LEPR) }\end{array}$ & & $\begin{array}{l}\text { CC/CA \& } \\
A G / G G\end{array}$ & & & & \\
\hline rs9939609 (FTO) & Hunger & TA/AA & 0.26 & 0.10 & 0.67 & $5.2 \cdot 10^{-3}$ \\
\hline rs992472 (DNMT3B) & & $\mathrm{CC} / \mathrm{CA}$ & 0.25 & 0.07 & 0.91 & $3.6 \cdot 10^{-2}$ \\
\hline rs1137101 (LEPR) & & $\mathrm{AG} / \mathrm{GG}$ & 0.32 & 0.11 & 0.90 & $3.0 \cdot 10^{-2}$ \\
\hline
\end{tabular}

SNP, the single nucleotide polymorphism included in the model; Hunger, the postprandial area under the curve for hunger; Satiety, the absolute postprandial response in satiety, that is, the absolute difference between the baseline value and the maximal postprandial value; MOI, mode of inheritance; OR, odds ratio; 95\% CI, 95\% confidence interval for odds ratio; For epistatic interactions, the effects shown are relative to the subjects with the TT genotype (for FTO) and the AA genotype (for DNMT3B and $L E P R)$. $P$-values $<0.05$ were considered statistically significant.
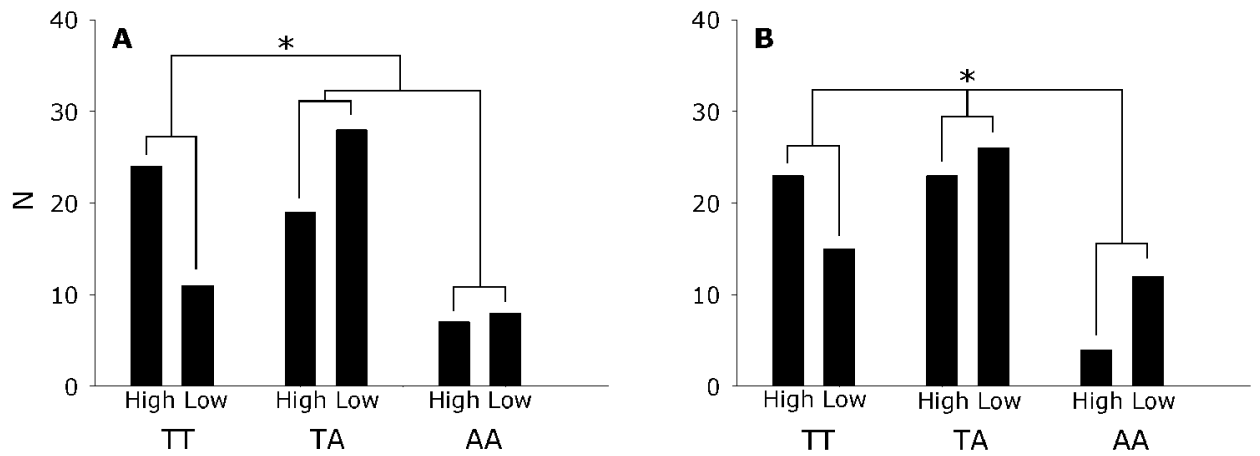

Figure 1. Postprandial responses in hunger and satiety as a function of the rs9939609 SNP in FTO. The number of subjects with a high and low postprandial response in hunger (Figure $1 \mathrm{~A}$, dominant model) and satiety (Figure 1B, additive model) expressed as a function of genotype in rs9939609. * $P<0.05$.

\section{Epistatic interactions involving rs9939609}

Multifactor dimensionality reduction (MDR) reveals two significant epistatic interactions for the postprandial response in hunger (area under the curve) involving rs9939609. One interaction is shown with rs992472 (DNMT3B), the other with rs1137101 (LEPR) (Prediction accuracy $66 \% \%, P=0.05$ and $68 \% \%, P=0.04$, respectively). Logistic regression 
shows that subjects with a low postprandial response in hunger are overrepresented among subjects carrying the TA/AA genotype in rs9939609 and the CC/CA genotype in rs992472 (DNMT3B) compared with subjects with the TT and/or AA genotypes in these SNPs, respectively $(P=0.00025)$ (Table 2 , Figure 2$)$. Subjects with a low postprandial response in hunger are also overrepresented among individuals carrying the TA/AA genotype in rs9939609 and the AG/GG genotype in rs1137101 (LEPR) compared with subjects with the $\Pi$ and/or AA genotype in these SNPs, respectively $(P=0.00013)$ (Table 2, Figure 3). When evaluating the combined effect of the three SNPs, subjects with a low postprandial response in hunger are significantly overrepresented among carriers of the risk allele in all three SNPs, that is, subjects with the TA/AA, CC/CA and AG/GG genotypes in rs9939609, rs992472 and rs1137101, respectively, compared with subjects homozygous for at least one protective allele (TT, AA or AA, respectively) $(P=0.000013)$ (Table 2, Figure 4). Each SNP has an additional effect (Table 2).
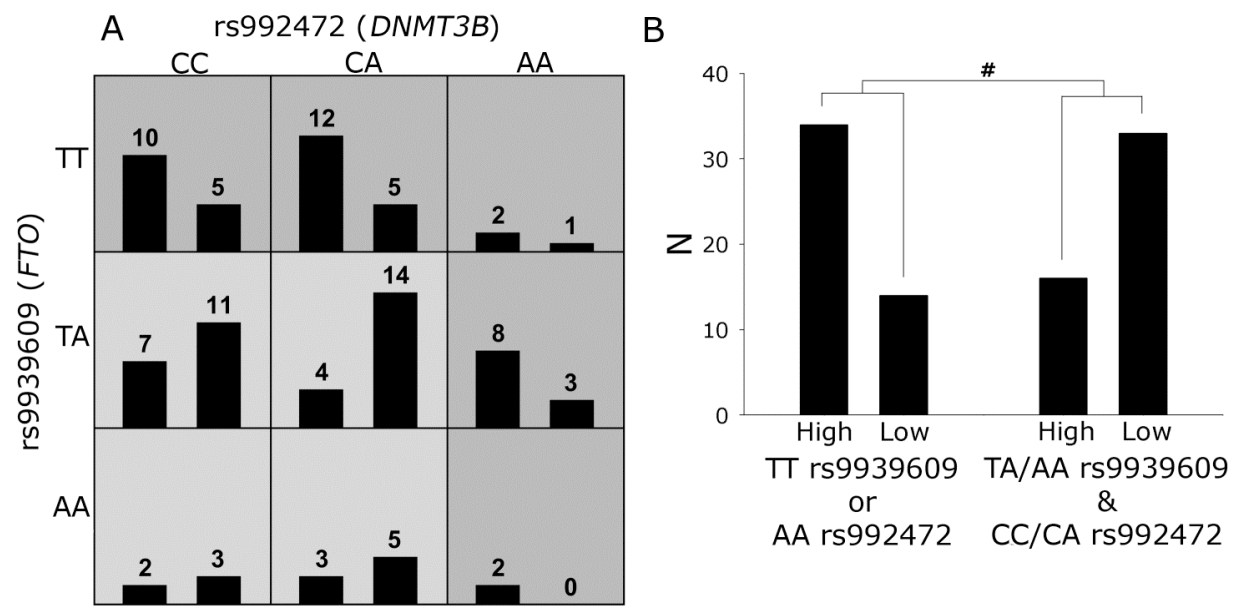

Figure 2. Epistatic interaction for the postprandial response in hunger involving rs9939609 (FTO) and rs992472 (DNMT3B). Figure 2A shows the output obtained using Multifactor Dimensionality Reduction. The squares represent possible combinations of genotypes with the bars on the left representing the number of subjects with a strong postprandial decrease in hunger and the bars on the right the number of subjects with a low postprandial decrease. Figure 2B shows the statistical interpretation of the model obtained using logistic regression. Subjects with the TA/AA genotype in rs9939609 and the CC/CA genotype in rs992472 are compared with subjects with the TT and/or AA genotype in these SNPS, respectively. \# $P<0.001$.

\section{Discussion}

The main result of the present study is that adult subjects with low postprandial responses in hunger and satiety are overrepresented among carriers of the TA/AA genotype in rs9939609 (FTO) compared with subjects with the TT genotype, independent of BMI. This implies that the results of Wardle et al., who show a reduced sensitivity to satiety cues in children with the AA compared with the TT genotype (14), are replicated in adults in an experimental setting. The increased adiposity associated with the TA and AA 
genotypes in rs9939609 can thus at least partly be explained by reduced postprandial responses in hunger and satiety, which increases the risk for overeating (16). The strength of the present study lies in the valid and accurate measurement of the phenotype, that is, the postprandial responses of hunger and satiety. Future studies with larger samples are required to draw firm conclusions about the most appropriate mode of inheritance.

In addition to the univariate associations shown for the rs9939609 SNP, a significant interaction is observed for the postprandial response in hunger, involving the rs9939609 SNP in FTO together with SNPs in the DNMT3B and/or LEPR genes. Subjects with a low postprandial response in hunger are significantly overrepresented among carriers of the TA/AA genotype in rs9939609 who also carry the CC/CA genotype in rs992472 (DNMT3B) and/or the AG/GG genotype in rs1137101 (LEPR), compared with subjects homozygous for one or more protective alleles in these SNPs.

Gerken et al. recently showed that FTO catalyzes Fe(II) and 2-oxoglutarate dependent DNA demethylation. This implies that FTO may regulate the transcription of genes involved in metabolism via DNA demethylation (10). DNA methylation is a major epigenetic modification that consists of the addition of a methyl group to the 5-position of cytosine within a CpG dinucleotide, thereby altering gene activity (17). Hypermethylation of the promoter and coding region of a gene decreases its transcription, which silences the gene. Hypomethylation on the other hand enhances the binding of transcription factors, thereby improving gene transcription (18).

Cellular DNA methylation is mediated by a complex interplay of the DNA methyltransferases (DNMTs) DNMT1, 3A and 3B. DNMT1 was originally thought to be responsible for the maintenance of pre-existing methylation patterns after DNA replication, whereas DNMT3A and 3B were considered essential for de novo DNA methylation after embryo implantation (17-19). More recent evidence suggests that DNMT1 and DNMT3B are jointly responsible for both maintenance of DNA methylation profiles and de novo DNA methylation $(17 ; 20 ; 21)$. DNA methylation appears to play a role in body weight regulation as well: Waterland et al. show that providing a hypermethylating dietary supplement to Agouti $\left(A^{v y}\right)$ mice prevents the transgenerational increase in body weight that occurs without supplementation (22). Given the role of FTO as a DNA demethylation catalyst (10) and given the apparent role of DNA methylation in body weight regulation, the association between the postprandial response in hunger and satiety and the rs9939609 variant in FTO was additionally determined whilst taking variants in DNMT1 and DNMT3B into account. Of these variants, the rs992472 variant in DNMT3B appears to be relevant for the effect of rs9939609 in FTO on the postprandial response in hunger.

Subjects with a low postprandial response in hunger are overrepresented among carriers of the TA/AA genotype in rs9939609 (FTO) who also carry the CC/CA genotype in rs992472 (DNMT3B), compared with subjects with the $\Pi$ and/or AA genotype in these SNPs, respectively. The rs992472 SNP in DNMT3B is located in the same linkage disequilibrium (LD) block as the rs2424913 C>T SNP in the same gene, for which the minor allele $(T)$ is associated with an increased DNMT3B promoter activity. Additionally, the minor allele in rs2424913 is associated with the risk for developing various types of cancer, probably by aberrant de novo methylation of $\mathrm{CpG}$ islands in some tumor suppressor 
genes (23). Given the LD between rs992472 and rs2424913, a post hoc analysis was performed to determine whether the epistatic interaction involving rs9939609 and rs992472 for the postprandial response in hunger was confirmed for rs9939609 and rs2424913. As this interaction was observed ( $P=0.002$, data not shown), it is tempting to speculate that a genotype-driven decrease in the capacity for de novo DNA methylation together with an increased capacity for DNA demethylation underlies the reduced postprandial response in hunger in subjects carrying the CC/CA genotype in rs992472 and the TA/AA genotype in rs9939609, respectively. Whether overall DNA methylation status is indeed lower in subjects with this genetic predisposition will have to be addressed in future studies. Nevertheless, the interaction involving rs9939609 and rs992472/ rs2424913 suggests that DNA methylation is a relevant process for food intake regulation in vivo.

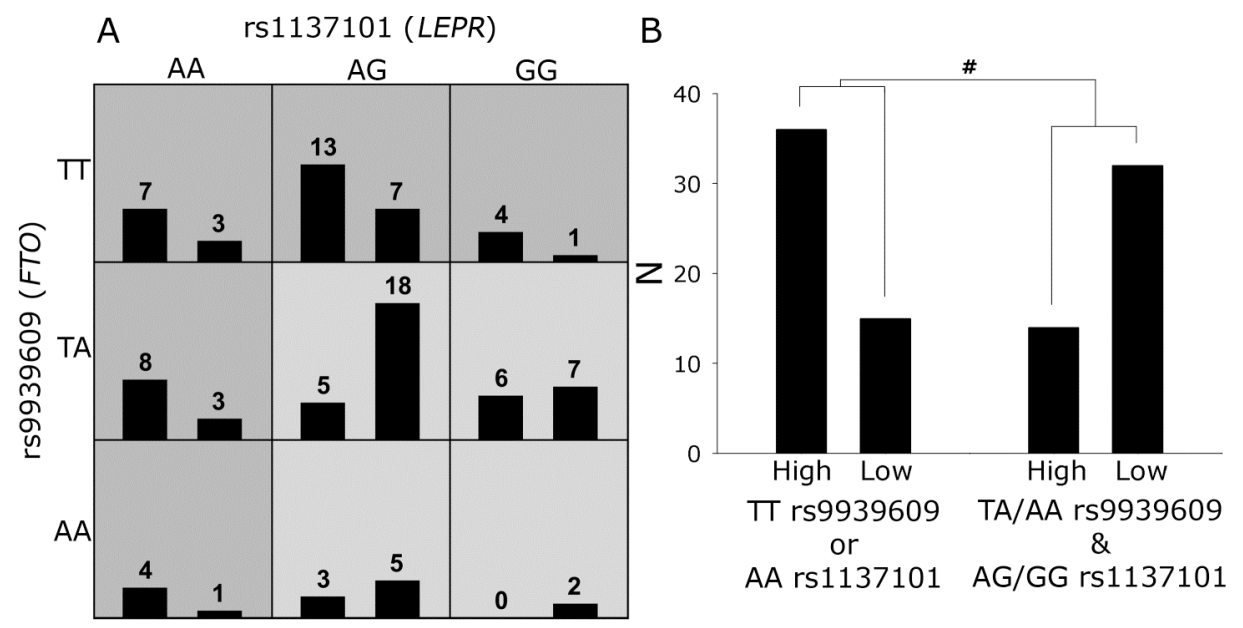

Figure 3. Epistatic interaction for the postprandial response in hunger involving rs9939609 (FTO) and rs1137101 (LEPR). Figure $3 \mathrm{~A}$ and $3 \mathrm{~B}$ are analogue to Figure $2 \mathrm{~A}$ and 2B. In Figure 3B, subjects with the TA/AA genotype in rs9939609 and the AG/GG genotype in rs1137101 are compared with subjects with the $T$ and/or AA genotype in these SNPs, respectively. \# $P<0.001$.

The rs1137101 SNP in LEPR, resulting in amino acid substitution Gln223Arg, was hypothesized earlier to affect the functionality of the leptin receptor, with the G allele (Arg) resulting in a reduced leptin sensitivity $(24 ; 25)$. Resistance to leptin is known to increase food intake, in extreme cases resulting in early-onset morbid obesity $(26 ; 27)$. The present study shows that the AG and GG genotypes in rs1137101 are more frequently present among subjects with a low postprandial response in hunger than would be expected based on chance when accompanied by the TA or AA genotype in rs9939609 (FTO). In other words, subjects hypothesized to be leptin resistant are characterized by a blunted postprandial response in hunger when also carrying the risk allele in rs9939609. This role for leptin is in line with results from Westerterp-Plantenga et al., who show in obese men on an energy-restricted diet that intravenous administration of leptin in- 
creases serum leptin levels and decreases postabsorptive as well as general feelings of hunger compared with placebo (28). As for the role of FTO; Qi et al., hypothesized that blocking leptin may inhibit downstream changes in adipose tissue inducing the expression of FTO. This is in line with the results of Stratigopoulos et al., who show a decreased FTO expression in the hypothalamus after fasting. However, the fasting-induced decrease in FTO expression observed by Stratigopoulos et al. was not mediated by leptin (11). Our results suggest that a decreased leptin sensitivity only functionally affects FTO expression in subjects with the TA/AA genotype in rs9939609.

The interaction between rs9939609 and rs1137101 probably affects the postprandial response in hunger via a mechanism other than DNA methylation. After all, if blocking leptin indeed decreases FTO expression (8), the catalytic capacity for DNA demethylation will be decreased, thereby increasing the relative capacity for DNA methylation. Based on the results of Waterland et al., this is anticipated to reduce the risk for obesity, which is the exact opposite of what is expected when the postprandial response in hunger is decreased. This implies that the impact of this alternative mechanism on the postprandial response in hunger should not be underestimated. Regardless of the mechanism responsible however, combining an increased drive to eat resulting from a reduced postprandial response in hunger with the current obesogenic environment of Westernized societies in which high-fat foods are abundant and readily available (29) provides a perfect recipe for the first obesity epidemic in human history.

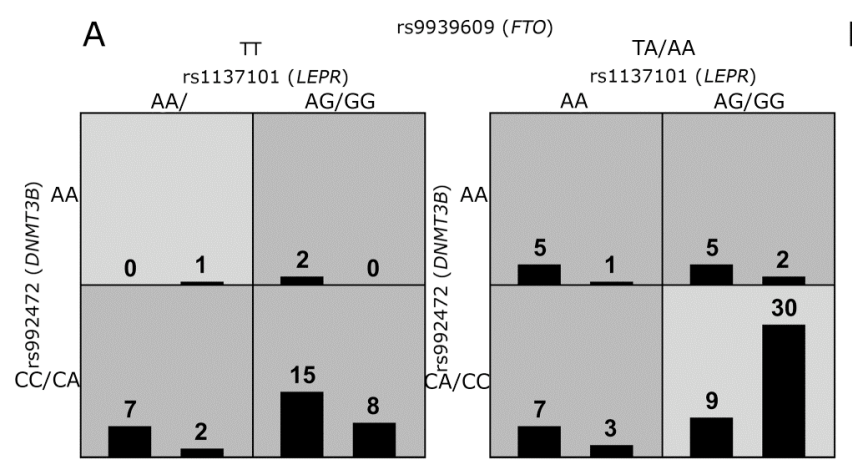

B

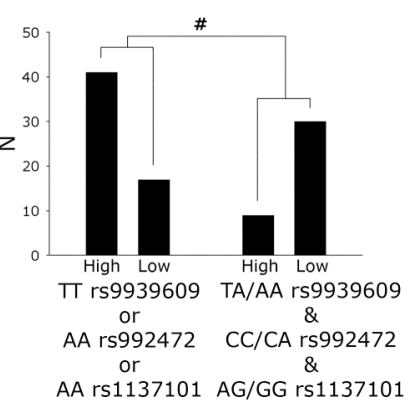

Figure 4. Three-way interaction for the postprandial response in hunger. In Figure $4 A$, the panel on the left shows the epistatic interaction for the postprandial response in hunger involving the rs 992472 and rs1137101 SNPs (DNMT3B and $\angle E P R$, respectively) for subjects with the TT genotype in rs9939609 (FTO). The panel on the right shows the interaction for subjects with the TA/AA genotype in rs9939609. In Figure 4B, subjects with the TA/AA genotype in rs9939609, the CC/CA genotype in rs992472 and the AG/GG genotype in rs1137101 were compared with subjects homozygous for at least one protective allele in these SNPs, that is, the other combinations combined. $P<0.0001$.

We did not confirm the association between BMI and the rs9939609 variant shown in previous studies. This can be explained by the range in BMI in our population, as well as by the character of the study and its concomitant sample size. In the current experimen- 
tal study, 103 subjects were recruited with a BMI ranging from 19 to 31 . In fact, only five subjects with a BMI over 30 were included. This contrasts sharply with case-control studies $(4 ; 7)$ as well as cohort studies $(3 ; 5)$ in which the association between BMI and rs9939609 was evaluated. In fact, the lack of association between BMI and the rs9939609 SNP is consistent with the results from Frayling et al., who did not observe a significant association between BMI and rs9939609 genotype in samples comprising less than 1000 individuals (3). This suggests that BMI, which incorporates both fat mass and fat-free mass, is probably not a suitable parameter for adiposity in genetic studies with a relatively small sample size.

In conclusion, evidence is provided for an association between postprandial responses in hunger and satiety with the rs9939609 SNP in FTO, with the TA/AA genotype predisposing individuals to a reduced postprandial response in hunger and satiety. The effect of the variant in FTO on the postprandial response in hunger appears to be mediated by an epistatic interaction involving variants in DNMT3B and $L E P R$. The latter interaction suggests that DNA methylation, an epigenetic process, is involved in food intake regulation.

\section{Methods}

Data were collected from intervention studies on the effect of proteins and/or protein contents on the postprandial responses in (an)orexigenic hormones as well as hunger and satiety (30-32). Subjects came to the university in the morning and received fixed meals provided in energy balance and according to energy requirement as calculated using the formula of Harris and Benedict (33). On average, the meals contained 27, 45 and 28 percent of energy from protein, carbohydrate and fat, respectively. The study conformed to the standards set by the Declaration of Helsinki and the local Ethics Committee approved the study. Subjects provided written informed consent before participating.

\section{Subjects and phenotypes}

Postprandial responses in hunger and satiety were determined in 103 subjects of Western European descent (62 women, 41 men, aged $31 \pm 14$ years, BMI $25.0 \pm 3.1 \mathrm{~kg} / \mathrm{m}^{2}$ ) using visual analogue scales. After adjusting for baseline levels, the postprandial responses in hunger and satiety were determined. For both hunger and satiety, subjects were characterized as having a high or low postprandial response based on 1) the initial rate of the response; 2 ) the absolute response, that is, the difference between the baseline level and the minimal/maximal postprandial level obtained; 3 ) the postprandial area under the curve, measured until 3-4.5 h postprandially. For 6 subjects, the postprandial area under the curve could not be determined for hunger due to a lack of sufficient data. This implies a total of 97 subjects for this phenotype. A high postprandial response can either refer to a strong postprandial decrease (for hunger) or increase (for satiety). 


\section{DNA isolation and SNP genotyping}

Genomic DNA was isolated from peripheral blood leukocytes using the QIAamp blood kit from Qiagen (Amsterdam, The Netherlands). Besides the rs9939609 SNP in FTO, SNPs were selected in the DNMT1, DNMT3B, LEP and LEPR genes. To ensure an ample number of subjects are homozygous for the minor alleles, SNPs were only considered candidates when the minor allele frequency in Europeans was at least $25 \%$ as indicated by the SNP public database (dbSNP; http://www.ncbi.nlm.nih.gov/SNP). SNPs that were associated earlier with relevant phenotypes, such as gene expression, protein levels or protein activity, were favoured in the selection process. This resulted in the selection of five SNPS (Table 1): the aforementioned intronic A>T SNP in FTO (rs9939609) (3-5; 8; 12-14); an intronic A>G SNP in DNMT1 (rs2290684), an intronic C>A SNP in DNMT3B (rs992472), the $-2548 G>A$ SNP in the coding region of $L E P$ (rs7799039) $(34 ; 35)$ and the $668 \mathrm{~A}>\mathrm{G}$ SNP in $L E P R$, resulting in amino acid substitution GIn223Arg (rs1137101) $(24 ; 25 ; 36)$;

Genotyping was performed using commercially available TaqMan SNP genotyping assays from Applied Biosystems (Foster City, California, USA). The procedure was performed according to the manufacturer's protocol and measured on an Applied Biosystems 7900 HT Fast Real-Time PCR System. Allelic calls were determined semi-automatically using the allelic discrimination software of Applied Biosystems.

\section{Statistics}

\section{Descriptive analysis}

Postprandial responses were dichotomized using sex- and study-specific median values, resulting in an approximately equal number of subjects with a high and low postprandial response for each phenotype, meanwhile taking sex into account $(' 0$ ' $=$ low postprandial response, ' 1 ' = high postprandial response).

Age and BMI were not normally distributed among subjects. Therefore, the Kruskal Wallis and Mann-Whitney $U$ tests were used to determine the associations between BMI and rs9939609 and between the postprandial responses and BMI, respectively. These variables were subsequently log-transformed for further analyses.

\section{Association analysis}

Before the association analyses were performed, the effects of potential covariates were evaluated for the postprandial responses in hunger and satiety. The influence of age and BMI was evaluated. Covariates were incorporated into the model when $P<0.05$. A general association test was performed without assuming a mode of inheritance by entering the genotype in the optimized model (with the significant covariates) as two class (dummy) variables. The mode of inheritance was further investigated by testing an additive, dominant and recessive model.

To identify epistatic interactions, the multifactor dimensionality reduction method (MDR) was used. MDR is a frequently used multi-locus method that was applied as previously 
described by Heidema et al. (37). Briefly, we applied the MDR software (http://www.epistasis.org) to our dataset using 10-fold cross-validation to determine the best model for main SNP-SNP effects. The 10 -fold cross-validation was repeated 10 times, using a different seed value each time to protect against chance divisions of the dataset. Finally, applying the MDR permutation module, we tested the significance of the testing accuracy of the best model by forming a 1000 datasets with the case status permuted randomly. This way, we validated for each phenotype whether the model was significantly associated with responder status. Subsequently, logistic regression was used for the significant models to obtain a statistical interpretation of the results (37). $P$ values $<0.05$ were considered statistically significant.

\section{Acknowledgements}

The authors would like to thank Margriet Veldhorst, Ananda Hochstenbach-Waelen, Astrid Smeets, Kristel Diepvens and Manuela Lejeune for their contributions in acquiring the data on postprandial responses in hunger and satiety. 


\section{References}

1. Faith MS, Pietrobelli A, Nunez C, Heo M, Heymsfield SB, Allison DB: Evidence for independent genetic influences on fat mass and body mass index in a pediatric twin sample. Pediatrics 104:61-67, 1999

2. Stunkard AJ, Foch TT, Hrubec Z: A twin study of human obesity. Jama 256:51-54, 1986

3. Frayling TM, Timpson NJ, Weedon MN, Zeggini E, Freathy RM, Lindgren CM, Perry JR, Elliott KS, Lango H, Rayner NW, Shields B, Harries LW, Barrett JC, Ellard S, Groves CJ, Knight B, Patch AM, Ness AR, Ebrahim S, Lawlor DA, Ring SM, Ben-Shlomo Y, Jarvelin MR, Sovio U, Bennett AJ, Melzer D, Ferrucci L, Loos RJ, Barroso I, Wareham NJ, Karpe F, Owen KR, Cardon LR, Walker M, Hitman GA, Palmer CN, Doney AS, Morris AD, Smith GD, Hattersley AT, McCarthy MI: A common variant in the FTO gene is associated with body mass index and predisposes to childhood and adult obesity. Science 316:889894, 2007

4. Hinney A, Nguyen TT, Scherag A, Friedel S, Bronner G, Muller TD, Grallert H, Illig T, Wichmann HE, Rief W, Schafer H, Hebebrand J: Genome wide association (GWA) study for early onset extreme obesity supports the role of fat mass and obesity associated gene (FTO) variants. PLoS ONE 2:e1361, 2007

5. Scuteri A, Sanna S, Chen WM, Uda M, Albai G, Strait J, Najjar S, Nagaraja R, Orru M, Usala G, Dei M, Lai $S$, Maschio A, Busonero $F$, Mulas $A$, Ehret GB, Fink $A A$, Weder $A B$, Cooper RS, Galan P, Chakravarti A, Schlessinger D, Cao A, Lakatta E, Abecasis GR: Genome-wide association scan shows genetic variants in the FTO gene are associated with obesity-related traits. PLoS Genet 3:e115, 2007

6. Dina C, Meyre D, Gallina S, Durand E, Korner A, Jacobson P, Carlsson LM, Kiess W, Vatin V, Lecoeur C, Delplanque J, Vaillant E, Pattou F, Ruiz J, Weill J, Levy-Marchal C, Horber F, Potoczna N, Hercberg S, Le Stunff C, Bougneres P, Kovacs P, Marre M, Balkau B, Cauchi S, Chevre JC, Froguel P: Variation in FTO contributes to childhood obesity and severe adult obesity. Nat Genet 39:724-726, 2007

7. Do R, Bailey SD, Desbiens K, Belisle A, Montpetit A, Bouchard C, Perusse L, Vohl MC, Engert JC: Genetic variants of FTO influence adiposity, insulin sensitivity, leptin levels, and resting metabolic rate in the Quebec Family Study. Diabetes 57:1147-1150, 2008

8. Qi L, Kang K, Zhang C, van Dam RM, Kraft P, Hunter D, Lee CH, Hu FB: FTO Gene Variant Is Associated with Obesity: Longitudinal Analyses in Two Cohort Studies and Functional Test. Diabetes, 2008

9. Fredriksson R, Hagglund M, Olszewski PK, Stephansson O, Jacobsson JA, Olszewska AM, Levine AS, Lindblom J, Schioth HB: The obesity gene, FTO, is of ancient origin, upregulated during food deprivation and expressed in neurons of feeding-related nuclei of the brain. Endocrinology 149:2062-2071, 2008

10. Gerken T, Girard CA, Tung YC, Webby CJ, Saudek V, Hewitson KS, Yeo GS, McDonough MA, Cunliffe S, McNeill LA, Galvanovskis J, Rorsman P, Robins P, Prieur X, Coll AP, Ma M, Jovanovic Z, Farooqi IS, Sedgwick B, Barroso I, Lindahl T, Ponting CP, Ashcroft FM, O'Rahilly S, Schofield CJ: The obesity-associated FTO gene encodes a 2-oxoglutaratedependent nucleic acid demethylase. Science 318:1469-1472, 2007

11. Stratigopoulos G, Padilla SL, Leduc CA, Watson E, Hattersley AT, McCarthy MI, Zeltser LM, Chung WK, Leibel RL: Regulation of Fto/Ftm gene expression in mice and humans. Am J Physiol Regul Integr Comp Physiol 294:R1185-1196, 2008

12. Timpson NJ, Emmett PM, Frayling TM, Rogers I, Hattersley AT, McCarthy MI, Davey Smith G: The fat mass- and obesity-associated locus and dietary intake in children. Am J Clin Nutr 88:971-978, 2008

13. Cecil JE, Tavendale R, Watt P, Hetherington MM, Palmer CN: An obesity-associated FTO gene variant and increased energy intake in children. N Engl J Med 359:2558-2566, 2008 
14. Wardle J, Carnell S, Haworth CM, Farooqi IS, O'Rahilly S, Plomin R: Obesity associated genetic variation in FTO is associated with diminished satiety. J Clin Endocrinol Metab 93:3640-3643, 2008

15. Wardle J, Llewellyn C, Sanderson S, Plomin R: The FTO gene and measured food intake in children. Int J Obes (Lond) 33:42-45, 2009

16. Schachter S: Obesity and eating. Internal and external cues differentially affect the eating behavior of obese and normal subjects. Science 161:751-756, 1968

17. Robertson KD, Wolffe AP: DNA methylation in health and disease. Nat Rev Genet 1:1119,2000

18. Lee SJ, Jeon HS, Jang JS, Park SH, Lee GY, Lee BH, Kim CH, Kang YM, Lee WK, Kam S, Park RW, Kim IS, Cho YL, Jung TH, Park JY: DNMT3B polymorphisms and risk of primary lung cancer. Carcinogenesis 26:403-409, 2005

19. Wang J, Bhutani M, Pathak AK, Lang W, Ren H, Jelinek J, He R, Shen L, Issa JP, Mao L: Delta $D N M T 3 B$ variants regulate DNA methylation in a promoter-specific manner. Cancer Res 67:10647-10652, 2007

20. Kangaspeska S, Stride B, Metivier R, Polycarpou-Schwarz M, Ibberson D, Carmouche RP, Benes V, Gannon F, Reid G: Transient cyclical methylation of promoter DNA. Nature 452:112-115, 2008

21. Li E, Bestor TH, Jaenisch R: Targeted mutation of the DNA methyltransferase gene results in embryonic lethality. Cell 69:915-926, 1992

22. Waterland RA, Travisano M, Tahiliani KG, Rached MT, Mirza S: Methyl donor supplementation prevents transgenerational amplification of obesity. Int $\mathrm{J}$ Obes (Lond) 32:1373-1379, 2008

23. Shen H, Wang L, Spitz MR, Hong WK, Mao L, Wei Q: A novel polymorphism in human cytosine DNA-methyltransferase-3B promoter is associated with an increased risk of lung cancer. Cancer Res 62:4992-4995, 2002

24. Chagnon YC, Chung WK, Perusse L, Chagnon M, Leibel RL, Bouchard C: Linkages and associations between the leptin receptor (LEPR) gene and human body composition in the Quebec Family Study. Int J Obes Relat Metab Disord 23:278-286, 1999

25. Yiannakouris N, Yannakoulia M, Melistas L, Chan JL, Klimis-Zacas D, Mantzoros CS: The Q223R polymorphism of the leptin receptor gene is significantly associated with obesity and predicts a small percentage of body weight and body composition variability. J Clin Endocrinol Metab 86:4434-4439, 2001

26. Clement K, Vaisse C, Lahlou N, Cabrol S, Pelloux V, Cassuto D, Gourmelen M, Dina C, Chambaz J, Lacorte JM, Basdevant A, Bougneres P, Lebouc Y, Froguel P, Guy-Grand B: A mutation in the human leptin receptor gene causes obesity and pituitary dysfunction. Nature 392:398-401, 1998

27. Lahlou N, Clement K, Carel JC, Vaisse C, Lotton C, Le Bihan Y, Basdevant A, Lebouc Y, Froguel P, Roger M, Guy-Grand B: Soluble leptin receptor in serum of subjects with complete resistance to leptin: relation to fat mass. Diabetes 49:1347-1352, 2000

28. Westerterp-Plantenga MS, Saris WH, Hukshorn CJ, Campfield LA: Effects of weekly administration of pegylated recombinant human $\mathrm{OB}$ protein on appetite profile and energy metabolism in obese men. Am J Clin Nutr 74:426-434, 2001

29. O'Rahilly S, Farooqi IS: Human obesity: a heritable neurobehavioral disorder that is highly sensitive to environmental conditions. Diabetes 57:2905-2910, 2008

30. Lejeune MP, Westerterp KR, Adam TC, Luscombe-Marsh ND, Westerterp-Plantenga MS: Ghrelin and glucagon-like peptide 1 concentrations, 24-h satiety, and energy and substrate metabolism during a high-protein diet and measured in a respiration chamber. Am J Clin Nutr 83:89-94, 2006

31. Smeets AJ, Soenen S, Luscombe-Marsh ND, Ueland O, Westerterp-Plantenga MS: Energy expenditure, satiety, and plasma ghrelin, glucagon-like peptide 1, and peptide tyrosine-tyrosine concentrations following a single high-protein lunch. J Nutr 138:698702,2008 
32. Veldhorst M, Smeets A, Soenen S, Hochstenbach-Waelen A, Hursel R, Diepvens K, Lejeune $M$, Luscombe-Marsh $N$, Westerterp-Plantenga $M$ : Protein-induced satiety: effects and mechanisms of different proteins. Physiol Behav 94:300-307, 2008

33. Harris JAB, F.G.: A biometric study of basal metabolism in man. Washington, DC: Carnegie institution of Washington:279, 1919

34. Hoffstedt J, Eriksson P, Mottagui-Tabar S, Arner P: A polymorphism in the leptin promoter region $(-2548 \mathrm{G} / \mathrm{A})$ influences gene expression and adipose tissue secretion of leptin. Horm Metab Res 34:355-359, 2002

35. Mammes O, Betoulle D, Aubert R, Herbeth B, Siest G, Fumeron F: Association of the G2548A polymorphism in the $5^{\prime}$ region of the LEP gene with overweight. Ann Hum Genet 64:391-394, 2000

36. Mattevi VS, Zembrzuski VM, Hutz MH: Association analysis of genes involved in the leptin-signaling pathway with obesity in Brazil. Int J Obes Relat Metab Disord 26:11791185, 2002

37. Heidema AG, Feskens EJ, Doevendans PA, Ruven HJ, van Houwelingen HC, Mariman EC, Boer JM: Analysis of multiple SNPs in genetic association studies: comparison of three multi-locus methods to prioritize and select SNPs. Genet Epidemiol 31:910-921, 2007 

Chapter 8 


\section{Discussion}

Habitual physical activity and food intake regulation are the most important determinants of energy balance and are essential for preserving health status. Both parameters are characterized by a large inter-individual variation that can party be explained by genetic factors. To increase our knowledge on the aetiology of habitual physical activity and food intake regulation, this thesis aims to confirm the degree of heritability shown earlier for habitual physical activity as well as to identify physiological parameters and genetic variants that contribute to the inter-individual variation of habitual physical activity and food intake regulation.

\section{Habitual physical activity}

In a group of 28 monozygotic and 24 dizygotic same-sex twin pairs, $57 \%$ of the interindividual variation in habitual physical activity as measured objectively using a validated triaxial accelerometer is explained by additive genetic factors. The remaining variance is confirmed to result from unique environmental variation $(1 ; 2)$. In addition, additive genetic factors contribute $55 \%$ and $47 \%$ to the explained variation of the time spent on moderate- and high-intensity physical activity, respectively. For both habitual physical activity and the time spent on low-, moderate- and high-intensity physical activity, unstandardized additive genetic path coefficients are equal for men and women.

As described in chapter 4, part of the inter-individual variation in habitual physical activity can be explained by single nucleotide polymorphisms (SNPs) in the gene encoding peroxisome proliferator-activated receptor (PPAR) $\delta(P P A R D)$. PPAR increases the capacity for $\beta$-oxidation and oxidative phosphorylation $(3 ; 4)$, the capacity for endurance exercise $(5 ; 6)$ as well as the proportion of type I muscle fibres $(5-7) . A C / C C$ carriers in rs2076168 are characterized by a lower level of habitual physical activity as measured objectively using the Tracmor compared with subjects carrying the AA genotype. AG/GG carriers in rs2267668 are also characterized by a less physically active lifestyle compared with subjects homozygous for the common A allele. Furthermroe, haplotype analysis reveals that carriers of the AA CG haplotype tend to be less physically active than carriers of the common AA AA haplotype. The minor $C$ and $G$ alleles in these SNPs were associated earlier with reduced PPAR $\mathrm{mRNA}$ levels (8) and a reduced mitochondrial capacity in vitro (7), respectively. This implies that a genetic predisposition for a reduced skeletal muscle oxidative capacity decreases the likelihood of individuals leading a physically active lifestyle, which is confirmed on the protein level for mitochondrial capacity (chapter 3) but not for skeletal muscle fibre-type distribution (chapter 2).

A positive association is observed between habitual physical activity and the capacity of citrate synthase (CS), succinate dehydrogenase (SDH) and cytochrome c oxidase (COX). Furthermore, a trend towards a positive association is observed between habitual physical activity and the capacity of $\beta$-hydroxyacyl-CoA dehydrogenase (HAD). For CS and $H A D$, the associations appear to be mediated by the intensity and duration of the activities performed. The association between habitual physical activity and CS is only observed in subjects spending more than $9 \mathrm{~min} /$ day on high-intensity physical activity, 
whereas the association between habitual physical activity and HAD is only revealed in subjects spending more than $39 \mathrm{~min} /$ day on moderate- and high-intensity physical activity combined. Although no direction of causality can be concluded based on crosssectional observations alone, the results confirm a genetic predisposition for habitual physical activity via SNPs in PPARD at the protein level.

Habitual physical activity is lower in AC/CC carriers in rs20761668 (PPARD), which was associated earlier with lower PPAR $\mathrm{mRNA}$ levels, than in subjects homozygous for the common A allele. Given the ability of PPAR $\delta$ to increase the expression of the type I myosin heavy chain isoform, an association between habitual physical activity and skeletal muscle fibre-type distribution was anticipated. However, the associations between $\mathrm{VO}_{2}-$ max and the time spent on sports with muscle fibre-type distribution cannot be extrapolated to habitual physical activity (chapter 2).

Most studies either do not show an effect of endurance or strength training on the proportion of type I muscle fibres (9-12) or observe only a small increase (5-10\%) (13-17). In the present study, the time spent on sports was used as an exclusion criterion. Consequently, the time spent on high-intensity physical activity is lower than observed earlier in endurance runners (11 versus $39 \mathrm{~min} /$ day, respectively) (18). An increase in the proportion of type I muscle fibres resulting from sports participation is therefore considered unlikely to explain the associations observed between $\mathrm{VO}_{2}$-max and the time spent on sports with the proportion of type I muscle fibres. This implies that an increased proportion of type I muscle fibres may predispose individuals to a higher $\mathrm{VO}_{2}$-max and sports participation instead. In conclusion, the results presented in chapters 2 and 4 show that a genetic predisposition for an increased proportion of type I muscle fibres predisposes individuals to leading a physically active lifestyle. The association is not confirmed at the protein level, which may be due to exclusion of subjects based on their participation in sports. Given that an association between habitual physical activity and mitochondrial capacity is confirmed at the protein level, the latter indeed appears to be a more accurate determinant of skeletal muscle oxidative capacity than fibre-type distribution per se (19-23).

The GA/AA genotypes in rs8192678 (PPARGC1A) are associated with more time spent on high-intensity physical activity compared with the common GG genotype. This contrasts sharply with the reduced skeletal muscle PGC-1 $\alpha$ mRNA levels and $\mathrm{VO}_{2}$-max (24) and increased risk for developing type 2 diabetes (25) in carriers of the Ser-encoding allele (A) compared with subjects homozygous for the common Gly-encoding allele (G). However, detrimental associations with the Ser-encoding allele were all observed in older subjects. More specifically, Ling et al. do not observe a genotype driven discrepancy in PGC-1 $\alpha$ mRNA levels and $\mathrm{VO}_{2}$-max in young adults (aged $28 \pm 0.2$ years) and conclude that age modifies the genetic susceptibility for developing type 2 diabetes (24). Franks et al. on the other hand show that older subjects (aged $58 \pm 7$ years) homozygous for the Serencoding allele are less physically fit than carriers of the Gly-encoding allele when sedentary but not when physically active (26). This suggests that a high level of habitual physical activity compensates for the detrimental effects associated with the Serencoding allele. Habitual physical activity and especially high-intensity physical activity are known to decrease with age (27), which may explain why the increased risk for de- 
veloping type 2 diabetes associated with the Ser-encoding allele only becomes evident at a later stage in life, when little high-intensity physical activity remains. The results stress the importance for GA/AA carriers to remain physically active throughout their lifespan in order to prevent or delay the genetically predisposed development of type 2 diabetes. In addition, physical activity interventions may be more beneficial for health status in middle-aged carriers of the Ser-encoding allele than in those homozygous for the common Gly-encoding allele. Future research should focus on this issue.

Taking body mass and height into account, habitual physical activity contributes a significant $17 \%$ to the explained variation of percentage body fat (\%BF) in young women. The lack of association between \%BF and habitual physical activity in middle-aged women observed by others is anticipated to result from women compensating a higher energy expenditure by increasing their energy intake more than men do (28). In young women, no compensation in energy intake was previously observed in response to an increased energy expenditure (29). Together with the association between \%BF and habitual physical activity observed in the study described in chapter 5, this suggests that the compensatory mechanism is age-dependent. In men, no association was initially observed between \%BF and habitual physical activity. However, two out of three men were participating in season-bound sports with peak activity levels in the summer season. Taking seasonality into account reveals the association between \%BF and habitual physical activity in men as well, with habitual physical activity increasing the explained variation in $\%$ BF with $6 \%$.

Habitual physical activity is concluded to significantly contribute to the inter-individual variation in body composition in young men and women with a continuous year-round level of habitual physical activity. Body mass, height, sex, seasonality and habitual physical activity together explain $80 \%$ of the inter-individual variation in $\% \mathrm{BF}$, implying that other contributing variables remain to be identified. One is suggested by the model's positive coefficient for seasonality, that is, the number of daylight hours during the period in which habitual physical activity was assessed. A positive coefficient for seasonality shows that on average, \%BF is higher in subjects participating in summer than in winter, in spite of higher levels of habitual physical activity in summer. This paradox may partly be explained by sleeping metabolic rate being lower in summer than in winter (30). However, this discrepancy is too small to explain the observed phenomenon. The only plausible explanation remaining is that in spite of \%BF being negatively associated with habitual physical activity and the latter being higher in the summer season, the effect is compensated for by a higher energy intake in summer than winter. This pinpoints the importance of food intake regulation for maintaining energy balance.

\section{Food intake regulation}

Homeostatic food intake regulation is mainly a behavioural physiological interaction between the individual and the environment with hypothalamic receptors responding to peripherally released anorexigenic and orexigenic hormones. The fasting levels of these hormones are a function of genetic variation in the genes encoding them (31-35). However, humans are in a postprandial state during the largest part of the day and the post- 
prandial responses of the (an)orexigenic hormones are therefore considered important for food intake regulation as well. Evidence is found for an association between postprandial responses in (an)orexigenic hormones and SNPs in the genes encoding both hormone and receptor. Some associations are anticipated to represent genotype-related long-term physiological adaptations required to facilitate homeostasis, others reinforce direct genetic effects (chapter 6).

One example of a genotype-related long-term physiological adaptation required to facilitate homeostasis is shown for rs26802 in GHRL. The minor C allele was shown earlier to increase fasting plasma ghrelin levels (34), thereby increasing the risk for overeating $(36 ; 37)$. The study described in chapter 6 shows that subjects with a high postprandial response (increase) in plasma peptide $Y Y$ (PYY) levels are overrepresented among CC carriers compared with AA carriers. Higher postprandial levels of PYY are anticipated to counteract the increased risk for overeating in subjects with the CC genotype by decreasing the subsequent preprandial rise in plasma ghrelin levels (38) and by switching from homeostatic to hedonic food intake regulation (39). Another example of a genotyperelated long-term physiological adaptation that facilitates homeostasis is shown for rs1137101 (LEPR). The minor Arg-encoding allele (G) results in a leptin resistant state $(40 ; 41)$, thereby increasing the risk for overeating $(42 ; 43)$. This is counteracted by increased plasma leptin levels in subjects with the GG compared with the AA genotype $(41 ; 44)$. In addition, subjects with a high postprandial response (decrease) in plasma ghrelin levels are overrepresented among GG carriers compared with AA carriers, which decreases the likelihood of initiating a new meal fast (36).

Whereas some associations between postprandial responses in (an)orexigenic hormones and SNPs in genes encoding hormones and receptors counteract direct genetic effects, other associations reinforce them. Subjects with the GG genotype in rs1058046 (PYY) for example are characterized by $20 \%$ lower fasting plasma PYY levels compared with CC carriers (45), which increases the risk for overeating. In addition, subjects with a low postprandial response (decrease) in plasma ghrelin levels are overrepresented among those with the GG compared with the CC genotype, thereby further increasing the risk for overeating and developing obesity in subjects with the GG genotype (45). Another example of a postprandial response that reinforces a direct genetic effect is shown for rs572169 (GHSR). The A allele was shown earlier to increase the risk for developing obesity, probably by 1 ) increasing ghrelin signalling; 2 ) increasing the response to ghrelin or 3 ) impairing the capacity to counterbalance inhibitory signals (46). In the present study, subjects with a low postprandial response (increase) in plasma PYY levels are overrepresented among GA/AA carriers in rs572169 compared with GG carriers. Lower postprandial PYY levels are anticipated to disinhibit the subsequent preprandial rise in plasma ghrelin levels in GA/AA carriers (38), which may either represent the mechanism suggested by Baessler et al. (46) or provide an alternative mechanism reinforcing a yet unidentified direct genetic effect of rs572169 on ghrelin receptor function. A cognitive component may also increase the susceptibility for overeating in GA/AA carriers in rs572169, as they are characterized by a higher dietary restraint, disinhibition and perceived hunger compared with subjects with the GG genotype $(47 ; 48)$. 
Ghrelin, PYY and glucagon-like peptide 1 (GLP-1) are generally referred to as 'hunger' and 'satiety' hormones and their effect on food intake regulation has been described in detail $(38 ; 49-53)$. However, postprandial responses in hunger and satiety do not always coincide with changes in plasma hormone levels (54), suggesting that important information regarding food intake regulation is ignored when solely focussing on the postprandial responses of hormones. Therefore, the association between postprandial responses in hunger and satiety with SNPs in genes encoding the aforementioned (an)orexigenic hormones and their receptors was determined as well.

SNPs in the fat mass and obesity-associated gene (FTO) are strongly associated with adiposity (55-60). FTO is highly expressed in the arcuate, paraventricular, dorsomedial and ventromedial regions of the hypothalamus, areas of the brain that are involved in food intake regulation $(61 ; 62)$. In line with this, Wardle et al. suggest that FTO may affect body composition by influencing responsiveness to satiety cues (63). Indeed, univariate analyses show that postprandial responses in hunger and satiety are significantly lower in TA/AA carriers in rs9939609 (FTO) under a dominant and additive model, respectively. Since FTO is suggested to be activated via a pathway downstream of leptin (59) and since FTO exerts its function by catalyzing DNA demethylation (61), SNPs in relevant candidate genes were subsequently taken into account using a multi-locus method.

Subjects with a low postprandial response (decrease) in hunger are overrepresented among TA/AA carriers in rs9939609 (FTO) when accompanied by the CC/CA genotype in rs992472 (DNMT3B) and/or the AG/GG genotype in rs1137101 (LEPR) compared with subjects homozygous for at least one of the protective alleles. Each SNP has an additional effect. DNA methyltransferase 3B (DNMT3B) is essential for de novo DNA methylation after embryo implantation (64-66) but is probably also required for maintenance of DNA methylation profiles (65). The rs992472 SNP in DNMT3B is located in the same linkage disequilibrium block as rs2424913, for which the common $C$ allele was associated earlier with a decreased DNMT3B promoter activity compared with the minor $\mathrm{T}$ allele (67). The interaction with rs9939609 (FTO) is confirmed for rs2424913 (DNMT3B), suggesting that the postprandial response in hunger is lower in subjects with a lower capacity for de novo DNA methylation. In line with this, Waterland et al., show that providing Agouti mice $\left(A^{v y}\right)$ with a hypermethylating dietary supplement prevents the transgenerational increase in body mass that occurs without supplementation (68). Given the results, it is tempting to speculate that a relative decrease in the capacity for DNA methylation resulting from an increased capacity for DNA demethylation (TA/AA genotype rs9939609) and a decreased capacity for de novo DNA methylation (CC/CA or CC/CT genotype in rs992472 or rs2424913, respectively) underlies the interaction for the postprandial response in hunger. Whether the capacity for DNA demethylation is indeed higher in TA/AA carriers in rs9939609 will have to be addressed in future studies. Furthermore, to our knowledge, no genes involved in food intake regulation that are susceptible to DNA methylation have yet been identified.

The additional effect of the Arg-encoding allele (G) in rs1137101 (LEPR) on the interaction between SNPS in FTO and DNMT3B probably affects the postprandial response in hunger via a mechanism other than DNA methylation. After all, the minor $G$ allele in 
rs1137101 results in a leptin resistant state $(40 ; 41)$ and blocking leptin decreases FTO expression (59). A decreased FTO expression would decrease the capacity for DNA demethylation, thereby increasing the relative capacity for DNA methylation. Based on the results of Waterland et al., a reduced risk for obesity is than anticipated, which is the exact opposite of what is expected when the postprandial response in hunger is decreased. One option is that FTO may additionally affect food intake regulation via pathways other than DNA methylation. Alternatively, leptin resistance may affect the postprandial response in hunger via the epistatic interaction with rs1047214 in the gene encoding the neuropeptide 2 receptor (NPY2R), as is discussed in chapter 6.

Subjects with a low postprandial response (decrease) in hunger are overrepresented among AG/GG carriers in rs1137101 (LEPR) when accompanied by the TC/CC genotype in rs1047214 (NPY2R) compared with subjects homozygous for the protective allele in at least one of the SNPs. Both the G allele in rs1137101 $(41 ; 44 ; 69)$ and the $C$ allele in rs1047214 (70) were associated earlier with a higher BMI than the protective alleles. The rs1047214 SNP is a silent T to $C$ transition in codon 195 of the NPY2R gene. No nonsynonymous SNPs were previously observed in the gene, suggesting that the functional polymorphism in linkage disequilibrium with rs1047214 is an intronic or intergenic polymorphism that regulates transcription or splicing of NPY2R (70). If replicated, the interaction for the postprandial response in hunger involving rs1137101 and rs1047214 represents a relevant mechanism for food intake regulation in vivo, as $44 \%$ of the subjects carried both risk alleles and the prediction accuracy for the postprandial response in hunger was $66.1 \%$.

Combining a reduced postprandial response in hunger with the current obesogenic environment of Westernized societies in which high-fat foods are abundant and readily available (71) predisposes individuals to overeating, ultimately resulting in the onset of obesity. The thrifty gene hypothesis argues that the alleles currently predisposing individuals for obesity once protected us from starvation during periods of famine (72). We speculate that the combined high-risk alleles in FTO, DNMT3B and LEPR probably do not meet this classification. First of all, diseases resulting from disastrous hunger-driven choices in food selection rather than starvation itself were recently concluded to increase mortality during famines (73). Given their reduced postprandial response in hunger, subjects carrying the high-risk alleles in rs9939609, rs992472 and rs1137101 are genetically predisposed to make such poor choices in food selection. In other words, the genotypes that are currently associated with an increased risk for overeating and developing obesity may have had a deleterious rather than a protective effect on survival during periods of famine. Furthermore, the human hypothalamic-pituitary-gonadal axis is exquisitely sensitive to maternal energy status mediated by circulating leptin levels (74). The combined effect of a famine-driven decrease in maternal leptin levels and a genotype driven reduction in leptin sensitivity are anticipated to decrease rather than increase fertility in AG/GG carriers in rs1137101 compared with subjects with the AA genotype. The combined TA/AA, CC/CA and AG/GG genotypes in rs993909, rs992472 and rs1137101 are thus anticipated to negatively affect both the chance on survivial and fertility during periods of famine. 


\section{Conclusions}

Physiological and genetic aspects of habitual physical activity and food intake regulation, the two main determinants of energy balance, were studied. A genetic predisposition for a reduced mitochondrial capacity in PPARD is associated with a less physically active lifestyle. This association is confirmed on the protein level for markers of mitochondrial capacity but not skeletal muscle fibre-type distribution. Body composition is associated with habitual physical activity and the latter appears to mediate the association between a genetic predisposition in PPARGC1A and the onset of type 2 diabetes mellitus. As for food intake regulation, postprandial responses in (an)orexigenic hormones are shown to either represent genotype-related long-term physiological adaptations required to facilitate homeostasis or reinforce direct genetic effects. The genotypes in rs9939609 (FTO) that predispose individuals to develop obesity (TA/AA) are shown to increase postprandial hunger and decrease postprandial satiety compared with the common $\Pi T$ genotype. The effect of the rs9939609 variant in FTO on the postprandial response in hunger appears to be mediated by an epistatic interaction involving variants in DNMT3B and LEPR. The interaction suggests that DNA methylation, an epigenetic process, is involved in food intake regulation. 


\section{Future research}

The aim of this thesis is to identify physiological parameters and genetic variants that contribute to the inter-individual variation of habitual physical activity and food intake regulation. Three relatively small populations were extensively phenotyped using objective and valid measurement techniques. For habitual physical activity, physiological parameters and SNPs in candidate genes within the pathway of physical fitness were selected. Other pathways like reward sensitivity and the hypothalamic regulation of energy expenditure were not included in the present analyses but are still anticipated to contribute to the inter-individual variation in habitual physical activity. These pathways should be studied in relation to habitual physical activity in the future. As for food intake regulation, the associations shown here should be replicated before firm conclusions can be drawn. The results suggest that DNA methylation, an epigenetic process, plays a role in food intake regulation. The functional relevance of the variants in FTO that are associated with adiposity however, are currently not clear. If shown to be relevant for DNA methylation status, genes involved in food intake regulation that are susceptible for DNA methylation should be identified.

Future studies should be based on larger populations while holding on to objectively and validly determining the phenotype. Such studies would enable more confident conclusions concerning epistatic interactions without sacrificing statistical power. In addition, combining candidate gene studies as performed here with genome-wide association scans is anticipated to increase our knowledge on the aetiology of both habitual physical activity and food intake regulation most. Candidate gene studies contribute by providing more insight in the relative importance of proteins within a pathway, whereas genomewide association scans can reveal pathways that were previously not anticipated to be associated with the phenotype of interest.

Intervention studies on physical activity, food intake regulation and body weight regulation should be performed with subjects genetically characterized beforehand with respect to relevant polymorphisms. The response of more and less vulnerable subjects can than be contrasted, resulting in more statistical power compared with post-hoc discrimination. 


\section{References}

1. Carlsson $S$, Andersson $T$, Lichtenstein $P$, Michaelsson $K$, Ahlbom A: Genetic effects on physical activity: results from the Swedish Twin Registry. Med Sci Sports Exerc 38:1396-1401, 2006

2. Joosen AM, Gielen M, Vlietinck R, Westerterp KR: Genetic analysis of physical activity in twins. Am J Clin Nutr 82:1253-1259, 2005

3. Grimaldi PA: Roles of PPAR $\delta$ in the control of muscle development and metabolism. Biochem Soc Trans 31:1130-1132, 2003

4. Luquet S, Lopez-Soriano J, Holst D, Fredenrich A, Melki J, Rassoulzadegan M, Grimaldi PA: Peroxisome proliferator-activated receptor $\delta$ controls muscle development and oxidative capability. Faseb J 17:2299-2301, 2003

5. Riserus U, Sprecher D, Johnson T, Olson E, Hirschberg S, Liu A, Fang Z, Hegde P, Richards D, Sarov-Blat L, Strum JC, Basu S, Cheeseman J, Fielding BA, Humphreys SM, Danoff T, Moore NR, Murgatroyd P, O'Rahilly S, Sutton P, Willson T, Hassall D, Frayn $\mathrm{KN}$, Karpe F: Activation of peroxisome proliferator-activated receptor (PPAR) $\delta$ promotes reversal of multiple metabolic abnormalities, reduces oxidative stress, and increases fatty acid oxidation in moderately obese men. Diabetes 57:332-339, 2008

6. Wang YX, Zhang CL, Yu RT, Cho HK, Nelson MC, Bayuga-Ocampo CR, Ham J, Kang H, Evans RM: Regulation of muscle fiber type and running endurance by PPAR $\delta$. PLoS Biol 2:e294, 2004

7. Stefan N, Thamer C, Staiger H, Machicao F, Machann J, Schick F, Venter C, Niess A, Laakso M, Fritsche A, Haring HU: Genetic variations in PPARD and PPARGC1A determine mitochondrial function and change in aerobic physical fitness and insulin sensitivity during lifestyle intervention. J Clin Endocrinol Metab 92:1827-1833, 2007

8. Nilsson E, Poulsen P, Sjogren M, Ling C, Ridderstrale M, Groop L, Vaag A: Regulation of skeletal muscle PPARd mRNA expression in twins. J Physiol 584:1011-1017, 2007

9. Coggan AR, Spina RJ, King DS, Rogers MA, Brown M, Nemeth PM, Holloszy JO: Skeletal muscle adaptations to endurance training in 60- to 70-yr-old men and women. J Appl Physiol 72:1780-1786, 1992

10. Gollnick PD, Armstrong RB, Saltin B, Saubert CWt, Sembrowich WL, Shepherd RE: Effect of training on enzyme activity and fiber composition of human skeletal muscle. J Appl Physiol 34:107-111, 1973

11. Ingjer F: Effects of endurance training on muscle fibre ATP-ase activity, capillary supply and mitochondrial content in man. J Physiol 294:419-432, 1979

12. Saltin B, Nazar K, Costill DL, Stein E, Jansson E, Essen B, Gollnick D: The nature of the training response; peripheral and central adaptations of one-legged exercise. Acta Physiol Scand 96:289-305, 1976

13. Howald $\mathrm{H}$, Hoppeler $\mathrm{H}$, Claassen $\mathrm{H}$, Mathieu $\mathrm{O}$, Straub R: Influences of endurance training on the ultrastructural composition of the different muscle fiber types in humans. Pflugers Arch 403:369-376, 1985

14. Sale DG, MacDougall JD, Jacobs I, Garner S: Interaction between concurrent strength and endurance training. J Appl Physiol 68:260-270, 1990

15. Simoneau JA, Lortie G, Boulay MR, Marcotte M, Thibault MC, Bouchard C: Human skeletal muscle fiber type alteration with high-intensity intermittent training. Eur J Appl Physiol Occup Physiol 54:250-253, 1985

16. Simoneau JA, Lortie G, Boulay MR, Marcotte M, Thibault MC, Bouchard C: Inheritance of human skeletal muscle and anaerobic capacity adaptation to high-intensity intermittent training. Int J Sports Med 7:167-171, 1986

17. Staron RS, Karapondo DL, Kraemer WJ, Fry AC, Gordon SE, Falkel JE, Hagerman FC, Hikida RS: Skeletal muscle adaptations during early phase of heavy-resistance training in men and women. J Appl Physiol 76:1247-1255, 1994

18. McClain JJ, Sisson SB, Tudor-Locke C: Actigraph accelerometer interinstrument reliability during free-living in adults. Med Sci Sports Exerc 39:1509-1514, 2007 
19. Bassett DR, Jr.: Skeletal muscle characteristics: relationships to cardiovascular risk factors. Med Sci Sports Exerc 26:957-966, 1994

20. Essen-Gustavsson B, Henriksson J: Enzyme levels in pools of microdissected human muscle fibres of identified type. Adaptive response to exercise. Acta Physiol Scand 120:505-515, 1984

21. Jaworowski A, Porter MM, Holmback AM, Downham D, Lexell J: Enzyme activities in the tibialis anterior muscle of young moderately active men and women: relationship with body composition, muscle cross-sectional area and fibre type composition. Acta Physiol Scand 176:215-225, 2002

22. Mootha VK, Lindgren CM, Eriksson KF, Subramanian A, Sihag S, Lehar J, Puigserver P, Carlsson E, Ridderstrale M, Laurila E, Houstis N, Daly MJ, Patterson N, Mesirov JP, Golub TR, Tamayo P, Spiegelman B, Lander ES, Hirschhorn JN, Altshuler D, Groop LC: PGC-1 $\alpha$-responsive genes involved in oxidative phosphorylation are coordinately downregulated in human diabetes. Nat Genet 34:267-273, 2003

23. Simoneau JA, Bouchard C: Skeletal muscle metabolism and body fat content in men and women. Obes Res 3:23-29, 1995

24. Ling C, Poulsen P, Carlsson E, Ridderstrale M, Almgren P, Wojtaszewski J, Beck-Nielsen $H$, Groop L, Vaag A: Multiple environmental and genetic factors influence skeletal muscle $P G C-1 \alpha$ and $P G C-1 \beta$ gene expression in twins. J Clin Invest 114:1518-1526, 2004

25. Barroso I, Luan J, Sandhu MS, Franks PW, Crowley V, Schafer AJ, O'Rahilly S, Wareham NJ: Meta-analysis of the Gly482Ser variant in PPARGC1A in type 2 diabetes and related phenotypes. Diabetologia 49:501-505, 2006

26. Franks PW, Barroso I, Luan J, Ekelund U, Crowley VE, Brage S, Sandhu MS, Jakes RW, Middelberg RP, Harding AH, Schafer AJ, O'Rahilly S, Wareham NJ: PGC-1 $\alpha$ genotype modifies the association of volitional energy expenditure with VO2max. Med Sci Sports Exerc 35:1998-2004, 2003

27. Meijer EP, Goris AH, Wouters L, Westerterp KR: Physical inactivity as a determinant of the physical activity level in the elderly. Int J Obes Relat Metab Disord 25:935-939, 2001

28. Westerterp KR, Goran MI: Relationship between physical activity related energy expenditure and body composition: a gender difference. Int J Obes Relat Metab Disord 21:184-188, 1997

29. Stubbs RJ, Sepp A, Hughes DA, Johnstone AM, King N, Horgan G, Blundell JE: The effect of graded levels of exercise on energy intake and balance in free-living women. Int J Obes Relat Metab Disord 26:866-869, 2002

30. Plasqui G, Kester AD, Westerterp KR: Seasonal variation in sleeping metabolic rate, thyroid activity, and leptin. Am J Physiol Endocrinol Metab 285:E338-343, 2003

31. Ahituv N, Kavaslar N, Schackwitz W, Ustaszewska A, Collier JM, Hebert S, Doelle H, Dent R, Pennacchio LA, McPherson R: A PYY Q62P variant linked to human obesity. Hum Mol Genet 15:387-391, 2006

32. Hoffstedt J, Eriksson P, Mottagui-Tabar S, Arner P: A polymorphism in the leptin promoter region (-2548 G/A) influences gene expression and adipose tissue secretion of leptin. Horm Metab Res 34:355-359, 2002

33. Mammes O, Betoulle D, Aubert R, Herbeth B, Siest G, Fumeron F: Association of the G$2548 \mathrm{~A}$ polymorphism in the $5^{\prime}$ region of the $L E P$ gene with overweight. Ann Hum Genet 64:391-394, 2000

34. Vartiainen J, Kesaniemi YA, Ukkola O: Sequencing analysis of ghrelin gene 5 ' flanking region: relations between the sequence variants, fasting plasma total ghrelin concentrations, and body mass index. Metabolism 55:1420-1425, 2006

35. Zitzmann M, Gromoll J, von Eckardstein A, Nieschlag E: The CAG repeat polymorphism in the androgen receptor gene modulates body fat mass and serum concentrations of leptin and insulin in men. Diabetologia 46:31-39, 2003

36. Cummings DE, Purnell JQ, Frayo RS, Schmidova K, Wisse BE, Weigle DS: A preprandial rise in plasma ghrelin levels suggests a role in meal initiation in humans. Diabetes 50:1714-1719, 2001 
37. Wren AM, Seal LJ, Cohen MA, Brynes AE, Frost GS, Murphy KG, Dhillo WS, Ghatei MA, Bloom SR: Ghrelin enhances appetite and increases food intake in humans. J Clin Endocrinol Metab 86:5992, 2001

38. Batterham RL, Cohen MA, Ellis SM, Le Roux CW, Withers DJ, Frost GS, Ghatei MA, Bloom SR: Inhibition of food intake in obese subjects by peptide $\mathrm{YY}_{3-36}$. N Engl J Med 349:941-948, 2003

39. Batterham RL, Ffytche DH, Rosenthal JM, Zelaya FO, Barker GJ, Withers DJ, Williams SC: PYY modulation of cortical and hypothalamic brain areas predicts feeding behaviour in humans. Nature 450:106-109, 2007

40. Chagnon YC, Chung WK, Perusse L, Chagnon M, Leibel RL, Bouchard C: Linkages and associations between the leptin receptor (LEPR) gene and human body composition in the Quebec Family Study. Int J Obes Relat Metab Disord 23:278-286, 1999

41. Yiannakouris N, Yannakoulia M, Melistas L, Chan JL, Klimis-Zacas D, Mantzoros CS: The Q223R polymorphism of the leptin receptor gene is significantly associated with obesity and predicts a small percentage of body weight and body composition variability. J Clin Endocrinol Metab 86:4434-4439, 2001

42. Clement K, Vaisse C, Lahlou N, Cabrol S, Pelloux V, Cassuto D, Gourmelen M, Dina C, Chambaz J, Lacorte JM, Basdevant A, Bougneres P, Lebouc Y, Froguel P, Guy-Grand B: A mutation in the human leptin receptor gene causes obesity and pituitary dysfunction. Nature 392:398-401, 1998

43. Lahlou N, Clement K, Carel JC, Vaisse C, Lotton C, Le Bihan Y, Basdevant A, Lebouc Y, Froguel P, Roger M, Guy-Grand B: Soluble leptin receptor in serum of subjects with complete resistance to leptin: relation to fat mass. Diabetes 49:1347-1352, 2000

44. Chagnon YC, Wilmore JH, Borecki IB, Gagnon J, Perusse L, Chagnon M, Collier GR, Leon AS, Skinner JS, Rao DC, Bouchard C: Associations between the leptin receptor gene and adiposity in middle-aged Caucasian males from the HERITAGE family study. J Clin Endocrinol Metab 85:29-34, 2000

45. Torekov SS, Larsen LH, Glumer C, Borch-Johnsen K, Jorgensen T, Holst JJ, Madsen OD, Hansen T, Pedersen O: Evidence of an association between the Arg72 allele of the peptide $Y Y$ and increased risk of type 2 diabetes. Diabetes 54:2261-2265, 2005

46. Baessler A, Hasinoff MJ, Fischer M, Reinhard W, Sonnenberg GE, Olivier M, Erdmann J, Schunkert $H$, Doering $A$, Jacob HJ, Comuzzie AG, Kissebah AH, Kwitek AE: Genetic linkage and association of the growth hormone secretagogue receptor (ghrelin receptor) gene in human obesity. Diabetes 54:259-267, 2005

47. Vogels N, Mariman EC, Bouwman FG, Kester AD, Diepvens K, Westerterp-Plantenga MS: Relation of weight maintenance and dietary restraint to peroxisome proliferatoractivated receptor $\gamma 2$, glucocorticoid receptor, and ciliary neurotrophic factor polymorphisms. Am J Clin Nutr 82:740-746, 2005

48. Vogels N, Westerterp-Plantenga MS: Categorical strategies based on subject characteristics of dietary restraint and physical activity, for weight maintenance. Int J Obes Relat Metab Disord 29:849-857, 2005

49. Chen HY, Trumbauer ME, Chen AS, Weingarth DT, Adams JR, Frazier EG, Shen Z, Marsh DJ, Feighner SD, Guan XM, Ye Z, Nargund RP, Smith RG, Van der Ploeg LH, Howard AD, MacNeil DJ, Qian S: Orexigenic action of peripheral ghrelin is mediated by neuropeptide $Y$ and agouti-related protein. Endocrinology 145:2607-2612, 2004

50. Drucker DJ: Glucagon-like peptides. Diabetes 47:159-169, 1998

51. Kamegai J, Tamura H, Shimizu T, Ishii S, Sugihara H, Wakabayashi I: Chronic central infusion of ghrelin increases hypothalamic neuropeptide $Y$ and Agouti-related protein mRNA levels and body weight in rats. Diabetes 50:2438-2443, 2001

52. McGowan BM, Bloom SR: Peptide YY and appetite control. Curr Opin Pharmacol 4:583588,2004

53. Tovar SA, Seoane LM, Caminos JE, Nogueiras R, Casanueva FF, Dieguez C: Regulation of peptide YY levels by age, hormonal, and nutritional status. Obes Res 12:1944-1950, 2004 
54. Smeets AJ, Soenen S, Luscombe-Marsh ND, Ueland O, Westerterp-Plantenga MS: Energy expenditure, satiety, and plasma ghrelin, glucagon-like peptide 1 , and peptide tyrosine-tyrosine concentrations following a single high-protein lunch. J Nutr 138:698702, 2008

55. Dina C, Meyre D, Gallina S, Durand E, Korner A, Jacobson P, Carlsson LM, Kiess W, Vatin V, Lecoeur C, Delplanque J, Vaillant E, Pattou F, Ruiz J, Weill J, Levy-Marchal C, Horber F, Potoczna N, Hercberg S, Le Stunff C, Bougneres P, Kovacs P, Marre M, Balkau B, Cauchi S, Chevre JC, Froguel P: Variation in FTO contributes to childhood obesity and severe adult obesity. Nat Genet 39:724-726, 2007

56. Do R, Bailey SD, Desbiens K, Belisle A, Montpetit A, Bouchard C, Perusse L, Vohl MC, Engert JC: Genetic variants of FTO influence adiposity, insulin sensitivity, leptin levels, and resting metabolic rate in the Quebec Family Study. Diabetes 57:1147-1150, 2008

57. Frayling TM, Timpson NJ, Weedon MN, Zeggini E, Freathy RM, Lindgren CM, Perry JR, Elliott KS, Lango H, Rayner NW, Shields B, Harries LW, Barrett JC, Ellard S, Groves CJ, Knight B, Patch AM, Ness AR, Ebrahim S, Lawlor DA, Ring SM, Ben-Shlomo Y, Jarvelin MR, Sovio U, Bennett AJ, Melzer D, Ferrucci L, Loos RJ, Barroso I, Wareham NJ, Karpe F, Owen KR, Cardon LR, Walker M, Hitman GA, Palmer CN, Doney AS, Morris AD, Smith GD, Hattersley AT, McCarthy MI: A common variant in the FTO gene is associated with body mass index and predisposes to childhood and adult obesity. Science 316:889894, 2007

58. Hinney A, Nguyen TT, Scherag A, Friedel S, Bronner G, Muller TD, Grallert H, Illig T, Wichmann HE, Rief W, Schafer H, Hebebrand J: Genome wide association (GWA) study for early onset extreme obesity supports the role of fat mass and obesity associated gene (FTO) variants. PLoS ONE 2:e1361, 2007

59. Qi L, Kang K, Zhang C, van Dam RM, Kraft P, Hunter D, Lee CH, Hu FB: FTO Gene Variant Is Associated with Obesity: Longitudinal Analyses in Two Cohort Studies and Functional Test. Diabetes 57: 3145-3151, 2008

60. Scuteri A, Sanna S, Chen WM, Uda M, Albai G, Strait J, Najjar S, Nagaraja R, Orru M, Usala G, Dei M, Lai S, Maschio A, Busonero F, Mulas A, Ehret GB, Fink AA, Weder AB, Cooper RS, Galan P, Chakravarti A, Schlessinger D, Cao A, Lakatta E, Abecasis GR: Genome-wide association scan shows genetic variants in the FTO gene are associated with obesity-related traits. PLoS Genet 3:e115, 2007

61. Gerken T, Girard CA, Tung YC, Webby CJ, Saudek V, Hewitson KS, Yeo GS, McDonough MA, Cunliffe S, McNeill LA, Galvanovskis J, Rorsman P, Robins P, Prieur X, Coll AP, Ma M, Jovanovic Z, Farooqi IS, Sedgwick B, Barroso I, Lindahl T, Ponting CP, Ashcroft FM, O'Rahilly S, Schofield CJ: The obesity-associated FTO gene encodes a 2-oxoglutaratedependent nucleic acid demethylase. Science 318:1469-1472, 2007

62. Stratigopoulos G, Padilla SL, Leduc CA, Watson E, Hattersley AT, McCarthy MI, Zeltser LM, Chung WK, Leibel RL: Regulation of Fto/Ftm gene expression in mice and humans. Am J Physiol Regul Integr Comp Physiol 294:R1185-1196, 2008

63. Wardle J, Carnell S, Haworth CM, Farooqi IS, O'Rahilly S, Plomin R: Obesity associated genetic variation in FTO is associated with diminished satiety. J Clin Endocrinol Metab 93:3640-3643, 2008

64. Lee SJ, Jeon HS, Jang JS, Park SH, Lee GY, Lee BH, Kim CH, Kang YM, Lee WK, Kam S, Park RW, Kim IS, Cho YL, Jung TH, Park JY: DNMT3B polymorphisms and risk of primary lung cancer. Carcinogenesis 26:403-409, 2005

65. Robertson KD, Wolffe AP: DNA methylation in health and disease. Nat Rev Genet 1:1119,2000

66. Wang J, Bhutani M, Pathak AK, Lang W, Ren H, Jelinek J, He R, Shen L, Issa JP, Mao L: $\triangle D N M T 3 B$ variants regulate DNA methylation in a promoter-specific manner. Cancer Res 67:10647-10652, 2007

67. Shen H, Wang L, Spitz MR, Hong WK, Mao L, Wei Q: A novel polymorphism in human cytosine DNA-methyltransferase-3B promoter is associated with an increased risk of lung cancer. Cancer Res 62:4992-4995, 2002 
68. Waterland RA, Travisano M, Tahiliani KG, Rached MT, Mirza S: Methyl donor supplementation prevents transgenerational amplification of obesity. Int J Obes (Lond) 32:1373-1379, 2008

69. Mattevi VS, Zembrzuski VM, Hutz $\mathrm{MH}$ : Association analysis of genes involved in the leptin-signaling pathway with obesity in Brazil. Int J Obes Relat Metab Disord 26:11791185,2002

70. Lavebratt C, Alpman A, Persson B, Arner P, Hoffstedt J: Common neuropeptide Y2 receptor gene variant is protective against obesity among Swedish men. Int J Obes (Lond) 30:453-459, 2006

71. O'Rahilly S, Farooqi IS: Human obesity: a heritable neurobehavioral disorder that is highly sensitive to environmental conditions. Diabetes 57:2905-2910, 2008

72. Neel JV: Diabetes mellitus: a "thrifty" genotype rendered detrimental by "progress"? Am J Hum Genet 14:353-362, 1962

73. Speakman JR: Thrifty genes for obesity, an attractive but flawed idea, and an alternative perspective: the 'drifty gene' hypothesis. Int J Obes (Lond) 32:1611-1617, 2008

74. Prentice AM, Hennig BJ, Fulford AJ: Evolutionary origins of the obesity epidemic: natural selection of thrifty genes or genetic drift following predation release? Int J Obes (Lond) 32:1607-1610, 2008 
Habitual physical activity and food intake regulation are the main determinants of energy balance and important for preserving health status. Twin studies show a moderate to high heritability for both variables, suggesting that genetic variation determines to a large extent whether someone is likely to lead a physically active lifestyle and to adequately match energy intake to energy expenditure. So far, the search for susceptibility genes has mainly focused on phenotypes related to adiposity, such as body mass index (BMI) and (relative) fat mass. The main aim of this thesis is to identify physiological and genetic parameters that contribute to the inter-individual variation of both habitual physical activity and food intake regulation.

To unravel the physiological and genetic background of habitual physical activity, the association was determined between this component of energy expenditure and skeletal muscle fibre-type distribution, mitochondrial capacity and single nucleotide polymorphisms (SNPs) in genes involved in mitochondrial biogenesis and energy metabolism (PPARD, PPARGC1A, NRF1 and FRAP1). The SNPS in PPARD and PPARGC1A were associated earlier with mitochondrial capacity and the risk for having type 2 diabetes. Fifty-two twins pairs of Western European descent (16 monozygotic (MZ) female, 15 dizygotic (DZ) female, $12 \mathrm{MZ}$ male and $9 \mathrm{DZ}$ male pairs (age $22 \pm 5$ years, BMI $21.8 \pm 3.4 \mathrm{~kg} / \mathrm{m}^{2}$ ) and 117 non-related individuals (65 women, 52 men, age $21 \pm 2$ years, BMI $22.0 \pm 2.5$ $\mathrm{kg} / \mathrm{m}^{2}$ ) were recruited. Habitual physical activity was measured for two weeks with a triaxial accelerometer for movement registration (Tracmor). The Tracmor registers accelerations of the trunk along three axes, stores data on a minute-by-minute basis and provides accurate, detailed and reproducible information about the total level of habitual physical activity as well as the intensity and duration of the activities performed. The accelerometer has been validated with doubly labelled water. Body composition was determined as a subject comparative measure by hydrostatic weighing and deuterium dilution according to Siri's three-compartment model. Muscle fibre-type distribution and mitochondrial capacity were determined in a biopsy obtained from the M. Vastus Lateralis.

Data obtained in intervention studies were used to identify genetic variants affecting food intake regulation. One-hundred-and-three non-related individuals of Western European descent were included (62 women, 41 men, aged $34 \pm 14$ years, BMI $25.0 \pm 3.1 \mathrm{~kg} / \mathrm{m}^{2}$ ). Subjects received standardized meals provided in energy balance as determined using the Harris and Benedict equation. Meals consisted of 27, 45 and 28 energy percent of proteins, carbohydrates and fat, respectively. Immediately before and at 4-7 moments after the meal, plasma ghrelin, peptide YY (PYY) and glucagon-like peptide 1 (GLP-1) levels were determined. In addition, hunger and satiety were measured using a visual analogue scale. For each parameter, the postprandial response was determined based on three characteristics: the rate of the initial response, the absolute response and the postprandial area under the curve. For each parameter, subjects were characterized as being a high- or a low responder based on the study- and sex-specific median value. The association between postprandial responses and SNPs in genes encoding the aforementioned hormones and their hypothalamic receptors was subsequently determined (GHRL, GHSR, LEP, LEPR, PYY, NPY, NPY2R, CART, FTO). 
Fifty seven percent of the inter-individual variation in habitual physical activity can be explained by genetic variation. Amongst the genes involved is PPARD, with SNPs predisposing individuals for a reduced mitochondrial capacity (the rs2267668 and rs2076168 variants). In a sub-population, this association was confirmed on the protein level: habitual physical activity correlates positively with markers for mitochondrial capacity like citrate synthase, succinate dehydrogenase and cytochrome c oxidase. No association was observed between habitual physical activity and skeletal muscle fibre-type distribution, which may be due to the exclusion of subjects based on their participation in sports.

Individuals with a genetic predisposition for an increased risk of having type 2 diabetes in the PPARGC1A gene are characterized by an increased time spent on high intensity physical activity compared with individuals without this predisposition. As (high intensity) physical activity decreases with age, it is suggested to mediate the association between the onset of type 2 diabetes and a genetic predisposition in PPARGC1A in our healthy young adults. Body composition is associated with habitual physical activity in men and women with a constant year-round activity pattern.

Postprandial responses in plasma PYY and ghrelin levels are associated with single nucleotide polymorphisms (SNPs) in the GHRL (rs26802) and LEPR (rs1137101) genes, respectively. The associations are anticipated to reflect genotype-driven long-tem physiological adaptations required to facilitate homeostasis in individuals who are at-risk for overeating based on a direct genetic effect. Postprandial responses in plasma PYY and ghrelin levels are associated with SNPs in the GHSR (rs572169) and PYY (rs1058046) genes, respectively. Instead of counteracting, the latter associations are anticipated to reinforce direct genetic effects on food intake regulation.

The TA and AA genotypes in rs9939609 (FTO) are known to increase the risk for developing obesity compared with the $\Pi$ genotype. This association can at least partly be explained by an effect on postprandial responses in appetite, with subjects with low postprandial responses in hunger and satiety being overrepresented among carriers of the TA and AA genotypes compared with subjects with the TT genotype. The postprandial response in hunger is additionally characterized by an epistatic interaction involving variants in DNMT3B and LEPR, with each SNP having an additional effect. This interaction suggests that DNA methylation, an epigenetic process, is involved in food intake regulation.

In conclusion, a genetic predisposition for a reduced mitochondrial capacity is associated with a less physically active lifestyle. Additionally, high intensity physical activity appears to mediate the association between the onset of type 2 diabetes and a genetic predisposition in PPARGC1A. As for food intake regulation, postprandial responses in (an)orexigenic hormones are associated with genetic variants in the genes encoding these proteins and their hypothalamic receptors. Finally, the increased risk for developing obesity associated with the TA and AA genotypes in the rs9939609 SNP (FTO) can at least partly be explained by reduced postprandial responses in hunger and satiety. 

Samenvatting 
Handhaving van de energiebalans en het voorkomen van metabole aandoeningen als obesitas, type 2 diabetes en hart-en-vaatziekten wordt in belangrijke mate bepaald door regulatie van de voedselinname en lichamelijke activiteit. De capaciteit om energie inname af te stemmen op energiegebruik en het al dan niet leiden van een actieve levensstijl worden beïnvloed door genetische aanleg en omgevingsfactoren. Tot nu toe is bij studies naar genen die een rol spelen bij de regulatie van de energiebalans vooral gekeken naar verbanden met fenotypes als body mass index (BMI) en (relatieve) vetmassa. Het doel van dit proefschrift is het identificeren van fysiologische en genetische parameters die bijdragen aan de interindividuele variatie van zowel lichamelijke activiteit als de regulatie van voedselinname.

Om de fysiologische en genetische achtergrond van lichamelijke activiteit te achterhalen is gekeken in hoeverre fenotypische variantie verklaard kan worden door spiervezelsamenstelling, mitochondriale capaciteit en single nucleotide polymorphisms (SNPs) in genen die betrokken zijn bij de mitochondriale biogenese (PPARD, PPARGC1A, NRF1, FRAP1). De SNPs in PPARD en PPARGC1A zijn eerder in verband gebracht met respectievelijk mitochondriale capaciteit en het risico op type 2 diabetes. Tweeënvijftig tweelingparen (16 monozygoot (MZ) vrouwelijke, 15 dizygoot (DZ) vrouwelijke, $12 \mathrm{MZ}$ mannelijke en 9 DZ mannelijke paren, leeftijd $22 \pm 5$ jaar, BMI 21,8 $\pm 3,4 \mathrm{~kg} / \mathrm{m}^{2}$ ) en 117 nietverwante individuen (65 vrouwen, 52 mannen, leeftijd $21 \pm 2$ jaar, BMI 22,0 $2,5 \mathrm{~kg} / \mathrm{m}^{2}$ ) van West-Europese afkomst zijn geïncludeerd. Lichamelijke activiteit is gedurende twee weken gemeten met behulp van een met tweevoudig gemerkt water gevalideerde, drieassige versnellingsopnemer (Tracmor). De Tracmor geeft zowel informatie over de totale hoeveelheid lichamelijke activiteit als over de intensiteit en duur van de verrichte activiteiten. Om proefpersonen onderling te kunnen vergelijken is de lichaamssamenstelling gemeten door bepaling van lichaamsvolume en lichaamswater volgens het driecompartimenten model van Siri. Spiervezelsamenstelling en mitochondriale capaciteit werden gemeten in een biopt uit de M. Vastus Lateralis.

Om genetische varianten te identificeren die van invloed zijn op regulatie van de voedselinname is gebruik gemaakt van data verkregen uit interventiestudies. Honderddrie nietverwante individuen van West-Europese afkomst zijn geïncludeerd (62 vrouwen, 41 mannen, leeftijd $34 \pm 14$ jaar, BMI $25,0 \pm 3,1 \mathrm{~kg} / \mathrm{m}^{2}$ ). Proefpersonen kregen een gestandaardiseerde maaltijd in energiebalans die gemiddeld voor 27, 45 en 28 energieprocent uit eiwitten, koolhydraten en vetten bestond. Direct voor en op 4 tot 7 tijdstippen na de maaltijd werden plasma ghreline, peptide YY (PYY) en glucagon-like peptide 1 (GLP-1) concentraties gemeten. Honger en verzadiging werden op dezelfde tijdstippen gemeten met behulp van een visuele analoge schaal. Voor elke parameter werd de snelheid van de initiële respons, de absolute respons en de oppervlakte onder de curve berekend. De postprandiale respons werd vervolgens gedichotomiseerd op basis van de geslachts- en studiespecifieke mediaan. Deze responsiviteit is in verband gebracht met SNPs in genen die coderen voor eerder genoemde hormonen en hun hypothalamische receptoren (GHRL, GHSR, LEP, LEPR, PYY, NPY, NPY2R, CART, FTO).

Zevenenvijftig procent van de variatie in lichamelijke activiteit tussen personen kan verklaard worden door genetische variatie. Één van de genen die hierbij een rol speelt is $P P A R D$, met SNPS die predisponeren tot een lage mitochondriale capaciteit (de 
rs2267668 en rs2076168 varianten). In een subpopulatie is deze relatie bevestigd op eiwitniveau: lichamelijke activiteit is positief gecorreleerd met mitochondriale capaciteit, gemeten als de capaciteit van citraat synthase, succinaat dehydrogenase en cytochroom c oxidase. Lichamelijke activiteit is niet gerelateerd aan spiervezelsamenstelling, wat mogelijk verklaard kan worden door het in deze subpopulatie gehanteerde exclusiecriterium voor sportparticipatie. Proefpersonen met een verhoogd risico op het ontstaan van type 2 diabetes als gevolg van een genetische variant in het PPARGC1A gen (rs8192678) worden gekenmerkt door meer hoog-intensieve lichamelijke activiteit dan individuen zonder deze variant. Gezien de leeftijd van de proefpersonen en het feit dat (hoogintensieve) lichamelijke activiteit daalt met de leeftijd kan op basis van deze studie en de literatuur worden verondersteld dat hoog-intensieve lichamelijke activiteit het ontstaan van type 2 diabetes in individuen met een genetische predispositie in het PPARGC1A gen kan voorkomen of vertragen. Lichaamssamenstelling is bij zowel mannen als vrouwen gerelateerd aan lichamelijke activiteit, mits het activiteitenpatroon gedurende het jaar constant is.

De respons van plasma PYY en ghreline concentraties na de maaltijd is geassocieerd met SNPs in respectievelijk de GHRL (rs26802) en LEPR (rs1137101) genen. Deze associaties lijken fysiologische adaptaties te zijn die homeostase op de lange termijn mogelijk maakt in individuen die als gevolg van hun genotype een verhoogd risico lopen op overeten. Daarnaast is de respons van plasma PYY en ghreline concentraties na de maaltijd geassocieerd met SNPs in respectievelijk de GHSR (rs572169) en PYY (rs1058046) genen. In tegenstelling tot de eerdere associaties lijken deze relaties directe genetische effecten te versterken in plaats van ze te compenseren.

Van de rs9939609 SNP in het FTO gen is bekend dat de TA en AA genotypes geassocieerd zijn met een hoger risico op het ontstaan van obesitas dan het $\Pi T$ genotype. Deze associatie kan tenminste deels verklaard worden door een effect op de postprandiale respons in honger en verzadiging: Individuen met een lage daling van honger en stijging van verzadiging na de maaltijd komen significant meer voor onder dragers van de TA en AA genotypes vergeleken met dragers van het $\Pi$ genotype. De postprandiale respons in honger wordt daarbij nog gekenmerkt door een epistatische interactie tussen SNPs in de FTO, DNMT3B en LEPR genen. Op basis van deze interactie lijkt DNA methylatie, een epigenetisch proces, een rol te spelen bij de regulatie van de voedselinname.

Uit het onderzoek beschreven in dit proefschrift kan worden geconcludeerd dat genetische aanleg voor een lage mitochondriale capaciteit is geassocieerd met minder lichamelijke activiteit in het dagelijks leven. Verder lijkt hoog-intensieve lichamelijke activiteit de relatie tussen genetische aanleg in PPARGC1A en het ontstaan van type 2 diabetes te beïnvloeden. Voor de regulatie van de voedselinname kan geconcludeerd worden dat de postprandiale respons in honger- en verzadigingshormonen wordt beïnvloed door genetische varianten in de genen die coderen voor deze hormonen en hun hypothalamische receptoren. Tenslotte kan worden geconcludeerd dat aanleg voor het ontstaan van obesitas als gevolg van een genetische variant in het FTO gen tenminste deels verklaard kan worden door een verlaagde postprandiale respons in honger en verzadiging. 

Dankwoord

153 
Een keer knipperen met je ogen... Zo snel ongeveer lijken de afgelopen vier jaar voorbij te zijn gevlogen. In die vier jaar is er geen werkdag geweest dat ik niet met plezier van Geldrop naar Maastricht ben gereden. Om deze reden en omdat het onmogelijk is om een promotietraject binnen de daartoe gestelde termijn af te ronden zonder de nadrukkelijke hulp van anderen is het nu de hoogste tijd om een aantal mensen te bedanken.

Laat ik beginnen bij de mensen zonder wie de in dit proefschrift beschreven studies niet verder zouden zijn gekomen dan hypotheses: de vrijwilligers die zich door mijn advertenties aangesproken voelden en zich voor een geringe vergoeding in hebben gezet voor de wetenschap. Zeker in het geval van de deelnemers aan de bioptstudie was dat geen sinecure. Daarom: ontzettend bedankt voor jullie bijdrage.

Daarnaast wil ik van deze gelegenheid gebruik maken om mijn promotoren te bedanken voor de steun die ik van hen heb gekregen bij het tot stand komen van dit proefschrift. Klaas, bedankt voor de efficiënte manier waarop je me de afgelopen jaren hebt begeleid. Je hebt me de vrijheid en de tijd gegeven om mijn hypotheses te kunnen toetsen en hebt daarbij steeds zowel de grote lijn van het project als de wekker in de gaten gehouden. Ik heb veel van je geleerd, bedankt daarvoor. Margriet, bedankt voor het scheppen van de randvoorwaarden die noodzakelijk zijn om ideeën om te kunnen zetten in resultaten. Bedankt ook voor het onwaarschijnlijke tempo waarmee bij jou ingeleverde manuscripten voorzien van (kritisch) commentaar hun weg terug vonden naar de auteur. Edwin tenslotte, bedankt voor de rust en humor waarmee je aan het tot stand komen van dit proefschrift hebt bijgedragen. Je keek met een andere bril naar de ingeleverde manuscripten en je deur stond altijd open, dat waardeer ik zeer.

Ook de leescommissie, voorgezeten door Prof. Dr. Frederik-Jan van Schooten en verder bestaande uit Prof. Dr. Joep Geraedts, Prof. Dr. Harm Kuipers, Prof. Dr. Roger Adan en Prof. Dr. Nick Wareham, wil ik bedanken voor hun kritische evaluatie van dit proefschrift. Wetenschap is een teamsport en als zodanig onmogelijk zonder de input van coauteurs. In chronologische volgorde wil ik graag als eerste Matthijs bedanken. In de beginfase van het project heb je ogenschijnlijk belangeloos meegedacht om te komen tot de juiste onderzoeksopzet. Vervolgens heb je na het afronden van het praktische werk geschaafd en meegeschreven aan de artikelen die hier hoofdstuk 2 en 3 heten totdat ze uiteindelijk rijp waren voor publicatie. In beide gevallen gingen er een aantal versies overheen voor het zover was; bedankt voor je hulp en je geduld. Gerrit, bedankt voor je bijdrage aan het meten van de capaciteit van de mitochondriale enzymen in het gehomogeniseerde bioptmateriaal, biopten die zonder de hulp van Luc, Milou, René en Ralph niet verzameld hadden kunnen worden; ook jullie bedankt.

Margriet, Ananda, Astrid, Kristel en Manuela, als jullie je data verkregen uit (arbeidsintensieve) interventiestudies niet beschikbaar hadden gesteld, zou ik op dit moment waarschijnlijk nog steeds mensen aan het voeden zijn geweest. Bedankt voor jullie praktische bijdrage aan het tot stand komen van de hoofdstukken 6 en 7. Freek, bedankt voor je duidelijke instructies en hulp bij het isoleren van DNA uit buffy coats, wangschraapsels en zelfs placentaweefsel. Ook voor het genotyperen zelf zou ik nergens geweest zijn zonder jouw uitleg. Geert, je hebt me geïntroduceerd in de wereld van de SNP-analyses en epistatische interacties. Zonder jouw bijdrage zouden hoofdstuk 6 en 7 
niet geworden zijn wat ze nu zijn en zou ook stelling 4 er anders uit hebben gezien; veel dank voor de prettige samenwerking.

In het kader van de tweelingstudie wil ik graag Catherine Derom en Lut Dezeure van het Oost-Vlaamse tweelingregister bedanken. Zonder jullie inzet bij het benaderen van de tweelingparen zou het niet gelukt zijn om binnen vijf maanden 41 tweelingparen thuis te bezoeken en zo de studie te voltooien. Als prettige bijkomstigheid heeft het mijn topografische kennis van Gent en omstreken naar een acceptabel niveau gebracht. Ook Marij wil ik graag bedanken. Jouw positieve instelling en statistische kennis waren onmisbaar bij het analyseren van de tweelingdata en hebben mede geleid tot het tot stand komen van hoofdstuk 4. Annemiek, bedankt voor de tweelingdata die je beschikbaar hebt gesteld. Bedankt ook voor je hulp als kamergenote bij het opstarten van mijn project 4 jaar geleden.

Van coauteurs nu de overstap naar paranimfen. Astrid en Guy, bedankt dat jullie me op 3 juli willen bijstaan bij het verdedigen van dit proefschrift. Astrid, jij bent mede verantwoordelijk voor de regels 2 en 3 van dit dankwoord. Een kleine rekensom leert dat we de afgelopen jaren minstens 30.000 kilometer naast elkaar op de A2 hebben doorgebracht. Je stak daarbij je mening niet onder stoelen of banken en dat waardeer ik. Bedankt voor de discussies die we (onderweg) hebben gevoerd. Guy, dat jouw achternaam 22 keer in dit proefschrift voorkomt verbaasde me eerlijk gezegd niet. Dat je voornaam her en der verstopt ook 12 keer voorkomt maakt de keuze voor jou als paranimf alleen maar logischer. Je hebt de afgelopen jaren keer op keer klaargestaan als ik iets te vragen had en daarnaast was het erg gezellig in zowel Colorado en Wyoming als Amsterdam en Rotterdam. Bedankt voor je collegialiteit.

Ook Paul en Loek wil ik via deze weg bedanken voor hun bijdrage. Loek, bedankt voor de vele deuteriumanalyse die je de afgelopen jaren voor me verrichtte. Bedankt ook voor het vernuft waarmee je 1 maand voor het afronden van dit proefschrift alle data van mijn gecrashte harde schijf hebt weten te recupereren. Paul, bedankt voor het grote enthousiasme waarmee je over zeer uiteenlopende onderwerpen kunt vertellen. Jij hebt me opnieuw leren luisteren.

Een woord van dank nu gericht aan de mensen waar ik de afgelopen jaren dagelijks mee te maken heb gehad binnen mijn werkzaamheden en in een aantal gevallen ook daarbuiten: Alberto, helaas is een systeem met 3 paranimfen nog altijd niet ingevoerd, bedankt voor je droge humor, je onvergetelijke speech over mijn broodtrommel en je vele onverwachte "pronto's" op de meest uiteenlopende plekken in Wyoming; Hanneke, we hebben 3.3124 jaar lang gedeeld. Je was een fijne kamergenote en ik denk dat we een goede balans tussen gezelligheid en werktijd hebben gevonden; Stijn en Arie, onder andere bedankt voor een nachtelijke taxirit in de kofferbak dwars door het bruisende Parijs; Sofie, bedankt voor het verzorgen van de logistieke organisatie bij de tweelingstudie; Rick, bedankt voor de avontuurlijke raclette-safari met wildtype en knock-out muizen; Anneke bedankt voor het snowboarden in mist zo dik als erwtensoep; Margriet, bedankt voor de gezamenlijke BHV oefeningen, trainingen en vergaderingen; Femke, bedankt voor de publicatiecompetitie die ik helaas vroegtijdig heb moeten staken, je tempo lag te hoog voor me; Sanne, bedankt dat ik nu echt de weg naar Echt weet; Gijs, bedankt voor je lay-out tips en de discussies tijdens mijn (voorlopig) laatste kilometers naar Maastricht en Anan- 
da, Jurriaan, Mieke, Steven, Andrea, Annemieke en Henrike, bedankt voor de hoognodige koffiepauzes waarbij de benen even gestrekt konden worden. De collega's die ik niet bij naam genoemd heb wil ik graag bedanken voor de prettige werksfeer.

De laatste woorden die ik in het kader van dit proefschrift schrijf wil ik graag richten tot drie mensen die op een indirecte maar essentiële manier hebben bijgedragen aan de totstandkoming ervan. Pap en mam, bedankt dat jullie me geleerd hebben zelf keuzes te maken in het leven. Bedankt ook dat jullie me in deze keuzes altijd hebben gesteund. Als ik de helft van het doorzettingsvermogen heb dat jullie de afgelopen jaren hebben laten zien dan zit het met mijn toekomst wel goed. Ik ben trots op jullie.

Mirjam, een eigen alinea is het minste dat ik je kan geven maar eigenlijk is dat nog veel te weinig om te laten zien hoeveel je voor me betekent. Bedankt voor je liefde en het geduld dat je, zeker de laatste tijd, met me hebt gehad. Bedankt ook voor de vrijheid die je me geeft om mijn dromen na te streven. Onze dromen zal ik in Engeland niet uit het oog verliezen.

Marcel 


\section{As first author}

- $\quad$ den Hoed M, Hesselink MKC and Westerterp KR. Skeletal muscle fibre-type distribution and habitual physical activity in daily life. Scand. J. Med. Sci. Sports, Epublication.

- den Hoed M, Hesselink MKC, van Kranenburg GPJ and Westerterp KR. Habitual physical activity in daily life correlates positively with markers for mitochondrial capacity. J. Appl. Physiol, 105(2): 561-568, 2008.

- den Hoed M and Westerterp KR. Body composition is associated with physical activity in daily life as measured using a triaxial accelerometer in both men and women. Int. J. Obes (Lond), 32(8): 1264-1270, 2008.

- den Hoed M, Smeets AJPG, Veldhorst MAB, Nieuwenhuizen AG, Bouwman FG, Heidema AG, Mariman ECM, Westerterp-Plantenga MS and Westerterp KR. SNP analyses of postprandial responses in (an)orexigenic hormones and feelings of hunger reveal long-term physiological adaptations to facilitate homeostasis. Int. J. Obes (Lond), 32(12): 1790-1798, 2008.

- den Hoed M, Gielen M, Westerterp-Plantenga MS, Bouwman FG, Joosen AMCP, Vlietinck R, Derom C, Zeegers MP, Mariman ECM and Westerterp KR. Genetic variants in PPARD and PPARGC1A contribute to the inter-individual variation of habitual physical activity in unrelated subjects and twins. Submitted.

- den Hoed M, Westerterp-Plantenga MS, Bouwman FG, Mariman ECM and Westerterp KR. Postprandial responses in hunger and satiety are associated with the rs9939609 SNP in FTO. Submitted.

\section{As co-author}

- Soenen S, Mariman ECM, Vogels N, Bouwman FG, den Hoed M, Brown L and Westerterp-Plantenga MS. Relationship between perilipin gene polymorphisms and body weight and body composition during weight loss and weight maintenance. Physiol Behav, 96: 723-728, 2009.

- Plasqui G, den Hoed M, Bonomi A, Westerterp KR. Body composition in 10-13 year old children: a comparison between air displacement plethysmography and deuterium dilution. Int $\mathrm{J}$ Pediatr Obes. In press.

- Westerterp KR, den Hoed M, Goris AHC, Bodlaender M. Body composition algorithm based on personal characteristics and physical activity. PH006821US1, 2007 (patent). 
Curriculum Vitae

159 
Marcel den Hoed was born on the $1^{\text {st }}$ of September 1980 in Nijmegen, The Netherlands. He was raised in Uden and Eindhoven, where he received his Athenaeum degree at the Stedelijk College Eindhoven in 1998. The same year, he started studying nutrition and dietetics at the Catholic University of Leuven. After one year Marcel decided to switch to Human Movement Sciences at the Vrije Universiteit in Amsterdam, where he received his Masters degree with a Major on the human movement system in 2004. After a year of travelling through Australia and New Zealand, he started working on a PhD-project at the department of Human Biology of Maastricht University in 2005. Under supervision of Prof. Klaas Westerterp, he aimed to unravel the physiological and genetic background of habitual physical activity and food intake regulation. With his PhD-thesis finished, the next chapter of his life will be written in Cambridge, where Marcel will continue studying the genetic background of habitual physical activity at the Medical Research Council Epidemiology Unit.

Marcel den Hoed werd op 1 september 1980 geboren te Nijmegen. Hij groeide op in Uden en later in Eindhoven, waar hij in 1998 zijn atheneum diploma behaalde aan het Stedelijk College Eindhoven. Aansluitend startte hij met een studie voedings- en dieetleer aan de Katholieke Universiteit Leuven. Na een jaar besloot hij bewegingswetenschappen te gaan studeren aan de Vrije Universiteit in Amsterdam, waar hij via de afstudeerrichting bewegingssystemen in 2004 zijn universitair diploma behaalde. Vervolgens zag Marcel een langgekoesterde wens in vervulling gaan door met Mirjam 9 maanden door Australië en Nieuw-Zeeland te reizen. Aansluitend startte hij als promovendus bij de capaciteitsgroep Humane Biologie van de Universiteit Maastricht. Daar deed hij onder begeleiding van Prof. Klaas Westerterp 4 jaar onderzoek naar de fysiologische en genetische determinanten van lichamelijke activiteit en eetgedrag. Nu het proefschrift af is zal de volgende stap in Cambridge gezet gaan worden, waar Marcel het onderzoek naar de genetische etiologie van lichamelijke activiteit een passend vervolg geeft bij de Epidemiologie groep van het Medical Research Council. 